\title{
Sedimentary processes and the Holocene development of Palmyra Atoll, Equatorial Pacific Ocean
}

\author{
Kim Nicole Owen
}

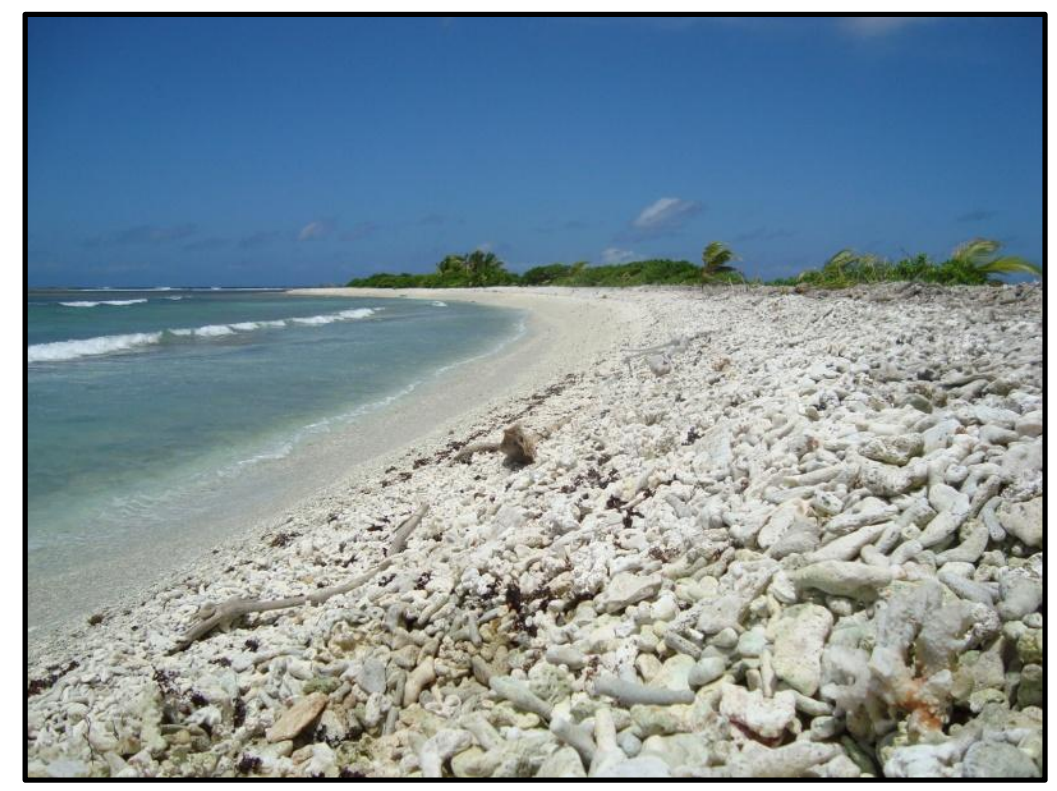

A thesis submitted in partial fulfilment of the requirements for the degree of Masters of Science in Geology

School of Geography, Environment and Earth Sciences

Victoria University of Wellington 
Coral atolls are unique landforms in that they are the physical manifestations of the interplay between both biological and geological processes. Prominent amongst these processes is the ability of the reef organisms to produce $\mathrm{CaCO}_{3}$ and its subsequent erosion and dispersal as sediment. Overriding controls on this process are organic productivity, wave energy, and relative sea level. The development and stability of atolls are thus critically dependent on the balance between several processes which may change over time. Atolls are regarded as being particularly vulnerable to environmental change.

This study investigates the Holocene geological history of Palmyra atoll, at $5^{\circ} 52^{\prime} \mathrm{N}$ $162^{\circ} 04^{\prime} \mathrm{W}$, in the northern Line Islands. Beachrock is used as an indicator of (a) paleosea level and (b) paleo-shoreline conditions from clasts trapped within the beachrock matrix. The study also models annual $\mathrm{CaCO}_{3}$ production and hydrodynamic conditions at the sea bed to provide an integrated assessment of the past and present sedimentary processes and reef island development at Palmyra Atoll. The atoll is currently the focus of intensive scientific study by the Palmyra Atoll Research Consortium and is particularly suited to this study because of the reduced human presence. This allows the examination of the relationship between beachrock, islet development and other processes, in an environment lacking ongoing anthropogenic development.

Beachrock was found at 10 locations at Palmyra Atoll and yielded ${ }^{14} \mathrm{C}$ ages ranging from 1249 to 105 cal. yrs BP. Typically, the beachrock contains mostly coral and algal clasts and is thought to form in the intertidal zone. Continual wetting and drying throughout a tidal cycle results in the precipitation of marine phreatic cements, which thus, indicate paleo-shorelines and sea level elevation. The production of $\mathrm{CaCO}_{3}$ sediment at Palmyra was estimated using reef habitat zones from Hopley (1996) and suggests that the most productive areas are reef terraces and the reef edge. An estimate total of 91,500 tonnes of $\mathrm{CaCO}_{3}$ is produced annually on the reefs, although only approximately $9 \%$ of this becomes sediment that remains on the reef islands.

Hydrodynamic processes were modelled using the SWAN model, a bathymetric grid from NOAA, and bottom conditions estimated from other studies. Input parameters were determined using a 13 year WAVEWATCHIII hindcast model of the wave climate for the central Pacific, as well as estimations of extreme wave events. Sediment transport was inferred from the modelled bed shear stress and these results show that to form most of the beachrock outcrops on Palmyra extremely strong wave action must be coupled with a higher sea level in order to allow the propagation of wave energy across the reef to some of the island shorelines.

Integration of all results suggests that growth of the reef islands at Palmyra Atoll was initiated as the sea level fell from the mid-Holocene Highstand, 1-2 $\mathrm{m}$ above present mean sea level. The islands subsequently grew progressively eastward, forming 3-4 island chains which strike north or northeast. The beachrock that formed on these island provided protection from later wave erosion. Despite limitations caused by lack of climatic and other environmental data due to the isolation of the study area, results are reliable and highlight the application of beachrock as a proxy for past climates and sea levels. 
For Dad,

With love 


\section{Acknowledgements}

I am indebted to my supervisors Dr. John Collen and Dr. Gavin Dunbar; without their support and encouragement I would not be writing this. I thank John for his open door, motivation and his assistance and discussion in all aspects of this thesis. I thank Gavin for his excellent feedback and many decision regarding this thesis. I cannot thank them enough.

Dr. Dan Zwartz has been instrumental in the production of this work. For his modelling and general computer expertise, as well as his patience in showing me the ropes, I am profoundly grateful. His replies to my late night why-isn't-it-doing-what-Itold-it-to emails saved many headaches. I am also grateful to Dr. Gareth Williams for his expertise in the coral of Palmyra. To all those who have advised, guided, helped, and constructively criticised along the way, including Dr. Rob McKay, John Creech, Dr. David Kennedy, Dr. Warren Dickinson, and the 2010 participants of STAR, I am indebted.

Studying geology in the field was one of the reasons I was attracted to the geology program at Victoria five years ago. Thus, the field work on Palmyra Atoll was a highlight of my research for this thesis. I thank those whose financial, logistical, and moral support made the field efforts successful. The on-island staff of the Nature Conservatory and the U.S. Fish and Wildlife Service, as well as my fellow field team members John Collen, Jonathan Gardner, David Garton and James Allen made the trip not only extremely comfortable, but also incredibly enjoyable and educational. It was a truly unforgettable trip..

A tip of the hat to my fellow VUW graduate students; they added enjoyment, interest and entertainment to five years of academia. I thank and acknowledge Ramona, Megan, Gemma and Katy for putting up with my angst and giving support when I needed it most. To Evie, my running buddy, I hope this doesn't make Dave awkward. To Ben, Zara, Chris, Sam, Holly, Alex, and everyone, who without their help and support these past two years would have been much more difficult. I also have to thank Liam, Kellie, Steph, Jeff, Jared, and all my friends who don't live in the Cotton building, and who have provided many timely distractions.

Above all, however, I would like to express my love and appreciation for my small and chaotic family. To John for his cooking, and being my first point of contact in 
Wellington, and to Andy for always re-grounding me in the mountains. Their emails and photos from faraway places have provided plenty of dreaming and inspiration. My Mum has given endless emotional (and financial) support and gentle-yet-firm nudges when I needed them. She is an incredible person and I will always look up to her. Lastly I give huge thanks to my Dad; he bears the responsibility for sparking my interest in science on those endless drives home from the mountains and his loss is keenly felt by us all. I love you.

Thank you. 


\section{Table of Contents}

Abstract........................................................................................................................

Dedication..........................................................................................................

Acknowledgements...............................................................................................................

Table of Contents............................................................................................................vi

List of Figures.............................................................................................................................

List of Tables..............................................................................................................

List of Equations................................................................................................................

List of Symbols...............................................................................................................

List of Acronyms.............................................................................................................

Chapter One: Introduction...................................................................................................1

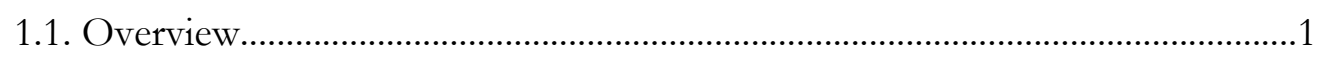

1.1.1. Thesis objectives.................................................................................

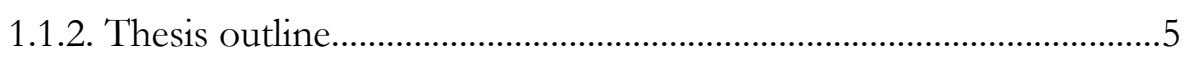

Chapter Two: Pacific sea levels and beachrock formation........................................6

2.1. Holocene sea level in the Pacific ...............................................................

2.1.1. Sea level change since the Last Glacial Maximum.............................6

2.1.2. Development of stable reef islets..........................................................9

2.1.3. Paleoshoreline proxies.......................................................................9

2.2. Relationship between beachrock and sea level.................................................10

2.3. Beachrock........................................................................................................

2.3.1. Beachrock occurrence......................................................................14

2.3.2. Formation mechanisms........................................................................13

2.3.3. Beachrock composition....................................................................15

2.3.4. Beachrock cements........................................................................... 18

2.3.5. Effect of beachrock on coastlines......................................................19

Chapter Three: Regional Setting......................................................................................21

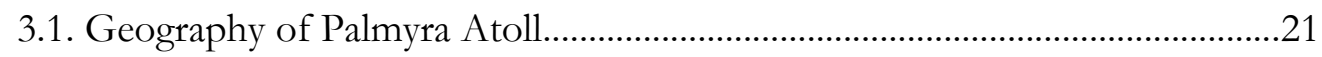

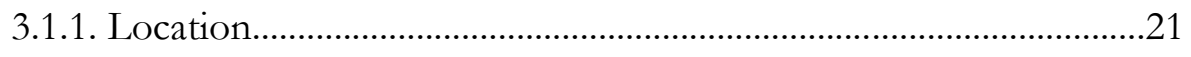

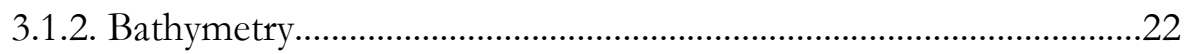

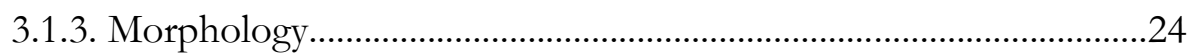




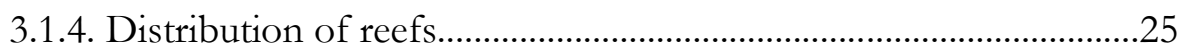

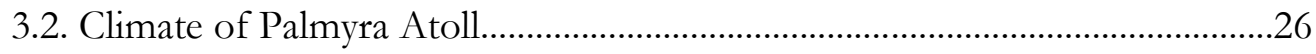

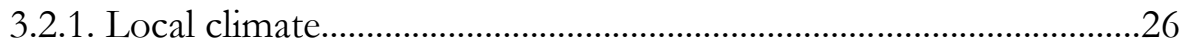

3.2.2.Cyclones and extreme wave events...................................................29

3.2.3. El Nino Southern Oscillation..................................................................30

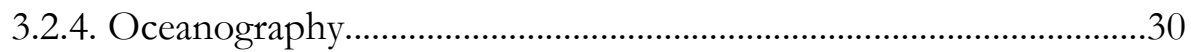

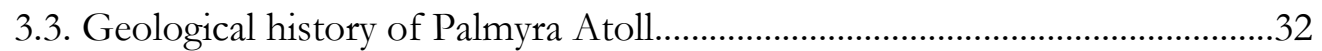

3.4. Palmyra Atoll over the past 100 years .................................................................34

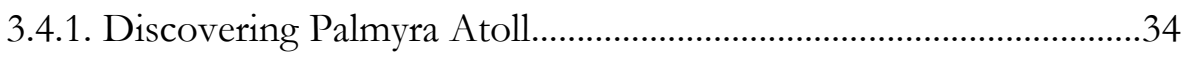

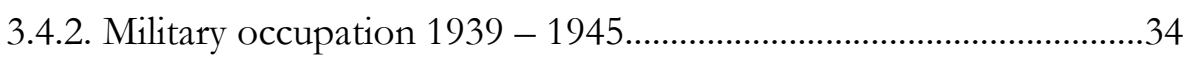

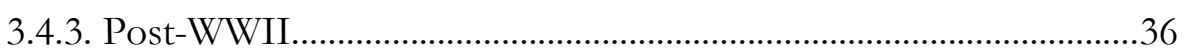

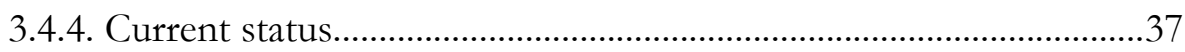

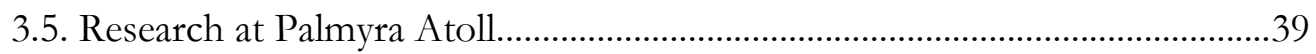

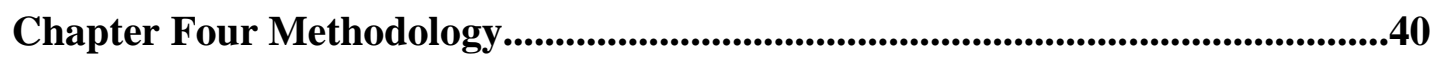

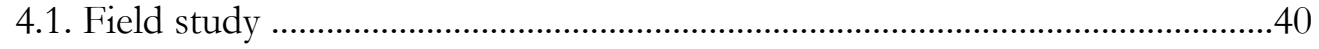

4.2. Lithofacies analysis .........................................................................................

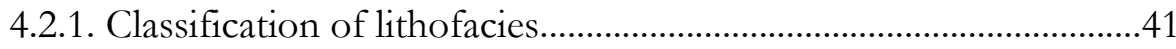

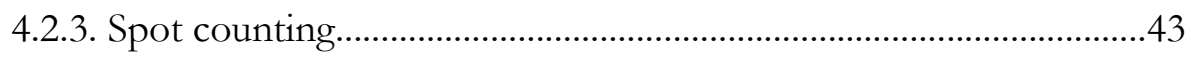

4.2.4. Election Probe Micro Analyser.............................................................4

4.2.5. Aragonite staining................................................................................ 44

4.3. Clast-orientation and paleo-flow estimation....................................................44

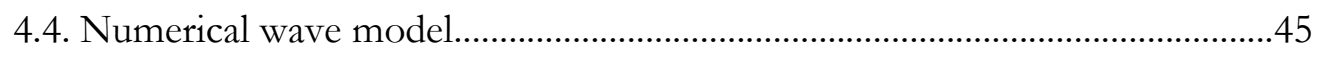

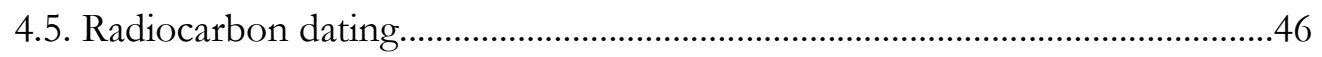

Chapter Five: Beachrock lithofacies and petrology...............................................48

5..1 Beachrock distribution on Palmyra Atoll...........................................................48

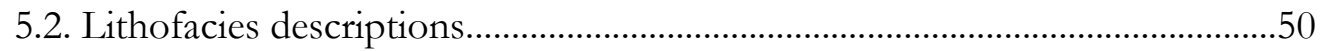

5.2.1. Lithofacies 1.a - Laminated Sandstone.............................................53

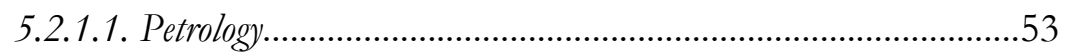

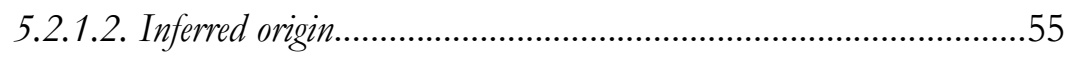

5.2.2. Lithofacies 1.b - Massive Sandstone....................................................55

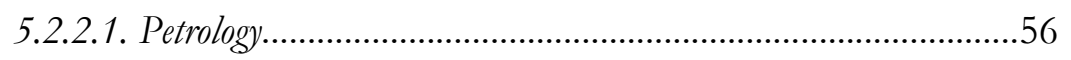

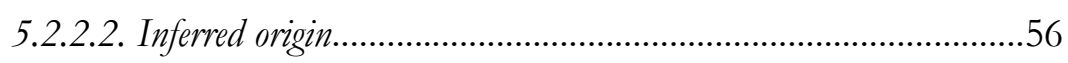

5.2.3. Lithofacies 2.a.i - Platey Rudstone.......................................................57 


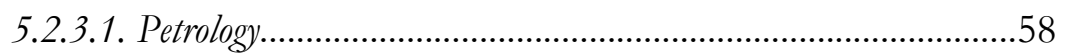

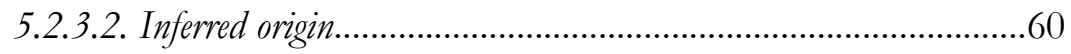

5.2.4. Lithofacies 2.a.ii -Branching Rudstone.............................................60

5.2.4.1. Petrology ………………………………………......................6

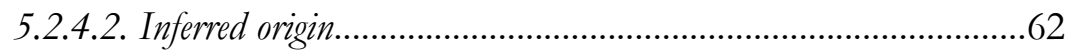

5.2.5. Lithofacies 2.b.i - Platy Floatstone....................................................62

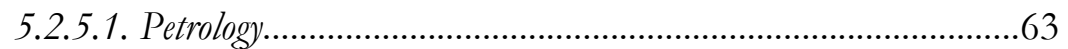

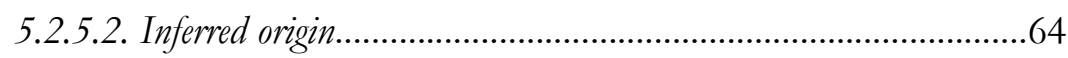

5.2.6. Lithofacies 2.b.ii - Branching Floatstone............................................64

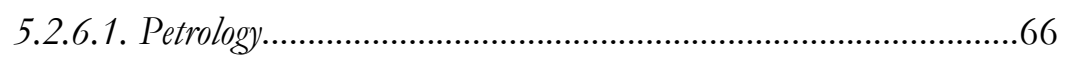

5.2.6.2. Inferred origin..............................................................................66

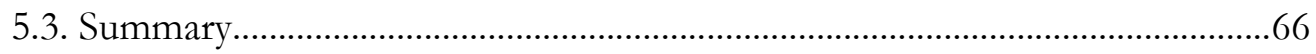

Chapter Six: Beachrock stratigraphy.........................................................69

6.1. Outcrop descriptions and stratigraphy...............................................................

6.1. 1. Cooper Island................................................................................... 72

6.1.2. Northern East Island...........................................................................

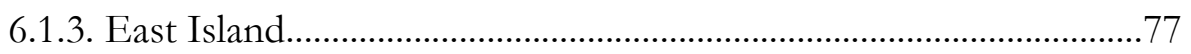

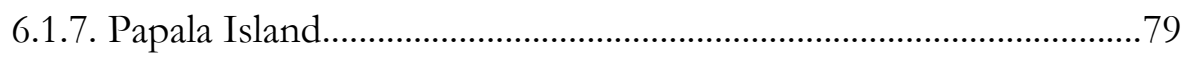

6.1.5. Lost Island and Fern Island..................................................................81

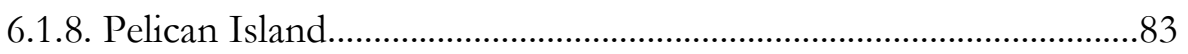

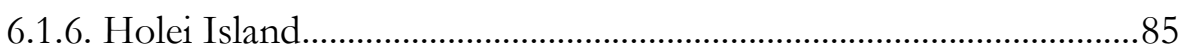

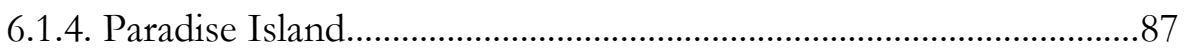

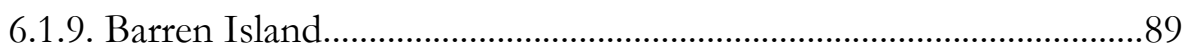

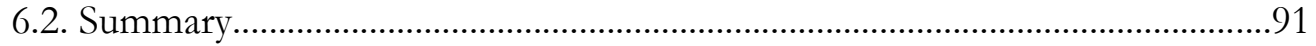

Chapter Seven: Numerical wave modelling........................................................93

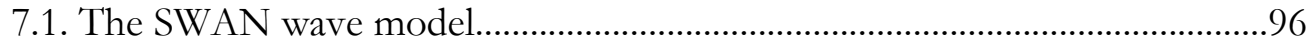

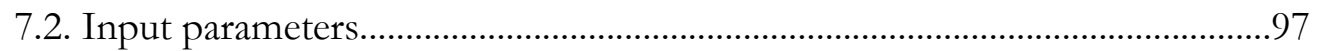

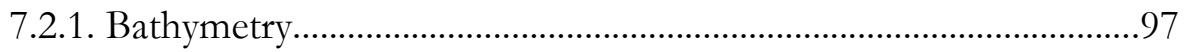

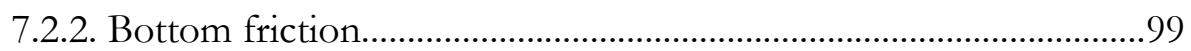

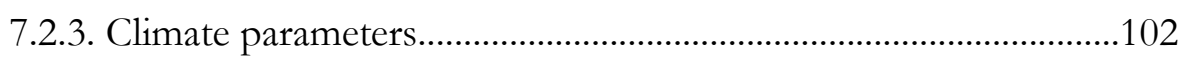

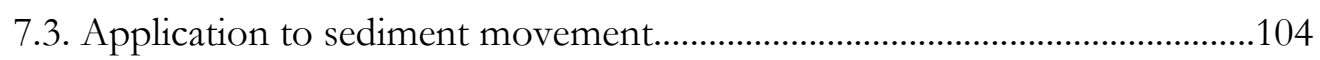

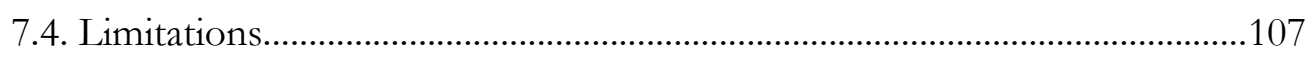


Chapter Eight: SWAN wave model results.............................................................110

8.1. Overview of wave modelling results..............................................................110

8.2. SWAN results and associated sediment movement.........................................112

8.2.1. Modelled annual conditions...............................................................112

8.2.1.1. Summer trade winds.................................................................112

8.2.1.2. Summer swells....................................................................113

8.2.1.3. Winter trade winds.............................................................114

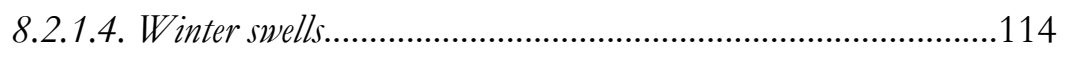

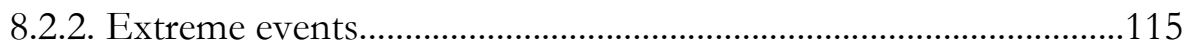

8.2.3. Influence of sea level variations.....................................................116

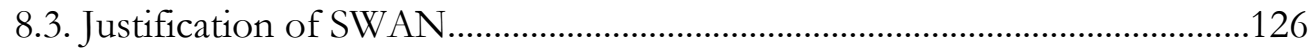

8.3.1. Wave height and direction................................................................126

8.3.2. Wave energy and deposits..................................................................128

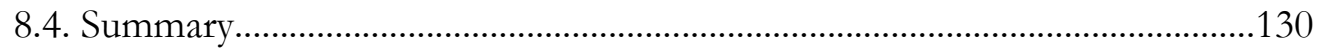

Chapter Nine: Associated atoll processes.....................................................132

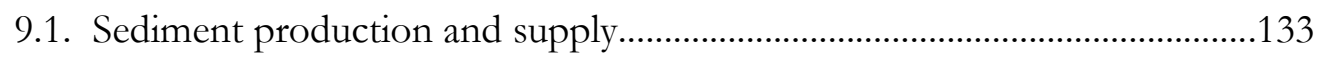

9.1.2. Carbonate growth zonation...............................................................134

9.2. Clast-orientation and paleo-flow estimation .................................................137

9.2.1. Results and discussion.....................................................................139

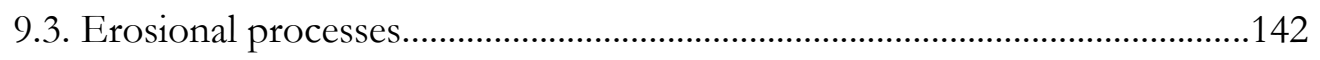

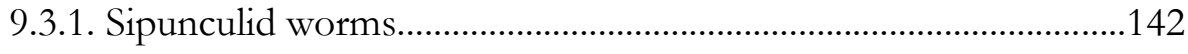

9.3.2. Microphytokarst erosion.......................................................................143

9.4. Insights from incipient beachrock and island growth Barren Island...........144

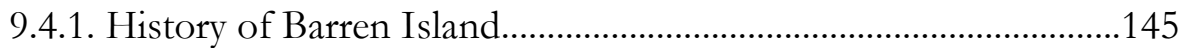

9.4.2. Island morphology and sediments..................................................145

9.4.3. A budget of sediment production for Barren Island......................149

9.4.3.1. Growth of Barren Island........................................................149

9.4.3.2. Source of sediment.....................................................................149

9.4.3.4. Sediment flux at Barren Island.............................................150

9.5 Summary of sediment supply and deposition at Palmyra Atoll......................151 
10.1. Formation of beachrock on Palmyra Atoll.

10.1.1. Radiocarbon dating of beachrock outcrops

10.1.2. Determination of the beachrock depositional environment by SWAN wave modelling. 154

10.1.3. Barren Island: incipient island growth and beachrock formation 161

10.1.4. Sediment budget and carbonate production. 161

10.1.5. Lithofacies and petrologic implications..........................................162

10.1.6. Orientation of beachrock clasts........................................................163

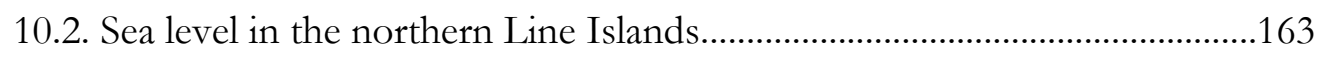

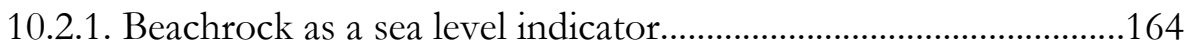

10.2.2. Sea level at Palmyra Atoll.................................................................165

10.3. Quaternary history of Palmyra Atoll.................................................................169

10.3.1. Development of beachrock and reef islands................................169

10.3.2. Additional shoreline changes............................................................171

10.3.3. Effects of beachrock on coastline evolution at Palmyra Atoll..172

10.4. Limitations and potential future studies.. 173

10.4.1. Beachrock: an underdeveloped proxy for environmental change? 173

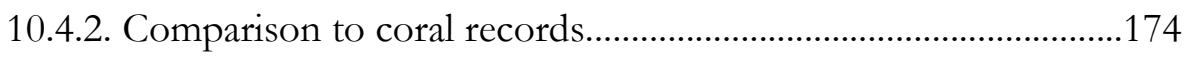

10.4.3. Comprehensive dating of reef islands..........................................175

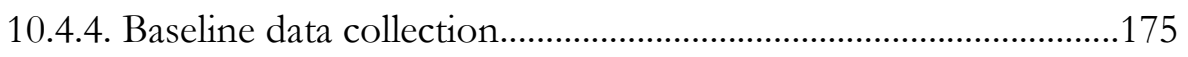

10.4.5. Developing the appropriate modelling tools..................................176

10.5. Summary: local and global conclusions............................................................177

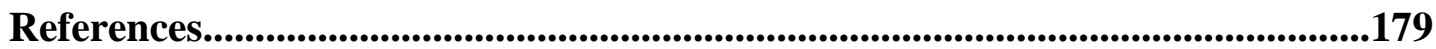

Appendix A: Compositional point counting data.....................................................A1

Appendix B: Example .swn file and WWIII plots..................................................B1

Appendix C: Paleo-flow data...................................................................... 


\section{List of Figures}

\section{Chapter One}

Figure 1.1: Location map of Palmyra Atoll and islets

\section{Chapter Two}

Figure 2.1: Sea level changes over the past 150,000 years....................................................

Figure 2.2: Late Quaternary sea-level curve for tropical Pacific island................................8

Figure 2.3: Ideal geometry of Pacific paleoshoreline proxies..................................................10

Figure 2.4: Beachrock and cayrock formation....................................................................15

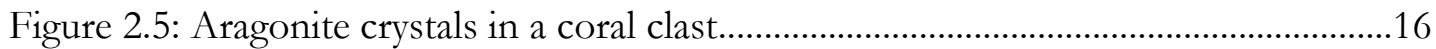

Figure 2.6: Cross sectional thin section of Tridacna maxima...................................................17

Figure 2.7: SEM images of Amphistegina sp.......................................................................17

\section{Chapter Three}

Figure 3.1: Major geological features of Central Pacific Ocean.............................................22

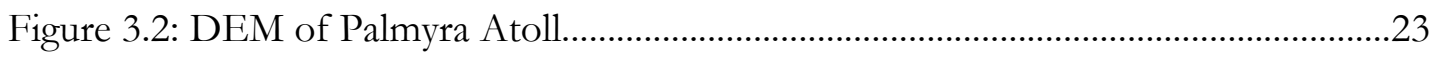

Figure 3.3: Key areas of Palmyra Atoll..............................................................................24

Figure 3.4: Map of dominant biological classes........................................................................25

Figure 3.5: Map of live coral cover classes...........................................................................26

Figure 3.6: Wind at Palmyra from WWIII hindcast model.................................................27

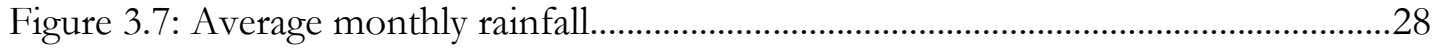

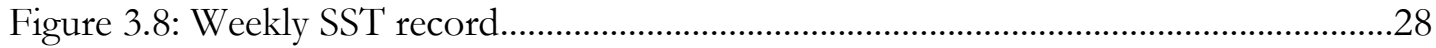

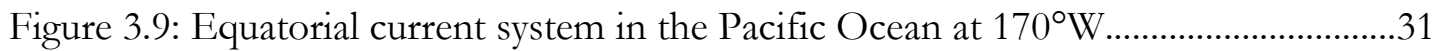

Figure 3.10: Sea floor and seamount ages in the central Pacific.............................................33

Figure 3.11: Outline of Palmyra's reef islands from 1874 to 2000......................................35

Figure 3.12: An aerial mosaic of Palmyra Atoll produced by the U.S. Navy in 1942........36

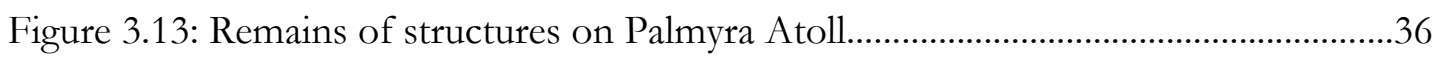

\section{Chapter Four}

Figure 4.1: Map of the beachrock outcrops at Palmyra Atoll...............................................40

Figure 4.2: Textural classification of reef limestones..............................................................42

Figure 4.3: Coral forms as a response to environmental stresses......................................42

Figure 4.4: Radiocarbon calibration curve for the past $2000 \mathrm{yrs..........................................4}$ 


\section{Chapter Five}

Figure 5.1: Northern edge of North fighter strip.................................................................49

Figure 5.2: Beachrock boulders on the reef flat at North Beach...........................................49

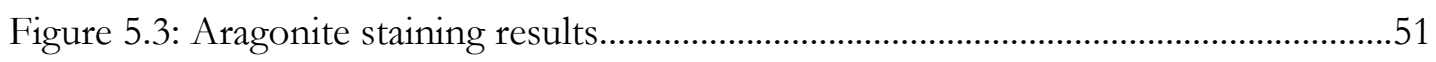

Figure 5.4: Average composition of Palmyra Atoll beachrock samples..............................52

Figure 5.5: Petrology of lithofacies 1a..................................................................................54

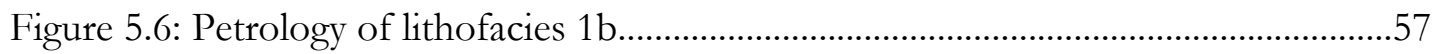

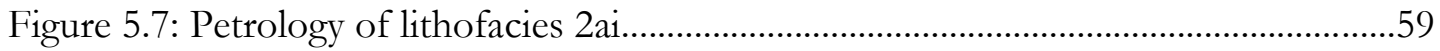

Figure 5.8: Petrology of lithofacies 2aii................................................................................61

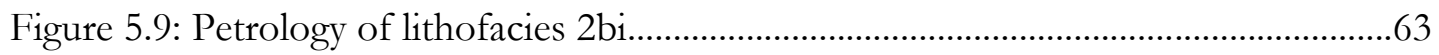

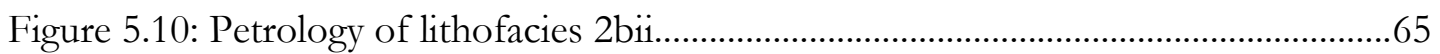

\section{Chapter Six}

Figure 6.1: Stratigraphic columns for Palmyra Atoll beachrock outcrops..........................71

Figure 6.2: Beachrock outcrop on Cooper Island...................................................................

Figure 6.3: Beachrock outcrop on northern East Island........................................................76

Figure 6.4: Beachrock outcrop on East Island........................................................................78

Figure 6.5: Beachrock outcrop on Papala Island......................................................................80

Figure 6.6: Beachrock outcrop of Lost and Fern islands........................................................82

Figure 6.7: Beachrock outcrop on Pelican Island..................................................................84

Figure 6.8: Beachrock outcrop on Holei Island.......................................................................

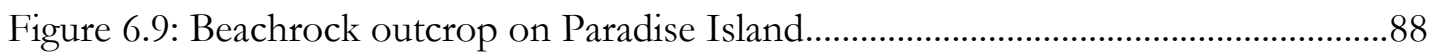

Figure 6.10: Beachrock outcrop on Barren Island...............................................................90

\section{Chapter Seven}

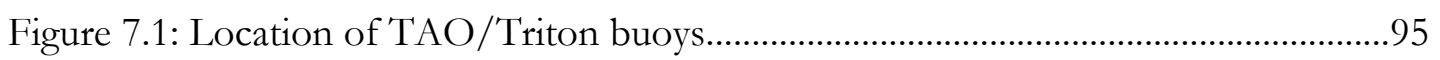

Figure 7.2: $5 \mathrm{~m}$ grid of the bathymetry surrounding Palmyra down to $300 \mathrm{~m}$ depth.........98

Figure 7.3: Bathymetry within the computational grid...........................................................98

Figure 7.4: Reef-scape photographs of reef terraces...............................................................101

Figure 7.5: Friction factor map of Palmyra Atoll...............................................................101

Figure 7.6: Wave climatologies for Palmyra Atoll.............................................................103

Figure 7.7: Historical photograph of waves on Cooper Island...........................................107 


\section{Chapter Eight}

Figure 8.1: Critical shear stress for sediment transport................................................111

Figure 8.2: SWAN results wave model for bed shear stress and orbital velocity...119-125

Figure 8.3: Modelled significant wave height across the reef at Palmyra Atoll................127

Figure 8.4: Validation of wave breaking heights at Palmyra Atoll....................................127

Figure 8.5: Reefal debris on Paradise Island.....................................................................128

Figure 8.6: A concrete structure on Home Island................................................................128

\section{Chapter Nine}

Figure 9.1: Calcium carbon production zones at Palmyra Atoll........................................135

Figure 9.2: Debris platforms on Barren Island...................................................................138

Figure 9.3: Examples of orientated beachrock beds............................................................139

Figure 9.4: Rose diagrams for beachrock beds..................................................................140

Figure 9.5: Rose diagrams for debris platforms on Barren Island.......................................141

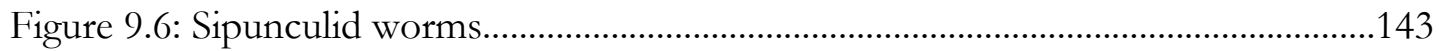

Figure 9.7: Microphytokarst erosion...............................................................................144

Figure 9.8: Oblique view of Palmyra Atoll in 1921 ..........................................................147

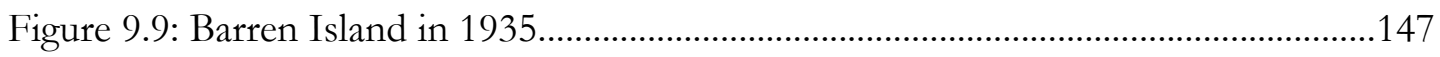

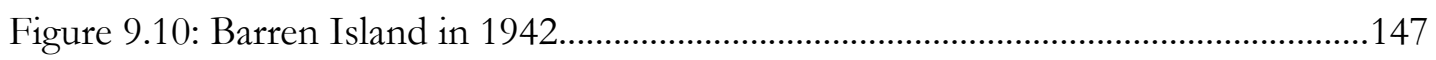

Figure 9.11: Map and cross sections of Barren Island.......................................................148

\section{Chapter Ten}

Figure 10.1: Map of beachrock ages and island chains...........................................................153

Figure 10.2: Plots of the additional wave -induced bed shear stress................................156

Figure 10.3: Williams et al. (2010) images of western terrace of Palmyra Atoll...............157

Figure 10.4: Holocene sea level curve at Palmyra Atoll.......................................................167

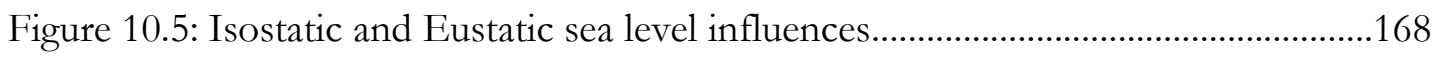

Figure 10.6: Cobb et al. (2003a) coral record.........................................................................174 


\section{List of Tables}

\section{Chapter Three}

Table 3.1: Timeline of Palmyra Atoll over the past 200 years. .38

\section{Chapter Five}

Table 5.1: Average composition of each beachrock lithofacies .51

Table 5.2: Summary of the lithofacies. .68

\section{Chapter Six}

Table 6.1: Radiocarbon ages of beachrock at Palmyra Atoll

\section{Chapter Seven}

Table 7.1: Friction factor of reef at Palmyra Atoll.................................................................101

Table 7.2: Typical average conditions of the wave climate at Palmyra Atoll....................104

Table 7.3: Critical shear stress for sediment transport......................................................106

\section{Chapter Eight}

Table 8.1: Area of sediment transport under conditions at high tide................................115

Table 8.2: Additional shear stress with increasing sea level..................................................117

Table 8.3: Area of transport under a $1 \mathrm{~m}$ sea level rise.......................................................118

\section{Chapter Nine}

Table 9.1: Zones of calcium carbonate growth at Palmyra Atoll........................................135

Table 9.2: Simplified model of calcium carbonate production at Palmyra Atoll............137

\section{Chapter Ten}

Table 10.1: Conditions where beachrock can be deposited .160

Table 10.2: Sea level highstand dates for selected island groups in the Pacific Ocean..166 


\section{List of Equations}

\section{Chapter Seven}

Equation 7.1: Bottom friction factor ........................................ 99

Equation 7.2: Wave-induced shear stress..................................... 105

Equation 7.3: Critical shear stress for sediment movement ......................105

\section{Chapter Nine}

Equation 9.1: Reef carbonate mass-balance ...................................132

Equation 9.2: Gross carbonate production .....................................132 


\section{List of symbols}

$\begin{array}{ll}\tau_{c} & \text { Critical shear stress }\left(\mathrm{Nm}^{2}\right) \\ \mathbf{U}_{\mathbf{b}} & \text { Orbital velocity of the wave on the bed } \\ \mathbf{g} & \text { Gravitational constant } \\ \mathbf{f}_{\mathbf{w}} & \text { Empirical friction factor } \\ \mathbf{f}_{\mathrm{e}} & \text { Wave energy dissipation factor } \\ \mathbf{D} & \text { Sediment diameter } \\ \mathbf{r} & \text { Hydraulic roughness length of the bed } \\ \mathbf{a} & \text { Amplitude of orbital excursion } \\ \mathbf{C}_{\mathbf{s}} & \text { Dimensionless constant } \\ \mathbf{Q}_{\mathbf{f}} & \text { Density of the fluid } \\ \mathbf{Q}_{\mathbf{s}} & \text { Density of the sediment } \\ \tau_{\mathbf{w}} & \text { Wave-induced bed shear stress }\left(\mathrm{Nm}^{2}\right) \\ \mathbf{G} & \text { Gross production } \\ \mathbf{P} & \text { Potential Production } \\ \mathbf{H}_{\mathbf{s}} & \text { Significant wave height } \\ \mathbf{T} & \text { Wave period } \\ \boldsymbol{\theta} & \text { Wave direction }\end{array}$




\section{List of acronyms}

\begin{tabular}{|c|c|}
\hline BSE & Backscatter Electrons \\
\hline BP & Before Present \\
\hline CAA & Civil Aviation Authority \\
\hline $\mathrm{CD}$ & Crossover Date \\
\hline C.E. & Common Era \\
\hline CMAP & CPC Merged Analysis of Precipitation \\
\hline DEM & Digital Elevation Model \\
\hline EDS & Electron Dispersive Spectrometer \\
\hline ENSO & El Nino Southern Oscillation \\
\hline EPMA & Electron Probe Microanalyser \\
\hline HMC & High-magnesium Calcite \\
\hline HTL & High-tide level \\
\hline IGOSS & Integrated Global Ocean Services System \\
\hline ITCZ & Inter-tropical Convergence Zone \\
\hline LTL & Low-tide level \\
\hline LGM & Last glacial maximum \\
\hline MHHS & Mid-Holocene Highstand \\
\hline MWP & Medieval Warm Period \\
\hline NECC & North Equatorial Counter Current \\
\hline NOAA & National Oceanic and Atmospheric Administration \\
\hline NSCC & North Subsurface Counter Current \\
\hline NWR & National Wildlife Reserve \\
\hline PARC & Palmyra Atoll Research Consortium \\
\hline SEC & South Equatorial Current \\
\hline SEM & Scanning Electron Microscope \\
\hline SSCC & South Subsurface Counter Current \\
\hline SSS & Sea surface salinity \\
\hline SST & Sea surface temperature \\
\hline SWAN & Simulating WAves Nearshore \\
\hline TNC & The Nature Conservatory \\
\hline USFWS & United States Fish and Wildlife Service \\
\hline WDS & Wavelength Dispersive Spectrometer \\
\hline WPWP & West Pacific Warm Pool \\
\hline WWII & World War II \\
\hline WWIII & WAVEWATCH III \\
\hline
\end{tabular}




\section{Introduction}

\subsection{Overview}

Coral reefs and $\mathrm{CaCO}_{3}$ shorelines are the results of the close relationship between biological and physical processes. Over $65 \%$ of the world's human population live in low-lying coastal regions and islands (Grossman et al., 1998) and, although small, coral reef islands can have high population densities (e.g. 8300 people $/ \mathrm{km}^{2}$ on Fongafale, Tuvalu and 47,400 people $/ \mathrm{km}^{2}$ on Male, Maldives; Webb and Kench, 2010). Furthermore, these environments are recognised as dynamic entities that respond rapidly to climate changes. The study of atolls and reef islands is extremely important due to their vulnerable coastlines that require comprehensive study to understand modern and future processes.

Atolls are the physical manifestation of the interplay between biological and geological processes, including sea level change. Indeed, stable atoll islets have only developed on emergent paleo-reef flats since the peak of the mid-Holocene hydroisostatic highstand (MHHS; Dickinson, 2009). Therefore, such islets are relatively young and the processes behind their formation and development are poorly known (Barry et al., 2007; Cowell and Kench, 2001). However, their development and stability is critically dependent on the balance between several competing processes, and this balance can change over time. One of the overriding influences on both biological and physical processes is sea level (reviewed in Chapter Two), and the effects of any future sea level rise on low lying atolls are unknown. Through a combination of eustatic and isostatic influences, global sea level has risen at a mean rate of $1.7 \pm 0.3 \mathrm{~mm} \mathrm{yr}^{-1}$ over the past 130 years (Church and White, 2006) and it has been widely suggested that if sea level rise continues, it may occur at a rate that is too high for coral growth to keep up with, resulting in a decline of sediment production, erosion of coastlines and risking the submergence of low lying tropical reef islands (Church et al., 2006; Webb and Kench, 2010).

Furthermore, knowledge of the impacts of the past and present wave climates in the Pacific is crucial for understanding the potential coastal impacts of climate change in the region. Surface winds and waves are a dominant contributor to both coastal inundation during periods of high water levels such as during storm surges, and empheral and chronic coastal erosion (Morton, 2002), and such major coastal impacts are expected to worsen with climate change and rising sea level (Christenson et al., 2007). 
In contrast, recent studies suggest that many Pacific atolls have increased in area over the past 50 years (Web and Kench, 2010), which highlights the dynamic and complicated nature of atolls and their islets. These issues highlight the importance of research to improve understanding of the processes and development of such areas and the impact of continuing environmental changes. Understanding the sedimentary processes of oceanic atolls is essential to understanding the present functioning of their environments, and thus feeds directly into management planning and decisions.

Palmyra Atoll, in the northern Line Islands (Fig.1.1), is an oceanic atoll that is unique for many reasons. Firstly, the atoll is located in an isolated region of the Pacific about which little is known. Secondly, Palmyra has never sustained a large, permanent human population, except for a few years during the Second World War (WWII), and is now a fully protected reserve area. This has created a natural laboratory in which atoll processes can be studied without human interference (Collen et al., 2009a). Unfortunately, this absence of human habitation has also resulted in lack of long term climate data and historical evidence of wind and wave patterns. Such a lack of baseline data is a common issue throughout the Pacific region and often hinders modern research and management efforts. Dealing with such a lack of data is a focus of part of this thesis (Chapter Seven).

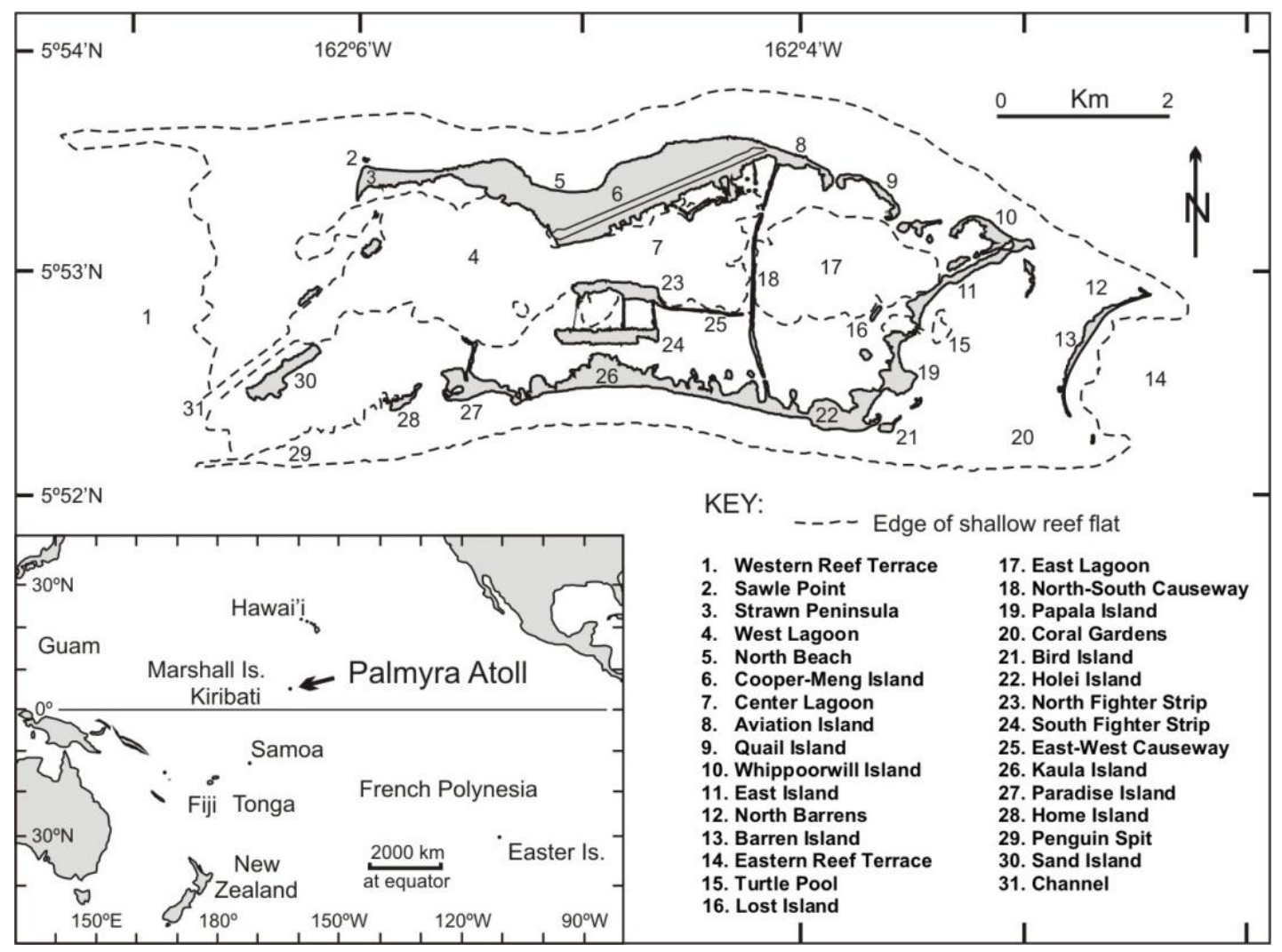

Figure 1.1: (From Collen et al., 2009a) Geographical Map of Palmyra Atoll showing labelled islands, lagoons and reefs 
The term 'beachrock' refers to cemented coastal sediments, and is essentially the lithified paleo-beach that has been rapidly cemented through the precipitation of $\mathrm{CaCO}_{3}$ cements (Vousdoukas et al., 2007). Beachrock is an important feature of many tropical coastlines as it appears to have an anchoring effect for dynamic islands and provides protection from erosion. Yet, much remains unknown or debated about its origin and properties. Beachrock outcrops may be one of the few physical records of past climate information on low-lying reef islands but research on their application as an indicator of paleo-environments in the Pacific is underdeveloped (Vousdoukas et al., 2007). As well as providing evidence about the physical depositional environment, beachrock is reported to cement in the intertidal zone (e.g. Rey et al., 2004) within just a few years (Frankel, 1968; Hopley, 1986); it, therefore, has the potential to provide an indication of past sea levels (Hopley, 1986; Nixon et al., 2009).

However, there are few dates for beachrock deposits in the Pacific although published ages are mostly between 3000-4000 yrs BP, with some as old as $5500 \mathrm{yrs}$ BP, such as in the Tuamotus Archipelago (Pirazzoli and Montaggioni, 1988). The lack of beachrock ages coincides with the scarcity of general paleo-climatic information for the Holocene in the oceanic Pacific (Nunn, 1998). Understanding and utilising possible recorders of past climates, such as beachrock, is crucial to predictions for future climatedriven changes.

This thesis examines the development of Palmyra Atoll using beachrock as an indicator for paleo-sea level and depositional environments through the beachrock stratigraphy, petrology and hydrodynamics. Additionally, a simple sediment transport model based on the SWAN hydrodynamic model, as well as a simple $\mathrm{CaCO}_{3}$ production model and a digital elevation model (DEM) derived from sonar measurements, are used as tools for understanding sedimentary processes at Palmyra. Radiocarbon dating is used together with these approaches to develop a history of the beachrock and reef island evolution. The need for long term climate and environmental records in an environment that is accepted as being extremely vulnerable to future climate changes is highlighted by the limitations to the numerical wave modelling. 


\subsubsection{Thesis objectives}

The research presented in the following chapters investigates the recent geological history of Palmyra Atoll, including the relationship to late Holocene sea level trends, and the use of beachrock as a proxy for environmental change. The research is part of the larger international scientific initiative to understand the natural systems on Palmyra Atoll and to provide baseline data for effective atoll management. The particular aims of this thesis are:

1) To describe the beachrock lithofacies and outcrops found on Palmyra Atoll in terms of their textural characteristics, including radiocarbon dating of individual outcrops;

2) To investigate the petrology of beachrock outcrops at Palmyra in order to determine the cementation process, and to establish the position of their formation on the beachface;

3) To interpret the depositional environment of the beachrock through the application of the SWAN (Simulating WAves Nearshore) numerical wave model; and

4) To provide a model of how the reef islands and beachrock outcrops of Palmyra Atoll have developed as a consequences of sea level change, $\mathrm{CaCO}_{3}$ production, and wave climates.

Overall, the results are integrated to describe the late Holocene history of Palmyra Atoll, including the definition of the MHHS in the equatorial Pacific. These results have implications for understanding the paleoclimate during beachrock deposition, including sea level, storm frequency, and the overall process of reef island development. This work compliments other research on Palmyra, especially those studies focusing on the long term record of climatic and sedimentary changes at the atoll.

Together, these studies highlight the delicate balance of systems in this very dynamic environment, and this important implications for the current management of Palmyra Atoll and also the management of natural coastal systems and processes on other tropical atolls and low-lying islands. 


\subsubsection{Thesis outline}

This thesis comprises ten chapters and three appendices. Chapter Two presents information on the sea level history through the Quaternary in the Pacific Ocean, and on the formation of beachrock, and how its formation can be related to sea level changes. The regional setting of Palmyra Atoll, including climate and geological history is described in Chapter Three. The methodology used in this thesis is explained in Chapter Four.

Chapter Five contains the sedimentology and petrology of the beachrock outcrops which are discussed through the definition of six major lithofacies. This is followed by the detailed stratigraphy and description of individual beachrock outcrops in Chapter Six, using the lithofacies previously defined.

Numerical wave modelling is then used to recreate the depositional environments of the beachrock outcrops based on the average clast size within them and the energy required to move these. Application of the SWAN model is described in Chapter Seven, including a description of the acquisition of input data from an area with limited environmental records. Results of the wave modelling are presented in Chapter Eight.

Other processes that influence the sedimentology of the atoll, such as sediment supply models and paleocurrent directions, are discussed separately in Chapter Nine. Finally, the discussion of all results and conclusions regarding beachrock, sea level, and the reef islands development are presented in Chapter Ten. 


\section{Pacific sea levels and beachrock formation}

This chapter briefly explains the sea level trends in the Pacific Ocean throughout the Holocene, as well as the nature of beachrock outcrops, including their characteristics, mechanisms of formation, occurrence and impacts on coastlines. In particular, the relationship between beachrock formation and sea level is discussed because it is an important and highly debated aspect. Sea level plays an important role in the formation and development of oceanic atolls, and therefore, the possibilities of beachrock as a paleo-sea level proxy are critical to resolve.

\subsection{Holocene sea level in the Pacific}

\subsubsection{Sea level change since the Last Glacial Maximum}

Sea level changes play an important part in the evolution of Pacific atolls. These variations reflect global geodynamic processes including glacio-eustatic sea level change and local and distinct isostatic responses. Low lying Pacific atolls are marginal environments, whose present form is a direct product of past sea level patterns. Relatively short term fluctuating sea levels have a considerable impact on atoll morphology (Peterson et al., 2006). During the Last Glacial Maximum (LGM; 20 ka), eustatic sea level was more than $120 \mathrm{~m}$ below the present level (Fig. 2.1) as a large amount of Earth's water was held in the polar ice caps (Nunn, 1999). From 19 ka there was a gradual rise in sea level until $6 \mathrm{ka}$. Melt water pulse around $14.5 \mathrm{ka}$ (Clark et al., 2004) caused a brief reversal in this trend.

Coral reefs kept pace as sea level continued to increase throughout the early Holocene, culminating in paleo-reefs at elevations of 1.0-2.4 $\mathrm{m}$ above modern low tide level during the mid-Holocene highstand (MHHS; Dickinson, 2009), before sea level fell again to the present level. This highstand in the tropics occurred as a result of global isostatic adjustment to the transfer of mass from circumpolar Pleistocene ice sheets to the Holocene oceans (Dickinson, 2001). "Equatorial ocean siphoning", a term coined by Mitrovica and Peltier (1991), led to a drawdown in the tropical Pacific sea level because of the transferral of the sea water required to cover the deepening continental shelves that downflexed under the load of increased meltwater offshore, and the collapsing forebulges of former ice sheets. The magnitude and the timing of termination of the highstand varied across the tropical Pacific Ocean, most likely as a result of varying mantle properties such as those associated with the South Pacific superswell (McNutt 
and Judge, 1990). Although the theoretical peak of the MHHS was at 4 ka (Dickinson, 2009), this peak was broad and both predictions and observations suggest the timing of the peak ranged from 5000 to 1500 years ago (Grossman et al., 1998).

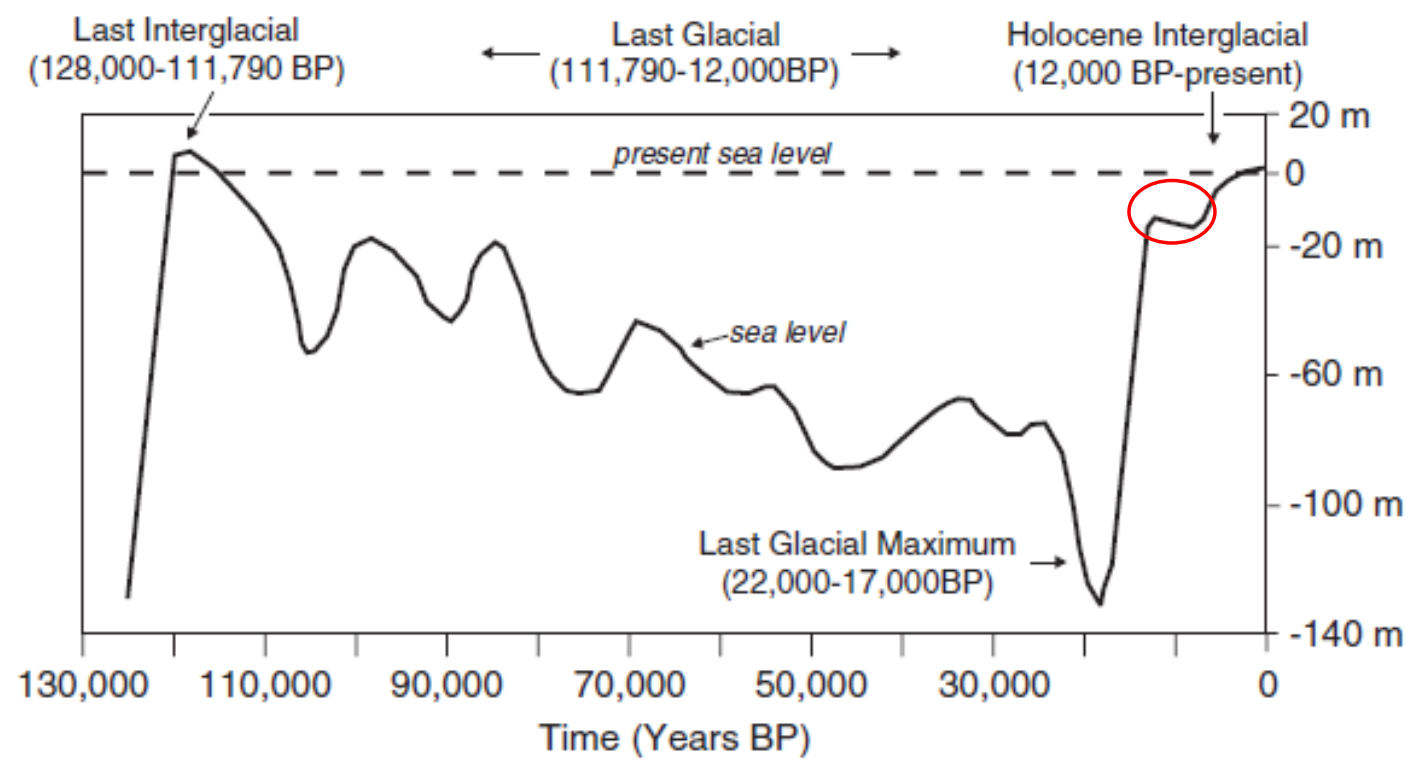

Figure 2.1: (From Nunn, 2007; after Nunn, 1999) Eustatic sea level changes over the past 150,000 years reconstructed from ages of emerged coral-reef terraces along the Huon Peninsula, Papua New Guinea The trend within the red circle was only observed at the Huon Peninsula. 


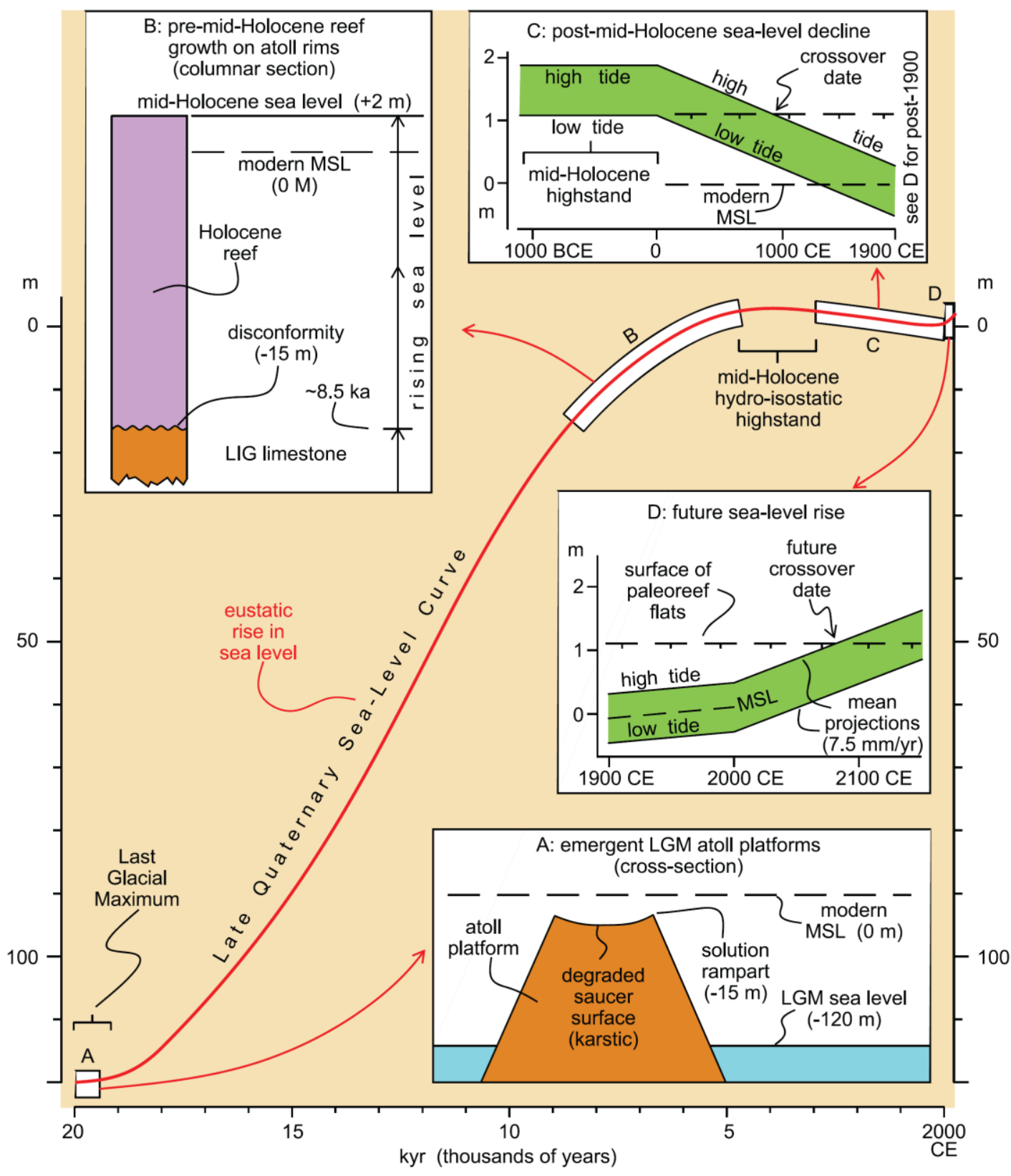

Figure 2.2: (From Dickinson, 2009) Late Quaternary sea-level curve for tropical Pacific islands (red line) and synoptic effects of changing sea level on atoll evolution (insets). (A) Atoll platforms emergent as subaerial limestone plateaus at Last Glacial Maximum (LGM). (B) Growth of Holocene reef limestone on atoll rims after rising eustatic sea level overtopped the degraded surfaces of Last Interglacial paleoreefs (upward limit of reef growth at low-tide level of mid-Holocene hydro-isostatic highstand in regional sea level). (C) Post-mid-Holocene decline in relative sea level carries ambient high-tide level below midHolocene low-tide level (crossover date), fostering the nucleation of stable atoll islets on resistant underpinnings of emergent mid-Holocene paleoreef flats. (D) Projected rise in sea level during continued global warming to carry ambient high-tide level above mid-Holocene low-tide level (overtopping midHolocene paleoreef flats at crossover date), thereby allowing fair-weather wave attack on unconsolidated sediment cover of atoll islets. Scale origins: elevation (m): 0-modern mean sea level (MSL); time (kyr): 0-2000 CE. 


\subsubsection{Development of stable reef islets}

The formation of stable islands on atolls requires the presence of an underlying consolidated base (e.g. cemented paleoreef flats) upon which sediment can accumulate. Such islands are termed "pinned" in the classification of Dickinson (2004) and are protected from wave attack by their paleo-reef underpinnings (Dickinson, 1999). Effective pinning requires a solid substrate and is preferentially formed under falling sea level. In comparison, sand cays that lack the solid interior of mid-Holocene paleo-reefs are transient and shift positions and morphology in irregular patterns under both fairweather and storm-wave conditions on atoll reefs (Richmond, 1992). As well as this fundamental difference between sand cays and pinned islets, they also form in different locations on atolls. Pinned islets are consistently formed on the windward side of atolls, where reef growth is more vigorous (Dickinson, 2009). These areas are also more exposed to storms and swells and as a result, the pinned islets form episodically (Woodroffe and Morrison, 2001). In contrast, sand cays tend to form on the low energy, leeward sides of atolls and show continuous deposition. The morphology of sand cays is a result of the continuous shaping by currents and wave refraction, and highlights the dynamic nature of oceanic atolls.

\subsubsection{Paleoshoreline proxies}

There are three complimentary groups of paleoshoreline proxies indicating paleo-high-tide, paleo-low-tide and the paleo-tidal-range (Fig. 2.3; Dickinson, 2001). Depending on the morphology and the degree of preservation, past shoreline elevations can be determined with varying degrees of precision. However, precision better than 0.1 $\mathrm{m}$ is not feasible due to the inherent irregularity of shorelines and reef flats. Modern tidal ranges are known to approximately the same level of uncertainty $( \pm 0.1 \mathrm{~m}$; Dickinson, 2001). Modern low tide level is marked by areas of reef flat, which are defined as the upward limit of reef growth. In contrast, high tide indicators on cliffed limestone are often represented by incised shoreline notches. However, low-lying atolls such as Palmyra lack sufficient relief to preserve such paleo-notches (Anthony, 2009). 


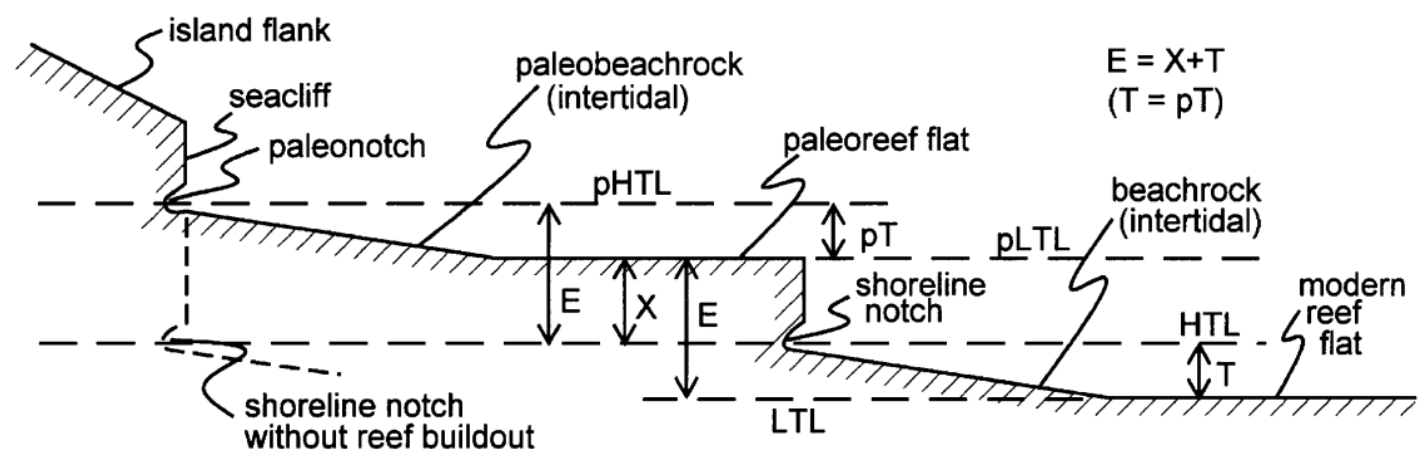

Figure 2.3: (From Dickinson, 2001) Ideal geometry (not to scale) of Pacific paleoshoreline proxies, although no all indicators are shown. LTL - low-tide level (pLTL - paleo-low-tide level); HTL - high-tide level (pHTL - paleo-high-tide level); T - tidal range (pT- paleo-tidal range); $\mathbf{E}$ - paleoshoreline emergence from a change in relative sea level.

On some island coasts, exposures of beachrock that are emergent above the modern intertidal zone serve as indicators of paleoshoreline position. The elevations of these outcrops must be interpreted with caution, though, as their occurrence is not restricted to the intertidal zone. This is because some cementation may occur in the supratidal swash zone where surf overtopping fringing reefs reaches island beaches. These paleoshoreline indicators are only preserved if favourable conditions are persistent. For example, paleo-reef surfaces are most likely to be preserved within protected embayments. Most often, indicators are preserved where instantaneous coseismic uplift occurs so that transient conditions during falling sea level did not make a comparable impact (Dickinson, 2001). However, this has not occurred at Palmyra. The indicators present, such as beachrock and micro-atolls, provide important physical evidence of past sea levels in environments where other physical records are limited.

\subsection{Relationship between beachrock and sea level}

Beachrock is a useful environmental proxy for several reasons. At the outcrop scale, it provides physical evidence of the energy of the depositional environment as determined by the size and morphology of the included coral clasts. Furthermore, oxygen isotope measurements from beachrock clasts have proven useful in sea surface temperature (SST) reconstructions along the coast of the Red Sea (Friedman, 2005). Most importantly, beachrock has been suggested as a proxy for Quaternary sea level and neotectonic studies as lithification takes place in the intertidal zone (Ramsey, 1995; Vieira et al., 2007; Vousdoukas et al., 2007). However, debate on the exact relationship between beachrock and sea level is vigorous (e.g. Kelletat, 2006; Kelletat, 2007; Knight, 
2007), and thus, still provides an inherent uncertainty when using beachrock for paleoenvironmental reconstructions.

Most literature on the topic suggests that beachrock lithification occurs in the intertidal zone (e.g. Stoddart and Cann 1965; Hanor 1978; Scoffin and McLean, 1978; Meyers 1987; Ramsey, 1995; Rey et al., 2004; Vousdoukas et al., 2007; David et al., 2009), although some authors suggest that this may also occur simultaneously within the supratidal spray zone (Viera and de Ros, 2006; Nixon et al., 2009). This reportedly occurs sub-aerially beneath a veneer of beach sediment (Neumeier, 1999), and beachrock is subsequently exhumed due to a recession of sea level (Hopley, 1986). However, there are suggestions that cementation instead occurs in the supratidal zone due to swash and sea spray at high tide, and this has been actively argued for by Kelletat (2006, 2007). Kelletat (2006) stated that the ridge-like morphology of most beachrock outcrops can only develop in two locations: the foreshore area where bars may form or the highest margins of storm beaches, where beach ridges are deposited. Kelletat argued that formation in subtidal bars is unlikely due to their mobility, whereas storm ridges may stay untouched for centuries. Kelletat (2006) concluded that beachrock deposits can be used as a sea level indicator "only in the sense that they bear witness to a former supratidal environment". However, this argument only deals with areas that, unlike the Pacific Ocean, have large tidal ranges.

Knight (2007) contradicted the above argument, stating that Kelletat (2006) did not take into account the age of the beachrock or the cementation style and formation processes. Knight considered the idea of cementation occurring in the supratidal position due to sea water spray to be incorrect and showed that cementation occurs in the main body of the beach due to a variety of processes. It has been suggested that beachrock can be related to periods of sea level regression, as studies suggest that $\mathrm{CO}_{2}$ degassing preferentially takes place during a falling tide (Meyers, 1987). This occurs as $\mathrm{CO}_{2}$ tends to dissolve in pore water during the first phase of the rising tides, which increases the saturation ratio. Saturation then decreases during the falling tide due to degassing, resulting in the precipitation of $\mathrm{CaCO}_{3}$.

Reviews of the literature highlight the issue that beachrock, and in particular its relation to sea level, is an underdeveloped area of research in coastal science. Further understanding can advance the understanding of marine and groundwater interactions and the role of biomineralization in addition to advancing the understanding of paleoenvironments and sea level patterns. 


\subsection{Beachrock}

Beachrock is defined as a hard coastal rock that consists of beach sediments that have been rapidly cemented through the precipitation of carbonate cements (Vousdoukas et al. 2007). Beachrock deposits typically form low, seaward-dipping, planar beds that mimic the original shoreline depositional environment. Thus, the inclination of the beds is generally related to the original sedimentary structures, although some of the latter may develop after cementation due to subsidence and tilting. The exhumation of beachrock is typically a result of coastal erosion due to a negative sediment budget or a sea level rise (Desruelles et al., 2009). The primary depositional feature of beachrock is bedding, often apparent due to variations in texture and composition. Although these typical morphological features of beachrock can be seen in almost all deposits, composition of the rock can be widely variable and include sand and gravels of both clastic and biogenic origin. Sand is the predominant grain size due to the easier cementation of a sandy matrix (Scoffin and Stoddart, 1983), and this may develop after the original deposition of clasts due to infiltration of the smaller sand grains between larger clasts.

\subsubsection{Beachrock occurrence}

Quaternary beachrock is a common feature on many tropical and subtropical shorelines. Most contemporary beachrocks have latitudinal limits similar to the 'Darwin Point' of coral atolls, where the ocean water temperatures are just sufficiently warm for upward reef growth to keep pace with the rate of subsidence (Grigg, 1982). Occasionally cemented beaches are found on temperate or even cold coasts, but these have significantly different origins to tropical beachrock (Kneales and Viles, 2000). Vousdoukas et al. (2007) summarised the available information on beachrock worldwide and identified areas with a high density of beachrock occurrences in the Mediterranean and Caribbean Seas, the tropical and subtropical Atlantic coasts, and the atolls of the Pacific and Indian Ocean. There appears to be a dominance of beachrock occurrence between $20^{\circ}$ and $40^{\circ}$ in both hemispheres, although Vousdoukas et al. (2007) suggest that this may reflect a bias of relevant research in certain areas.

It is generally accepted that beachrock preferentially forms on microtidal shorelines, as larger tidal ranges may not allow sufficient time for the beach sediment to consolidate before being eroded. This understanding has allowed beachrock to be 
distinguished from other lithified deposits, such as cayrock, by its cementation location. Similar to beachrock, cayrock is a sandstone that cements in the supratidal zone (Fig. 2.4; Gischler and Lomando, 1997). Cayrock may be easily confused with true intertidal beachrock, along with emerged reef rock, phosphate rock, or cemented soil. Analysis of the cements can help to differentiate beachrock from similar deposits. Whereas beachrock has marine-phreatic cements, cayrock is dominated by meteoric vadose cementation.

The position on the beachface at which beachrock forms often determines the broad morphology of the outcrop (Scoffin and Stoddart, 1983). Sandy beaches are often typical of the leeward islands of coral reefs and cementation at these beaches takes place in situ or under a thin veneer of sediment. In contrast, beachrock from the windward side is often characterised by coarse coral shingle banked in series. Acropora (staghorn) coral deposits can help the lithification process because, once deposited, the interlocking rods of coral branches stabilise the deposit and allow finer sediment to accumulate in the interstices.

\subsubsection{Formation mechanisms}

Beachrock originates from beach deposits that have been cemented by the precipitation of calcium carbonate. However, this formation can be the result of a wide range of sedimentary processes and various ages, cementing agents and diagenetic environments have been identified (e.g. Gischler and Lomando, 1997; Schmalz, 1971; Davis and Kinsey, 1973; Hanor, 1978). The origin of tropical beachrock has been the subject of long-standing debate, with several theories having been proposed that relate either to physiochemical or biological mechanisms (Scoffin and Stoddart, 1983; Vousdoukas et al., 2007). Formation mechanisms can be classified into four main processes: direct cement precipitation, mixing of marine and meteoric waters, degassing of $\mathrm{CO}_{2}$, and formation by biological activity. However, most authors agree that several mechanisms may be a factor in different locations and that the formation of beachrock is dependent on the location and environment.

The most widely proposed mechanism for beachrock formation is by the direct precipitation of cement from marine or fresh waters (Vousdoukas et al., 2007). Cement precipitation from marine waters is considered to take place in or near the intertidal zone due to the alternating wetting and drying of the sediments (Gischler and Lomando, 1997; Kelletat, 2006), aided by increased water temperatures due to warming of the 
beach during the day. This theory is supported by the presence of aragonite cements, indicating a marine provenance, within most beachrocks.

An alternative theory is that cementation is due to the mixing of marine and meteoric waters. This developed from the understanding that due to the decrease of solubility in water of $\mathrm{CaCO}_{3}$ with decreasing salinity, mixing of marine and fresh water may result in carbonate saturation and lead to precipitation of the cement (Schmalz, 1971). However, Hanor (1978) showed through thermodynamical experimentation that precipitation of $\mathrm{CaCO}_{3}$ cannot be induced through the mixing of marine and meteoric waters.

Degassing of $\mathrm{CO}_{2}$ from groundwater can produce calcite crusts similar to some cements observed in beach sediments (Hanor, 1978). Carbon dioxide is produced in the sediment column by plants and subsequently washed seaward by the flux of groundwater. Therefore, the concentration of $\mathrm{CO}_{2}$ is highest in the phreatic zone and continually diffuses upwards because of the potential gradient between the phreatic zone, the vadose zone and the atmosphere. This process is self-limiting due to the relative volume of pore space, which can be obstructed by cement, as well as the maximum thickness of the cemented zone that can develop. As cement is precipitated, the porosity of the sediment decreases, which in turn decreases the ability of the system to degas (Hanor, 1978). However, this hypothesis requires waters to have sufficient residence time in the landward areas to acquire a high $\mathrm{P}_{\mathrm{CO} 2}$ and dissolved calcium and carbonate, and sufficient residence time in the forebeach areas such that degassing can take place before the waters reach the oceans. Sufficient residence times may be lacking on oceanic atolls due to the small and extremely porous nature of reef islands (Stoddart and Cann, 1965).

Many authors have considered the influence of the direct biological precipitation of beachrock cements (Davis and Kinsey, 1973; Kumbrien, 1979; Neumeier, 1999). Indirect biological precipitation may be possible in anaerobic environments where bacterial processes can control the partial pressure by $\mathrm{CO}_{2}$ consumption (Berner, 1971). Nuemeier (1999) suggested that micro-organisms have strong influence over the formation of the first micritic cement and the development of the subsequent prismatic cement probably results from abiotic precipitation during times of higher fluid circulation. 


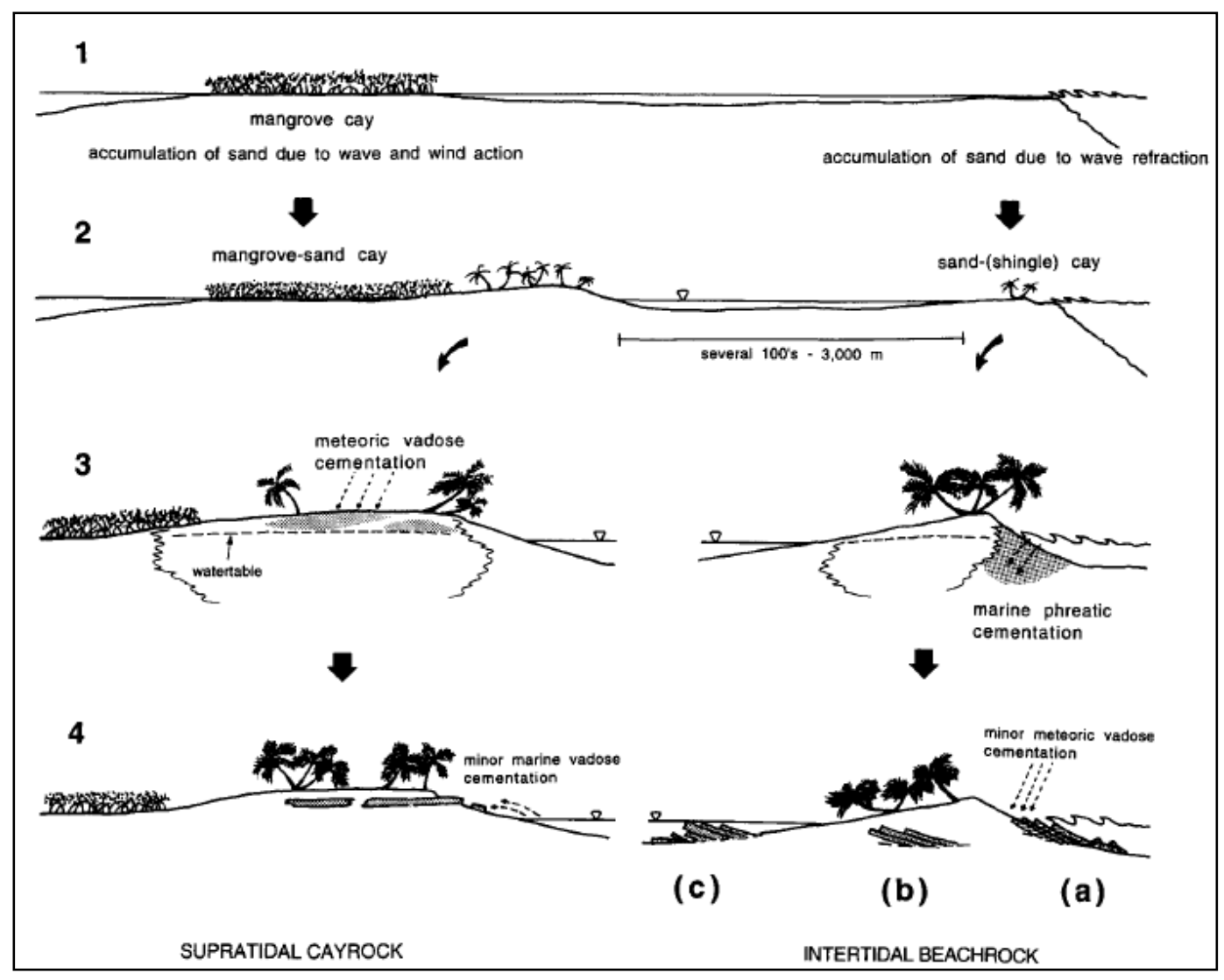

Figure 2.4: (From Gischler and Lomando, 1997) Model of beachrock and cayrock formation. (1) Idealized cross-section through a marginal barrier or atoll reef that has mangrove cays in the lagoon area. (2) Due to wave refraction at the reef crest small sand cays may build up on the reef flat. (3) Intertidal beachrock forms on the windward side of small sand and sand-shingle cays on the reef due to rapid, subaerial cementation. Supratidal cayrock forms due to vadose cementation of sand or beach ridges of larger mangrove-sand cays. (4) Due to movement of the cays, intertidal beachrock gets exposed mainly on the windward side (a), but may also be covered (b), or exposed on the leeward side (c).

\subsubsection{Beachrock composition}

Analysis of the beachrock lithofacies requires determining the composition of the rock, which is determined from thin sections. Typically, carbonate rocks have six main components (Adams and MacKenzie, 1998):

a) Grains are known as the allochemical components (allochems). They include coated grains, peloids, intraclasts and bioclasts.

b) The matrix occurs as carbonate mud sediments of clay and silt-sized particles, which are deposited either during or after the deposition of the allochems.

c) Terrigenous components are detrital quartz, clay or other non-carbonate minerals.

d) Carbonate cement of aragonite, calcite or high-Mg calcite. Staining techniques (described below) were used in order to determine the mineralogy of the cement 
e) Replacive crystals of dolomites, evaporate minerals or other non-carbonate minerals.

f) Pore space is any space in the sediment filled with air, water or hydrocarbons.

Due to the nature of the atoll environment and the young age of the beachrock, terrigenous components and replacive crystals are not observed at Palmyra. The allochemical constituents were separated into the following 11 groups: coral fragments, algal fragments, pore space, cement, bivalves, molluscs, foraminifera, intraclasts, echinoderms, bryozoans, and 'other'.

Scleractinian corals found on the reefs at Palmyra are represented within the beachrock as gravel clasts and finer matrix material. These corals have hard parts that are composed almost exclusively of aragonite and are usually identified in thin section from their size and gross morphology. Such clasts are made of radiating bundles of very fine fibrous aragonite, which are clearly seen under plain- and cross-polarised light (Fig.2.5). The radiating bundles give small areas of sweeping extinction as the stage of the microscope is turned. However, in smaller fragments, the sweeping extinction is not always seen.

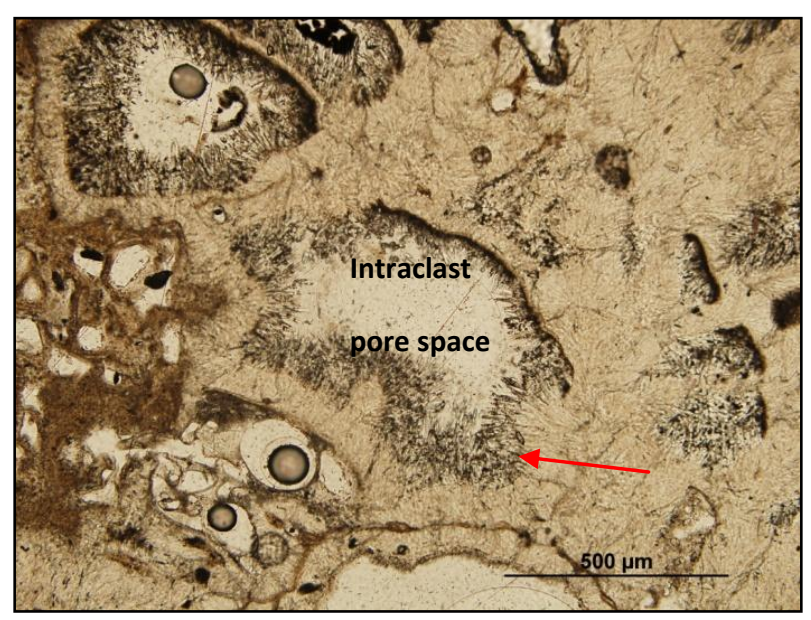

Figure 2.5: Photomicrograph of a coral clast from the Paradise Island beachrock showing bundles of aragonite crystals (red arrow) growing into the intraclast pore space.

Bivalves are an important contributor to the bioclast content of limestones out of the major molluscan groups. Bivalve shells can be wholly aragonite, wholly calcite, or a mixture of the two. Shell structure also varies with the most important forms being foliated, prismatic, cross-lamellar and homogenous (Fig. 2.6; Adams and MacKenzie, 1998). Gastropods are next in importance as molluscan contributors to limestones. Gastropod shells are nearly all composed wholly of aragonite, although a few have 
mixed mineralogy. The most common gastropod shell structure shows a cross-lamellar structure similar to that of some bivalves.

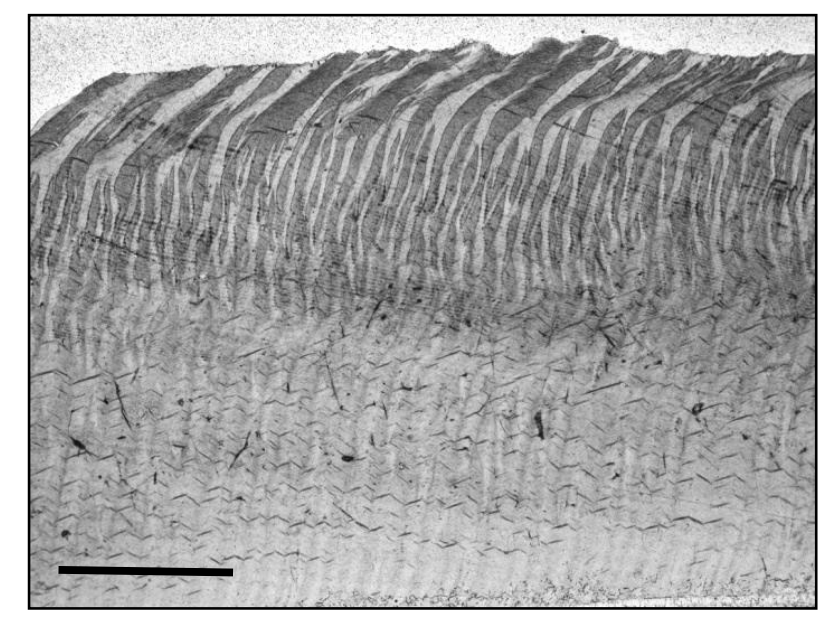

Figure 2.6: Cross sectional thin section through the shell of a Tridacna maxima bivalve. Scale bar is $1 \mathrm{~mm}$.

Foraminiferan tests show a great variety of shapes and sizes; most are multichambered and many are coiled. Difficulties of identification in thin section often arise because random sections through the same organism can appear quite different. However, the most common genus present in the beachrock at Palmyra is Amphistegina spp., which has a finely porous test of low-Mg calcite (Fig. 2.7). This genus houses diatom symbionts in the inner lateral walls, which are structured in an 'egg crate' fashion (Resig, 2004). The accumulation of lamellae in the umbilical region of each chamber addition produces a think umbo both dorsally and ventrally (Resig, 2004). The dense micro-architecture causes Amphistegina to be almost three times more resistant to abrasion than other major constituents of Hawaiian beach sand (Moberly, 1968). Therefore, even fragmented tests or residual umbos are identifiable.

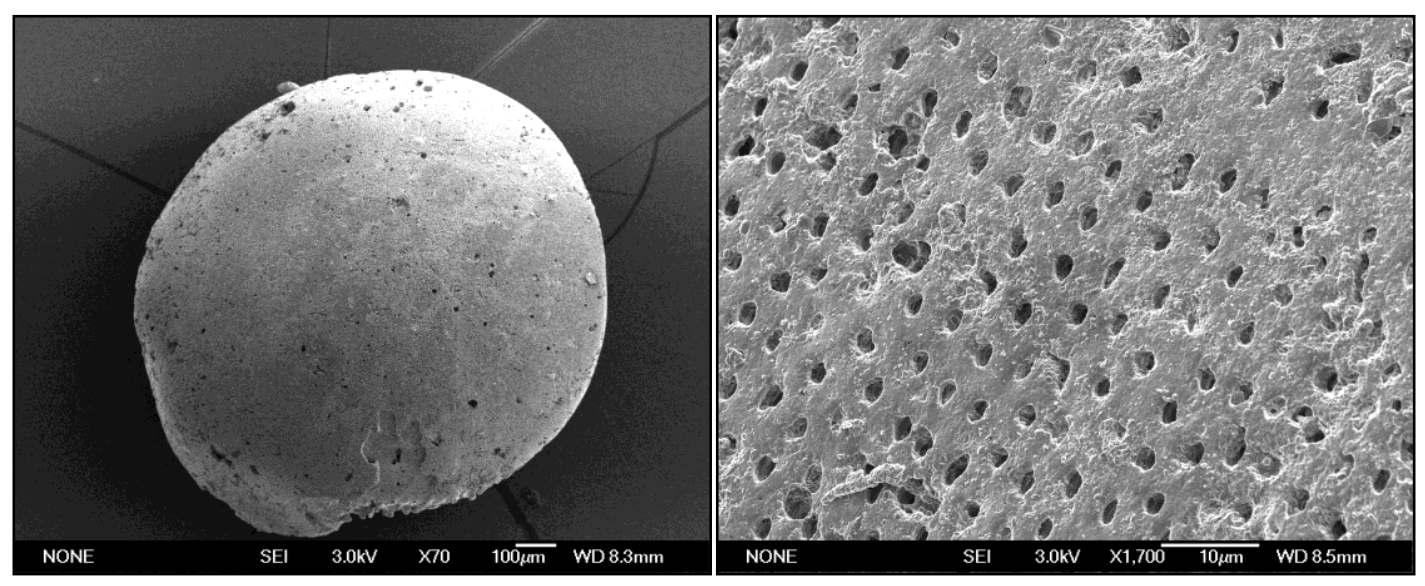

Figure 2.7: Scanning election microscope images of a modern Amphistegina test showing the whole test on the left and a close up of the porous microstructure on the right (Images courtesy of R. Mucadam). 
Intraclasts are fragments of carbonate sediment that have been reworked from within the basin of deposition. In this study, these are most likely to be eroded fragments of older beachrock or reef pavement incorporated into the younger material. They can be identified as aggregates comprising a number of separate particles bound together by cement separate to the beachrock in which they are found.

The calcite skeletons of echinoderms consist of plates of high-Mg calcite permeated by a meshwork of organic material. However, the calcite in each plate is secreted in the same crystallographic orientation so appears as a single crystal and hence behaves anisotropically, making identification easy. Echinoid spines are the most common echinoderm components of beachrock. Cross sections through these show porous, radial morphology. Most echinoid spines have calcite crystal c-axes parallel with their length, and transverse sections show interference colours lower than those often seen with other carbonates. Cross sections of spines are often tangential and, therefore, elliptical in shape.

Bryozoans are colonial marine organisms with a calcareous skeleton and are relatively common in the reef environment but rarely found within the beachrock samples studied. Finally, the 'other' category refers to any material that is not included in the other groups, or is too small to be successfully identified. This group includes, for instance, sponges, ooids, peloids, and other types of molluscs.

\subsubsection{Beachrock cements}

Calcium carbonate cements that lithify tropical beachrock are either highmagnesium calcite ( $\mathrm{HMC} ; 10-14 \mathrm{~mol}^{\%} \mathrm{MgCO}_{3}$ ) or aragonite. Salt water is generally aragonite-saturated and freshwater is undersaturated in aragonite (Stoddart and Cann, 1965). Thus, unstable aragonite will convert to calcite when transferred from salt water to freshwater (Cloud, 1962). Therefore, cements can be diagnostic of the environment of formation, where needles of aragonite cement are characteristic of the marine phreatic zone, and HMC sparitic cements with stalactitic disposition are characteristic of the marine vadose zone (Desruelles et al., 2009). Additionally, the formation of acicular aragonite and micritic HMC may be related to the leeward and windward sides of an island respectively, as recorded by Scoffin and McLean (1978) on islands of the Great Barrier Reef.

Cement fabric formation is also dependent on the environment. Such fabrics occur in three main morphologies: micritic coatings, fibrous or bladed crusts 
(commonly aragonite) or equant crusts of HMC (Scoffin and Stoddart, 1983). It is the formation of micritic cement with irregular undulations that often seems to control and initiate beachrock diagenesis (Neumeier, 1999; Desruelles et al., 2009). The micritic texture forms as thin isopachous fringes or as a meniscus fabric between grains. Isopachous and meniscus fringes are the most common fabric of cements and suggest that the grains were cemented in a phreatic environment. Meniscus fabrics result from periodic water saturation in the intertidal zone where, during low-tide and evaporation, seawater is held by capillary action at grain contacts. This results in varying thicknesses of cements precipitating within the meniscus and causing rounding of the pore space. Furthermore, the crystals are typically blunt due to undernourishment at their tips. During the drainage of impermanently saturated sands, a thicker film of water persists at the under-surface of grains; this develops small-scale "stalactites" beneath grains and is known as gravitational cement (Scoffin and Stoddart, 1983).

\subsubsection{Effect of beachrock on coastlines}

The formation of beachrock can irreversibly alter the coastline, especially in highly dynamic environments such as small Pacific atolls. It has significant effects on the ecology as well as affecting beach morphodynamics. For instance, in many cases outcrops of beachrock have been found to act as effective natural beach defences which mitigate the erosion of the beach (Bird, 2000). This is particularly true on the coasts of dynamic and fragile small islands and atolls (e.g., Dickinson, 1999). Once the beachrock has formed, it sets a limit to which the beach bed can erode, in effect locking the beach profile. The expression of the beach is thus controlled by the relationship between beachrock and the nearshore hydrodynamics (Vousdoukas et al., 2007).

The nearshore hydrodynamics may also be affected by the presence of beachrock outcrops which alter sea bed roughness and subsequently change the friction of the sea bed (Fredsoe and Deigaar, 1992). Additionally, outcrops of beachrock can have significant effects on the transport and supply of sediment on beaches. Vousdoukas et al. (2009) showed that submerged beachrock outcrops impede onshore transport of sediment and may act as offshore transport conduits for beach sediment. Patches of beachrock may also act as traps for sediment being transported by longshore drift (Vousdoukas et al., 2007).

Beachrock may also have erosional effects on the beach. The addition of impermeable beachrock layers can modify the infiltration and extraction process of 
water percolation through beach sediments and increase the volume of wetted, and thus more buoyant sediment in the swash zone that could make the area more prone to erosion (Vousdoukas et al., 2007). 


\section{Regional setting}

Palmyra Atoll lies near the centre of the Pacific Ocean. Located at $5^{\circ} 52^{\prime} \mathrm{N}$ and $162^{\circ} 04^{\prime} \mathrm{W}$, Palmyra is one of the most northern islands in the Line Island chain (Fig. 3.1). Palmyra is unique because it has never been permanently inhabited and it remains as the only unpopulated (except for scientific staff) "wet" atoll $(>400 \mathrm{~cm}$ of rain per year) of the tropical Pacific Ocean. All other atolls with similar conditions are permanently inhabitated, often with large populations and the consequent necessity to protect infrastructure. Palmyra thus gives researchers an exclusive opportunity to study an atoll system and the surrounding reefs without anthropogenic influences. This chapter outlines the natural and anthropogenic history of Palmyra as well as the known climate and oceanographic information for the area.

\subsection{Geography of Palmyra Atoll}

\subsubsection{Location}

Palmyra Atoll is at the northern extremity of the Line Islands, lying along a linear submarine ridge and surrounded by ocean waters approximately $4000 \mathrm{~m}$ deep. Today, the Line Islands border the Central Pacific Basin, a complex and poorly understood area of the sea floor which has had only limited geological drilling and dredging (Davis et al., 2002). The NW-SE trending features of the Line Island ridge are intersected by three fracture zones: Molokai, Clarion, and Clipperton (Fig. 3.1). 


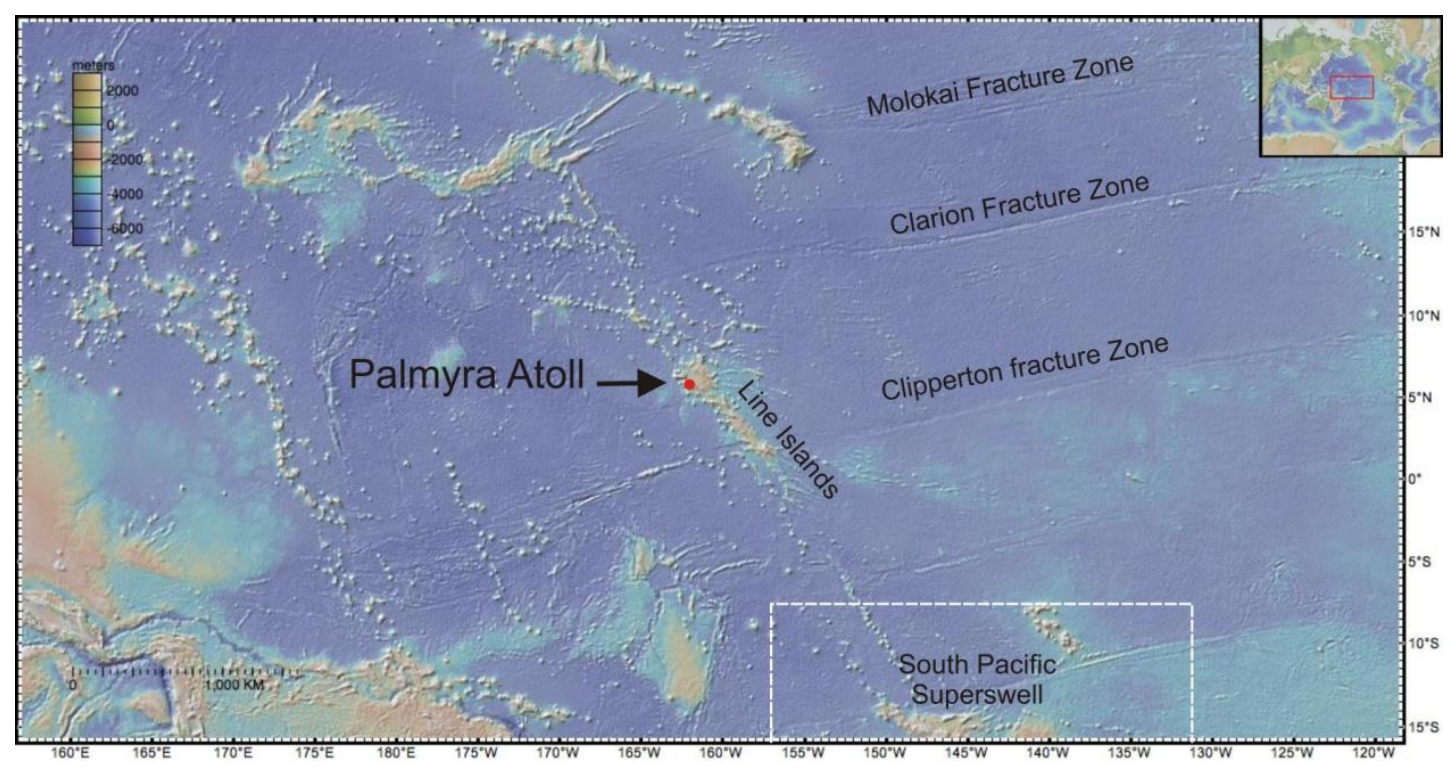

Figure 3.1: Major geological features of Central Pacific Ocean. Bathymetric map obtained from http://www.geomapapp.org/ (Ryan et al., 2009).

\subsubsection{Bathymetry}

The islands of Palmyra are at most only 3 metres above sea level and is surrounded by $61 \mathrm{~km}^{2}$ of reef to a maximum of $30 \mathrm{~m}$ depth. Recent multibeam sonar mapping around the U.S. Pacific remote island areas (Vroom et al., 2006; Fergeson et al., 2006) provides a detailed look at the morphology of Line Islands, in particular at the surrounding shelf and slopes of Palmyra Atoll. The DEM produced here from these data (Fig. 3.2) highlights the steepness of the slopes around the atoll and the depth of the ocean in which it stands. At the reef edge, the sea floor drops very steeply to $1000 \mathrm{~m}$ depth over $2 \mathrm{~km}$ and to $4000 \mathrm{~m}$ depth within $45 \mathrm{~km}$. This is the typical depth of the Line Islands submarine ridge (Hanmann et al., 2004). 


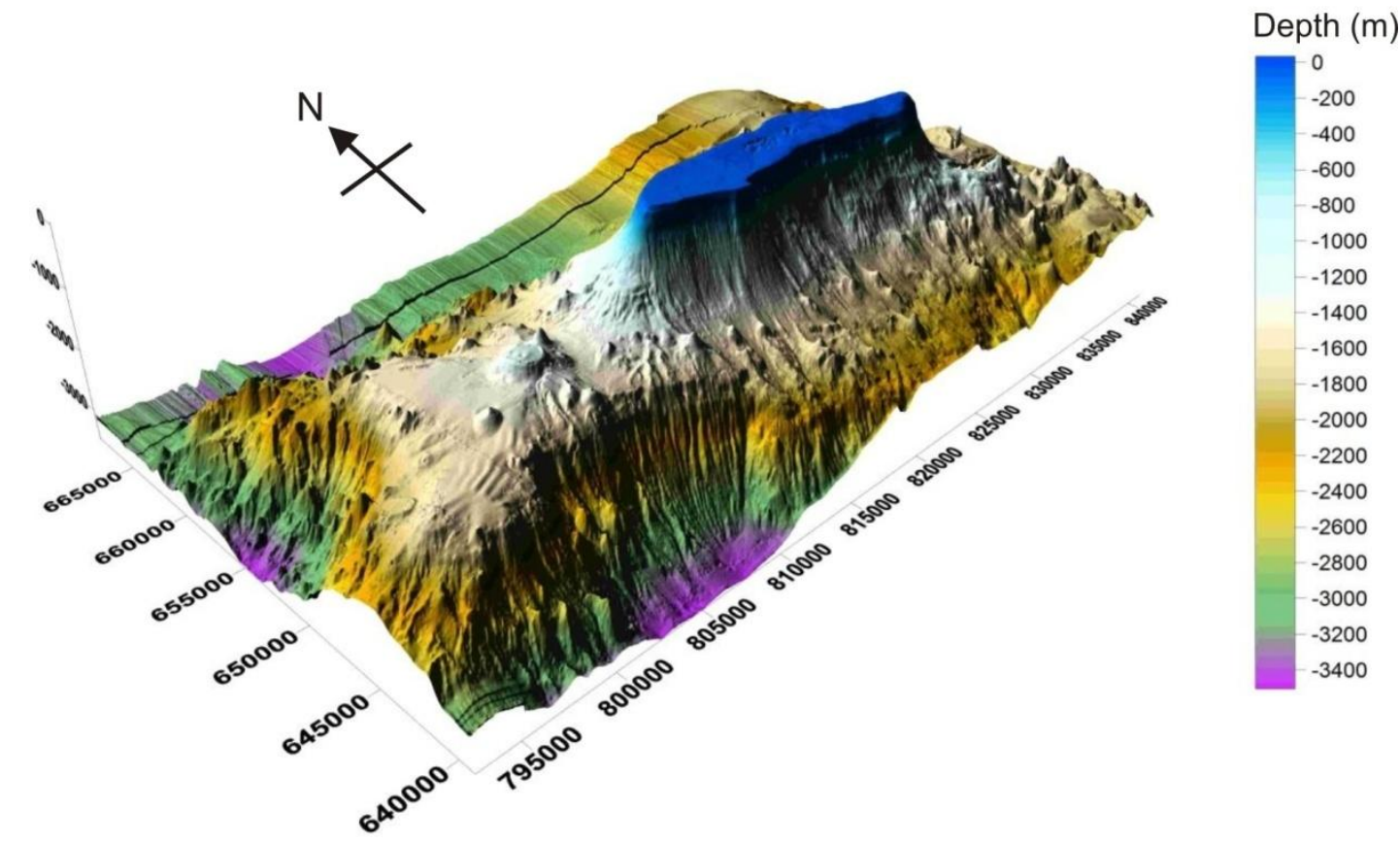

Figure 3.2: DEM of Palmyra Atoll looking to the northeast of the bathymetry surrounding Palmyra Atoll down to $3400 \mathrm{~m}$ depth. Depth scale bar is in meters. The lagoons can be seen as depressions in the centre of the atoll. Bathymetry data from Gaia Geo-Analytical et al. (2009; http://soest.hawaii.edu/pibhmc/ pibhmc_pria_pal_bathy.htm)

Analysis of the sea floor surrounding the atoll is beyond the scope of this study. However, in brief, the sea floor has varying morphology and shows a range of slope environments. To the immediate north of Palmyra, the sea floor drops nearly vertically from sea level and flattens out towards the bottom at about $3000 \mathrm{~m}$ depth. This area of sea floor is relatively smooth and appears free from any debris or significant reef growth other than around the atoll. In comparison, the sea floor on the southern side of the atoll, which shows significantly more debris or rubble, extends to the south before eventually reaching the depths equal to those on the north. This debris is hypothesised to be reef material that has washed or slumped off the reef terraces into deeper water but this cannot be confirmed without further investigation.

A significant feature of the bathymetry is the area to the west of the atoll. There, a large area about equal to the atoll edifice itself and lies at around $1500 \mathrm{~m}$ depth. This area is highly irregular and has multiple cone-like features scattered across its platform (Fig. 3.2). Little is known about this area and it may represent an extension of the original volcanic edifice or significant flank failure from a once-larger atoll. 


\subsubsection{Morphology}

One of the most notable features about Palmyra Atoll is the east-west elongation of the reefs and overlying atoll islands (Fig. 3.3). Palmyra Atoll is approximately $7 \mathrm{~km}$ long from east to west and nearly $3 \mathrm{~km}$ wide from north to south. The atoll is also unique due to the four main lagoons of approximately equal size, each approximately $1 \mathrm{~km}$ across. The lagoons were separated by areas of shallow reef prior to the U.S. military occupation in the 1930's, and two of these areas remain today. Although there has been no in-depth study of lagoon bathymetry, three of the lagoons (East, Center and West lagoons) have developed karst topography, and reach a maximum depth of 55 to $60 \mathrm{~m}$. The inner slopes of the lagoons are extremely steep and drop sharply away from the sand flats that are mostly exposed during low tide. A fourth unnamed lagoon is defined between East Island and Barren Island and in thesis is referred to as the 'Eastern Flats' (Fig. 3.3).

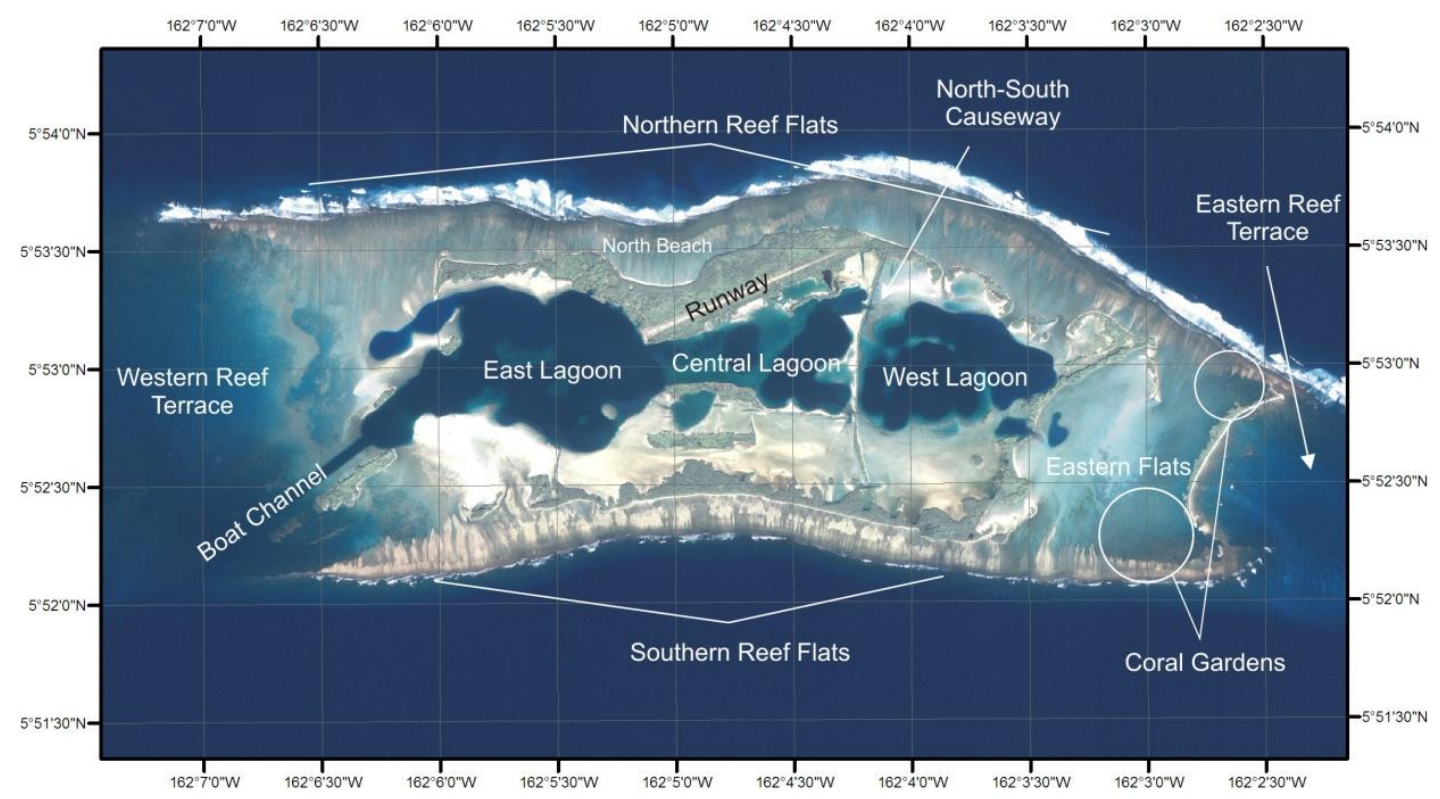

Figure 3.3: Key areas of Palmyra Atoll discussed in this thesis. Ikonos image (2000) of Palmyra Atoll, courtesy of the U.S. Fish and Wildlife Service and Space Imaging, Inc.

Most islets have been connected since artificially joined during the 1940s (see below), except for Sand and Home islands in the west, and Barren Island in the east. The largest island is Cooper-Meng Island in the north, followed by Kaula Island in the south. The northern and southern islets are broken by several channels between the lagoons and the outer reefs which allow the flow of water into the lagoons. The islands 
have a combined total land area of $2.5 \mathrm{~km}^{2}$ with an average elevation of approximately 2 metres above sea level (Collen et al., 2009a).

An important feature is the pattern formed by the north-to-south elongate islands and causeway that connect the northern and southern coasts. These are represented by Barren Island, the East Island chain, the Lost Island chain and the northsouth causeway. All strike north-south and have a westward concavity. The north-south causeway was constructed on a shallow shoal that is similar in shape to the eastern island chains and it is presumed that this may represent part of the reef flat on which reed islets never developed.

\subsubsection{Distribution of reefs}

Palmyra Atoll has around $60 \mathrm{~km}^{2}$ of reef, which includes the two large reef terraces to the east and west of the islands. Reef habitat mapping by NOAA's Biogeography group was published in November, 2010, and relevant maps are provided in Figures 3.4 and 3.5. Figure 3.4 highlights algae and coral as the two main biological classes on Palmyra's reef, where the Eastern Terrace is dominantly algae and the Western Terraces is dominantly covered in coral. There is little to no biological cover within the lagoons or on the northern or southern reef edge, as these areas are mostly bare or covered in sand and mud.

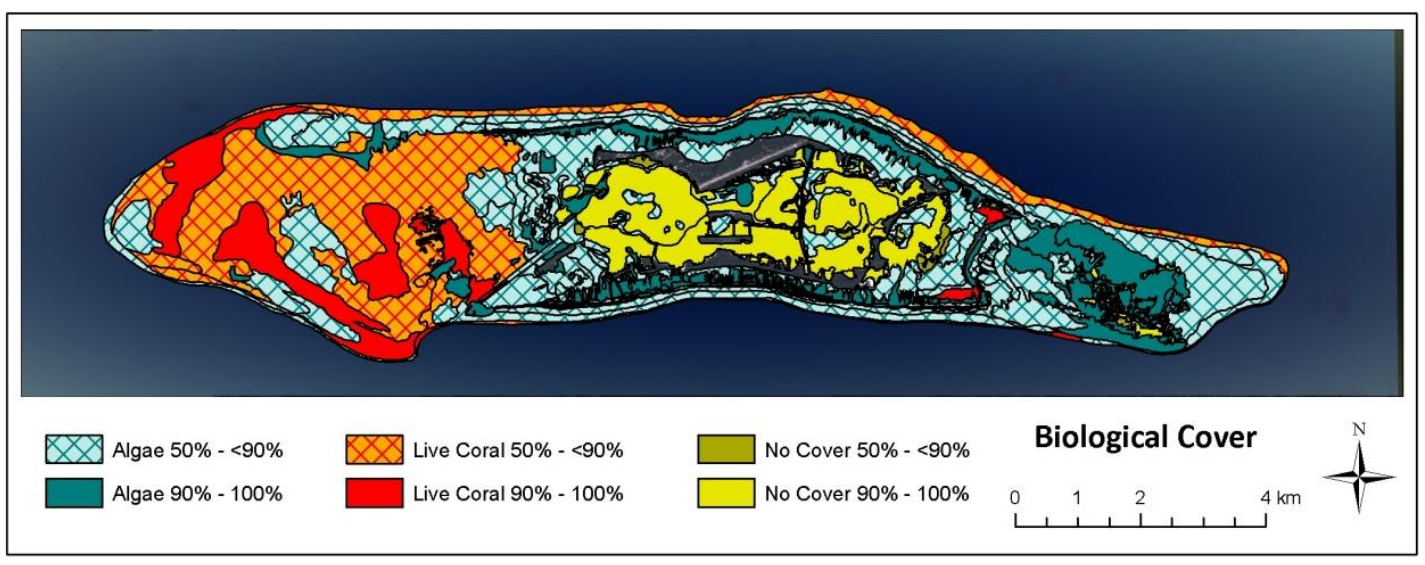

Figure 3.4: (From: U.S. Dept. of Commerce et al., 2010) Map of dominant biological classes on Palmyra Atoll 


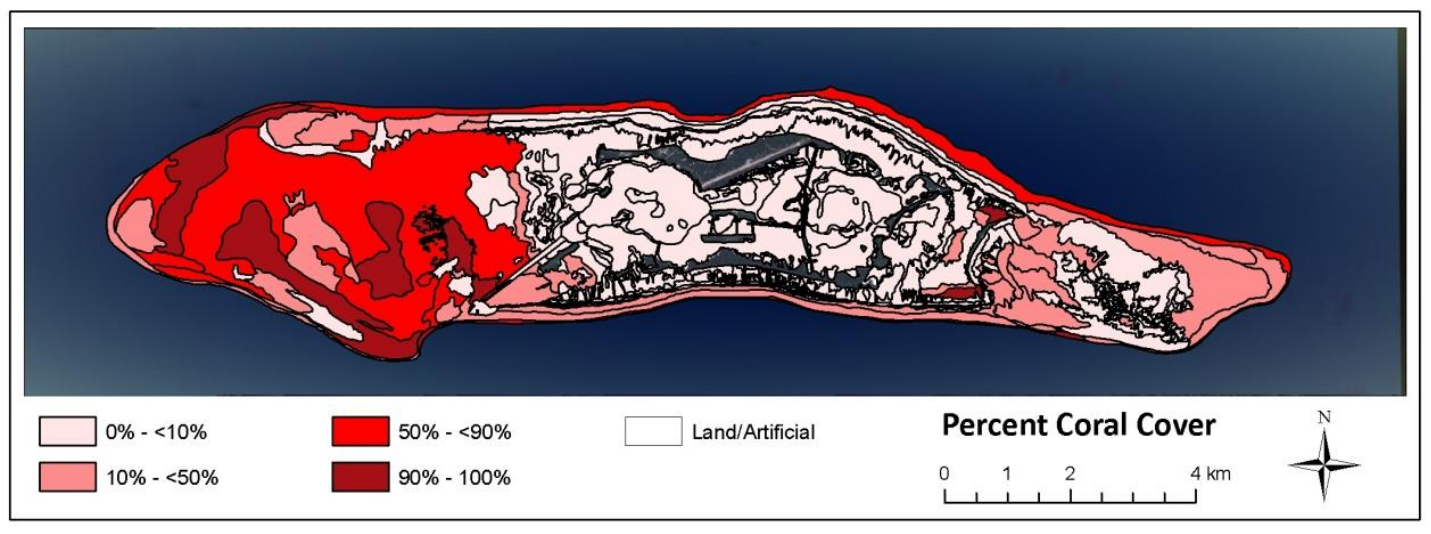

Figure 3.5: (From: U.S. Dept. of Commerce et al., 2010) Map of live coral cover classes at Palmyra Atoll.

A large proportion of the $\mathrm{CaCO}_{3}$ sediment at Palmyra is produced by corals on the reef edge and the cover of coral, determined by reef habitat mapping, is illustrated in Figure 3.5. Coral cover is densest on the Western Terrace with coral cover up to $100 \%$. The Eastern Terrace has comparatively sparse coral cover and is only reaches above 50 $\%$ on the northern edge of the reef. The back reef has a high number of corals within the genera Montipora and Astreopora, whereas the fore reef has more Pocillopora, Hydrnophora, Leptoseris, Gardineroseris, Fungia, Favites, and Favia individuals (Williams et al., 2008). Branching Acropora species, an important source of gravel to the reef islands of Palmyra, were generally more abundant within the back reef compared to the fore reef (Williams et al., 2008).

\subsection{Climate of Palmyra Atoll}

Palmyra's proximity to the equator dictates the atolls overall low seasonality, high temperatures and light winds. This area is commonly referred to as the doldrums, where the light easterly trade winds allow very calm conditions to develop. The ocean currents surrounding Palmyra have a large influence on the local climate and the currents often fluctuate as a result of seasonal and inter-annual variations.

\subsubsection{Local climate}

Due to the location of the atoll close to the equator, the wind climate at Palmyra is low and consistent throughout the year. The winds at Palmyra are dominated by the trade winds originating to the east or northeast of the atoll. Although no physical records for periods longer than a few days are available for Palmyra, wind records have 
been reconstructed from hindcast data using the WAVEWATCH III (WWIII) model between 1997 and 2009 (Fig. 3.6; Tolmann, 2002). This shows that most wind velocity is less than $10 \mathrm{~m} / \mathrm{s}$, originating from $50^{\circ}$ to $120^{\circ}$.

Palmyra has rainforest conditions as a result of the atolls location on the southern edge of the Inter-Tropical Convergence Zone (ITCZ). Palmyra receives in excess of $4500 \mathrm{~mm}$ of precipitation annually. On average $10.1 \mathrm{~mm}$ of rain falls daily at Palmyra, with a monthly average of $310 \mathrm{~mm}$ of rain (Fig. 3.7). The ocean surrounding Palmyra has a surface layer that is approximately 75 to $100 \mathrm{~m}$ deep with an almost constant temperature between 28 and $29^{\circ} \mathrm{C}$ (Hamann et al., 2004). Between November $8^{\text {th }}, 1981$, and December $29^{\text {th }}, 2010$, there was an average weekly SST of $28.37^{\circ} \mathrm{C}$ (Reynolds et al., 2002; Fig. 3.8).
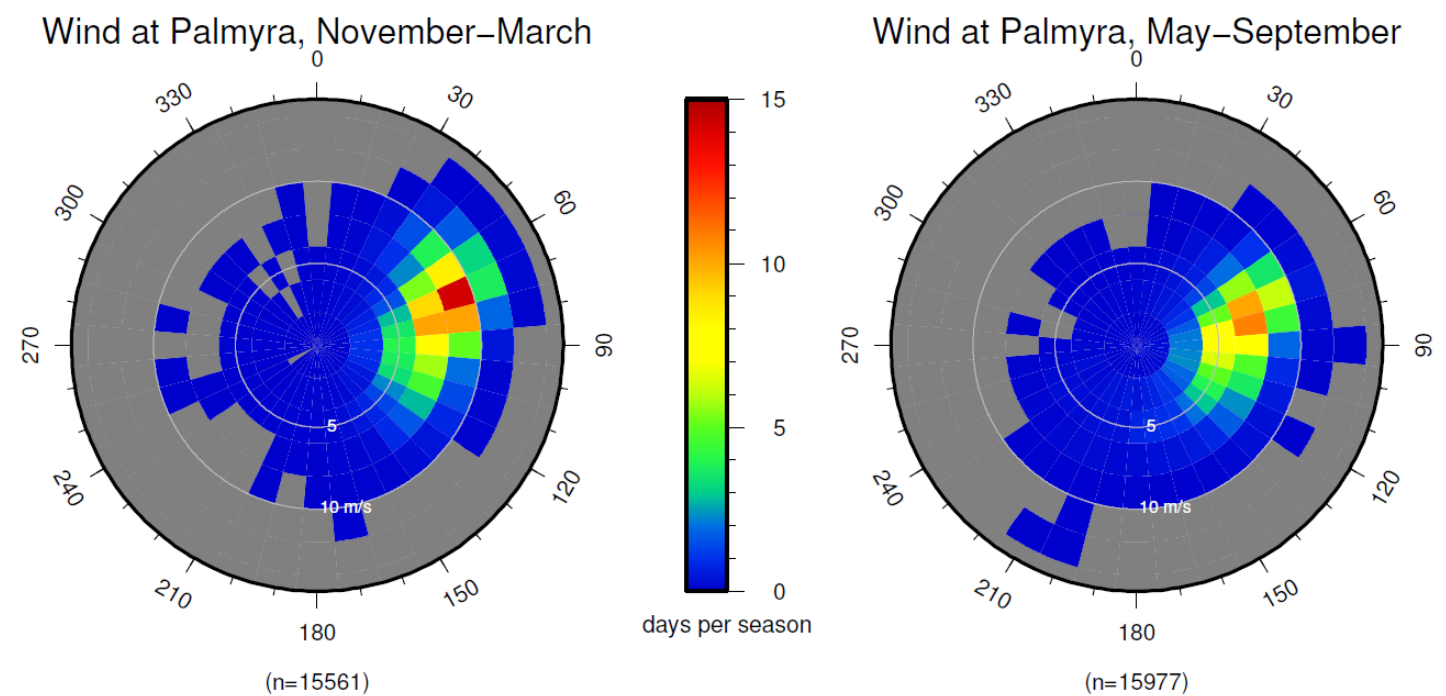

Figure 3.6: Wind climatologies for Palmyra Atoll compiled from 13 years of NOAA WWIII global model data by D. Zwartz, showing that east-northeast is the only significant wind direction at Palmyra in an average year. 


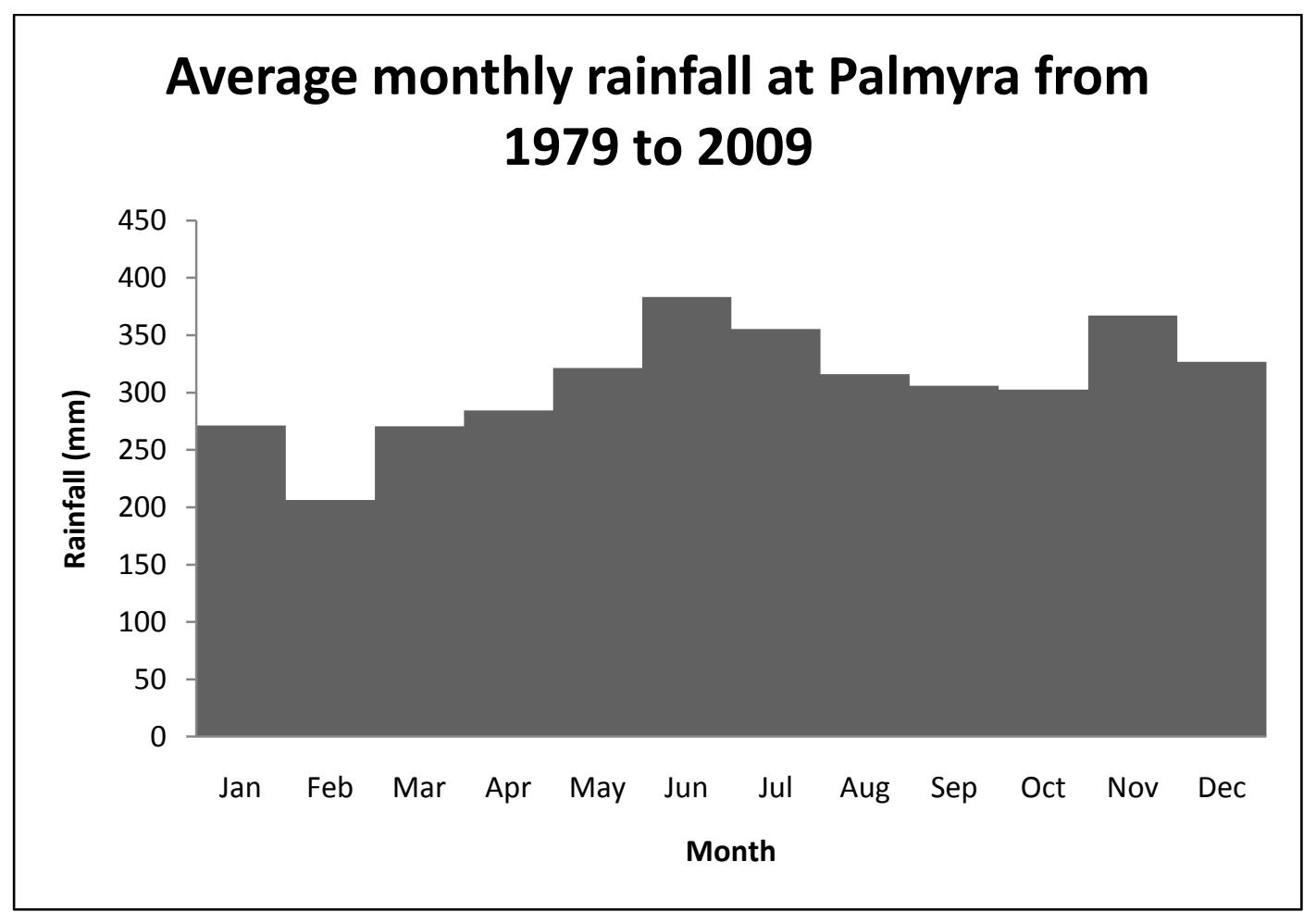

Figure 3.7: Average monthly rainfall for Palmyra from CMAP (Climate prediction centre Merged Analysis of Precipitation) estimated precipitation, average between 1979 and 2009 (Huffman et al, 1997)

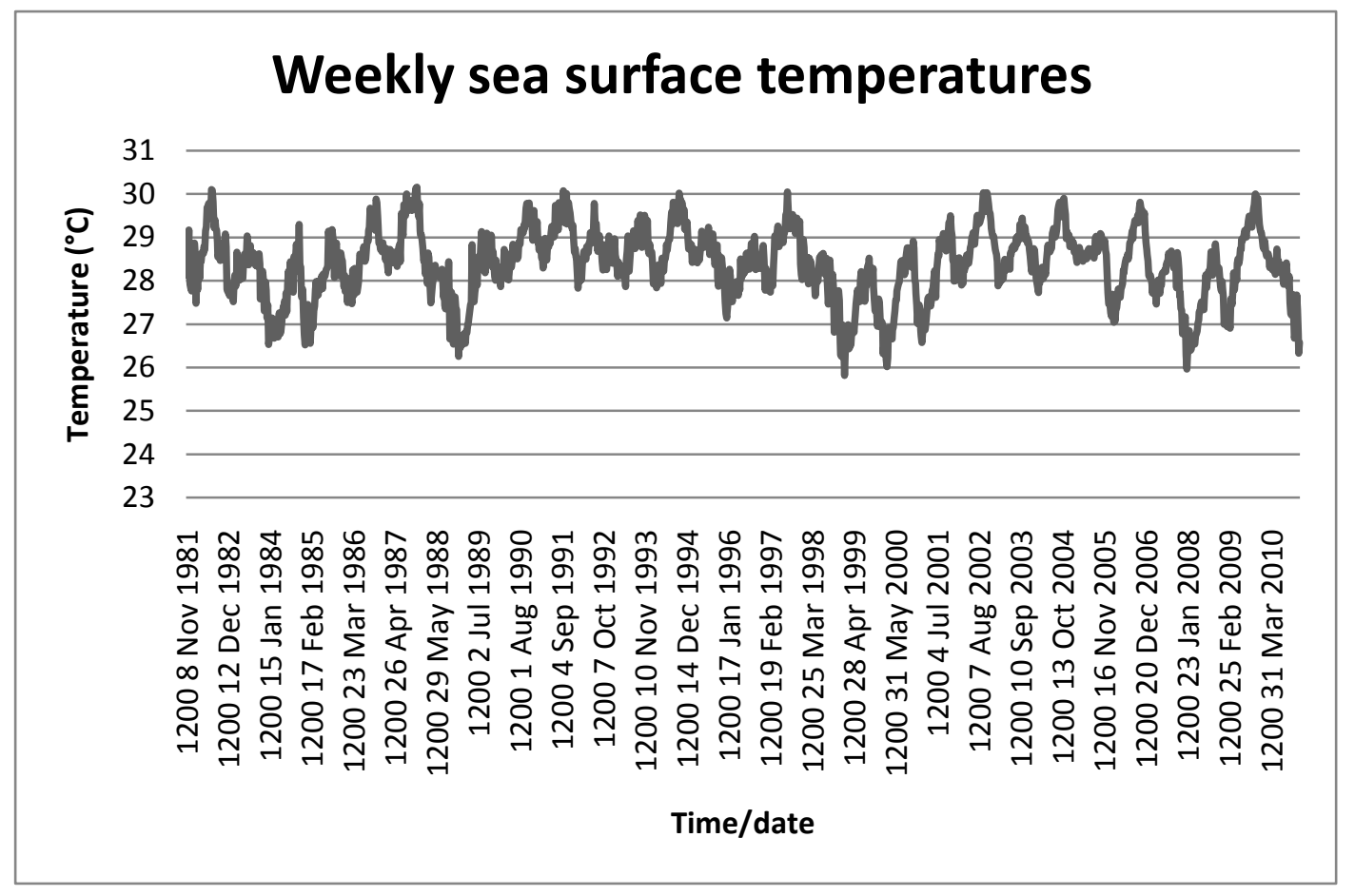

Figure 3.8: Weekly sea surface temperatures from Integrated Global Ocean Services System (IGOSS) between November, 1981, and December, 2010 (Reynolds et al., 2002). 


\subsubsection{Cyclones and extreme wave events}

Palmyra Atoll receives very few tropical storm events due to its location outside the major tropical storm centres to the east and west, and its proximity to the equator means there is insufficient vorticity for cyclogenesis (storm formation) to occur. Cyclogenesis to the west and northwest of Palmyra produces tropical depressions that head towards the western Pacific. Storms that develop off the coast of Mexico and move westward generally undergo cyclosis (storm death) or track northwards before reaching Palmyra. Therefore, the atoll is located out of the path of almost all tropical cyclones of any significant intensity. There have been only three cyclones observed in the locality of Palmyra over the past 60 years, and only one of those reached wind speeds in excess of 60 knots (Cyclone Ekeka in 1992; Brainard et al., 2005).

Although uncommon at Palmyra Atoll, the effects of tropical cyclones are important to understand as it has been suggested that sediment entrainment across a reef is limited to spring high tide conditions and decreases landward, as water level is a major control of energy across the reef (Brander et al., 2004). Therefore, for most of the time, the reef platform is relatively inert in terms of sediment movement, and any significant changes in sediment production, transport rates and reef island sediment budgets are dependent on extreme waves or storm conditions (Brander et al., 2004). For instance, Hurricane Bebe in 1972 deposited an extensive storm rubble rampart onto the reef flat of Funafuti Atoll in Tuvalu (Maragos et al., 1973). Subsequently, this rampart has been reworked onto island shorelines (Baines and McLean, 1976) and increased the island area along the eastern reef rim (Webb and Kench, 2010). Thus, hurricanes have been shown to have constructional as well as erosional impacts on atolls (Bayliss-Smith, 1988).

Tsunamis generated by distant earthquakes are not observed at Palmyra Atoll due to the steep topography surrounding the reefs. Since there is no continental shelf to allow run-up for a tsunami to generate a destructive wave, tsunamis that propagate across the Pacific Ocean have little impact on Palmyra, as happened as a result of the Samoan earthquake on September $27^{\text {th }}$, 2009, and the Chilean earthquake on February $29^{\text {th }}, 2010$. However, tsunami can occur on oceanic atolls when there is catastrophic flack failure. This can be caused by numerous exogenic and endogenic processes, such as oversteepening and thermal alteration, that lead the sudden backwash onto the atoll (Keating and McGuire, 2000). Such tsunamis give little to no warning and can have catastrophic impacts on atolls; none, however, are known for Palmyra. 


\subsubsection{El Niño Southern Oscillation}

The El Niño Southern Oscillation (ENSO) phenomenon is a quasi-periodic climate pattern that occurs over a period that varies from 3 to 7 years. El Niño events are characterised by high air surface pressures in the west Pacific Ocean, which cause the easterly trade winds to weaken or head west and the degree of cool upwelling to decline (Philander, 1983). This leads to sea surface temperature (SST) anomalies in the eastern tropical Pacific. Conversely, La Niña events are characterised by cooler SST and lower air surface pressure in the western Pacific (Philander, 1983). ENSO causes variations in sea level on the order of $20-30 \mathrm{~cm}$ and tidal crests during the peak of an ENSO cycle can produce wash-over of low-lying barrier islands on continental coasts of the Pacific Ocean (Morton et al., 2000).

The coupled atmosphere-ocean dynamics that occur during the course of an ENSO cycle greatly affect the surface water properties at Palmyra. Cessation of the wind-driven upwelling of cooler, deeper waters at the equator during El Niño years leads to positive SST anomalies throughout the central and eastern equatorial Pacific. During strong El Niño events, inter-annual SST anomalies on the order of $1{ }^{\circ} \mathrm{C}$ occur at Palmyra, which drive enhanced convection over most of the central tropical Pacific (Ropelewski and Halpert, 1987). On the other hand, La Niña events are characterised by enhanced equatorial upwelling, which maintains cooler drier conditions in the central Pacific Ocean. In-situ measurements suggest that inter-annual salinity anomalies over the last large ENSO cycle may have been as large as \pm 0.50 psu (Cobb, 2002).

\subsubsection{Oceanography}

The equatorial Pacific, as with other oceans, is subject to the upwelling of cool subsurface water. In the equatorial Pacific, there exists a tongue of cool water stretching from the coast of Peru to longitude $180^{\circ} \mathrm{E}$, which is caused by both upwelling and horizontal advection of cool water from the east (Wyrtki and Eldin, 1982). This upwelling is caused by the divergence of the surface Ekman drift at the equator because of the easterly trade winds (Wyrtki, 1981). As a result, Palmyra Atoll is located in the strong SST gradient between the West Pacific Warm Pool (WPWP), with SSTs near $30^{\circ} \mathrm{C}$, and the East Pacific cold tongue, where deeper waters with temperatures below $25^{\circ} \mathrm{C}$ are brought to the surface. 
The surrounding warm tropical oceans contain four major ocean currents (Fig. 3.9). The area is dominated by the easterly trade winds, which results in a complex system of westward-flowing surface currents and eastward-flowing surface and subsurface counter-currents. For the most part, Palmyra Atoll lies in the path of the North Equatorial Countercurrent (NECC) $\left(3^{\circ} \mathrm{N}\right.$ to $\left.10^{\circ} \mathrm{N}\right)$; a warm, eastward flowing surface counter-current.

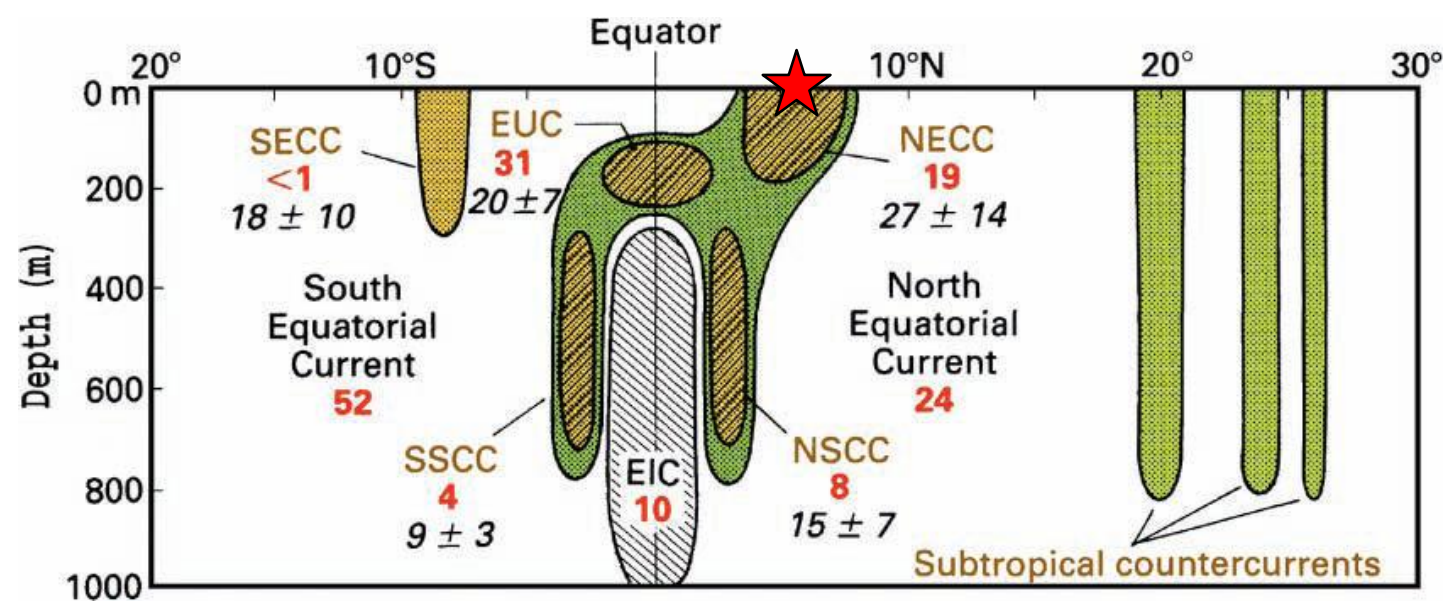

Figure 3.9: (From: Maragos et al., 2008; modified from Tromczak and Godfrey, 2003). Cross section of the equatorial current system in the Pacific Ocean at $170^{\circ} \mathrm{W}$. The crosshatching shows the NECC and SECC, subsurface Equatorial Intermediate Current (EIC), North and South Subsurface Countercurrents (NSCC and SSCC), and the Equatorial Undercurrent (EUC). Green and brown represents eastward flow and white represents all westward flow. Black numbers in italics were observations from January 1984 to June 1986 (latitude $165^{\circ} \mathrm{E}$ ), and bold red numbers were observations from April 1979 to March 1980 (latitude $\left.155^{\circ} \mathrm{W}\right)$, with both representing transport in Sverdrups $\left(\mathrm{Sv}=10^{6} \mathrm{~m}^{3} / \mathrm{s}\right)$ The red star shows the position of Palmyra Atoll.

Due to the combination of high precipitation and the influence of freshwaters advected from the WPWP by the NECC, ocean waters surrounding Palmyra maintain a relatively low salinity of 34.7 psu (Wyrtki and Kilonsky, 1984). Seasonal migration of the ITCZ also occurs as a result of the variation in trade winds. In boreal summer the ITCZ resides at $10^{\circ} \mathrm{N}$ and moves to $5^{\circ} \mathrm{N}$ during boreal winter. This means that the ITCZ passes Palmyra twice throughout the course of a year (Cobb, 2002).

Seasonal shifts in trade wind direction can influence the surface water properties at Palmyra because of the proximity of the cool, salty westward-flowing South Equatorial Current (SEC; $15^{\circ} \mathrm{S}$ to $3^{\circ} \mathrm{N}$ ). During boreal winter strong north-easterly trade winds drive the Ekman transport of water northward resulting in a dominance of cool, salty water at Palmyra. Conversely, during boreal summer, weakened trade winds allow 
the influence of relatively warm, fresh NECC water to dominate. This variability amounts to $1.2{ }^{\circ} \mathrm{C}$ in SST and 0.3 psu in sea surface salinity (SSS; Cobb, 2002).

\subsection{Geological History of Palmyra Atoll}

The Line Island submarine ridge was first assumed to have formed by the movement of the Pacific plate over an oceanic hot spot similar to the Hawaiian chain (Haggerty et al., 1982), which created a chain of islands as the Pacific plate moves north over a stationary hotspot. This theory was abandoned when Leg 33 of the Deep Sea Drilling Project (Nov-Dec, 1973) investigated the geochronology of the Line Islands and the Tuamotu chain (Fig. 3.10; Schlanger et al., 1974). The minimum "basement age" for the Line Islands was determined at site 164 (approximately $600 \mathrm{~km}$ northwest of Palmyra Atoll) and was placed at between 79 and $83 \mathrm{Ma}$. The southern end of the Line Islands shows a volcanism cessation age of 81-83 Ma BP, and at site 315 (located nearer the middle of the chain) the age of cessation is $85 \mathrm{Ma}$ (Fig. 3.10). Therefore, the central part appears older than the northern and southern ends of the chain. As a result, systematic movement of the Pacific plate over a melting anomaly beneath cannot account for the geochronology of the Line Island volcanism.

The dates from nine volcanic edifices along the Line Island chain presented by Davis et al. (2002) exhibit two major episodes of Cretaceous volcanism, each lasting about $5 \mathrm{Ma}$ and separated by approximately $8 \mathrm{Ma}$, which occurred synchronously over long distances. These volcanic episodes also occurred at nonaligned edifices. The extensive coeval volcanism along major segments of the chain is compatible with decompressional melting of heterogenous mantle due to diffuse lithospheric extension along pre-existing zones of weakness. The episodes of volcanism, therefore, are most likely related to broad upwarping of the Superswell region in the eastern South Pacific (Davis et al., 2002). The South Pacific Superswell is a broad region beneath French Polynesia that is subsiding at a slower rate than predicted for a plate of the same age. The area also correlates with an area that has a high density of volcanoes, low seismicity velocity in the upper mantle, and a reduced thickness of the lithosphere (McNutt and Fischler, 1987). 


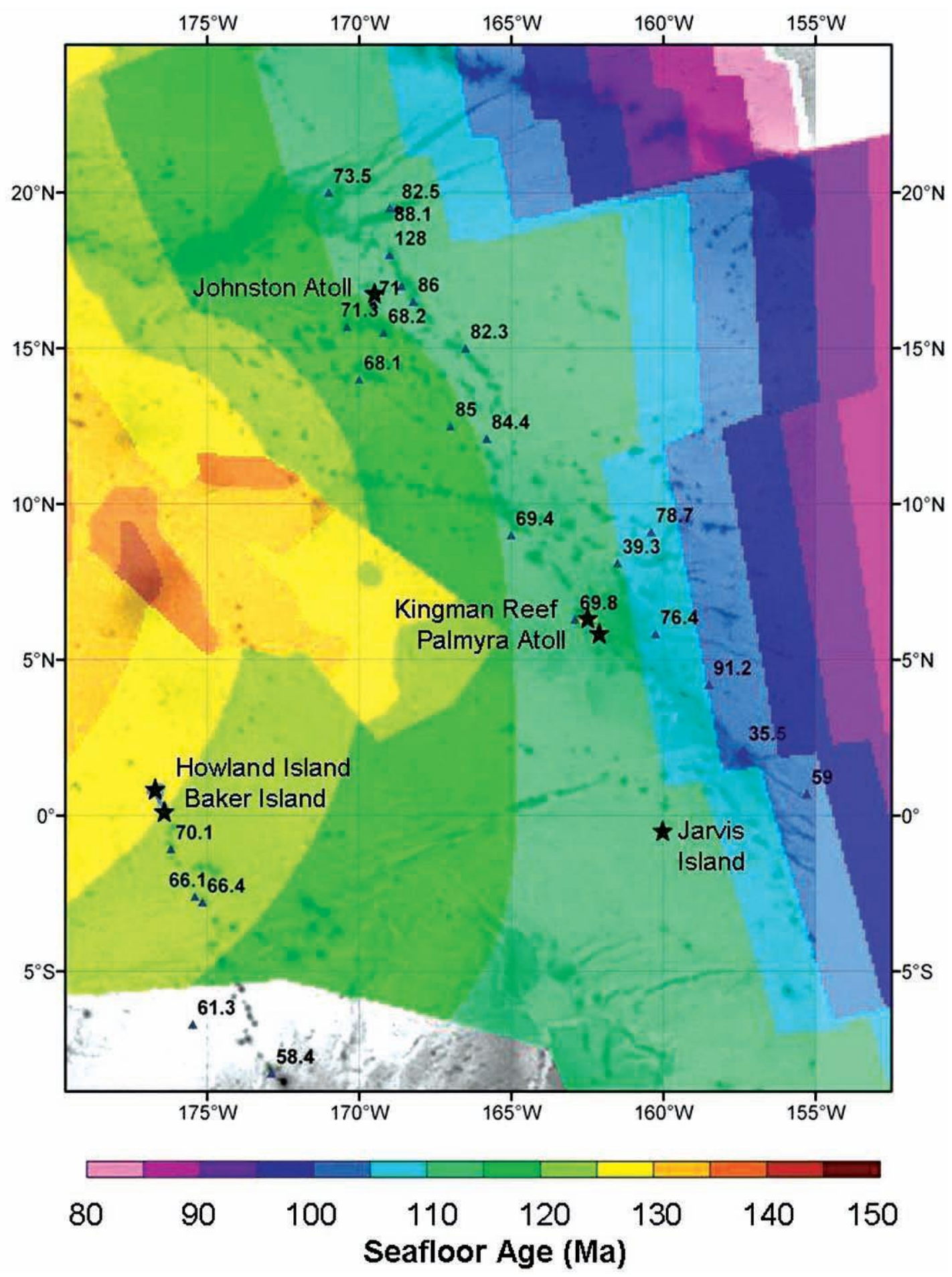

Figure 3.10: (From: Maragos et al., 2008; seafloor ages from Muller et al. 1997; map by CRED/PIFSC) Sea floor and seamount ages in the central Pacific. Triangles indicate locations of dredge or drill age data, and stars indicate location of multibeam data 
The initiation of a mid-oceanic atoll is explained by the subsidence theory of reef development originally proposed by Darwin (1842). As a central land mass (volcanic edifice) subsides, the surrounding fringing reef grows upward and outward to form a widening barrier reef and lagoon system (Darwin, 1842). As the oceanic lithosphere cools, it becomes denser and sinks relative to local sea level. It is this relative increase in sea level which overtops the volcanic edifices and creates accommodation space allowing coral to grow and the modern atoll to form.

During the LGM (18-23 ka), lowered sea level caused karstic erosion of Pleistocene limestone, over which reefs did not re-establish in the Pacific region until around 8000 yrs BP (Woodroffe, 2008). However, stable reef islets did not begin to form until after the MHHS in the tropical Pacific, around $3000 \mathrm{ka}$ (Dickinson, 2009). Since the initial volcanic edifice is no longer evident at the surface, the atoll maintained through the growth of the surrounding coral reef, sedimentation of limestone and fringing beachrock outcrops (Keating, 1992).

\subsection{Palmyra Atoll over the past 100 years}

Table 3.1 lists some of the major events at Palmyra Atoll since 1802.

\subsubsection{Discovering Palmyra Atoll}

No Polynesian knowledge or occupancy of Palmyra is known and the atoll was first sighted by European voyagers in 1802, by the captain of the American ship Palmyra. However, it was not until 1862 that Palmyra was claimed by Captain Zenas Bent and J.B. Wilkinson for the Kingdom of Hawai'i. Twelve years later the atoll was first mapped by Commander Skerret of the USS Portsmouth (Collen et al., 2009a). Discovery of the atoll, along with four other Pacific island (Jarvis, Baker, Howland and Kingman reef), led to Palmyra being claimed for the United States under the Guano Islands Act of 1865 (Maragos et al., 2008a). However, the U.S. foreign office never ratified the claim and, regardless Palmyra is too wet for the major accumulation of guano and was never commercially mined.

\subsubsection{Military occupation 1939 - 1945}

The atoll was part of the Kingdom of Hawai'i until the latter was annexed by the United States. It remained in private ownership until in 1939, with the threat of war, it 
was appropriated from the Fullard-Leo family by the U.S. Navy and construction of a naval base was authorized by the U.S. Congress. Throughout World War II (WWII) up to 6000 service men occupied the Palmyra Atoll Naval Air Station (Maragos et al., 2008a). Although this period of occupation was relatively brief, significant changes occurred during that time in order for the atoll to be used as an air base. Figure 3.11 summarises physical changes in Palmyra from 1874 to 2000.

Construction of the ship channel began in 1940, when contactors dredged a channel $9 \mathrm{~m}$ deep and $60 \mathrm{~m}$ long between West Lagoon and the southwest ocean reef (Fig. 3.11 and 3.12). Additionally, the reef which prior to construction separated West and Center Lagoon was also dredged to a depth of $3 \mathrm{~m}$ to serve as a seaplane runway. The shallow perimeter reef flats around most of West and Center lagoons provided a base upon which to build the elevated road causeways that connected most islets. This included the North-South Causeway built on the reef flat that separates Center and East lagoons, which led to significant impacts on the circulation of the atoll through isolation of lagoon water from the surrounding reefs (Dawson, 1959; Maragos, 1993). CooperMeng Island (Fig. 3.13) was used as the main base and was enlarged to provide sufficient area for two runways, the largest of which was $2000 \mathrm{~m}$ long, as well as a deep draft dock and other facilities.

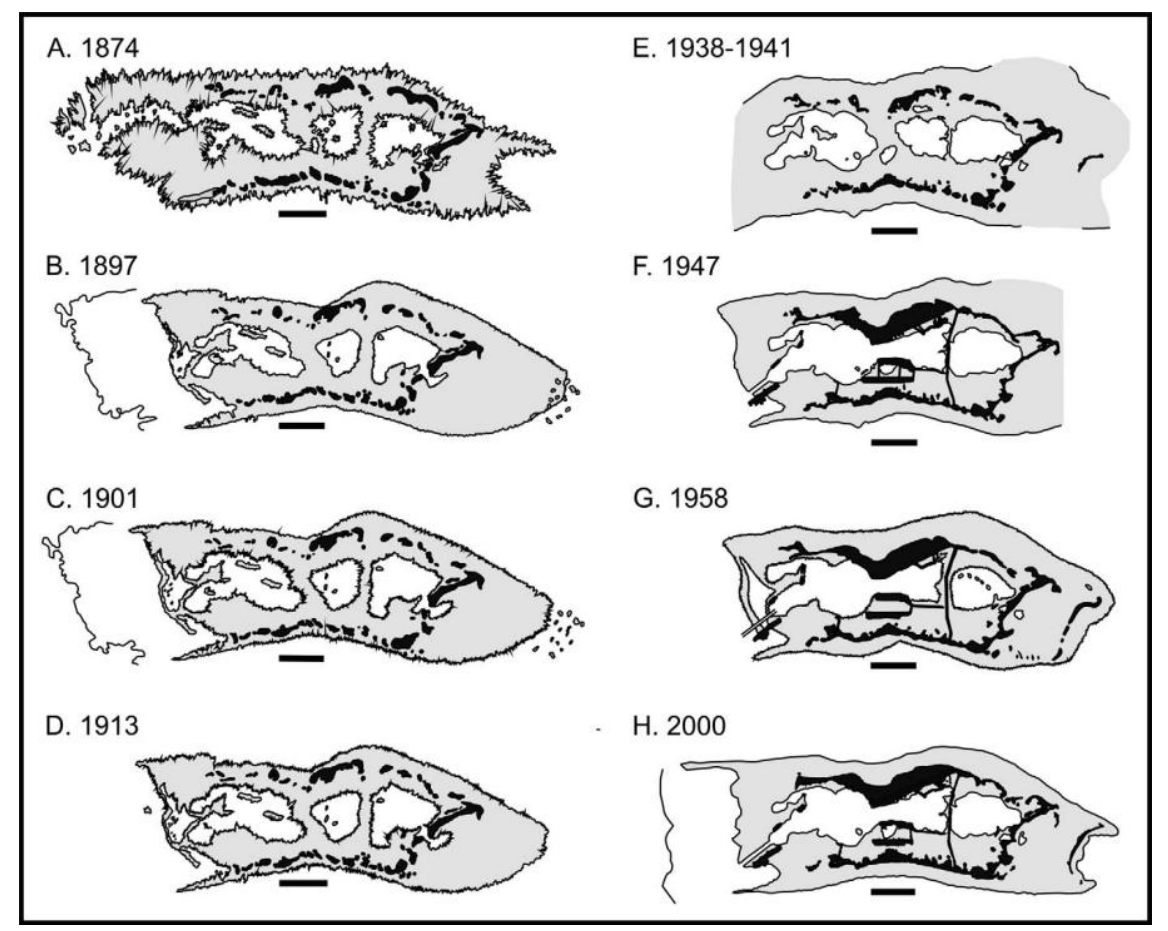

Figure 3.11: (From: Collen et al., 2009a) Outline of Palmyra's reef islands recreated from maps and photographs from 1874 to 2000 . Black areas represent land above sea level, grey areas are shallow reef flats and white are the lagoons or the surrounding ocean. The scale bars represent $1 \mathbf{~ k m}$ and are taken from the original photographs. 


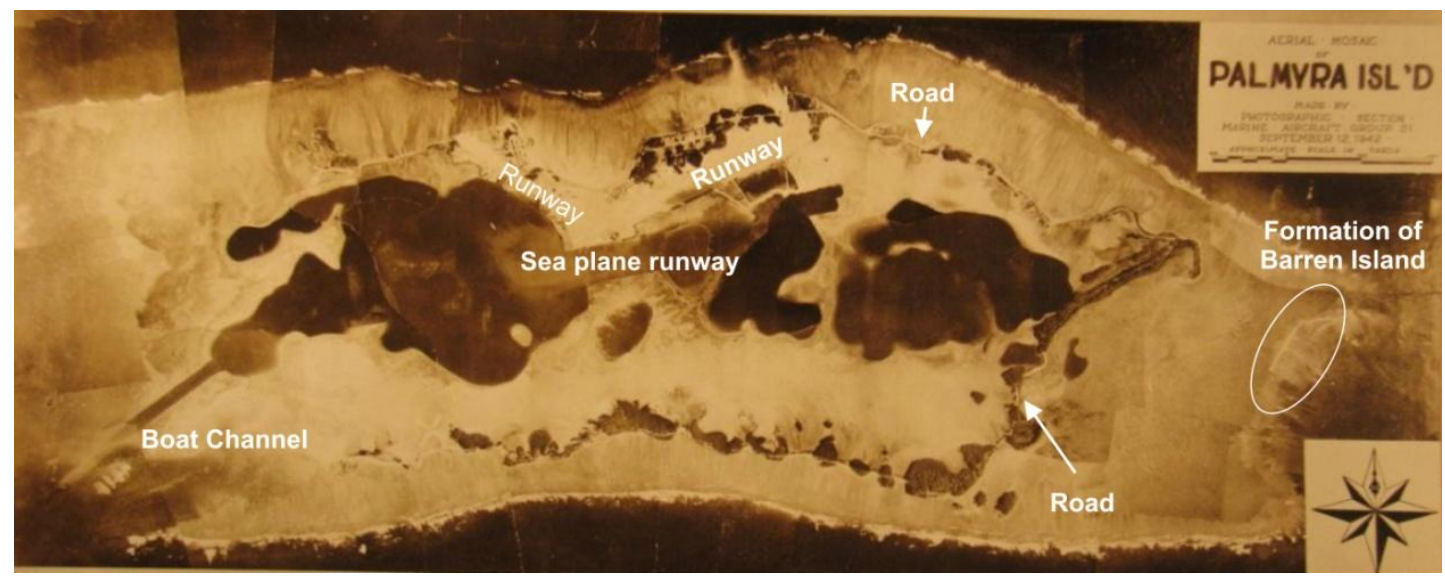

Figure 3.12: An aerial mosaic of Palmyra Atoll produced by the U.S. Navy in 1942 during construction of the Palmyra Atoll air base. In the centre of the mosaic is the dredged seaplane runway and the ship channel can be seen in the bottom left.

\subsubsection{Post-WWII}

Upon cessation of hostilities, ownership of the atoll was returned to the FullardLeo family in 1947, although it was used by the Civil Aviation Authority (CAA) for several years. After the departure of the military and the CAA, the atoll was effectively abandoned, with most equipment and temporary buildings removed. However, many concrete bunkers are still present (Figs. 3.13A \& B). As it was specifically excluded from the 1959 Hawai'i Statehood Act, it remains the sole U.S. unorganised and incorporated Territory. In subsequent years, Palmyra Atoll was left to natural forces with only occasional visitors, including scientists to survey the reef.

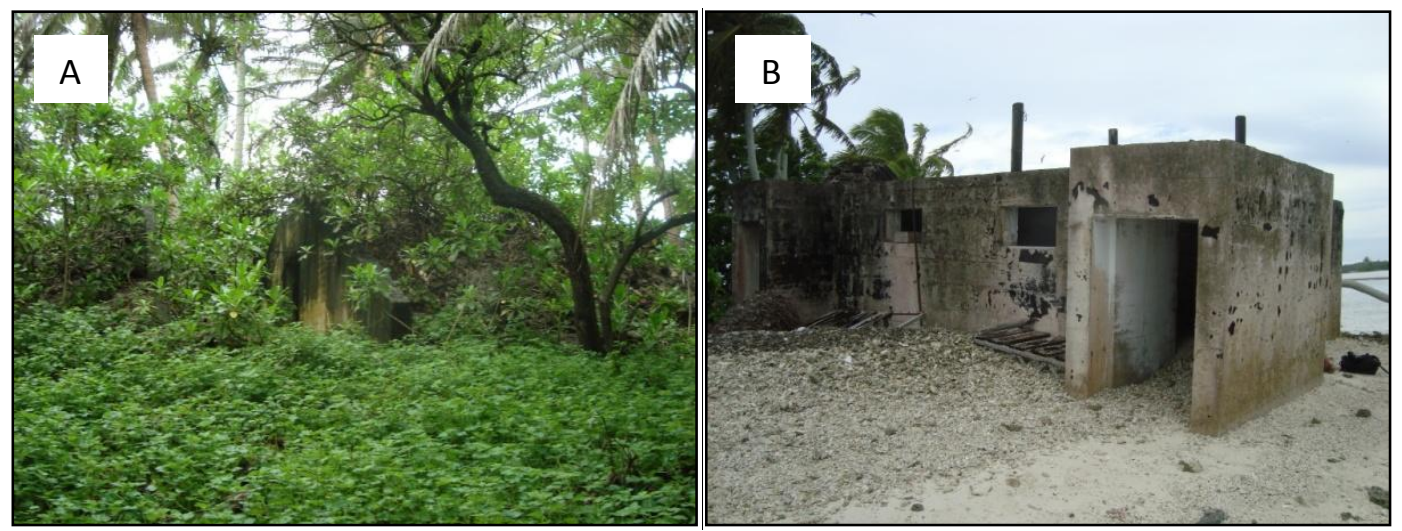

Figure 3.13: A) A bunker remains on Cooper-Meng Island, now overgrown with vegetation. B) A concrete structure sits dislodged on the coast of Home Island. 


\subsubsection{Current status}

In January, 2001, the atoll was established as a National Wildlife Reserve (NWR) under administration of the U.S. Fish and Wildlife Service (USFWS). This followed the purchase of the atoll in 2000 by The Nature Conservancy (TNC) and the transferral of the surrounding waters to USFWS. TNC then established a field research station capable of housing up to 20 scientists and staff on Cooper-Meng Island (see Fig. 1.1).

Today, Palmyra is jointly managed by TNC and the USFWS and since 2005 there has been a small TNC base staff with parties of up to a dozen scientific researchers visiting the island as members of the Palmyra Atoll Research Consortium (PARC). PARC at present, consists of nine research institutions: The American Museum of Natural History, California Academy of Sciences, Scripps Institution of Oceanography of the University of California (UC) at San Diego, Stanford University, UC at Irvine, UC at Santa Barbara, UC at Santa Cruz, University of Hawai'i, and Victoria University of Wellington. Research undertaken by PARC has many applications to decision-making in island and coastal conservation worldwide.

Palmyra is the one of seven islands and atolls included in the Pacific Remote Islands Marine National Monument, which was declared a national monument by President George W. Bush in January, 2009. This monument represents "the most widespread collection of marine- and terrestrial-life protected areas on the planet under one country's jurisdiction" (Bush, 2009). 
Table 3.1: Timeline of the significant events at Palmyra Atoll over the past 200 years

\begin{tabular}{|c|c|}
\hline 1802 & Palmyra first sighted by European voyagers \\
\hline 1862 & $\begin{array}{l}\text { Palmyra claimed by Captain Zenas Bent and J.B. Wilkinson for } \\
\text { the Kingdom of Hawai'i }\end{array}$ \\
\hline 1874 & First survey of the atoll's islands by USS Portsmouth \\
\hline 1935 & Growth of Barren Island above sea level \\
\hline 1939 & Initiation of military construction \\
\hline 1945 & Cessation of hostilities and most military construction \\
\hline 1947 & The atoll is returned to the Fullard-Leo family \\
\hline 1958 & $\begin{array}{l}\text { Channels develop into East Lagoon, including the separation of } \\
\text { East Island and Papala Island }\end{array}$ \\
\hline 1961 & $\begin{array}{l}\text { By September, the North-South Causeway has been breached in } \\
\text { two places }\end{array}$ \\
\hline 2000 & Palmyra is purchased by The Nature Conservatory \\
\hline 2001 & Palmyra becomes a fully protected National Wildlife Refuge \\
\hline 2009 & $\begin{array}{l}\text { Palmyra Atoll incorporated into the Pacific Remote Island Marine } \\
\text { National Monument }\end{array}$ \\
\hline
\end{tabular}




\subsection{Research at Palmyra Atoll}

Palmyra Atoll has been the subject of numerous ecological surveys throughout its brief history and today remains the focus of a largely biological research effort. The first botanical survey of the atoll was completed in 1913, by a scientific party from the Bishop Museum and College of Hawai'i, Honolulu, led by Joseph Rock (Rock, 1916). Today, research by PARC is examining many facets of the modern atoll, with a large focus on marine biology given Palmyra's unique status.

Despite this intense scientific effort focussed on Palmyra and its surrounding waters, little research has looked holistically at the atoll system or the geological past. As previously mentioned, these are limited to analysis of moderns sediment movement (Collen et al., 2009a) and coral records (Cobb et al., 2003a). The recent geological and hydrological changes at Palmyra have been documented by Collen et al. (2009a) and record changes in the atoll morphology since 1874, the changes during WWII, and modern behaviour of the atoll. Investigations into sediment movement and lagoon hydrology (e.g. Collen et al., 2009b; Gardner et al., 2010) have the potential to make a significant contribution to the management of the atoll and its reefs.

In 2003, Cobb et al. published a study of coral records from Palmyra in order to understand the tropical Pacific climate variability. Multiple young modern and fossilised massive corals were collected from Palmyra and precisely dated using uranium series dating, enabling information from different corals to be spliced together to create one continuous record. Using this method, monthly climate variations back to 1022 yrs B.P. were able to be determined. This is gives the potential for reconstructing continuous, multi-millennial climate records from different corals and is also important because it is the only study to date fossil material from Palmyra Atoll.

Victoria University of Wellington is establishing long term research at Palmyra on the importance of the carbonate sedimentology of the atoll and surrounding reefs, and the ecophysical effects on corals and tridacnid clams. This includes the investigation of the sources of carbonate production, the movement of sediment into and through the lagoon, across the reef and off the atoll. The research presented here is complimentary to the ongoing projects at Palmyra, and those of similar nature in other locations in the wider Pacific Ocean. 


\section{Methodology}

This chapter, describing the methods used in this study, has been structured in the chronological order in which the analysis were undertaken. Except for radiocarbon dating, analytical work for this thesis was undertaken in laboratories at Victoria University of Wellington. Many techniques, with the exception of the numerical wave modelling, are standard processes and are briefly described here.

\subsection{Field study}

Field work at Palmyra Atoll (Fig. 4.1) was completed in one field season in May/June, 2009. This primarily involved outcrop mapping, descriptions of lithofacies, sampling and photography. Day trips were taken from the base station on Palmyra Atoll to study all of the previously known outcrops and to explore for additional outcrops. Many of the outcrops are located around East Lagoon and the Eastern Flats area (Fig. 3.3), furthest away from the base station, which meant that access was limited to periods of high tide. Beachrock heights were measured from the modern reef flat. Some additional samples and photographs were collected for the author by the June 2010 field party.

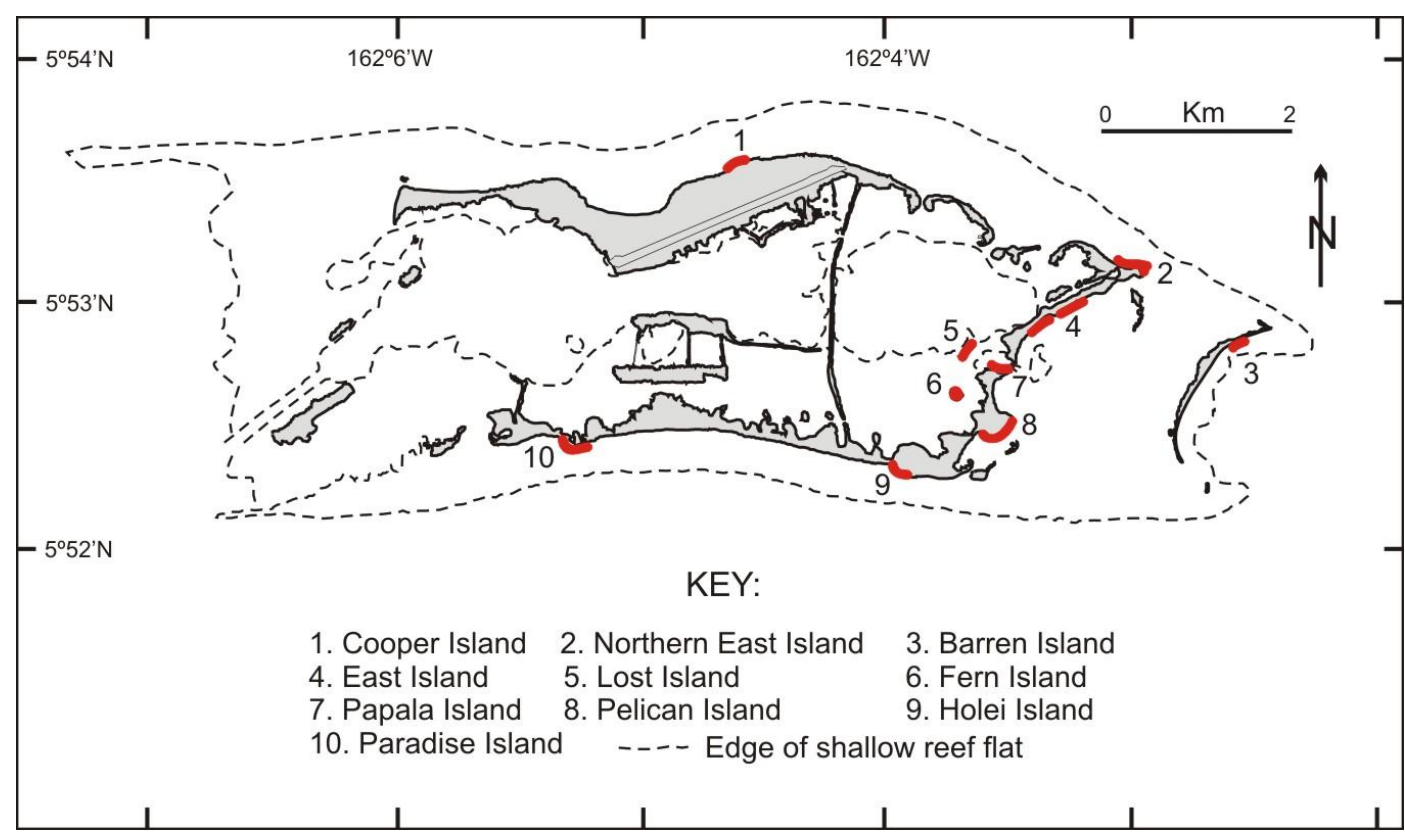

Figure 4.1: Map of the beachrock outcrops at Palmyra Atoll, highlighted in red (after Collen et al., 2009a). 


\subsection{Lithofacies analysis}

Vertical stratigraphic sections were described for 13 outcrops distributed along the beachrock ledges located on ten islands on Palmyra Atoll (Fig. 4.1). Textural and sedimentary structures were used to group the examined sections into six lithofacies. Descriptions were accompanied by the collection of samples, 18 of which were impregnated with epoxy resin, slabbed, thin-sectioned and point counted using a petrographic microscope. A catalogue of samples used for petrographic analysis, including locations and associated lithofacies is proved in Appendix A. Petrographic descriptions are provided in Chapter Five.

\subsubsection{Classification of lithofacies}

The beachrock lithofacies described in this thesis were defined by physical and biological characteristics, primarily grain size. The two most widely used limestone classifications are based on those of Dunham (1962) and Folk (1959, 1962). In the classification of Dunham, rocks are assigned names according to their depositional textures, which is the simplest descriptive classification. The method of classification followed here is that proposed by Embry and Klovan (1971), which expands the work of Dunham to include terminology for coarse grained allochthonous limestones where $>10 \%$ of the particles are larger than $2 \mathrm{~mm}$. These are termed 'rudstone' for clast-supported limestones, and 'floatstone' for matrix-supported limestones (Fig. 4.2). This terminology is appropriate for the large clasts and the texture of the beachrock on Palmyra Atoll. In accordance with the Embry and Klovan classification, matrix material here is defined as particles smaller than $2 \mathrm{~mm}$. This classification has advantages in that it has a partially quantifiable, descriptive terminology that reflects environmental "energy" and thus conveys genetic information more easily. However, it is also not as detailed as the Folk classification and offers little flexibility in classifying diagenetically-altered rocks (Scholle and Ulmer-Scholle, 2003). 


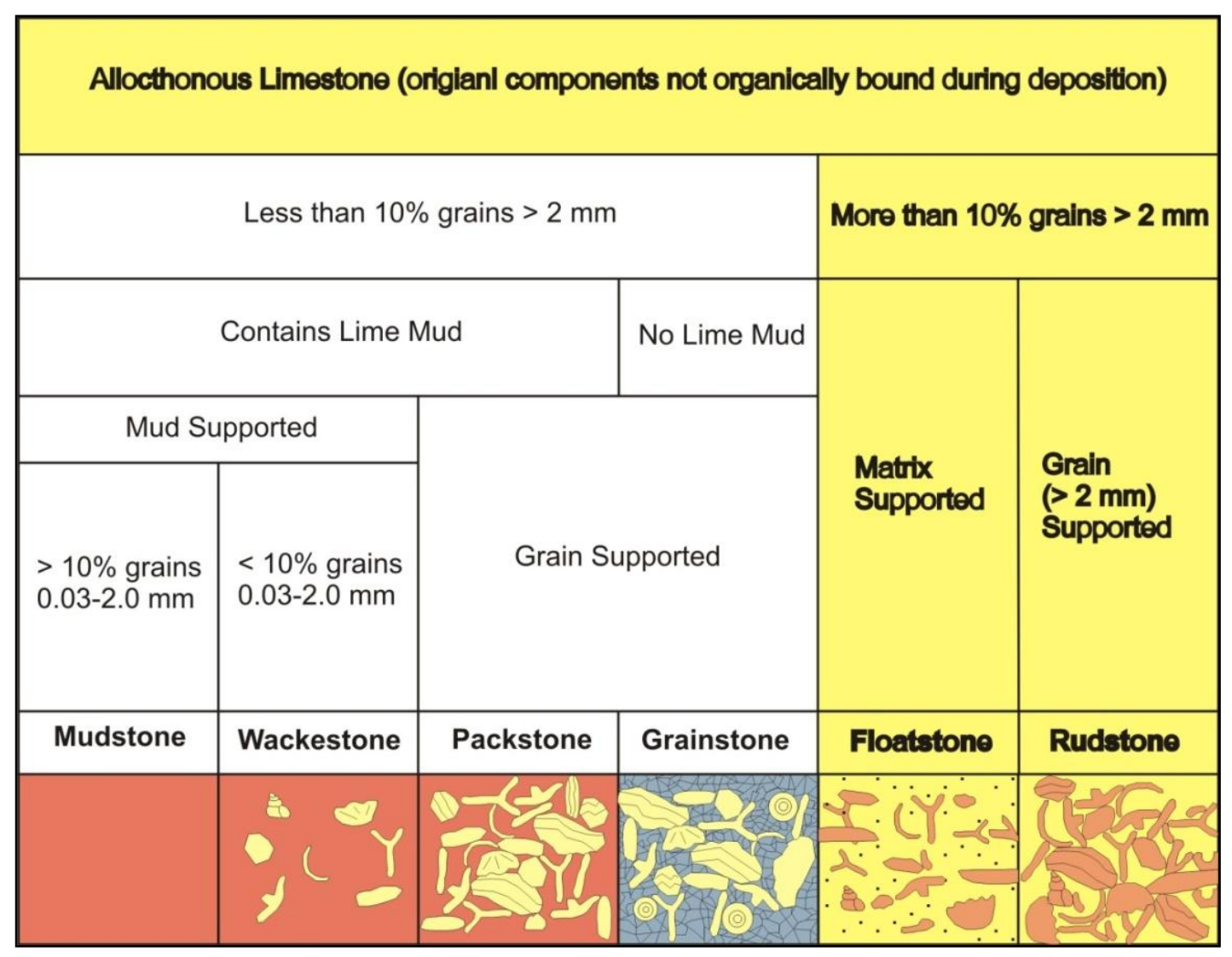

Figure 4.2: Textural classification of reef limestone after Embry and Klovan (1971), images highlighted in yellow are used in this study.

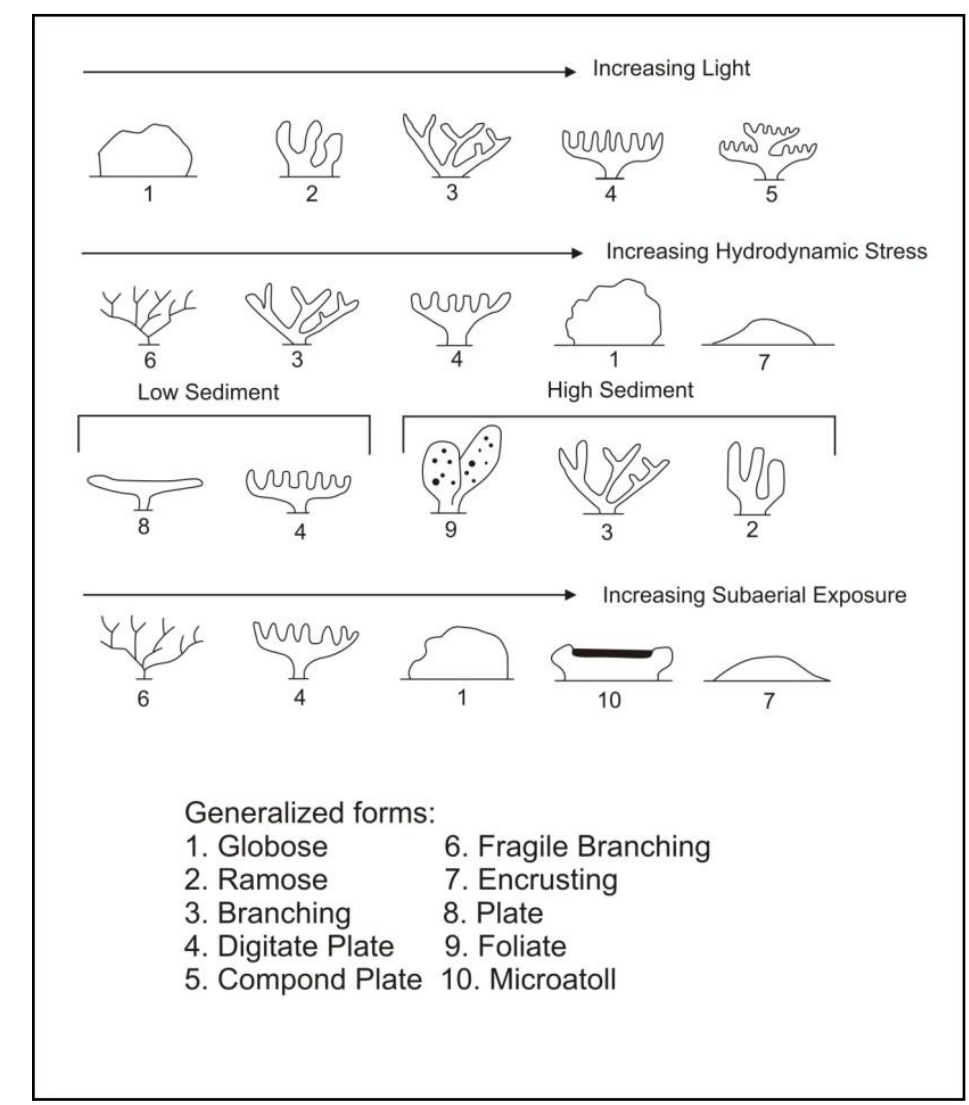

Figure 4.3: (From Chappell, 1980) Coral forms as a response to environmental stresses. 
The allochthonous conglomerates were also characterized by their biological content. This differentiates the main coral clast morphology between massive, platy or the more friable, branching forms. Identification of coral species in beachrock, beyond the broad morphologies, becomes difficult as key features for distinction are lost after death of the coral through abrasion and erosion (G. Williams, pers. comm.). However, identification of the gross morphology alone is very important as it has implications for the source of the sediments as well as the energy required to fracture and transport the clasts. Light, wave stress, sediment and sub-aerial exposure are the four main stress factors that affect the development of coral morphologies and their position on the reef (Fig. 4.3).

\subsubsection{Point counting}

Compositional data for the thin sectioned samples were collected through repetitive point-counting under $10 \mathrm{x}$ optical magnification. Each sample was subjected to three counts of 500 points, with a stage interval of $2 \mathrm{~mm}$. The final appearance of a carbonate rock is often as much a product of the secondary, diagenetic processes it has experienced, as it is of the primary depositional features. For this reason, the original constituents are considered separate from the cement. Data were analysed using all counts normalised to $100 \%$, both without pore space and without pore space plus cement. Point count data are presented in Appendix A.

\subsubsection{Election Probe Micro Analyser}

The Electron Probe Microanalyser (EPMA) allows geochemical investigation beyond the scope of the petrographic microscope. Its primary use in this study was the qualitative investigation of element distribution through the use of backscatter imaging as well as mapping of the concentration select elements using a wavelength dispersive spectrometer (WDS) in addition to the energy dispersive spectrometer (EDS). The VUW JEOL 733 Electron Microprobe was used to conduct back scattered electron (BSE) imaging and elemental maps of the samples. Accelerating voltage of the probe current was constant at $150 \mathrm{kV}$, with a dwell time of $50 \mathrm{~m} / \mathrm{s}$. Raw data are presented in the elemental maps according to relative concentration. Strontium $(\mathrm{Sr})$, calcium $(\mathrm{Ca})$, magnesium $(\mathrm{Mg})$ and barium $(\mathrm{Ba})$ were mapped using the WDS. Additionally, sodium $(\mathrm{Na})$, aluminium $(\mathrm{Al})$, silicon $(\mathrm{Si})$, titanium $(\mathrm{Ti})$, and iron $(\mathrm{Fe})$ were mapped using the less precise EDS. 


\subsubsection{Aragonite staining}

The cement of the beachrock was tested for aragonite, calcite and high magnesium calcite by staining with both Alixarian Red S solution and Feigl's solution as described in Reid (1969, pg. 4). Sample material was etched in dilute $\mathrm{HCl}$ for $\sim 6$ minutes and then washed in running water prior to staining.

Alizarian Red S (Dihydroxyanthraquinone; $\mathrm{C}_{14} \mathrm{H}_{8} \mathrm{O}_{4} ;$ ) solution was prepared by dissolving $0.1 \mathrm{~g}$ of Alizarian Red S in $100 \mathrm{ml}$ of $0.2 \% \mathrm{HCl}$. The cleaned and etched surface of the sample was covered with the cold reagent solution and allowed to react for about 5 minutes. The solution was then poured off and the etched surface was washed carefully by decantation. Calcite, witherite, high-Mg calcite, and aragonite are stained deep red by this process.

To distinguish between calcite and aragonite, Feigl's solution was used (Feigl, 1958, p. 470). This was prepared by placing $1 \mathrm{~g}$ of $\mathrm{Ag}_{2} \mathrm{SO}_{4}$ in a solution of $11.8 \mathrm{~g}$ of $\mathrm{MnSO}_{4} \cdot 7 \mathrm{H}_{2} \mathrm{O}$ in $100 \mathrm{ml}$ of demineralised water and boiled. After the solution had cooled, it was filtered and 2 drops of dilute $\mathrm{NaOH}$ solution were added. After 90 minutes, the solution was again filtered to separate any precipitate. It was then stored in a dark bottle to prevent the solution reacting with light. When staining, the etched surface of the samples was covered with the cold reagent solution and allowed to react for approximately 20 minutes. Aragonite is stained black by this treatment, while both calcite and high-Mg calcite are unaffected. Results from these tests were examined using a petrographic microscope.

\subsection{Clast-orientation and paleo-flow estimation}

Many sedimentary structures yield depositional data that shows the direction of the current at the time of deposition. In fluvial conglomerates, the orientation or imbrication of the clasts relate to the strength and direction of the currents during deposition (Selley, 1968; Graham, 1988). The beachrock at Palmyra shows similar qualities and are investigated in this thesis as a tool for paleo-environmental studies. However, clasts at Palmyra are affected by oscillatory flow, unlike the unidirectional flow of a river, and thus may result in different trends.

Here, analysis of paleocurrents may aid in the interpretation of depositional events and in the understanding of the geometry and trend of lithological units. This is 
feasible because the beachrock outcrops have undergone no tectonic deformation or tilting, and therefore clast orientation data can be compiled and summarized directly. The gravel clasts on Palmyra may show a preferred paleo-orientation because much of the sediment deposited on the beaches consists of broken clasts of Acropora coral which have an elongate, rod shape. Due to their shape, these clasts tend to interlock and as a result become resistant to subsequent currents or erosion.

During the 2009 and 2010 field seasons, overlapping, orientated photographs were taken of bed surfaces in plan view at four individual locations. From these photographs, paleocurrent analysis was accomplished by measuring the long-axis orientation of coral clasts. To obtain a statistically reliable paleocurrent trend, numerous orientation measurements must be made within a given stratigraphic unit. To achieve this, every identifiable clast larger than $2 \mathrm{~cm}$ was measured within each photograph, or of smaller size if necessary to give a minimum sample size of 30. Commonly, directional data from a particular bed or stratigraphic unit show considerable scatter, and thus, data are treated statistically to reveal primary and secondary directional trends.

In studies of large field areas, paleocurrent data often have their greatest value when plotted on a regional scale to, reveal paleocurrent patterns. However, because Palmyra has very little land area and the beachrock beds are relatively confined and isolated, paleo-flow data were analysed individually for each beachrock bed. Measurements (Appendix C) were combined to give total measurements for each bed, and are presented as rose diagrams in Chapter Eight.

\subsection{Numerical wave modelling}

The hydrodynamics of Palmyra were modelled using the numerical wave model SWAN (Simulating WAves Nearshore), developed by the Delft University of Technology. From this model, a simple sediment transport model was inferred from a well established relationship between bed shear stress (as determined by SWAN) and the particle size and density. However, no attempt is made to produce a sediment dynamics model. Here, the use of the numerical model to Palmyra Atoll is unique due to application for the wave model to an oceanic atoll reef, and in the application to determining past depositional environments of beach sediments. Due to this unique nature of the wave modelling at Palmyra, which includes modelling an area with limited baseline data, the full description of the methods and the acquisition of input data 
employed in the application of the SWAN wave model to Palmyra is provided in Chapter Seven.

\subsection{Radiocarbon dating}

Conventional radiocarbon dating of beachrock clasts and cement was achieved at the Waikato Radiocarbon dating laboratory. Samples were checked for recrystallization of aragonite prior to dating and two were discarded. Dense calcite samples provided by Tridacna maxima (giant clam) fossils were the preferred material for dating because the dense shell is relatively resistant to recrystallization. However, where Tridacna clasts were not present, a common genus of gastropod fossils (Turbo spp.) was used. Although these are more numerous in the beachrock, they are also more subject to erosion due to their thinner, more fragile shells. However, the Turbo sp. fossils that were dated were well preserved and relatively unaltered, to the extent that the nacre layer was still intact. A sample of Porites sp. was also dated, when Tridacna or Turbo samples were absent. Additionally, a sample of cement was dated to determine the minimum age of the beachrock at Lost Island. Although an ideal dating method, sufficient cement could not be extracted at other locations and AMS dating was not available.

In tropical surface waters, there is a depletion of ${ }^{14} \mathrm{C}$ compared to atmospheric concentrations mainly due to mixing with older, deep ocean waters. This offset is known as the 'reservoir age' and the late Holocene reservoir ages in the Atlantic, Pacific and Indian oceans depend on the geographic latitude of the region. Currently the reservoir age is relatively consistent for pre-atomic testing tropical waters and ranges between 300 and 500 years in the western tropical and subtropical regions between $40^{\circ} \mathrm{N}$ and $40^{\circ} \mathrm{S}$ (Fairbanks et al., 2005). The ages of material on Palmyra Atoll were corrected for an oceanic reservoir effect of $350 \pm 55$ yrs. This is the reservoir age measured at Kiritimati ( $\mathrm{n}=4$; Fairbanks et al., 2005), as no estimates presently exist for Palmyra Atoll.

The corrected radiocarbon ages are presented in this thesis as calibrated years BP (Before Present.; Table 6.1), as well as calendar ages in the C.E (Common Era). to facilitate comparison to other reported ages and records. Conventional ${ }^{14} \mathrm{C}$ ages can be calibrated into calendar years using numerous calibration curves based on absolutely dated tree-ring chronologies and other archives. Precisely dated corals have provided a calibration curve back to 50,000 yrs BP (Fairbanks et al., 2005). The conversion into 
calendar ages here was achieved used the online calibration by Fairbanks et al. (2005; Fig. 4.2; http:/ /www.radiocarbon.LDEO.columbia.edu/).

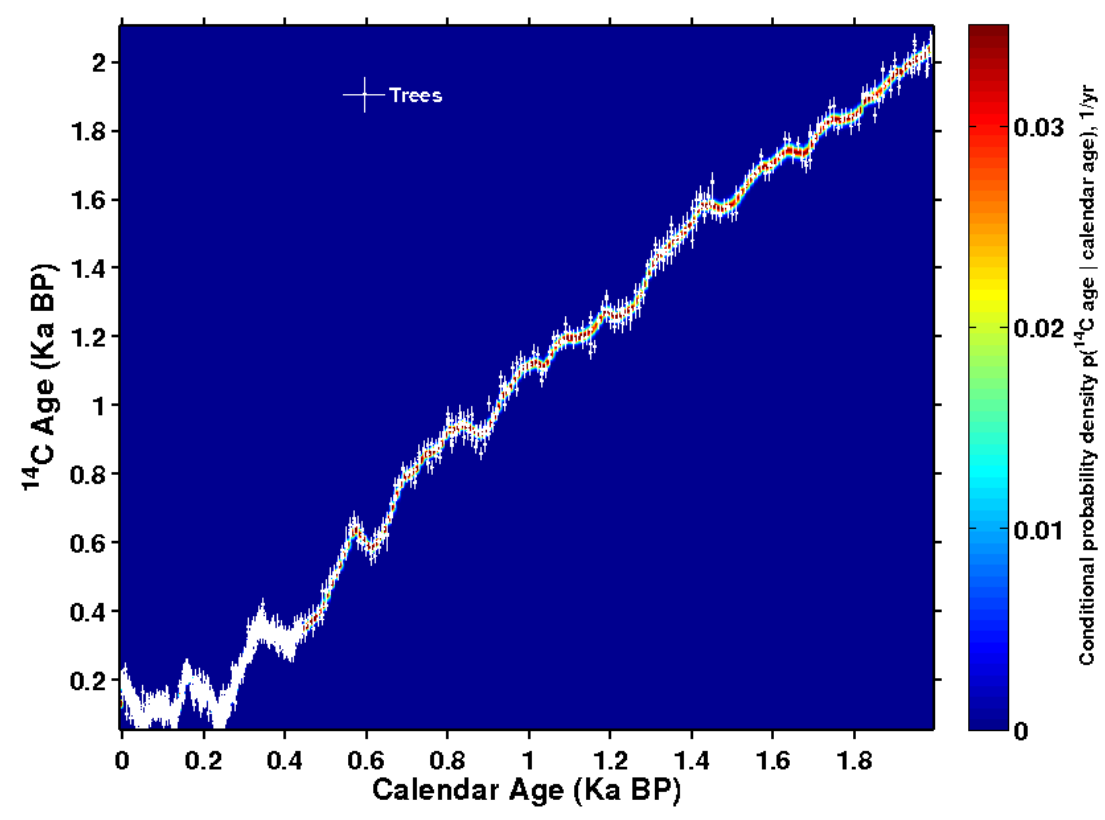

Figure 4.4: (From Fairbank et al. 2005; http://www.radiocarbon.LDEO.columbia.edu/) Calibration curve for radiocarbon for the past 2000 year. 


\section{Beachrock lithofacies and petrology}

\subsection{Beachrock distribution on Palmyra Atoll}

Beachrock outcrops occur on 10 islets on Palmyra Atoll (Fig. 4.1), and although beachrock is exposed along these shorelines, it is not possible to determine the extent of original beachrock outcrops on Palmyra Atoll due to the significant modification of the islands during military occupation (Chapter Three). During field work, care was taken to distinguish between naturally occurring beachrock and the artificial rock which has formed from the compacted rubble sourced from dredging of the lagoons and shipping channel. Such deposits may have undergone natural cementation after artificial compaction, or may possibly have had cement included. They are often found along stretches used for roads and around relict structures as well as composing the composite Cooper-Meng Island and the six completely artificial islands. An example of this along the shoreline of the North and South Fighter Strip (Fig. 5.1), which were constructed as runways for fighter planes and are now eroding on the northern edge.

Only one in situ outcrop of beachrock is found on Cooper-Meng Island due to the major alteration from the natural state of several small, disconnected reef islands into the single large island which was centre of military activity (Fig. 3.11). However, disconnected and isolated smaller outcrops and boulders can be found scattered along the coast, suggesting that more extensive outcrops did exist. For example, material at North Beach (Fig. 5.2) appears to be beachrock but now sits loosely on the reef flat and appears to be out of place. Its original position and orientation are unknown, and thus it is of limited use to the present study.

Today, remaining beachrock outcrops are predominantly located on the eastern islands of the elongated atoll, as well as along the north and south coasts. Most outcrops exhibit typical beachrock characteristics, being parallel to the coast and dipping seaward at a low angle. Additionally, beachrock comprises all of Lost and Fern islands within East Lagoon (Fig. 4.1) 


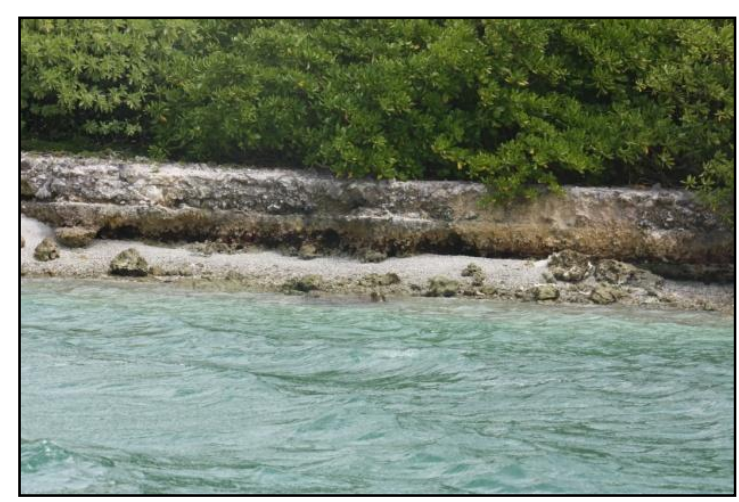

Figure 5.1: Northern edge of North fighter strip, which has eroded since its construction during the military occupation.

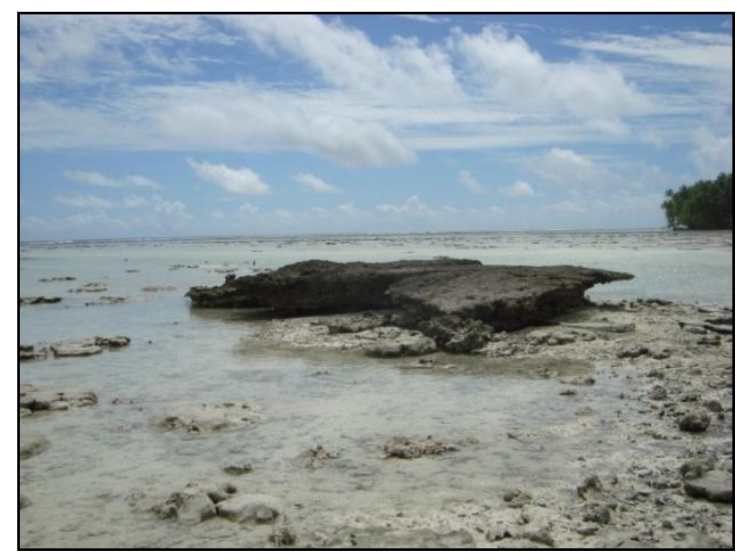

Figure 5.2: Disconnected beachrock boulders on the reef flat at North Beach. Boulder is $5 \mathrm{~m}$ across. The beachrock here is coarse grained and clast-supported, with mostly branching coral species.

As the process of cementation generally occurs sub-aerially, beachrock is only exposed at the surface when the area has undergone significant erosion. Therefore, headlands and the outer edge of islands, areas subjected to a higher degree of erosion, tend to have more exposures of beachrock. It is unknown to what degree the beachrock identified in this study extends inland due to the vegetation and unconsolidated materials covering the outcrops from the edge of the beach.

Six lithofacies have been defined for the beachrock outcrops of Palmyra Atoll using the classification described in Chapter Four, and the observed textures and petrology related to their environment of deposition. The beachrock on Palmyra typically has bimodal clast populations, consisting of the gravel portion that were described from outcrop and in hand samples, and the smaller, matrix populations that were analysed from thin sections. However, lithofacies 1a and 1b (Fig. 5.3) are heavily dominated by sand grains, and thus are distinguished as separate lithofacies. The following lithofacies are recognised on Palmyra Atoll and are described in detail in section 5.2: 
1. Carbonate Sandstone
a. laminated
b. massive

2. Allochthonous Conglomerate

a. Rudstone

i. platy coral species

ii. branching coral species

b. Floatstone

i. platy coral species

ii. branching coral species

\subsection{Lithofacies descriptions}

In addition to the descriptions, samples were collected from the six lithofacies and 19 of these were impregnated with epoxy resin, slabbed, thin sectioned and analysed quantitatively using a petrographic microscope. Selected samples were chosen as representative samples and analysed further with the EPMA. The observations from the petrographic analysis were integrated with field data to help in the description of the lithofacies, and determination of the origin of the cements. The cement is identified to be predominantly aragonite (confirmed using Feigl's solution; Fig. 5.3) and did not vary with different forms of cement, mostly either acicular needles or micritic rims. Average percentages of the allochemical components, as well as the cement and porosity, are given in Table 5.1 and shown in Figure 5.4.

The underlying reef/algal platform is exposed at almost all locations studied here, except where covered by modern sand, and has been subjected to a high degree of erosion. This pavement extends out from the base of the beachrock outcrop towards the modern reef and represents the oldest surface of sedimentation of the beachrock. The lithified coralgal platform is excluded from the following classification of lithofacies as it is beyond the scope of this study. Additionally, it is still growing and morphologically distinct from beachrock as it is not a single depositional entity. 

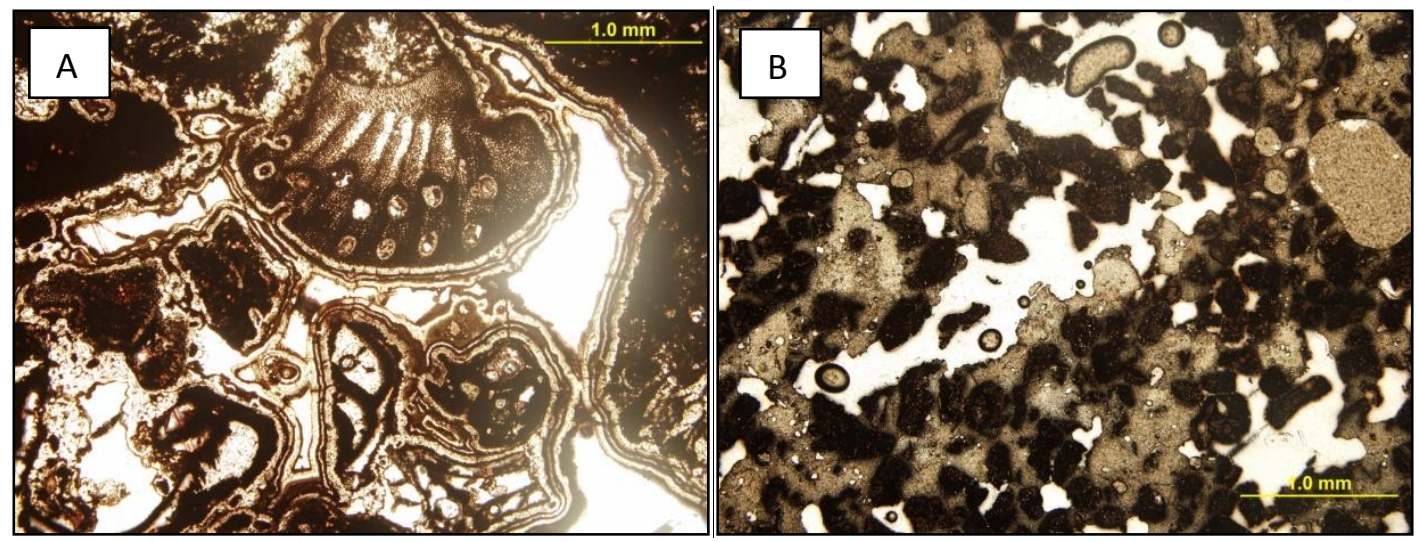

Figure 5.3: (A) Thin section of sample KO 031 (Cooper Island, lithofacies 2bii) showing banded aragonitic cement stained black by Feigl's solution. (B) Thin section of KO 010 (Holei Island, lithofacies 1a) showing blocky aragonitic cement stained black by Feigl's solution.

Table 5.1: Average composition of each beachrock lithofacies, as determined from raw point count data in Appendix A.

\begin{tabular}{l|cccccc}
\hline & \multicolumn{7}{|c}{ Lithofacies } \\
\cline { 2 - 7 } & \multicolumn{1}{|c}{$\mathbf{1 . \mathbf { a }}$} & $\mathbf{1 . b}$ & $\mathbf{2 . a . i}$ & $\mathbf{2 . a . i i}$ & $\mathbf{2 . b . i}$ & $\mathbf{2 . b . i i}$ \\
\hline No. of samples & $\mathbf{3}$ & $\mathbf{1}$ & $\mathbf{2}$ & $\mathbf{4}$ & $\mathbf{1}$ & $\mathbf{8}$ \\
Coral & 11.36 & 10.33 & 8.83 & 32.71 & 17.27 & 28.48 \\
Algae & 42.13 & 34.00 & 50.40 & 26.05 & 44.93 & 29.83 \\
Pore Space & 24.27 & 21.00 & 13.14 & 20.89 & 22.20 & 21.63 \\
Cement & 20.51 & 13.13 & 26.47 & 13.37 & 10.93 & 16.76 \\
Bivalve & 0.14 & 0.73 & 0.80 & 0.88 & 0.93 & 0.60 \\
Gastropod & 0.00 & 0.00 & 0.00 & 0.02 & 0.00 & 0.43 \\
Foraminifera & 2.67 & 19.87 & 0.37 & 0.90 & 0.93 & 1.49 \\
Intraclast & 0.00 & 0.00 & 0.00 & 0.49 & 0.00 & 0.05 \\
Echinoderm & 0.00 & 0.00 & 0.00 & 3.90 & 0.00 & 0.14 \\
Bryozoa & 0.36 & 0.93 & 0.00 & 0.73 & 2.80 & 0.30 \\
Halimeda & 0.00 & 0.00 & 0.00 & 0.07 & 0.00 & 0.32 \\
Other & 0.00 & 0.00 & 0.00 & 0.00 & 0.00 & 0.18 \\
\hline
\end{tabular}




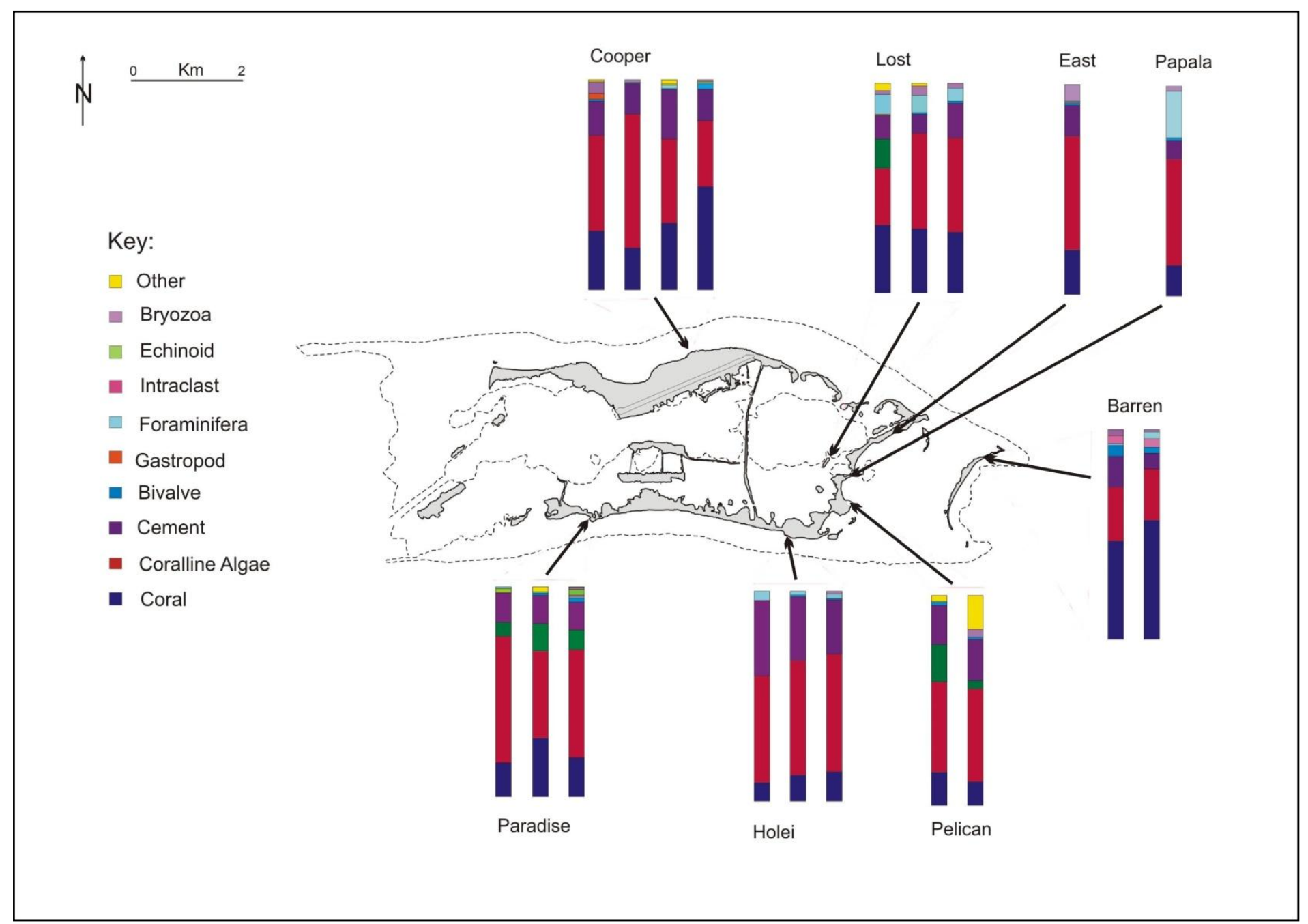

Figure 5.4: Average composition of Palmyra Atoll beachrock samples. This shows that coralline algae and coral fragments are the most common constituents. 


\subsubsection{Lithofacies 1.a - Laminated Sandstone}

Lithofacies 1.a represents approximately $4 \%$ of the total described beachrock and is only present at Holei Island (Fig. 6.1). It consists almost entirely of weakly cemented, well sorted sand similar to the modern beach sand on the adjacent beaches. It has a uniform pale cream colour and consists entirely of coarse sand-sized particles. The distinguishing feature of this lithofacies is the laminated effect resulting from large, elongated pore spaces that average approximately $5 \mathrm{~mm}$ across and $1 \mathrm{~mm}$ deep (Fig. 5.5A). The laminations are a post-depositional feature and possibly occur due to the weak compaction and friable nature of the lithofacies. The laminations are present in both hand samples $(\sim 1 \mathrm{~cm})$ and at outcrop scale $(5-10 \mathrm{~cm})$ and appear to be due to localised dissolution of $\mathrm{CaCO}_{3}$. Lithofacies $1 \mathrm{a}$ is also highly susceptible to bioerosion due to its friable nature and contains numerous burrows occupied by sipunculid worms (Fig. 5.5B).

\subsubsection{Petrology}

In thin section (Fig. 5.5C), this lithofacies consists mostly of uniform clasts between 150 and 400 microns in diameter. On average, these are well sorted, subrounded, non-spherical grains. The average porosity of this lithofacies is approximately $25 \%$. The composition of the laminated sandstone is difficult to obtain accurately because of the small size of the clasts; further, these are also sufficiently abraded that the identifiable structure of the organism or skeleton has often been lost (Fig. 5.5C). However, there is a dominance of calcareous algae $(\sim 42 \%)$ compared to the coral fragments $(\sim 11 \%)$ which form the second most common constituent. The remainder consists of minor parts of bivalves, gastropods, foraminifera, bryozoans and other unidentifiable material. 


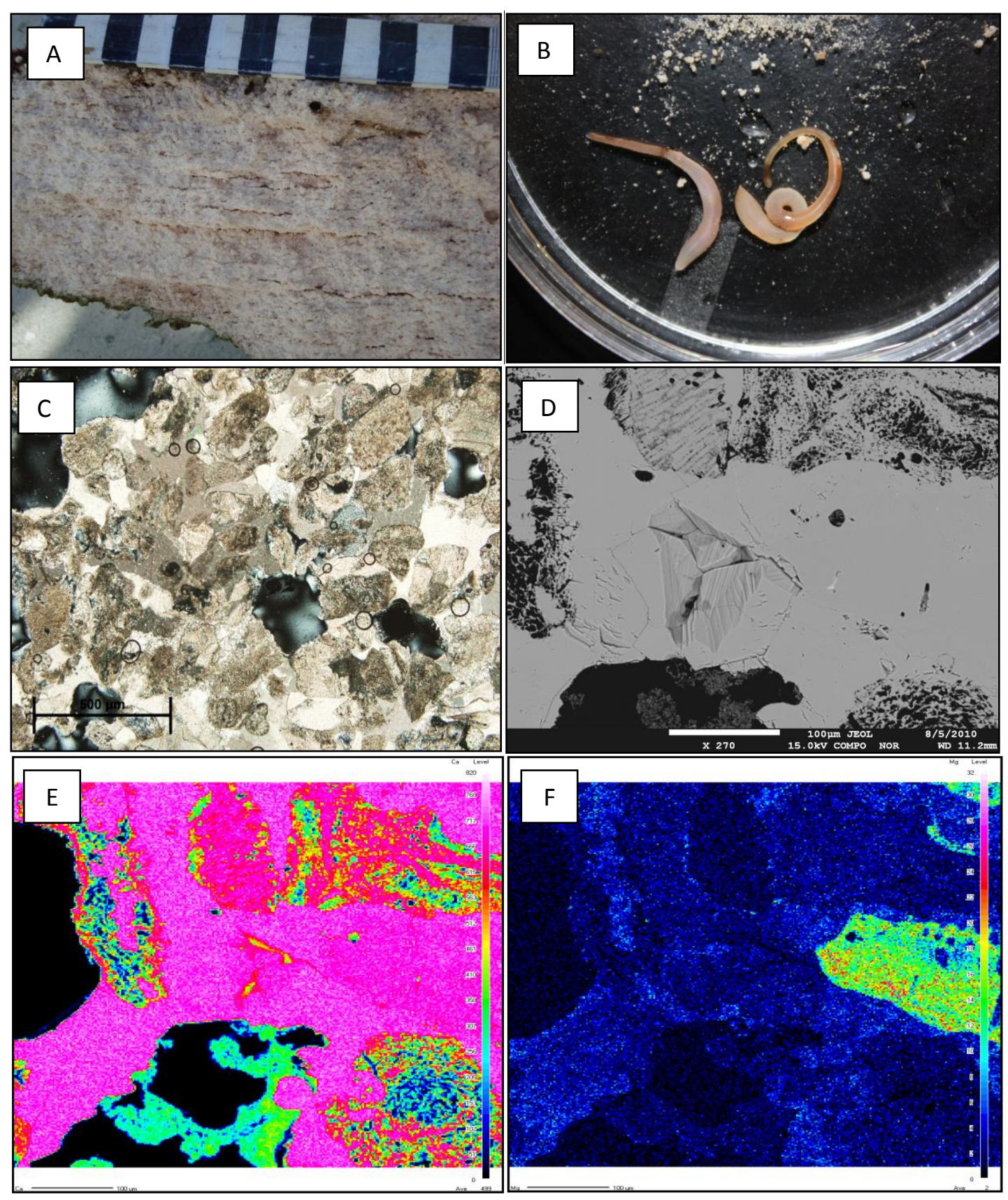

Figure 5.5: (A) Hand sample from lithofacies 1.a, showing fine scale laminations created by elongated pore spaces. Scale bar is in centimetres. (B) Sipunculid worm extracted from beachrock at Holei Island. (C) Thin section of lithofacies 1a under cross-polared light. Dark areas are pore spaces and the lighter, white areas show the blocky cement. Scale bar is $\mathbf{5 0 0}$ microns. (D) Backscattered electron image of sample $\mathrm{KO}$ 010, highlighting homogenous cement. Scale bar is 100 microns. Three clasts of coral and algae can be seen on the edges of the image, as well as the black pore space at the bottom of the image. The triangular area in the centre is most likely caused by plucking of a crystal during the thin sectioning process. (E) WDS image of the concentration of $\mathrm{Ca}$ in the section of KO 010 shown in (D), including more of the pore space. (F) WDS image of concentration of Mg in the same section as the previous figures. This highlights a high-Mg object that is otherwise homogenous with the rest of the material. 
The blocky cement is very well developed locally, constituting about $20 \%$ of the rock (Table 5.1), with an evident meniscus fabric. The cement fabric is most clearly seen under cross-polarised light, where the cement is easily identified (Fig. 5.5C). In BSE images, the cement appears extremely homogenous (Fig. 5.5D). However, elemental mapping of $\mathrm{Mg}$ (Fig. 5.5F) show areas of significant variation in the concentrations of $\mathrm{Mg}$ within the cements. This may be due to dense coralline algae that have been subjected to severe cementation. With the exception of such areas, the majority of the cement appears to be relatively low-Mg calcite that has formed with a large blocky morphology.

\subsubsection{Inferred origin}

The small, even clast size is evidence that this lithofacies represents a low energy environment, similar to that of the present day North Beach and the sheltered beaches on Holei Island and the southern coast. The laminated porosity also suggests that it did not form under a thick overburden and has thus undergone little compaction. Considering the grain size and the degree of sorting, this lithofacies would have been subject to considerable reworking on the beachface prior to cementation.

The meniscus fabric presented in this lithofacies is diagnostic of a vadose or intertidal environment of cementation. During low-tide and evaporative conditions, seawater is held by capillary action at grain contacts. The uneven cements precipitated within each meniscus result in pore rounding and, further, the crystals typically have blunt terminations due to undernourishment from pore fluids, or dissolution, at their tips. The consistency of the solid, blocky cements suggest that there was a significant supply of seawater during cementation, leading to the conclusion that this lithofacies formed lower down in the intertidal zone, beneath a thin veneer of sediment.

\subsubsection{Lithofacies 1.b - Massive Sandstone}

Lithofacies 1.b also has limited distribution and is found only along the inner coastline of Papala Island (Fig. 6.1), making up only about $7 \%$ of the total beachrock on Palmyra. This lithofacies is a massive, fossiliferous sandstone, which is generally darker than other beachrock found on Palmyra. This colour is due to a reddish brown tinge around the outer surface of the grains, which is most likely due to algal pigments. It contains a number of randomly-oriented coral and shell clasts up to $10 \mathrm{~cm}$ in the longest dimension that, together with the lack of lamination, distinguishes it from the other sandstone lithofacies. Both of the dominant molluscan species, Turbo cornutus and 
Tridacna maxima, are present as clasts as well as numerous species of platy coral in varying states of preservation.

\subsubsection{Petrology}

In thin section (Fig. 5.6A-B), this lithofacies shows well sorted material, of approximately 500 microns average size, with a porosity of about $21 \%$. This subrounded to rounded clasts have relatively dark colouration when compared to other lithofacies. Compositionally, calcareous algae are the main constituent $(\sim 34 \%)$, with coral fragments a relatively minor component $(\sim 10 \%)$. However, foraminifera play a significant part in the composition, compared to all other lithofacies, and contribute around $20 \%$ of the original components.

The cement has formed in two main episodes. The first generation is a rim of dense, irregular micritic cement, which is succeeded by the more porous, acicular cement. This second generation of cement is irregular in thickness. Close examination of these cements using backscattered election imaging shows that both types are composed of numerous smaller bands (Fig. 5.6C-D).

\subsubsection{Inferred origin}

This lithofacies must have formed in a medium to low energy environment, due to the small grain size and also the presence of randomly distributed larger clasts. The high degree of sorting and rounding of the grains suggest significant abrasion during transport and reworking on the beachface. This lithofacies represents beach material, similar to that of lithofacies $1 \mathrm{a}$, that has been reworked sufficiently to remove laminations, but includes a higher proportion of gravel clasts. The banded cements show that cementation occurred during a series of brief episodes, resulting in the extremely fine banding shown in the backscattered electron images. 

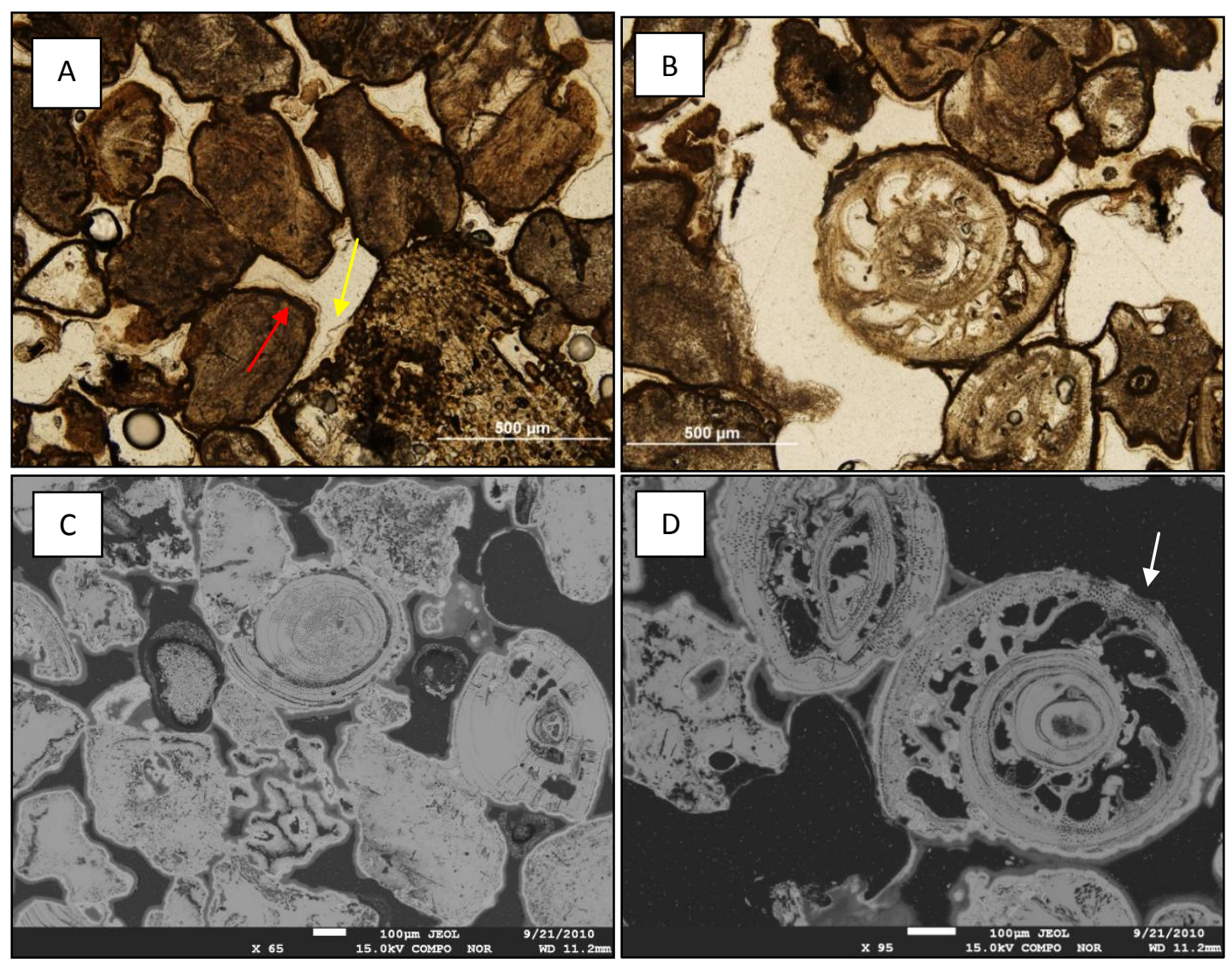

Figure 5.6: (A) Thin section of KO 038 (Papala Island) showing the dominance of algal fragments. A

fragment of an echinoid spine is present in the bottom right of the frame. The image also shows the micritic rims (red arrow) followed by irregular sparry cement (yellow arrow). (B) Same section of KO 038 centred on two species of foraminifera. The cement surrounding the foraminifera have partially eroded (arrow). (C) Backscattered electron image a different part of the same sample with a variety of constituents. (D) Backscattered electron image of (B).

\subsubsection{Lithofacies 2.a.i - Platey Rudstone}

Lithofacies 2 sediments are classified by their biofacies as well as their lithofacies. Clast-supported is defined as occurring when the matrix material of the beachrock is so low in proportion to the clasts that the individual clasts are in contact with each other. In this lithofacies, the matrix material, usually coarse sand, only exists in the pore spaces between larger clasts. Lithofacies 2.a.i occurs at three locations on the atoll, at Pelican, Lost and Cooper islands (Fig. 6.1); overall it makes up approximately $20 \%$ of the beachrock at Palmyra. The lithofacies is a clast supported, platy conglomerate with the larger clasts consisting almost entirely of platy and massive coral species. At outcrop scale, this lithofacies is extremely variable and visibly coarse with clasts up to $30 \mathrm{~cm}$ in diameter. 


\subsubsection{Petrology}

The matrix material is generally well sorted, sub-rounded grains. Cement exists in greater amounts $(26 \%)$ than the porosity $(13 \%)$. The pre-cement detrital components are also unevenly split between calcareous algae (50\%) and coral (9\%), with minor components of bivalves, foraminifera, echinoderms and bryozoans.

For most of this lithofacies, the cement is dominated by up to five generations of micritic cement. The dark rims of micritic cement are interspersed with brighter layers of sparry aragonite (Fig. 5.7A-D). In discrete locations, the rims of micritic cement appears to have disintegrated into a fine mud (Fig. 5.7B). Through microanalysis, BSE images (Fig. 5.7C-D) show multiple layers of sparry cement of varying densities. The cement appears to be homogenous in its composition and variations in the element intensity; in particular $\mathrm{Mg}$ and $\mathrm{Ca}$ (Fig. 5.7E-F) are most likely due to density differences between layers of cement. For instance, the outer most layer of cement is composed of fine needles of aragonite, which are less densely cemented than older layers. Most elements are homogenous between the cement and the clasts, except for $\mathrm{Mg}$, which exists in lower concentrations in the cement than in the clasts (mostly high-Mg algae and foraminifera).

Lithofacies 2.a.i was analysed from two separate locations (Lost Island and Pelican Island) which contained different amounts of cements. While the Lost Island samples have cement averaging about $100 \mu \mathrm{m}$ thick, Pelican has thick cement bands visible to the naked eye in outcrop. The latter cement averages approximately $250 \mu \mathrm{m}$ in thickness (Fig. 5.7D) but can be up to $600 \mu \mathrm{m}$ 

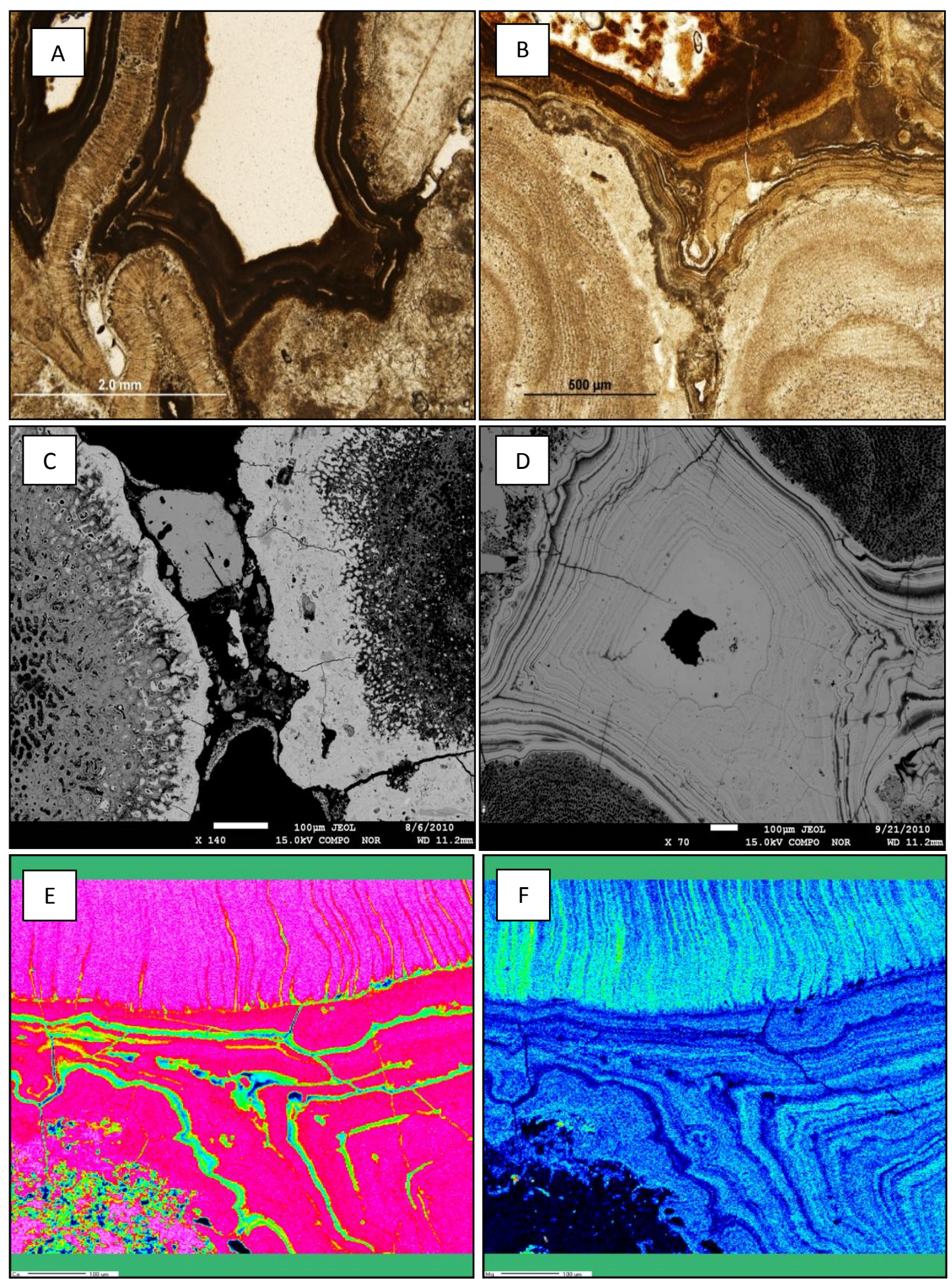

Figure 5.7: (A) Thin section of sample KO 031 (Cooper Island) showing rounded algal clasts surrounded by multiple generations of micritic cement. (B) KO 016 (Pelican Island), shows similiar features to KO 031. (C) Backscattered electron image of a sample from Pelican Island showing cementation around algal clasts. The cement also extends approximately $100 \mu \mathrm{m}$ into the outer layer of the clast. (D) Backscattered electron image of beachrock from Pelican Island showing numerous bands of cement filling a pore space between four algal clasts. (E) WDS element map of Ca on a thin section of beachrock cement from Pelican Isand. In the top portion of the image is a section of shell, and an algal fragment is the lower left hand corner. Banding of the cement is highlighted by the varying concentration of $\mathrm{Ca}$, which is due to variations in the density of the cement. (F) The same image as (E) but mapped for Mg. This shows that the cement and the shell material have similar concentrations of $\mathrm{Mg}$ in them. 
The cement contains some five dark bands that, on closer examination, appear to be gaps in the thick, dense cements that are filled with sparry, sparse cements. Concentrations of $\mathrm{Mg}$ in all of the cements are relatively low when compared to the clast materials, especially those dominated by high-Mg Amphistegina tests.

\subsubsection{Inferred origin}

This lithofacies was deposited under extremely high energy conditions, such as significant storm events, and cemented rapidly afterwards. Platy corals and large Tridacna shells are generally more resistant to mechanical breakdown than other species and therefore are indicative of high energy transport. Due to the large overall grain size of the clasts, energy from waves must have reached to the lower portions of the reef where platy corals form. The lack of significant material smaller than $2 \mathrm{~mm}$ suggests either that all finer material was transported elsewhere or was cemented so rapidly after deposition that smaller material carried in by lower energy events was unable to penetrate into the pore spaces.

\subsubsection{Lithofacies 2.a.ii -Branching Rudstone}

Lithofacies 2.a.ii. occurs mainly at the eastern end of the atoll, on Barren and northern East islands, but is also present at Cooper Island on the northern coast (Fig. 6.1), and is representative of approximately $26 \%$ of the beachrock on Palmyra. This lithofacies is a clast supported conglomerate similar to lithofacies 2.a.i, but is dominated by branching coral species, such as Acropora. Beds of branching rudstone have variable grain size and sorting within hand samples, with coarser material closer to the top of the bed. This lithofacies generally has a much higher proportion of smaller clasts than in lithofacies 2.a.i. Beds with larger clast sizes are preferentially eroded, resulting in a staggered or stepped appearance to the outcrop.

\subsubsection{Petrology}

The petrographic texture of branching rudstone is similar to that of 2.a.i.; that is, it is composed of coarse, poorly sorted, sub-angular, non-spherical grains. It is the most porous lithofacies present, with a porosity of $21 \%$. There are almost equal amounts of the two major constituents, coral fragments $(33 \%)$ and calcareous algae (26\%). The remaining material is composed of minor portions of bivalves, foraminifera, intraclasts and bryozoans, each of which comprises about $0.5-4 \%$ of the total. Gastropod fragments are very minor $(0.1 \%)$. 


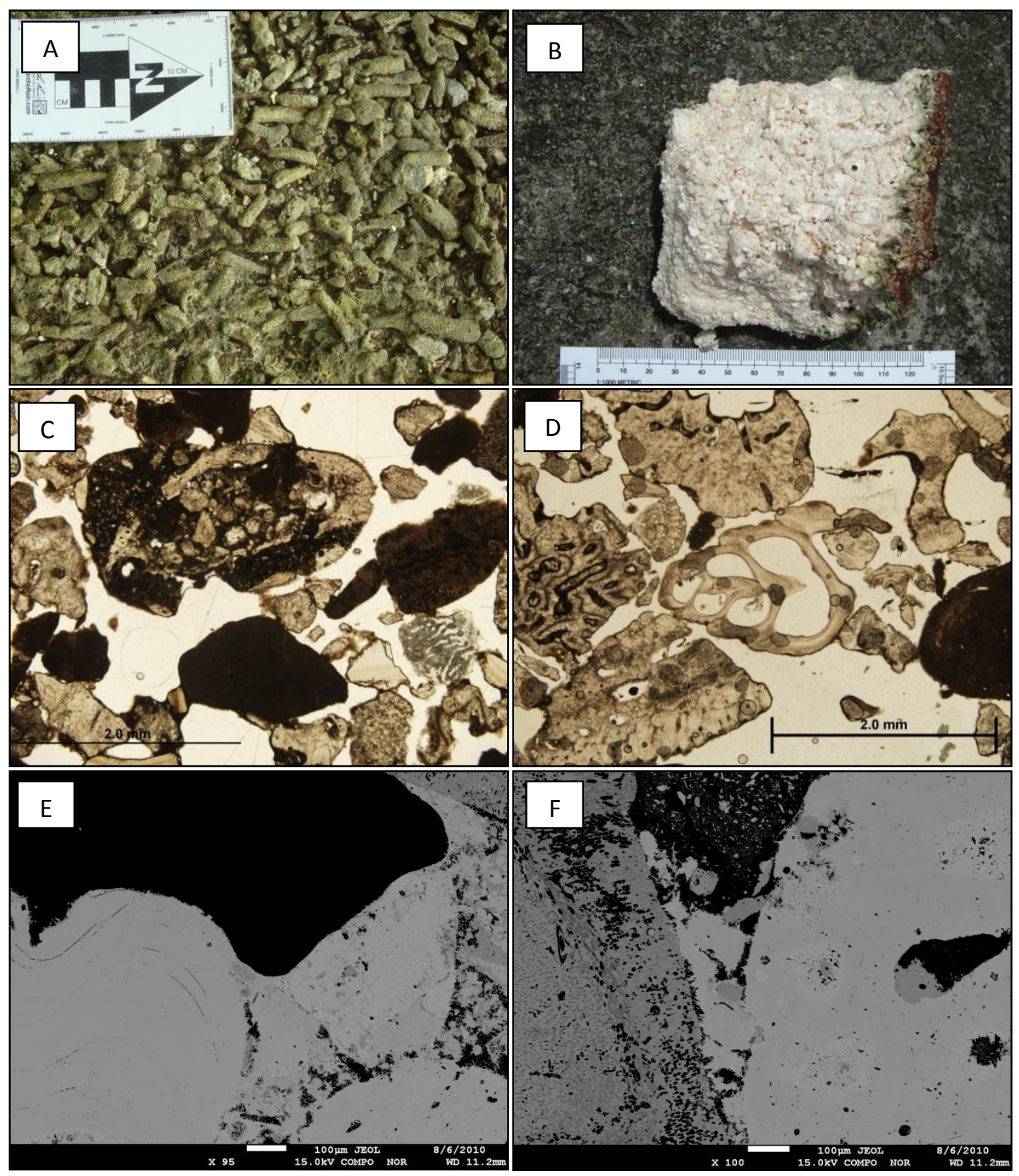

Figure 5.8: (A) Top surface of lithofacies 2.a.ii at the beachrock outcrop on Cooper Island. (B) A hand sample of fine-grained branching rudstone from Barren Island. (C) Thin section of KO 026, from Barren Island, which exhibits a large intraclast in the upper centre of the photo, surrounded by largely algae fragments. (D) Thin section of KO 027, also from Barren Island, showing a section through a small gastropod in the centre of the view surrounded by coral and algal fragments. (E) BSE image of KO 026 shows thin meniscus cement around the pore space and minor bundles of acicular needles between the clasts. (F) BSE image of the same sample as (E) showing an algal fragment and a coral clast with minor matrix material between them. 
This lithofacies has the least amount of cement, making up only $11 \%$ of the rock. This is because it contains only one generation of bladed aragonite cement, which has not formed complete rims around the grains. Similar to elsewhere where larger coral clasts are present, needles of aragonite have formed within the intra-clast pore spaces of coral clasts.

Backscattered electron imaging of a sample from the Barren Island outcrop shows relatively homogenous individual clasts, as well as the cement material (Fig. 5.8EF). Some clasts show infilling of the pore space or borings with cement that is compositionally different to the cement binding the rock. The dominant cement type is unique to this lithofacies and forms highly irregular acicular needles in clumps around the smaller matrix material (Fig. 58-F). However, this is not consistent throughout the sample and some areas lack cement.

\subsubsection{Inferred origin}

It is likely that this lithofacies formed in a medium to high energy environment, much like the conditions that are present today along the eastern side of Barren Island. Material deposited on the beach during high energy events is combined with finer material from moderate conditions. The presence of numerous beds of varying grain size also suggests that the outcrops of this lithofacies formed from numerous depositional events. Today, greater wave energy affects the eastern coast of Barren Island than anywhere else on the shorelines of Palmyra, giving coarse, modern deposits. The moderate to high energy suggested by the beachrock texture may be a combination of storm deposits and normal but relatively high energy conditions.

\subsubsection{Lithofacies 2.b.i - Platy Floatstone}

Lithofacies 2.b (both i and ii) differ from the previously described lithofacies in that they are conglomerates with sufficient matrix material that the clasts are not in direct contact with each other. These matrix-supported facies are defined as only containing 20-30 \% clast material. Lithofacies 2.b.i is encountered only on East Island (Fig. 6.1), and makes up approximately $10 \%$ of the described beachrock. The matrixsupported, platy conglomerate lithofacies is poorly sorted and contains very angular clasts of a variety of platy coral morphologies, which give the outcrop a very rough, jagged and uneven appearance. 


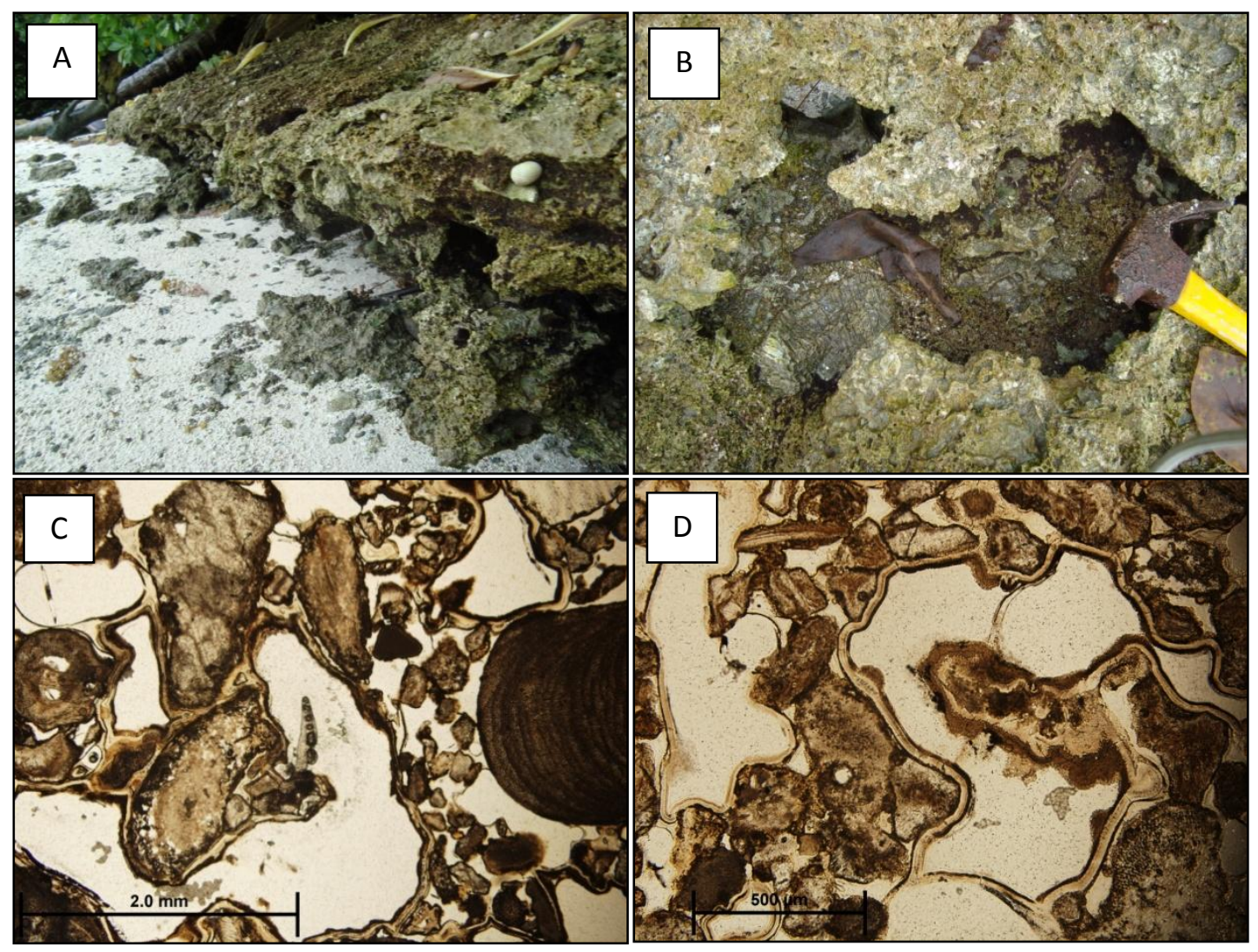

Figure 5.9: (A) Outcrop of platy floatstone on East Island. (B) Closer view of a weathered portion of platy floatstone on East Island. (C) Thin section of KO 035 from East Island, showing a variety of grain types and sizes cemented with a thick meniscus fabric. (D) A different section of the sample in (C) at a higher magnification. This is mostly matrix material and highlights at least three generations of cement binding the grains. White areas within (C) and (D) are inter-clast pore space.

\subsubsection{Petrology}

In thin section, the matrix of lithofacies 2.b.i consists of poorly sorted, subrounded grains. There is a high proportion of grains smaller than $2 \mathrm{~mm}$ that comprise the matrix. These are mainly composed of calcareous algae $(45 \%)$, with lesser coral fragments $(17 \%)$. The rest is composed of minor portions of bivalves, gastropods, foraminifera and bryozoans. It is a relatively porous facies with an average porosity of $22 \%$.

Cement in this platy floatstone lithofacies is not as common as in other lithofacies and only accounts for $11 \%$ of the composition. This lithofacies has on average two generations of micritic rims of cement, interspersed intermittently with sparry cement (Fig. 5.9C-D). The micritic cement has formed as a meniscus fabric around the pore spaces, creating the rounding effect also seen in other lithofacies. 


\subsubsection{Inferred origin}

The meniscus fabric formed by the cement in this lithofacies shows that it was dominantly formed in the intertidal/vadose zone, similar to the laminated sandstone lithofacies. However, unlike the laminated sandstone, it must have formed from much higher energy deposits, similar to platy rudstone, to create the coarse, poorly sorted deposits. The cementation process may have taken a longer period of time, perhaps due to a lower position on the beach, further into the intertidal zone. This allows time for finer clasts that would have been washed away during the initial depositional event, to subsequently infiltrate the deposits and cement synchronously with the original material. The combination of high energy deposits and considerably reworking is rare and may be a reason why lithofacies 2.b.i is a minor lithofacies at Palmyra

\subsubsection{Lithofacies 2.b.ii - Branching Floatstone}

Lithofacies 2.b.ii is the most common lithofacies on Palmyra and is present on Paradise, Holei, Cooper and Lost islands (Fig. 6.1). Together it makes up approximately $33 \%$ of the total described beachrock. This lithofacies is similar to the previous one, being a matrix-supported, branching conglomerate with a high proportion of small $(<2$ $\mathrm{mm}$ ) particles. It differs in that it is largely made up of branching, Acropora sp. coral clasts. Clasts are generally smaller than those of platy corals so outcrops have a higher degree of sorting of clasts. Beds appear to be sorted by size differences and contain a variety of fossilised material besides corals including gastropods, bivalve shells and echinoderm fragments (Table 5.1). The branching floatstone lithofacies is common along both the north and south coasts of Palmyra Atoll as well as on the inner lagoonal islands.

Lithofacie 2.b.ii is the most common lithofacies on the atoll and as a result shows a high degree of variation. For instance, it is extremely variable in the degree of sorting, ranging from very poorly sorted to well sorted. However, it contains consistently sub-angular, non-spherical grains. The matrix grains range from approximately 50 microns in diameter up to $2 \mathrm{~mm}$, and are mostly calcareous algae (30\%) and coral fragments $(29 \%)$. There are minor components of other allochemical grains, the most common of which are foraminifera $(1.5 \%)$, and by minor proportions of bryozoans, bivalves, gastropods, intraclasts, echinoderms, and other clasts. This lithofacies has an average porosity of $22 \%$. 


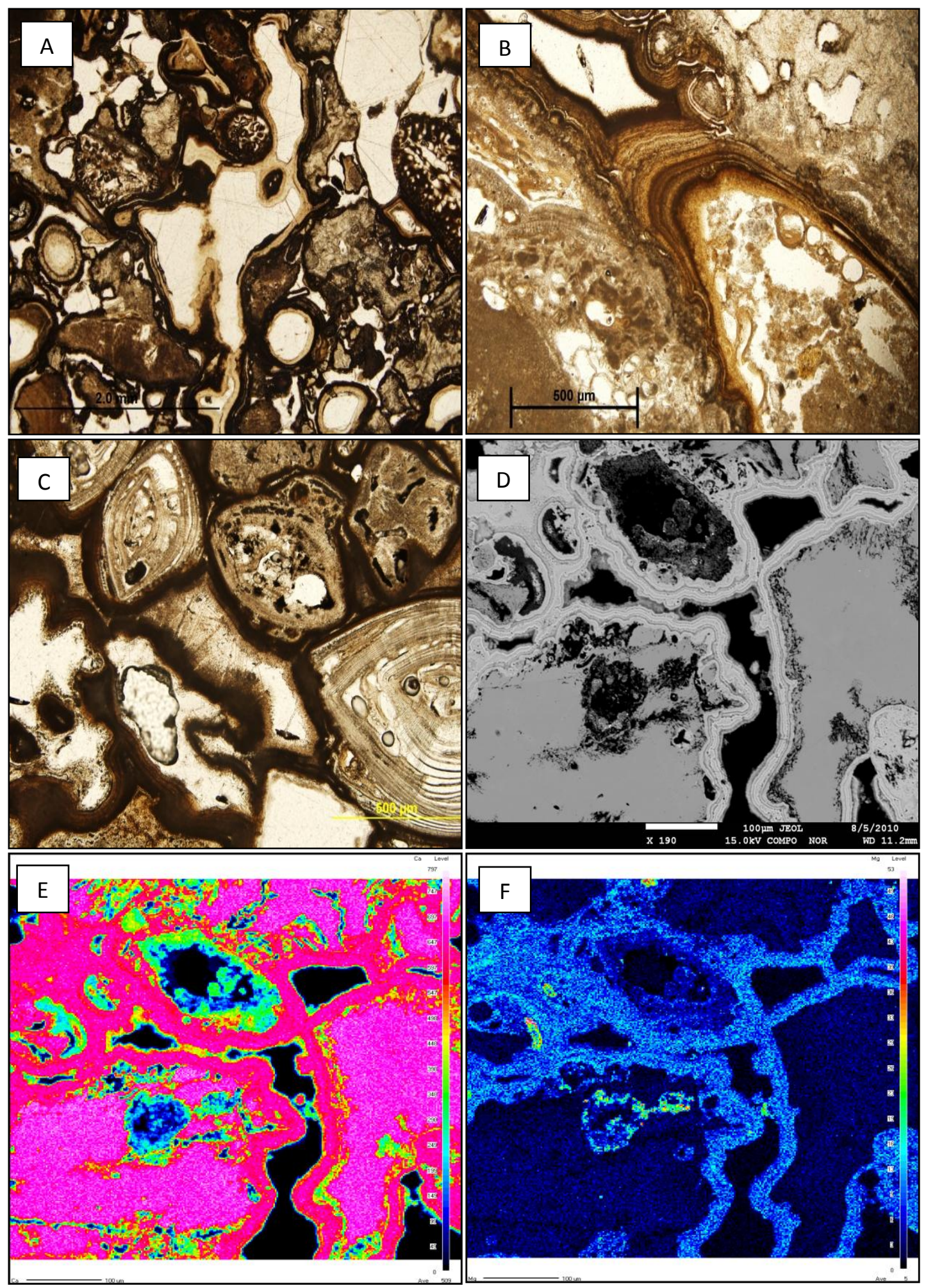

Figure 5.10: (A) Thin section of sample KO 003 from Paradise Island, showing mostly coral and algal fragments surrounding by thick, irregular, micritc (dark) and sparry (light) cement. Scale bar is 2 mm. (B) Thin section of beachrock from Cooper Island showing variation in banding of the cement. (C) Thin section of lithofacies 2.b.ii from Lost Island showing dense micritic cement and acicular aragonite needles. This also highlights the large number of foraminifera present at Lost Island. (D) BSE image of sample KO 002 (E) Element map of Ca for KO 002, which shows mostly homogenous calcium content throughout the sample. (F) Element map of $\mathrm{Mg}$ for $\mathrm{KO} 002$ showing relatively high $\mathrm{Mg}$ cement compared to the low $\mathrm{Mg}$ clasts. 


\subsubsection{Petrology}

Branching floatstone has a significant amount of cement (around $21.2 \%$ ), which generally consists of a few thick layers of dark, micritic cement enclosed by a lighter, sparry cement (Fig. 5.10A-F). This cement forms a meniscus fabric around the grains, creating smooth, rounded pore spaces. An exception is sample KO 013, from Holei Island, where there is no dark, micritc cement present and the sole cement is blocky.

BSE imaging reveals variable numbers of cement bands in the samples from this lithofacies (Fig. 5.10D). Sparry, acicular cement is dominant throughout the lithofacies. The cement has low concentrations of $\mathrm{Mg}$; however, the cement still has relatively higher concentrations of $\mathrm{Mg}$ than the clasts except in the case of high-Mg foraminifera, echinoderms and red algae (Fig. 5.10F). Very low but detectable amounts of $\mathrm{Na}$, K, and $\mathrm{Ti}$ are homogeneous throughout the cements, and are generally absent from the clasts.

\subsubsection{Inferred origin}

The textural characteristics of the branching floatstone are representative of a relatively low to moderate energy environment where clast materials are transported to the shore during significant wave events and are then subject to reworking on the beach face before cementation. The rounding of the pore spaces due to the meniscus fabric of the cement in this lithofacies suggests it was cemented in the phreatic or intertidal zone.

The concentrations of $\mathrm{Na}, \mathrm{K}$, and $\mathrm{Ti}$ within this and all other lithofacies analysed is a result of the presence of seawater during the cementation process. This supports the formation of these cements as being due to cementation from seawater, rather than fresh water.

\subsection{Summary}

The classification of the beachrock at Palmyra Atoll is diagnostic of the environmental conditions during the deposition of each lithofacies. A summary of the lithofacies characteristics are shown in Table 5.2. Overall, the textural characteristics and sedimentary structures identified in each of these lithofacies are diagnostic of deposition in the shallow marine coastal environment. The dominance of large clasts in many lithofacies suggests high energy was required to transport the sediment from their origin on the reef edge to the shore. This is particularly true for the large platy coral morphologies, which typically grow deeper on the reef and have a higher mechanical 
strength than friable branching coral morphologies. Therefore, they are only removed and transported under high wave energy conditions.

Analysis of the petrology of the beachrock lithofacies suggests that most were positioned within the intertidal zone of the beach during deposition. This is largely due to the dominance of cement-forming aragonite, which only precipitates from shallow marine phreatic zones (Desruelles et al., 2009). This is significant as it has implications for the sea level at the time of deposition. Currently the beachrocks that are stratigraphically youngest are all above the high tide mark although within reach of waves during storm events. This suggests that the mean sea level at Palmyra Atoll was higher when these rocks were deposited.

The structure of the rock is also indicative of the depositional environment. For instance, the two clast-supported rudstone lithofacies were either deposited higher on the beachface so that they were not affected by subsequent deposition, or cemented before smaller particles could be incorporated into the rock. The presence of meniscus cements indicative of the intertidal zone suggests the latter is most likely. In contrast, floatstone lithofacies, which are matrix supported, most probably form well within the intertidal zone due to the large amount of smaller, low energy material that may have infiltrated during reworking. 
Table 5.2: Summary of the main characteristics of each lithofacies and inferred energy of depositional environment.

\begin{tabular}{|c|c|c|c|c|}
\hline Lithofacies & Lithofacies name & $\begin{array}{l}\text { Percentage of } \\
\text { total beachrock } \\
\text { at Palmyra } \\
\text { Atoll }\end{array}$ & Brief Description & $\begin{array}{l}\text { Depositional } \\
\text { energy (inferred } \\
\text { from grain size) }\end{array}$ \\
\hline 1.a & Laminated sandstone & $4 \%$ & $\begin{array}{l}\text { Well sorted, sand with fine scale laminations of } \\
\text { pore spaces due to post depositional processes. }\end{array}$ & Low \\
\hline $\mathbf{1 . b}$ & Massive sandstone & $7 \%$ & $\begin{array}{l}\text { Well sorted sand that shows no lamination or } \\
\text { layering and has abundant, randomly distributed } \\
\text { fossil clasts }\end{array}$ & Low \\
\hline 2.a.i & Platy Rudstone & $20 \%$ & $\begin{array}{l}\text { Sandy matrix supported conglomerate consisting } \\
\text { of predominantly platy coral species and } \\
\text { morphologies }\end{array}$ & Very high \\
\hline 2.a.ii & Branching Rudstone & $26 \%$ & $\begin{array}{l}\text { Sandy matrix supported conglomerate consisting } \\
\text { of predominantly branching coral species and } \\
\text { morphologies. Cross bedding present in certain } \\
\text { locations. }\end{array}$ & High \\
\hline 2.b.i & Platy Floatstone & $10 \%$ & $\begin{array}{l}\text { Clast supported conglomerate of platy coral } \\
\text { species and morphologies. Multiple layers of } \\
\text { dense aragonite cement. Very porous and easily } \\
\text { eroded. }\end{array}$ & $\begin{array}{l}\text { High to } \\
\text { moderate }\end{array}$ \\
\hline 2.b.ii & Branching Rudstone & $33 \%$ & $\begin{array}{l}\text { Clast supported conglomerate of platy coral } \\
\text { species and morphologies }\end{array}$ & Moderate \\
\hline
\end{tabular}




\section{Outcrop stratigraphy}

This chapter provides details of the outcrops of beachrock currently exposed on Palmyra Atoll. The following descriptions are important in addition to the lithofacies descriptions because of the high variability of beachrock at each outcrop, which gives each a distinctive stratigraphy and depositional history. To understand the paleoenvironment of Palmyra, each location is examined individually as it is unique to its location on the atoll. Stratigraphic sections were constructed for each outcrop as shown in Figure 5.3., which are representative of the seaward face of the exposed beachrock. Overall, each unit within an outcrop appears to represent a singular depositional event over a relatively short time period and many suggest relatively high depositional energy. Radiocarbon dating of six outcrops is summarised in Table 6.1. 
Table 6.1: Radiocarbon ages of seven samples from six sites at Palmyra Atoll. Barren Island beachrock is too young to be to be converted from ${ }^{14} \mathrm{C}$ yrs $\mathrm{B} . \mathrm{P}$ to calender years.

\begin{tabular}{cccccc}
\hline Outcrop & $\begin{array}{c}\text { UTM coordinates } \\
\text { (zone 3N) }\end{array}$ & Material & 14C years B.P. & $\begin{array}{c}\text { Reservoir } \\
\text { corrected } \\
\text { years B.P. }\end{array}$ & $\begin{array}{c}\text { Calender } \\
\text { years B.P. }\end{array}$ \\
\hline Paradise Island & 822460.56 E 650010.12 N & Tridacna & $1295 \pm 34$ & $945 \pm 55$ & $864 \pm 67$ \\
Cooper Island & 823720.15 E 652171.93 N & Gastropod & $1031 \pm 36$ & $681 \pm 55$ & $645 \pm 40$ \\
East Island & 826258.29 E 650801.09 N & Tridacna & $1279 \pm 33$ & $929 \pm 55$ & $846 \pm 69$ \\
Pelican Island & 825781.42 E 650209.65 N & Tridacna & $1370 \pm 32$ & $1020 \pm 55$ & $797 \pm 68$ \\
Papala Island & 825606.76 E 650593.34 N & Tridacna & $1236 \pm 33$ & $886 \pm 55$ & $934 \pm 47$ \\
Lost Island & 825470.73 E 650788.55 N & Tridacna & $1660 \pm 20$ & $1310 \pm 55$ & $1249 \pm 52$ \\
Lost Island & 825454.89 E 650766.72 N & Cement & $1009 \pm 20$ & $659 \pm 55$ & $631 \pm 44$ \\
Barren Island & 827467.94 E 650801.09 N & Coral & $454 \pm 35$ & $104 \pm 55$ & $\mathrm{n} / \mathrm{a}$ \\
\hline
\end{tabular}




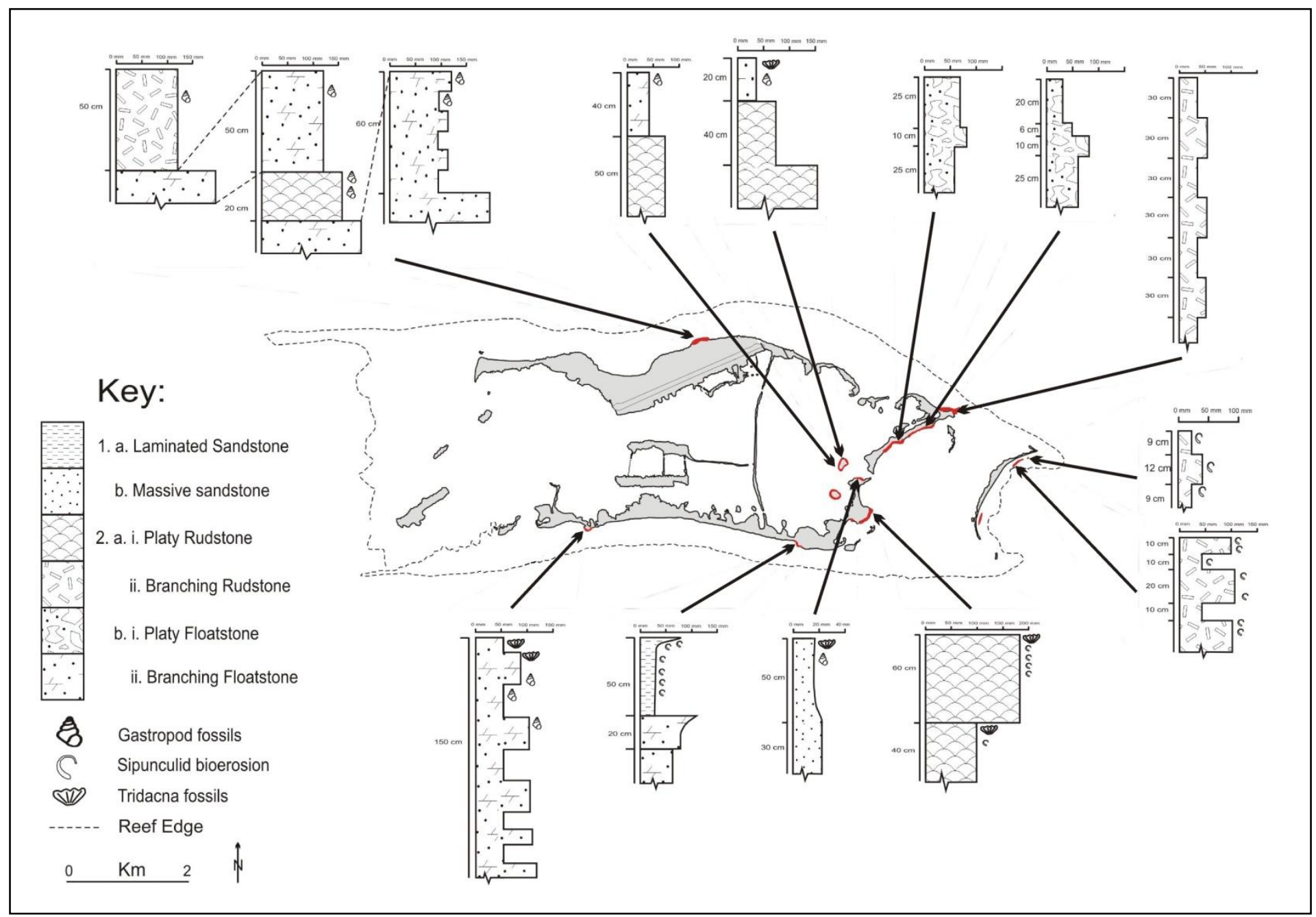

Figure 6.1: Stratigraphic columns for Palmyra Atoll beachrock outcrops. Scale bar at the top of the stratigraphic sections refer to average clast size of the unit. 


\subsection{Outcrop descriptions and stratigraphy}

The beachrock outcrops at Palmyra show characteristics similar to typical beachrock (Vousdoukas et al., 2007). The outcrops generally form ledges on the edge of vegetated islands $0.2 \mathrm{~m}$ to $1.5 \mathrm{~m}$ above low tide level (LTL). They strike parallel to the shoreline and dip seaward at a shallow angle, and most consist of two or three beds. More detailed description of individual outcrops follows.

\subsubsection{Cooper Island}

The main outcrop of beachrock (Figs. 6.2A-F) on Cooper Island ( $5^{\circ} 53^{\prime} 32.17^{\prime} \mathrm{N}$, $162^{\circ} 04^{\prime} 37.03^{\prime \prime}$ W) encompasses a section of coastline along the eastern edge of the north coast of Cooper Island, approximately $50 \mathrm{~m}$ long, near the northern end of the runway. This outcrop is one of the most complex outcrops on Palmyra Atoll as it is highly irregular and variable both vertically throughout the section and laterally both east to west, and north to south. The outcrop is discussed here as eastern and the western sections on either side of a relict gun bunker (Fig. 6.2A). Erosional processes appear to have affected the two sections differently. On the east, the outcrop is highly segmented but not eroded to a flat surface, whereas to the west the continuous outcrop has seen significant vertical erosion. Comparisons between 2006 and 2009 show significant erosion of the unconsolidated sediment from the eastern section of the outcrop, which has led to higher exposure of the outcrop.

In the western section, the segments of beachrock range from boulders as small as $30 \mathrm{~cm}$ in diameter disconnected from the original outcrop to in situ sections up to approximately $15 \mathrm{~m}$ long. Almost all of the units at this outcrop are dipping north at a maximum angle of $5^{\circ}$. The exception is the youngest unit in the western section, where the bottom contact is represented by an angular unconformity and dips north-northwest at $10^{\circ}$.

On the whole, the outcrop is separated into three beds, each representing a different lithofacies with sharp contacts (Fig. 6.2G). The stratigraphically oldest unit consists of lithofacies 2.b.ii (Table 5.2) and dominates the eastern portion of the outcrop as well as the older section on the western side. Layers within this lithofacies are bounded by sharp contacts due to changes in the mean clast size, which vary between approximately 10 and $20 \mathrm{~cm}$. The upper contact is a sharp contact with lithofacies 2.a.i, which is approximately $20 \mathrm{~cm}$ thick and found on the seaward side of the western 
portion. This unit has an average clast size of $15 \mathrm{~cm}$ and is considerably more porous than the rest of the outcrop and as a result has been much more susceptible to erosion. Lithofacies 2.b.ii is again present stratigraphically above this unit and remains relatively uniform over approximately $50 \mathrm{~cm}$. The most landward unit consists of lithofacies 2.a.ii. and is made up entirely of small Acropora clasts, averaging $3 \mathrm{~cm}$ in length. These clasts have a high degree of orientation, trending north-south. 


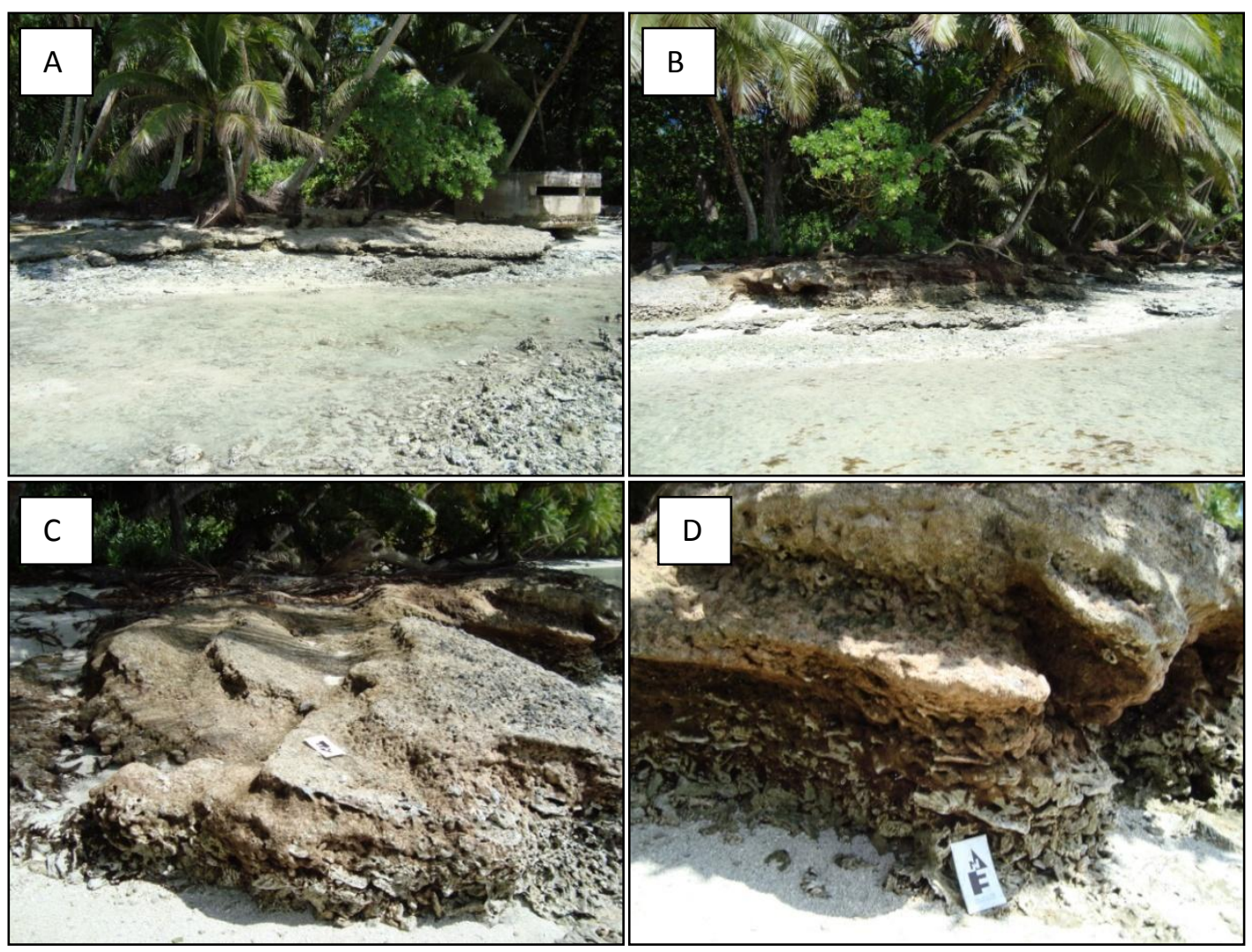

E

Cooper Island
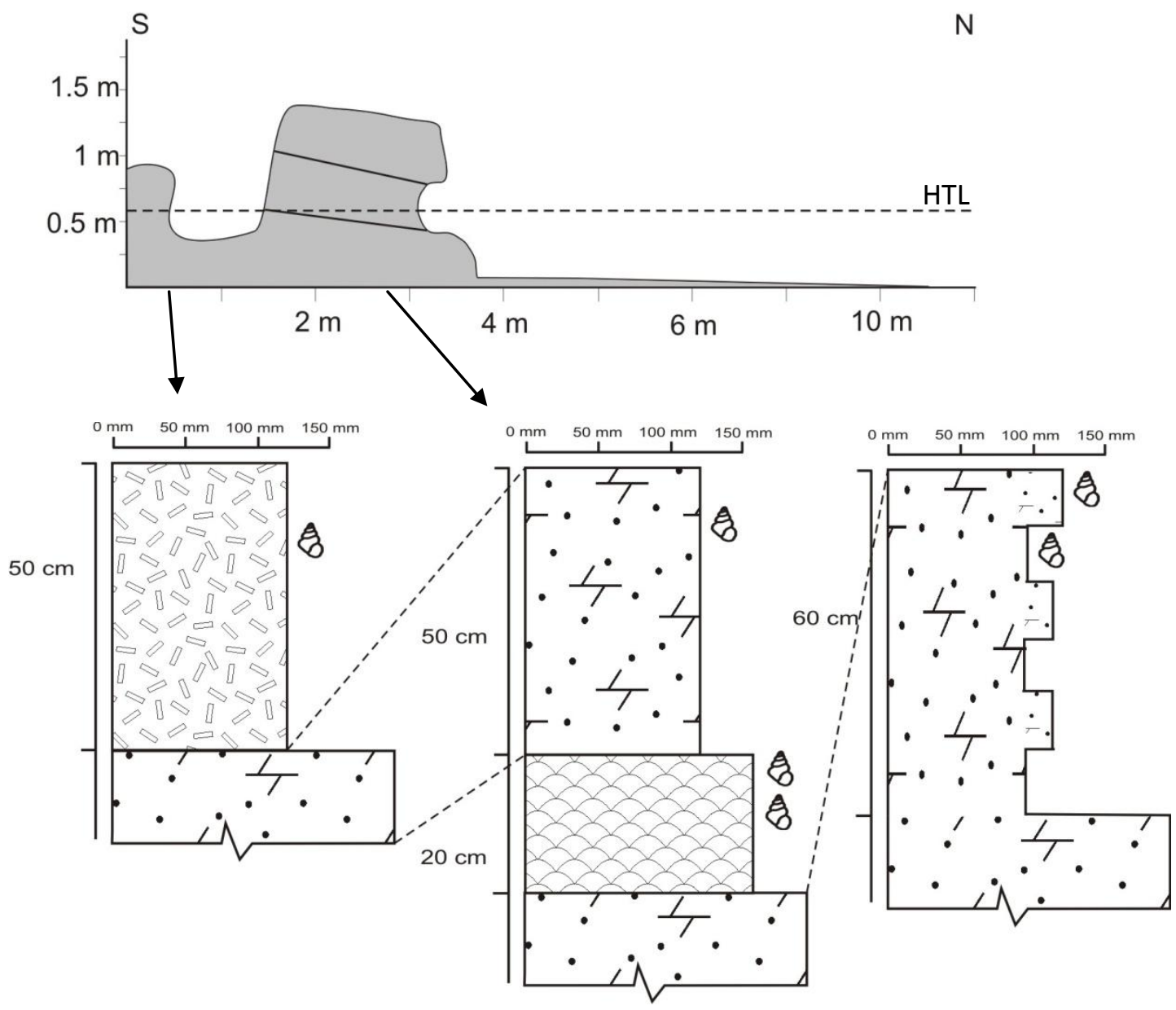
Figure 6.2 (previous page): (A) The eastern portion of beachrock on Cooper Island. (B) The western section of beachrock on Cooper Island. (C) The youngest unit on the western section of beachrock dips eastward. (D) Section of beachrock showing three units, with the bottom unit partially covered by sand. (E) Cross-sectional scetch of the western portion of the outcrop through which two of the stratigraphic sections were taken showing the position of the modern high tide level (HTL; dashed line, as determined through observation during field study). The dark grey represents observed beachrock and the light grey is inferred beachrock. The sloping lines show the contact between beachrock units. This highlights preferential erosion of the porous platy rudstone lithofacies. Stratigraphic sections across the beachrock outcrop section at Cooper Island are shown below. The top axis represents the average clast size of the unit.

Gastropod fossils are common throughout the outcrop (Fig. 6.2F), but no Tridacna fossils were found. Coral forms are variable throughout, although branching Acropora sp. is the most common species. An age of $645 \pm 40$ cal. yrs BP was determined for the beachrock at Cooper Island through radiocarbon dating of a Turbo spp. shell.

\subsubsection{Northern East Island}

Further east, beachrock outcrops on the northern point of East Island as a large, rough platform wrapping the northwest end of the island for approximately $180 \mathrm{~m}$ from east to west (Fig. 6.3A). It extends out from the vegetated part of the island to, at most, $60 \mathrm{~m}$ from the coast, where the majority of the outcrop is covered by water for most of the tide cycle. However, it is distinguished from the fossil reef platform due to its conglomerate nature and dipping bedding, and appears to entirely consist of lithofacies 2.a.ii (Fig. 6.3C). The outcrop has a dark grey colouration. The majority of clasts are well sorted fragments of branching corals with larger clasts apparently randomly distributed. The bedding is largely defined by variations in size of the clasts. It is made up of layers averaging about $30 \mathrm{~cm}$ thick, and although the dip is relatively constant at $5-10^{\circ}$, the dip direction is variable across the entire platform (Fig. 6.3A). On the eastern side, the dip direction is almost perpendicular to the shoreline. On the northern point, however, it appears to curve and extend out towards the reef edge. This may be a result of different events of shoreline propagation, and may record the previous edge of the island. Overall the bedded sequence is approximately $2 \mathrm{~m}$ in stratigraphic thickness. No age for this outcrop was obtained. 

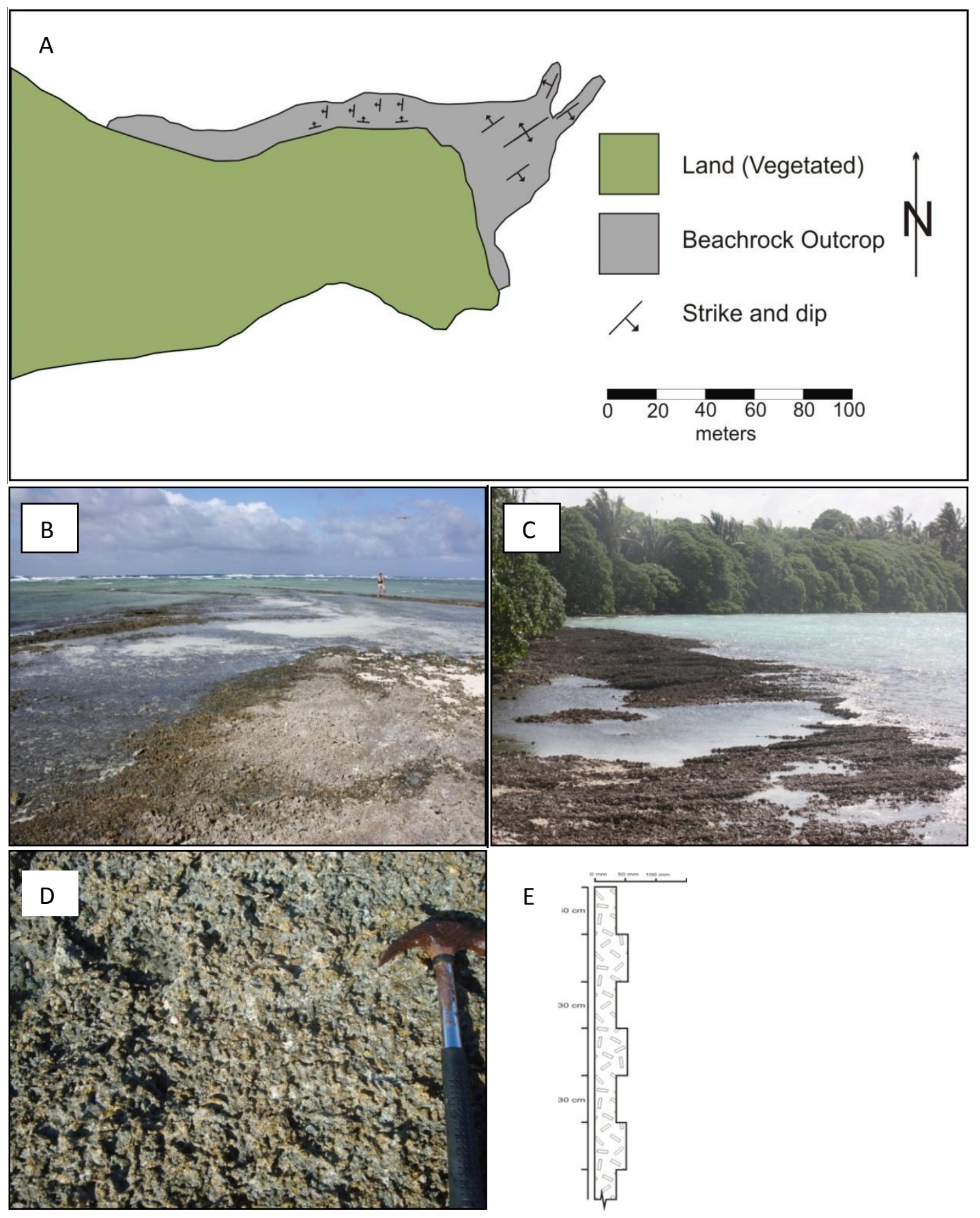

Figure 6.3: (A) Map of the beachrock outcrop on northern East Island indicating the overall strike and dip pattern. (B) View of partially submerged beachrock platform at the northern end of East Island, looking northeast. (C) Continued beachrock platform wrapping the coastline to the west. (D) Close up of the beachrock lithofacies showing coarse grain size but few identifiable features. (E) Stratigraphic column of the original beachrock section at the Northern East Island outcrop. The top axis represents the average clast size of the unit. 


\subsubsection{East Island}

The eastern coast of East Island is almost $1.3 \mathrm{~km}$ long and contains numerous beachrock sections that are here treated as a single exposure. The island itself is $140 \mathrm{~m}$ wide at its widest point but beachrock only occurs on the eastern edge. Each section of beachrock strikes north and is located at the contact between the sandy beach and the land, above the low tide mark. At each location, only about $1 \mathrm{~m}$ of lithographic section is exposed. These dip east at an angle between $11^{\circ}$ and $15^{\circ}$. The beachrock along East Island is highly variable but largely consists of lithofacies 2.b.i (Fig. 6.4A-F), although significant changes in the average grain size are observed. The platy coral clasts that are present range up to $30 \mathrm{~cm}$ in length. The larger clasts of coral, as well as the fossil gastropods and giant clams, in this outcrop are well preserved and imply that these were deposited in an environment with sporadic high energy events and were followed by periods of low energy. The absence of later reworking is highlighted by the presence of fossilised Fungia sp. coral in the outcrop (Fig. 6.4D) with fragile costal spines intact. Species of Fungia occur occasionally on exposed reef fronts but do not relate to any specific environmental conditions.

Further north, the beachrock shows a gradation in sorting. The sorting increases rapidly upwards so there is a bed of well sorted, finer clasts at the top of the stratigraphic column, with a decreasing proportion of matrix material. Mechanical erosion has had a large influence at East Island and many sections of the beachrock show significant undercutting, which has lead to the collapse and subsequent destruction of the youngest unit. This has occurred because the youngest unit is unaffected by wave action due to its supra-tidal position, whereas the older units are subject to mechanical erosion by wave energy throughout the tide cycle. An age of 846 \pm 69 cal. yrs BP was determined for the beachrock at East Island from a large Tridacna shell (Fig. 6.4C). 

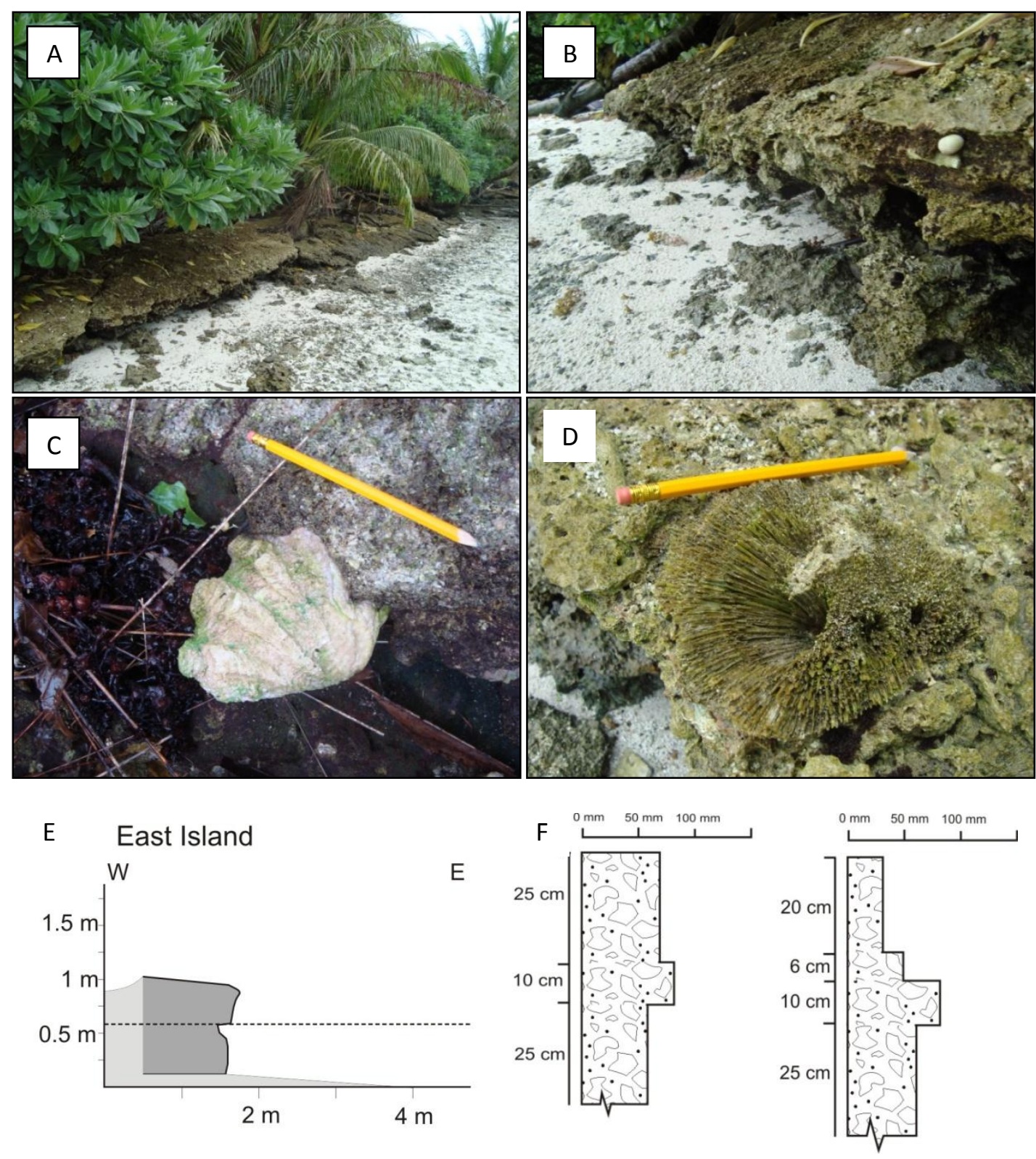

Figure 6.4: (A) View to the northwest of a typical section of beachrock on East Island. (B) Photo of the outcrop at East Island highlighting the undercutting present. (C) In situ Tridacna shell, which was used for radiocarbon dating of this outcrop. (D) Well preserved Fungia sp. indicating low energy during cementation. (E) Cross sectional sketch of a portion of beachrock showing the position of the modern HTL (dashed line, as determined through observation during field study). The dark grey represents observed beachrock and the light grey is inferred beachrock under vegetation or koose sediment. (F) Stratigraphic columns for two section of beachrock on East Island, one on the northern half and one on the southern half. The top axis represents the average clast size of the unit. 


\subsubsection{Papala Island}

Prior to human intervention, Papala Island was disconnected from the surrounding islands in the gentle arc of the eastern islands. Today this stretch of islands separates East Lagoon from the eastern shallows. The outcrop on the modern Papala Island (Fig. 6.5A-E) is located along the north to northeast coast (Fig. 6.1), which is located within the channel between East Lagoon and the Eastern Flats.

Lithofacies 1.b, fossiliferous sandstone, is unique to the outcrop. The beachrock has a reddish tan colour throughout that appears not be the result of a modern algal coating, but instead may have formed prior to cementation and then been incorporated into the cement. The upper unit is approximately $50 \mathrm{~cm}$ thick and is continuous along the northern coast of Papala Island. The lower unit was beneath the high tide mark and appeared to be about $30 \mathrm{~cm}$ thick and defined by coarser sand with fewer coarse clasts. Both units are comprised of poorly sorted sandstone with sparse coral, gastropod and small Tridacna clasts up to $15 \mathrm{~cm}$ across. The maximum age of deposition of the beachrock at Papala Island is $797 \pm 75$ cal. yrs BP. 

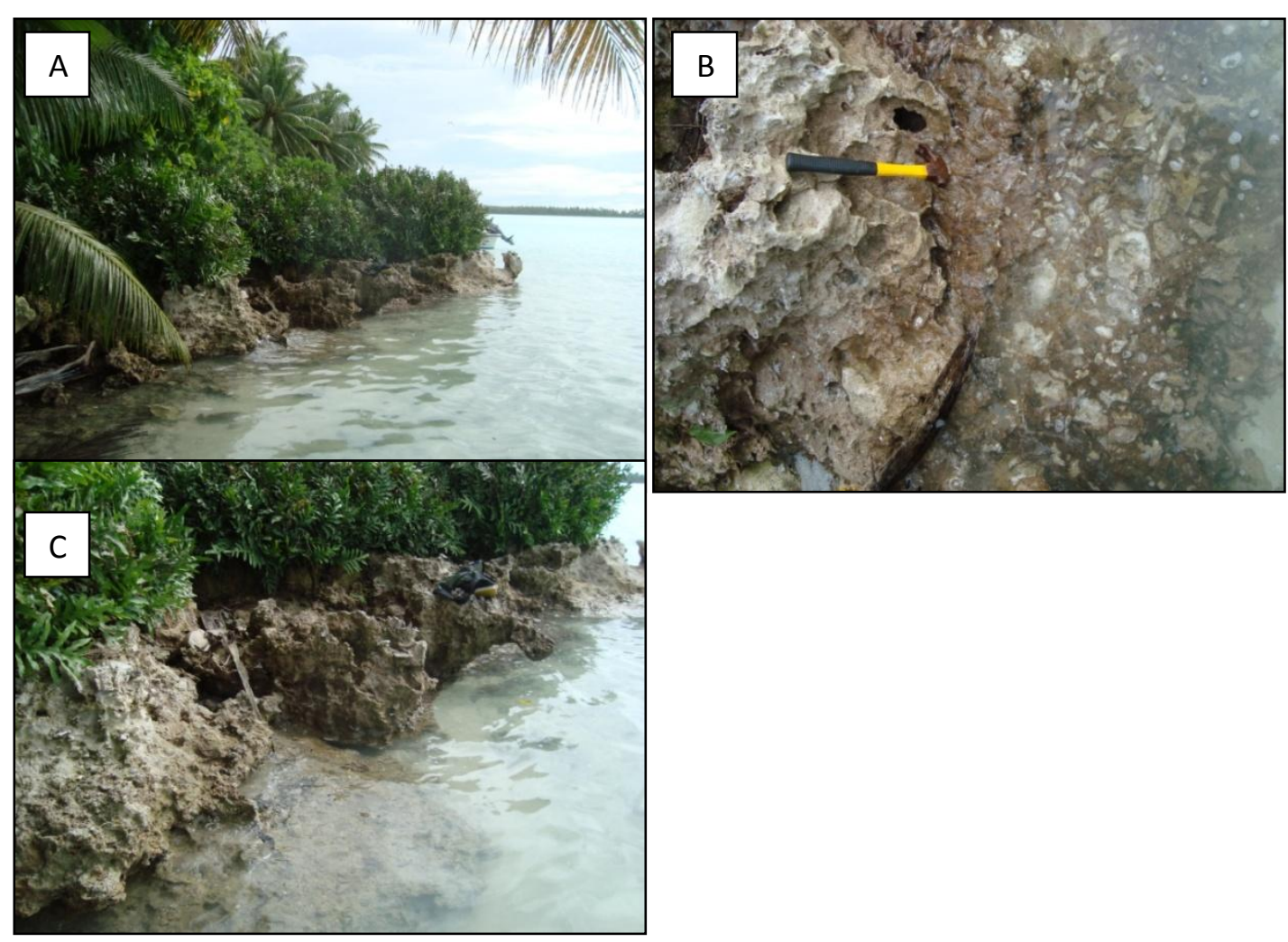

D

\section{Papala Island}
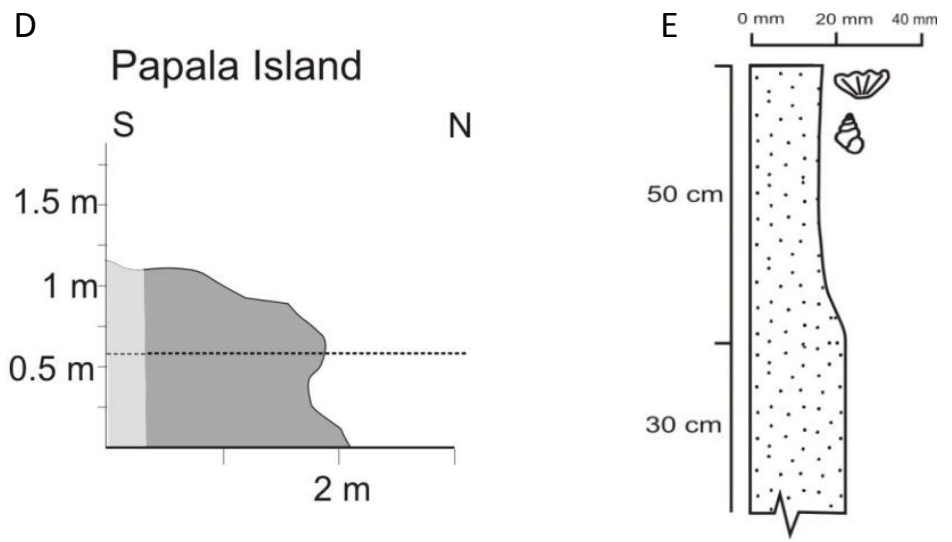

Figure 6.5: (A) View of the beachrock outcrop at Papala Island looking west. (B) Beachrock just above the high tide mark at Papala Island. (C) A section of beachrock at Papala Island looking west. (D) Cross sectional sketch of a portion of beachrock showing the position of the modern HTL (dashed line, as determined through observation during field study). The dark grey represents observed beachrock. (E) Stratigraphic column for the Papala Island beachrock. The top axis represents the average clast size of the unit. 


\subsubsection{Lost Island and Fern Island}

Lost Island, located on the inner edge of the sand flats within East Lagoon, has an elongated elliptical shape stretching for $140 \mathrm{~m}$ north northeast and is approximately $30 \mathrm{~m}$ across (Fig. 6.1). The occurrence of beachrock here and at Fern Island is atypical because they are entirely enclosed within a lagoon. The beachrock is also significant because it contains some of the coarsest sediments found on Palmyra (Fig. 6.6B), but is surrounded by an extremely low energy modern day environment. This suggests significant changes to both the terrestrial environment and the sediment flux have occurred to Palmyra since the beachrock deposition. Radiocarbon dating of both fossilised Tridacna and the cement show that the oldest age of deposition is $1249 \pm 52$ cal. yrs BP and that one of the last episodes of cementation occurred $631 \pm 44$ cal. yrs BP. This shows that there was approximately 600 years between the formation of sediment (through death, transport and deposition of the organism) and cementation of the outcrop.

The entire outcrop at Lost Island is dipping east at an angle between $5^{\circ}$ and $10^{\circ}$, exposing a large portion of the stratigraphic section on the western side, which is composed of three units, which represent two lithofacies (Fig. 6.6D). The oldest portion of beachrock is composed of lithofacies 2.a.i, which has an average thickness of approximately $60 \mathrm{~cm}$. The stratigraphically oldest section is only around $20 \mathrm{~cm}$ thick but consists of platy clasts averaging $20-25 \mathrm{~cm}$ in length. Above this the clast size decreases to approximately $10 \mathrm{~cm}$, but the clasts are equally poorly sorted, and extremely coarse. In these units, there is a significant amount of mechanically strong cement. This contributes to the rough appearance of the outcrop as a result of erosion in places removing clast material but leaving the encasing cement. The youngest unit is slightly less coarse, and consists of lithofacies 2.b.ii. with an average clast size of $5 \mathrm{~cm}$. Considerable undercutting of this unit has occurred by the erosion of the more porous, older layers, leading to collapse of the outcrop on the eastern side of the island. 

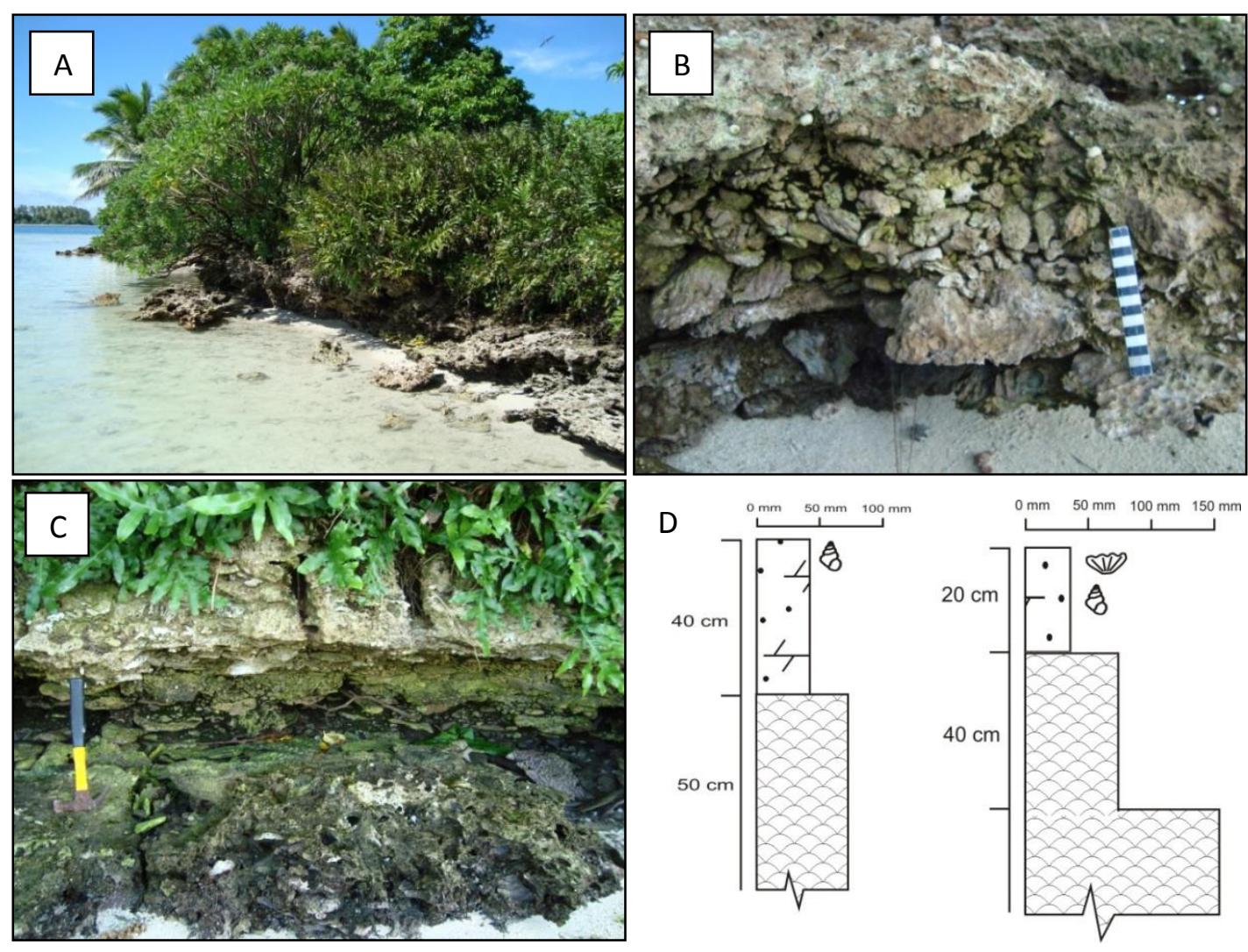

E Lost Island

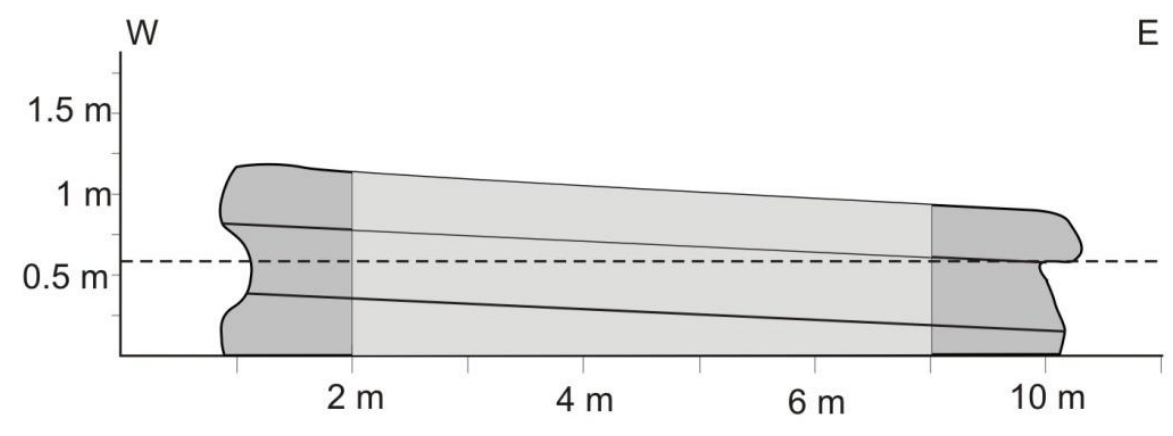

E
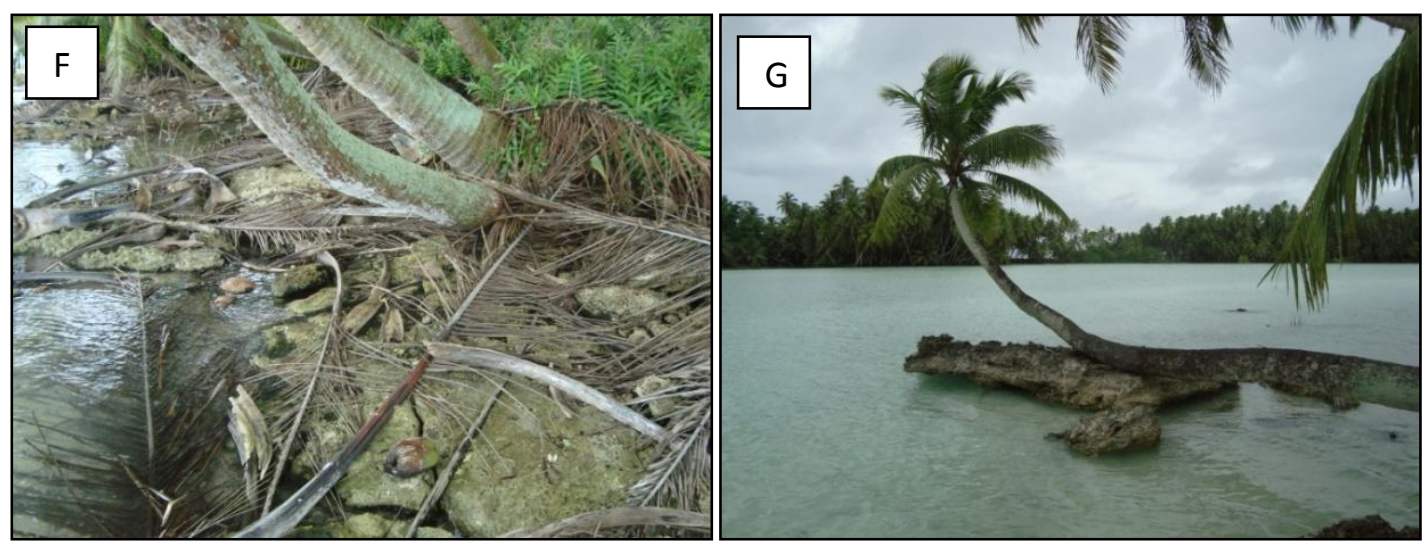
Figure 6.6 (previous page): (A) View, looking north, of the western coast of Lost Island. (B) Beachrock section showing 3 units on the eastern coast of the island. (C) Similar to $B$, but further to the north of the island. (D) Stratigraphic columns for the northern and southern ends of Lost Island. The top axis represents the average clast size of the unit. (E) Cross sectional sketch of Lost Island beachrock from west to east showing the position of the modern HTL (dashed line, as determined through observation during field study). The dark grey represents observed beachrock and the light grey is inferred beachrock under the vegetation of the island. The sloping lines show the contact between beachrock units. (F) Debris and vegetation cover beachrock outcropping at Fern Island. (G) Beachrock segment disconnected from Fern Island on the northern shore now supporting a coconut palm that is growing on the eroding edge of the island.

Fern Island is located approximately $300 \mathrm{~m}$ south of Lost Island and shows similar features (Fig. 6.6F and G). This island is kidney shaped and $90 \mathrm{~m}$ long by $50 \mathrm{~m}$ wide. The position of the island adjacent to Lost Island suggests that both formed as part of a chain similar to the modern eastern islands chain. The beachrock present at Fern Island is very similar to that of Lost Island but exists in low-lying slabs along the coast that have undergone significant amounts of erosion.

\subsubsection{Pelican Island}

Beachrock on Pelican Island extends from the north-eastern corner and follows the coast round to the south-western coast of the island for approximately $200 \mathrm{~m}$ (Fig. 6.1). This outcrop can be divided stratigraphically into two units, both of which are lithofacies 2.b.i. and distinguished by clast size. The youngest unit is approximately $60 \mathrm{~cm}$ thick and lenses out to the south. It consists of poorly sorted brittle and very angular clasts of platy coral with random orientation. The older unit is defined by a clast size of less than $10 \mathrm{~cm}$, as well as an increase in sorting in both clasts and matrix material. To the south, the clasts become considerably larger and more rounded. The rounding may be either a result of more reworking on the beach before incorporation into the beachrock or more exposure of that section of the outcrop to erosion over time. In this southern section, micro-phytokarst features (see Chapter Nine) are present as a surface phenomenon which also suggests increased exposure of the section due to a decrease in vegetation cover. Sipunculids are also actively bioeroding this material. Pelican Island had numerous samples of well preserved, fossilised Tridacna, one of which was dated at $796 \pm 68$ cal. yrs BP. 

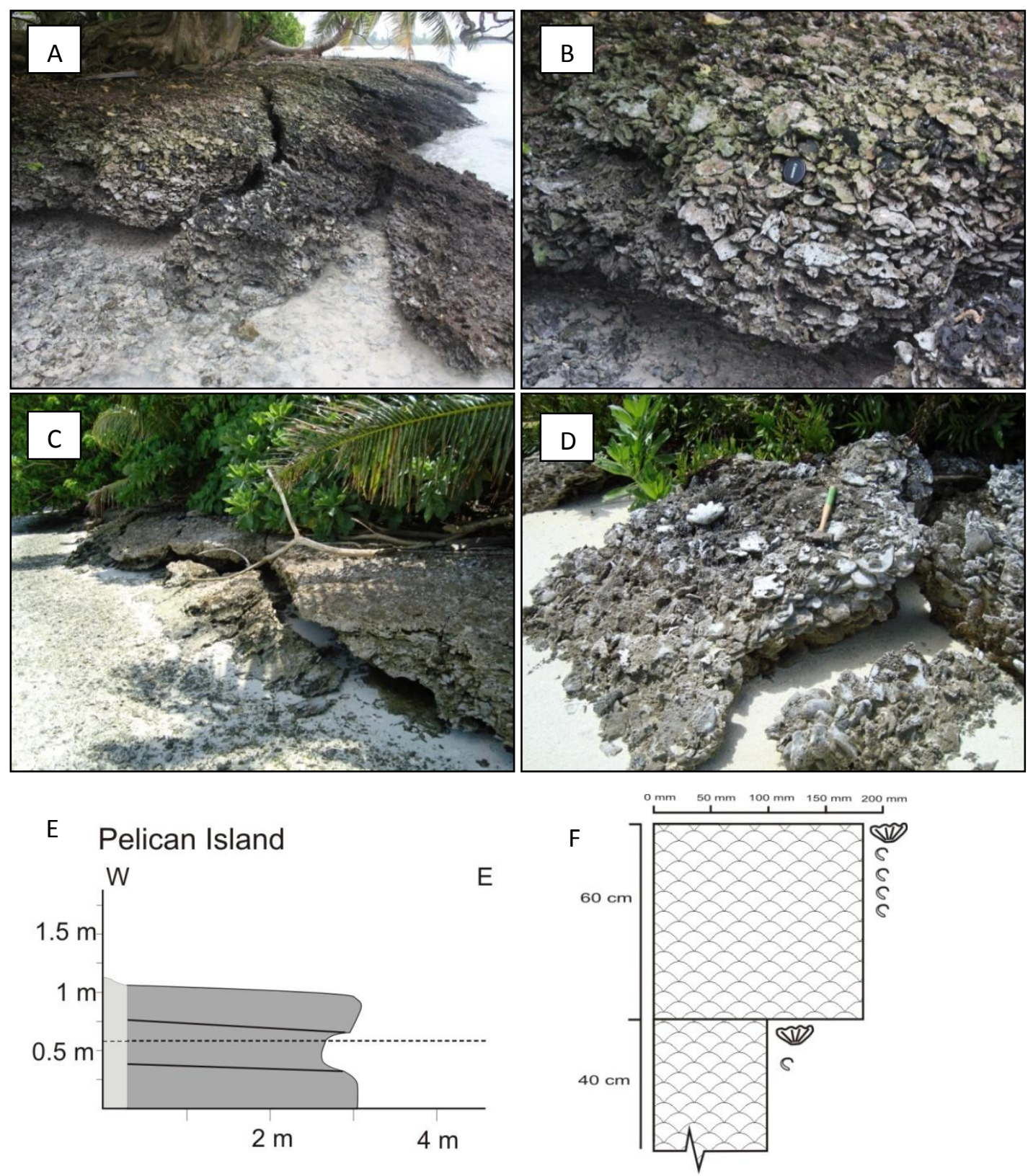

Figure 6.7 (A) Beachrock outcrop at Pelican Island looking north. (B) Close up photograph showing the coarse, poorly sorted nature of the beachrock lithofacies. (C) View of southern section of beachrock at Pelican Island. (D) Eroded section of beachrock on the southern end of the island, which is subject to micro-phytokarst erosion. Fossilised Tridacna are also present. (E) Cross sectional sketch from west to east at Pelican Island showing the position of the modern HTL (dashed line, as determined through observation during field study). The dark grey represents observed beachrock. (F) Stratigraphic column for the beachrock at Pelican Island. 


\subsubsection{Holei Island}

This outcrop is laterally uniform and dips south at a low angle $\left(<5^{\circ}\right)$. The upper surface has hollows and irregularities (Fig. 6.7A-B) and is covered to varying degrees with algae, cynobacteria and fungi that weather the outcrop orange-brown. Lithofacies 1.a (Fig. 5.6) is unique to this location and consists of a fine, well sorted sandstone with noticeable but poorly defined laminations. In hand samples, these laminations appear to be defined by layering of the large pore spaces within the rock. The unit is very pale cream in colour where not externally altered. There are occasional clasts of platy corals $(\sim 5-6 \mathrm{~cm})$ confined to the upper $10 \mathrm{~cm}$ of the unit. These coral clasts are well rounded and, along with the sandstone, appear to be similar to modern day beach deposits of fine sand with scattered pebbles of broken and rounded coral. This bed is host to large numbers of sipunculid worms (see Chapter Nine), which may contribute to the formation of the laminations.

The middle unit consists of lithofacies 2.b.ii, a matrix supported, branching conglomerate, which has a gradational contact with lithofacies 1.a. This porous, clastrich layer is being preferentially eroded and as a result is undercutting the bed above. The vertical variations within the bed show clast size increasing towards the top, leaving a layer of pebbles near the contact with the younger unit.

The lowest bed is also lithofacies $2 \mathrm{~b} . \mathrm{ii}$, but distinguished from the unit above by a sharp contact, change in grain size and a large degree of cementation, all of which suggest a separate depositional event. This bed is extremely hard and well cemented, and extends out from the bottom of the outcrop to the south for up to $20 \mathrm{~m}$. It is distinguished from the fossilised reef platform by its conglomeratic nature. It is mostly fine grained with lenses of coral pebbles on its upper surface. However, it is difficult to analyse thoroughly as the unit is low-lying and thin. 

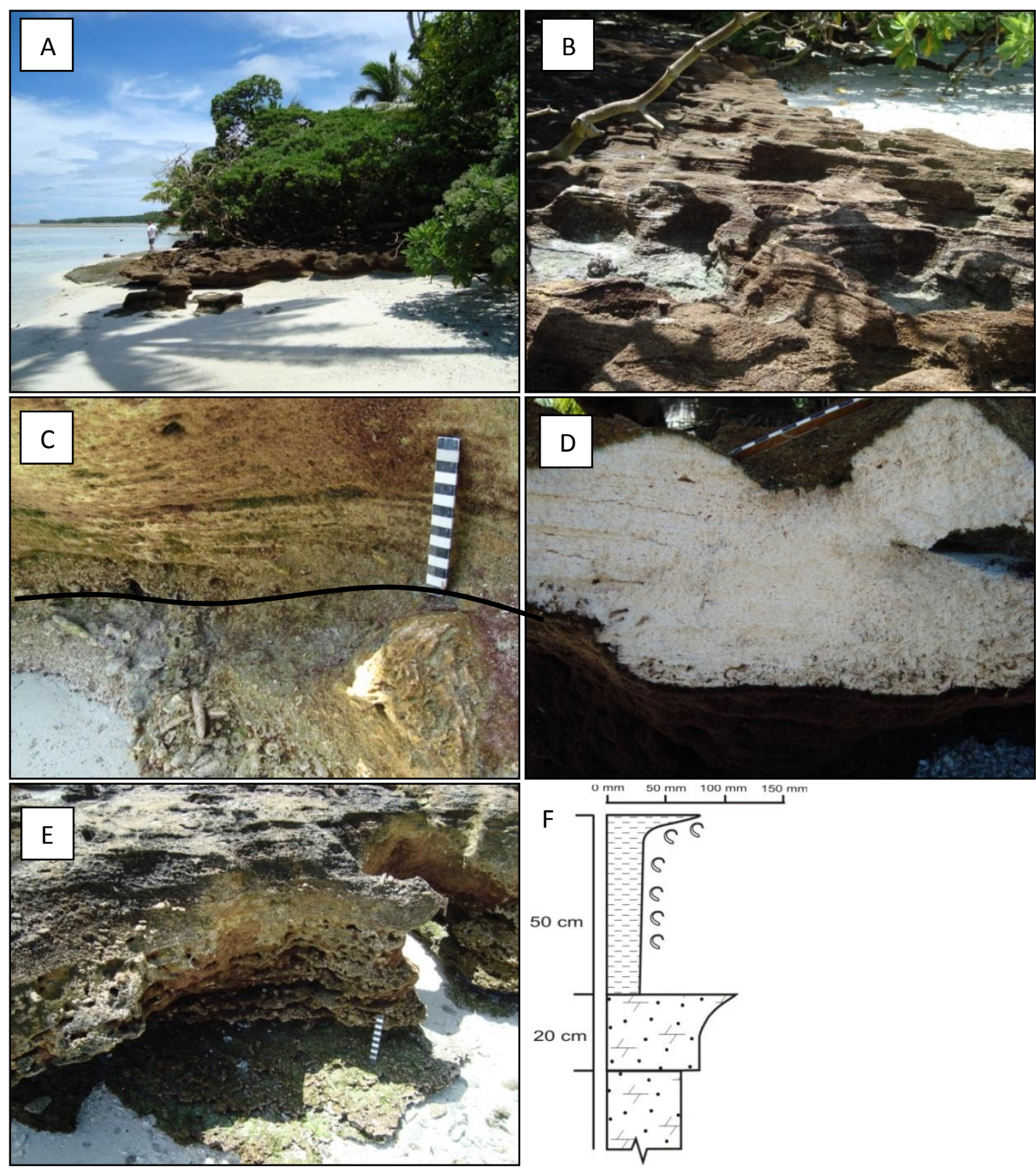

Figure 6.7: (A) View of the outcrop at Holei Island, looking west. (B) Closer view of the top surface of the outcrop, looking northeast. (C) View of the contact between the middle and top units, indicated by the black line. (D) A fresh vertical surface of the upper 1a lithofacies unit showing laminations. (E) Seaward edge of the outcrop showing the stratigraphy. (F) Stratigraphic column for the Holei Island beachrock. 


\subsubsection{Paradise Island}

The beachrock on the south coast of Paradise Island stretches around the coast for a distance of approximately $120 \mathrm{~m}$. The entire outcrop consists of similar material representing lithofacies 2.b.ii (Fig. 6.8F). However, layers are defined by differences in clast sizes and proportion of matrix, and are on average approximately $30 \mathrm{~cm}$ thick. These layers are all dipping approximately $10^{\circ}$ to the east and striking approximately at $320^{\circ}$. Several layers within the lower section of the outcrop show indistinct cross bedding. Additionally, most layers appear to show a decrease in clast size upwards, as well as developing increased sorting (Fig. 6.8A-E).

At the highest point, the beachrock on Paradise Island reaches $1.5 \mathrm{~m}$ above the reef platform and thus is well beyond the tidal range. The eastern section of this outcrop is significantly more eroded than the section to the west. Similarly to Cooper Island, these sections of outcrop are separated by a relict concrete bunker built in the 1940's. In both circumstances, it is the eastern section that is eroded more, which may be due to protection of the western side from the alongshore currents by the gun bunkers.

Tridacna and gastropods are present throughout the entire outcrop (Fig. 6.8D). A Tridacna shell used for dating the beachrock here gave an age of $864 \pm 67$ cal. yrs BP. 

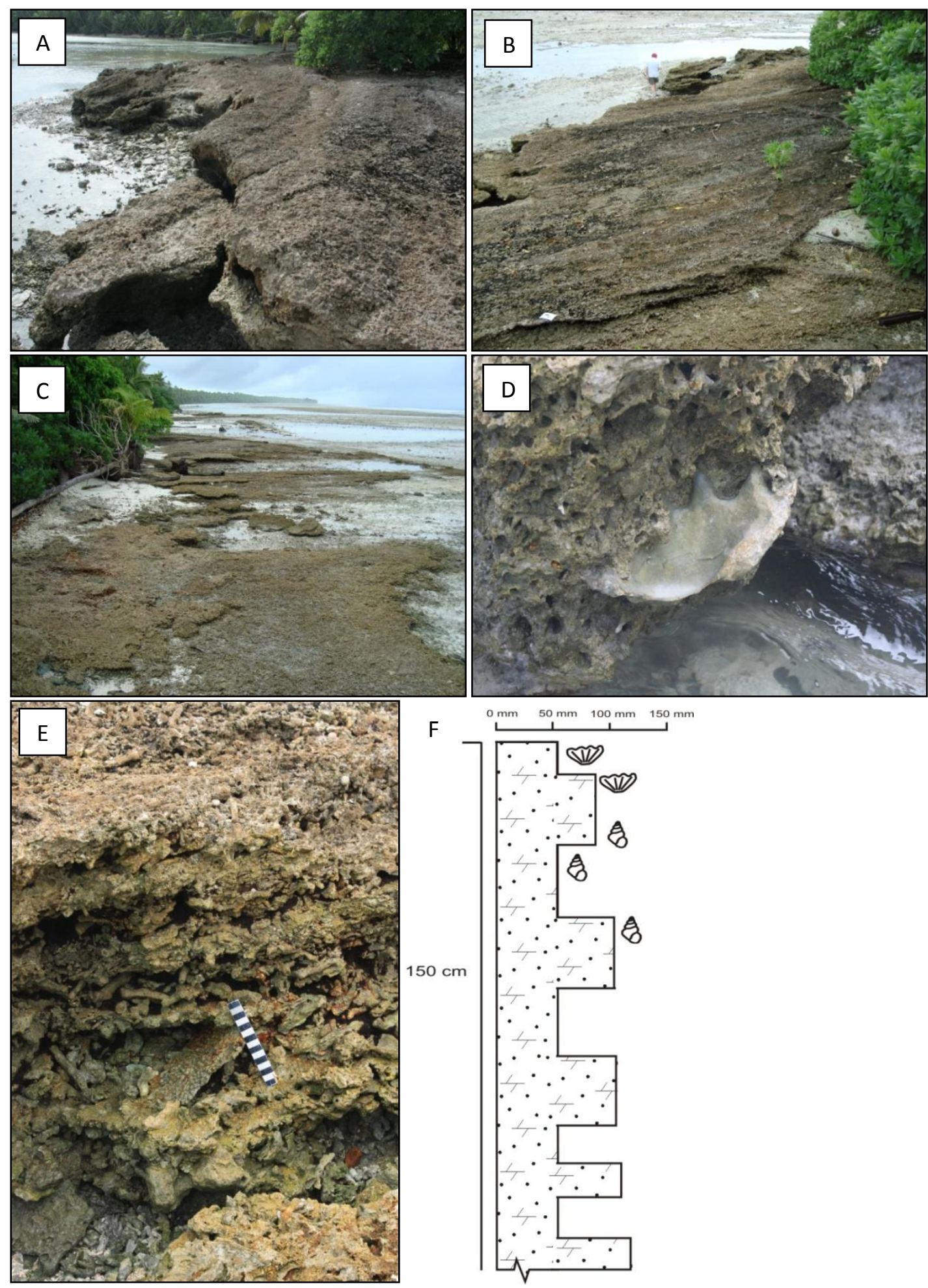

Figure 6.8 (A) Beachrock outcrop at Paradise Island showing angle and direction of dip, photo is looking northwest. (B) Oblique aerial view of the western section of beachrock at Paradise Island, looking west. (C) Oblique aerial view of the eastern section of the Paradise Island beachrock, which is considerably more eroded than the western section. (D) Example of a well preserved, fossilised Tridacna cemented into the beachrock. (E) View of the layers within the western section of beachrock. (F) Stratigraphic section of beachrock at Paradise Island. 


\subsubsection{Barren Island}

There are three outcrops of beachrock present on the eastern coast of Barren Island, each a few metres offshore on the eastern coast where they are located in intertidal positions. Two of these outcrops are found at the northern end of the island and the third is located at the southern end. This southern outcrop appeared to be more extensive than those found in the north. However, it was also located well below the water level at the time of the survey and thus was inaccessible; therefore only its existence is noted here. Observations here at low tide were not possible because access for lagoon boats to the eastern end of the atoll limits visits to periods immediately adjacent to high tide only.

The two northern outcrops were found in shallower water close to the shore and were therefore somewhat more accessible for observation (Fig. 6.9A-F). Both of these are represented by lithofacies 2.a.i. The northern-most outcrop is small, consisting of three sections ranging from 0.5 to $1.5 \mathrm{~m}$ across. The second outcrop, $\sim 150 \mathrm{~m}$ to the south, is approximately $50 \mathrm{~m}$ long, stretching north-south parallel to Barren Island. The entire outcrop is dipping east at an average angle of $5^{\circ}$ and has a red-brown colouring. Approximately $0.8 \mathrm{~m}$ of beachrock is exposed stratigraphically divided into beds averaging $0.2 \mathrm{~m}$ thick (Fig. 6.9F). The beachrock consists of coarse, well sorted sand and broken (Acropora sp.) coral fragments up to $0.3 \mathrm{~m}$ in length. However, rounding, size and sorting are highly variable throughout the outcrop. Generally, it appears size decreases and sorting and rounding increase vertically within the section. The unaltered interior of the beachrock is pale pink/white in colour, similar to the modern day beach sands on Barren Island (Fig 6.9D and 6.9E). The pink colouration is due to the presence of red algal fragments in the rock. However, red algae lose their colour over long periods of time (hundreds of years), which suggests that the beachrock of Barren Island is relatively young.

This outcrop is estimated at being the youngest beachrock on Palmyra because of the age of the island at which it is situated. Unfortunately, there were no Tridacna or gastropod shells available from this location and, in their absence, a sample of coral was used for radiocarbon dating. The age for the coral was $104 \pm 65$ calibrated years BP, which is outside of the calibration range into calendar years (Fairbanks et al., 2005). 

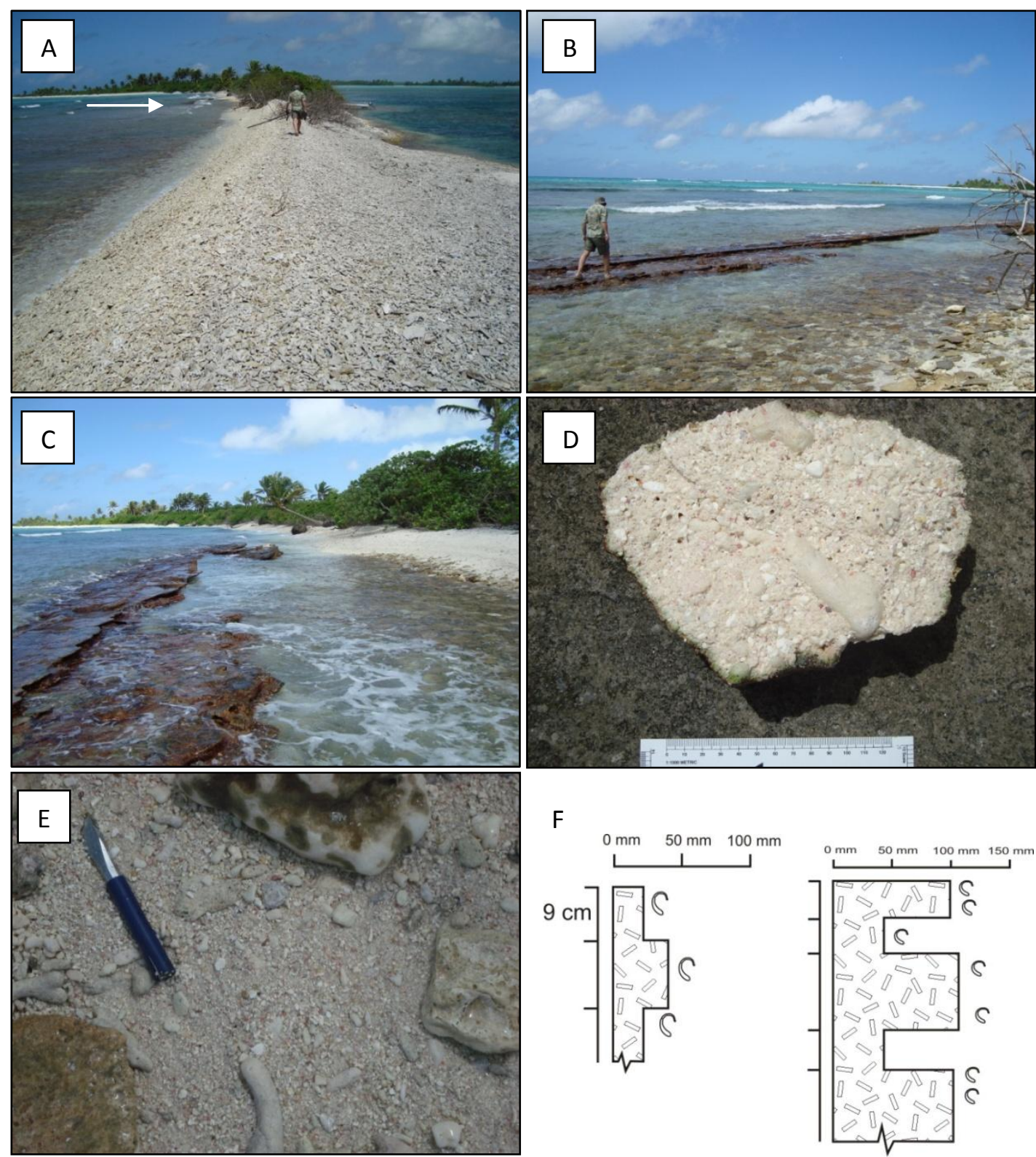

F

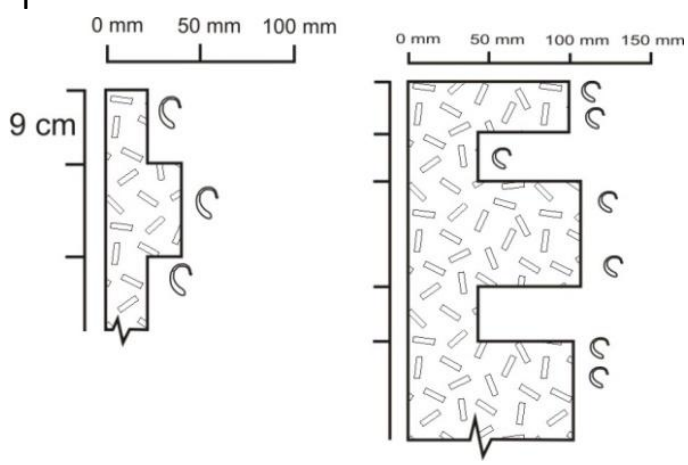

G Barren Island

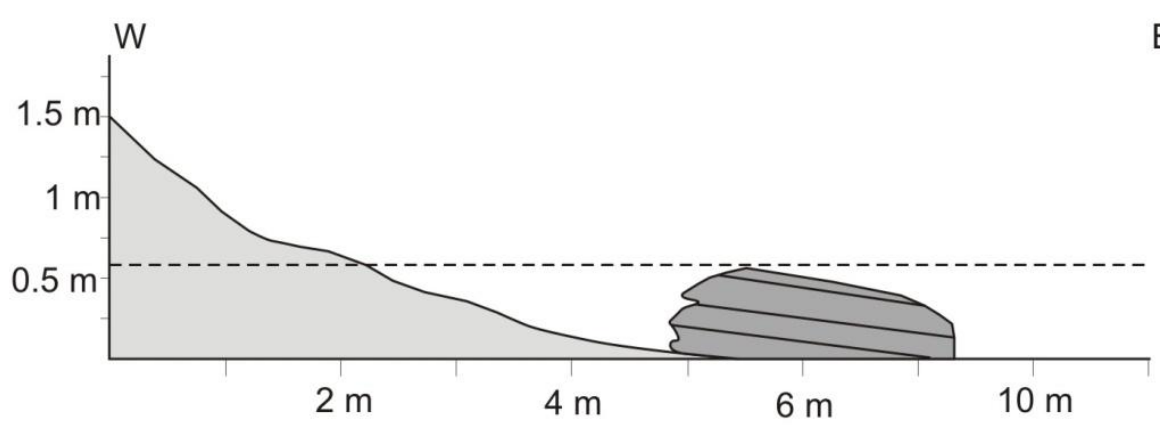

E 
Figure 6.9 (previous page); (A) Photograph taken looking south down the centre of Barren Island, the northern beachrock outcrop can be seen offshore to the left (indicated by the white arrow). (B) Main beachrock outcrop at Barren Island (looking east) extending parallel to the coastline. (C) View south from the beachrock outcrop at the north of Barren Island (D) Fresh surface of beachrock broken off the Barren Island outcrop. (E) Material typical of the modern beach sediments at Barren Island. (F) Stratigraphic columns of an example of the two portions of beachrock at the northern end of Barren Island. (G) Cross sectional sketch from west to east of the beachrock outcrop at Barren Island showing the position of the modern HTL (dashed line, as determined through observation during field study), the dark grey represents the beachrock outcrop and the light grey represents the island.

This is therefore assumed to be modern and to have formed in the past 80 years during which Barren Island has grown. During this time, Barren Island has migrated westward leading to the exposure of the beachrock outcrop a few meters offshore today. There have been no significant sea level changes in this region since the outcrops formation and therefore this is evidence that tropical beachrock, such as that at Palmyra, forms within the intertidal zone. This is in agreement with the majority of the literature on the topic (Chapter Two).

\subsection{Summary}

There is a concentration of beachrock outcrops on the eastern portion of Palmyra Atoll. Although each outcrop is distinctive, they also show similarities between one another. Almost all outcrops form small cliff or benches between the sea and the islands they are found on. Radiocarbon ages date the upper surface of six beachrock outcrops, and are considerably young and range from 1249 yrs B.P., at Lost Island, to present day, at Barren Island. Beachrock forms in an intertidal position, which is suggested by the Barren Island outcrops, thus the other outcrops at Palmyra suggest formation during an elevated sea level.

It is important to note that many of the outcrops show depositional environments that are out of equilibrium with the present conditions. In particular, Lost Island sediments suggest that the island was once exposed to high energy conditions, such as are generally found on the reef edge. This suggests that Lost Island was originally located on the exposed edge of the atoll, and therefore should be older than beachrock to the east, which is confirmed through radiocarbon dating. It is also important to note how variable lithofacies are between and within individual outcrops. This implies that unique conditions govern the deposition of each outcrop. The ability to model deposition of the units of beachrock given their location on the atoll and the 
average clast size allows a more in-depth and detailed understanding of their depositional environments, as well as furthering the understanding of the hydrodynamics. This is achieved in the following chapters through the use of a numerical wave model. 


\section{Numerical wave modelling}

Understanding the wave climate at Palmyra, both across the outer reef and within the lagoon, is an important contribution to the overall understanding of this complex atoll system, and has implications for management of the overall environment. Currently, there is no readily available model of the effect of waves or sediment transport across coral reefs on oceanic atolls. However, sediment transport is important to understanding reef history and to projecting future changes in reef geomorphology. Therefore, the SWAN (Simulating Waves Nearshore; www.swan.tudelft.nl) wave model is used here as a tool for an intermediate step towards the understanding of atoll processes with associated implications for sediment transport across the reef. A key determinant of transport of sediment is bed shear stress, which can be calculated from oceanic- and local-wave conditions by the SWAN wave model, provided valid assumptions can be made regarding bed roughness. Using SWAN, it is possible to understand the effect of breaking waves at the reef edge and the effect of wave propagation across the submerged reef, especially on the Eastern and Western terraces. This is important in order to understand the contribution of these reefs as sediment sources for Palmyra Atoll, and in turn can aid understanding of the past depositional environment through modelling the energy required to form the beachrock deposits of the atoll.

Surface waves across coral reefs are important because as waves break on the reef, the resulting increase of mean water surface elevation creates a pressure gradient that drives reef circulation. The currents formed by this process can transport nutrients, sediment, plankton, and larvae across the reef flat. Secondly, as sediment supply on coral reefs is entirely derived from organic activity, understanding the transport and other processes involved from growth on the reef to the site of deposition is extremely important to understanding the atoll system. However, wave environments on oceanic atolls are hydrodynamically complex (Karambas, 2003). Not only is the modelling of breaking waves physically complex compared to understanding non-breaking waves, but the former also create two directions of possible sediment movement due to their oscillatory flow under non-breaking waves. The asymmetric shape of wave form results in faster flow for a shorter duration in the direction of wave propagation, whereas by contrast flow is slower but for a longer period in the opposite direction. As a result, 
coarse material is often moved in the forward direction due to the higher energy requirements, and finer material is moved in the opposite direction to wave propagation.

Wave energy is progressively dissipated across the reef and thus sediment transport at the landward margin is limited to spring high tide conditions, as water level is a major control of energy across the reef (Brander et al., 2004). Therefore, for most of the time, the reef platform is relatively inert in terms of sediment movement, and any significant changes in sediment production from wave abrasion, transport rates and reef island sediment budgets are dependent on extreme waves or storm conditions (Brander et al., 2004).

This study presents results from a detailed investigation of wave processes, through the use of numerical modelling, across the reef surrounding Palmyra Atoll in an attempt to define the relationship between wave environments and the sediment texture of the beachrock outcrops at Palmyra. The results have implications not only for understanding paleo-environments and beachrock formation, but also for helping to understand marine benthic communities and modern movement of sediment on the atoll. Wave-induced bottom shear stress, calculated by SWAN, is not only fundamental for sediment movement but has also been identified as a major factor in determining benthic community composition, especially in wave-dominated areas (Dollar, 1982; Storlazzi et al., 2005; Peterson et al., 2006).

The application of three-dimensional hydrodynamic models to oceanic atolls has been limited (Andrefouet et al., 2006), and only three atolls have had any type of 3D modelling published. For example, finite-difference models have been used to study water movement at Mururoa and Majuro atolls (Tartinville et al., 1997; Kraines et al., 1999) and a finite-element model has been applied to Rongelap Atoll in the Marshall Islands (Peterson et al., 2006). The latter study is important with respect to this work as it attempts to relate bottom shear stress and hydrodynamic conditions to ecosystem function and resource management. However, these studies all focus on circulation within partially closed lagoons rather than across the outer reef, which is the focus of this study. The review of models applied to $\mathrm{CaCO}_{3}$ platforms, reefs, and continental lagoons bounded by barrier reefs is slightly more extensive but excludes true atoll settings (Fernandez et al., 2006; Jouon et al., 2006; Andrefouet et al., 2006). Therefore, the present study is the first of its kind and is applied in an area where there are few long term climate and environmental records available. 
A sediment transport model for Palmyra Atoll is based on the SWAN hydrodynamical model, which is a numerical wave model primarily used to model the effects of winds and waves on continental shelves and in embayments. The overall aim of using the SWAN programme in this study to model the wave environment at Palmyra Atoll is to determine the bottom conditions, primarily shear stress, across the reef and use these to understand the past and present distribution of sediment at Palmyra, including the determination of conditions under which the beachrock clasts were deposited. Rather than predicting waves through the use of wind and climate data, the wave conditions for the model are obtained through hindcast data. The resulting effect on the sea floor is examined and depositional conditions are defined by the wave conditions necessary for sediment movement. Sediment movement is inferred from well established relationships between bed shear stress, which is calculated in SWAN, and particle size. No attempt is made, though, to produce a sediment dynamics model as it is beyond the scope of this study.

A major impediment to hydrodynamical studies on Palmyra Atoll is the lack of wave data. This deficiency has been addressed in the SWAN wave model by the application of modelled hindcast data for conditions at Palmyra. These were defined using the WAVEWATCH III (WWIII) model (Tolmann, 2002) together with information collected from Triton buoys located closest to Palmyra (Fig. 7.1). The result of this gives 3 hourly reconstructions interpolated from the WWIII model for the period 1996 to 2009, and used as the basis for modelling the wave energy conditions.

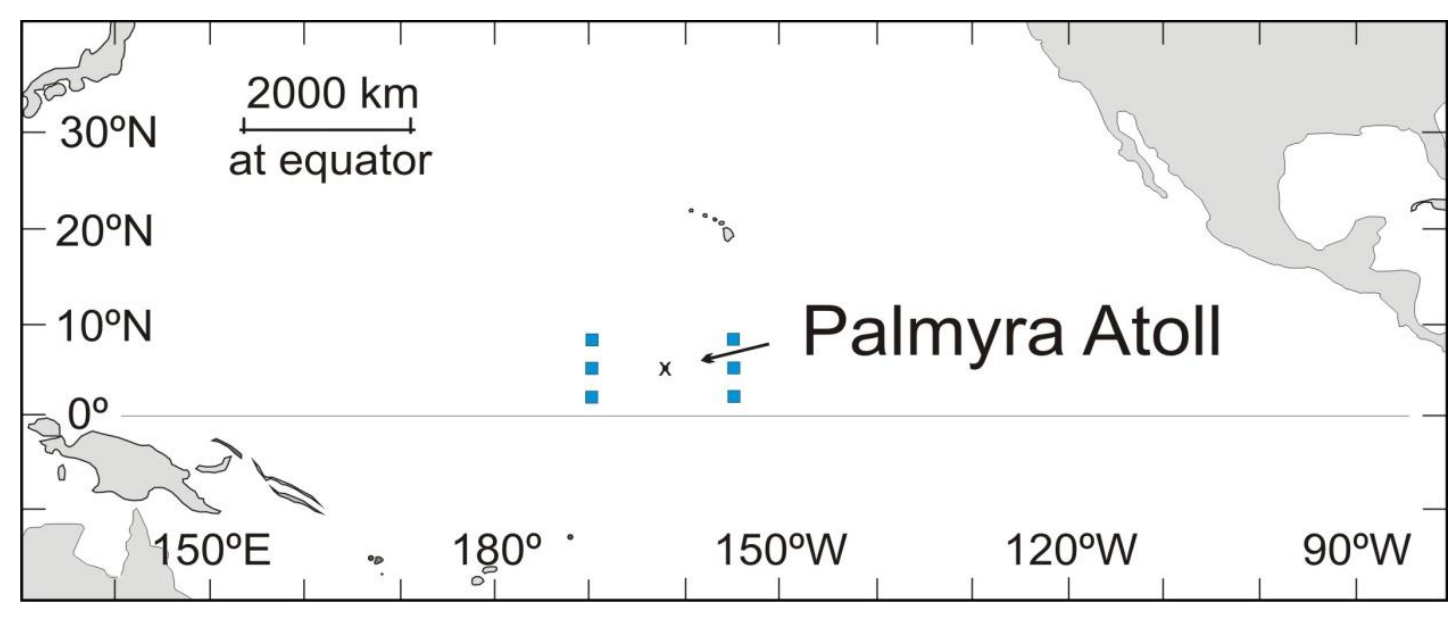

Figure 7.1: Location of the six closest TAO/Triton buoys to Palmyra Atoll 


\subsection{The SWAN wave model}

SWAN is a third generation wave model developed by Delft University of Technology and computes random, short-crested wind-generated waves in coastal regions and inland waters (Booij et al., 1999). Given wind, bottom and current conditions it is possible to obtain realistic estimates of wave parameters in coastal areas, lakes and estuaries. It can also simulate the evolution of prescribed wave boundary conditions. It is a widely accepted computer model, which explicitly accounts for propagation, generation by wind, interactions between waves and the decay of wave power by breaking and bottom friction. This model has most commonly been used for modelling conditions within coastal embayments (Ou et al., 2002; Hoeke et al., in press) but no published studies have previously applied SWAN to oceanic atoll settings.

SWAN has an advantage over other third-generation wave models, such as WAM (WAMDI Group, 1988; Komen et al., 1994) as the latter are not able to be applied to coastal regions at horizontal scales of less than $20-30 \mathrm{~km}$ and water depths of less than 20-30 $\mathrm{m}$. This is because the shallow water effects of depth-induced wave breaking and wave-wave interactions are not included and therefore such models are best suited to predicting the waves at the surface of the deep ocean (Booij et al., 1999). In the SWAN programme, waves are described with the two-dimensional wave action density spectrum even in the surf zone, where conditions are highly non-linear. The evolution of the wave spectrum is described by the spectral action balance equation (Booij et al., 1999; Hasselmann et al., 1973). Further implementation and validation of SWAN is described in Booij et al. (1999), and verification of the model is also given by Ris et al. (1999). Other studies using the model include the modelling of Hanalei Bay in Kauai by Hoeke et al. (in press), which is a bathymetrically complex fringing coral reef embayment, as well as the modelling of typhoon waves in Taiwan by Ou et al. (2002).

Modifications to the application of SWAN have been required for the present study, because of the lack of observational wind and wave data. Rather than predicting wave conditions through climate data, wave conditions are forced to match hindcast wave records and the subsequent effects on the sea floor are examined. These wave conditions are used to set the boundary conditions, which are then modelled across the computational grid. The results are then compared to observations of sediment accumulation on the reef to validate the results. Input parameters required to run the model are bathymetry, wind and/or wave data, and the bottom conditions. 


\subsection{Input parameters}

\subsubsection{Bathymetry}

A 3-dimensional model of the bathymetry of Palmyra's lagoon, shelf and slope environments is based on two merged datasets downloaded from the NOAA Coral Reef Ecosystem Division, Pacific Islands Fisheries Science Centre and the Pacific Islands Benthic Habitat Mapping Centre, School of Ocean and Earth Science and Technology, University of Hawaii (http://www.soest.hawaii.edu/pibhmc/pibhmc_pria_pal.htm on March 30 ${ }^{\text {th }}$, 2010; Gaia Geo-Analytical et al., 2009) and compiled by D. Zwartz (Victoria University of Wellington; Fig. 7.2). The first data set comprises a $40 \mathrm{~m}$ grid of the deeper sea floor and the second comprises a $5 \mathrm{~m}$ grid of the shallow reef flat using a combination of swath bathymetry in the deepest parts and IKONOS satellite data, where depth is obtained from pixel colour, across the shallows (Fig. 7.2). The bathymetry dataset includes Simrad EM300, EM 3002D, and Reson 8101ER multibeam data collected between the $24^{\text {th }}$ and the $28^{\text {th }}$ of March, 2006. Northerly, easterly and depth values were extracted using Generic Mapping Tools and manipulated by Surfer8, a contouring and 3D surface mapping programme to create a 3D surface map of the sea floor surrounding Palmyra (Fig. 3.2 and 7.2).

The computational grid was defined by the coordinates given in Table 7.1. However, the IKONOS data show considerable variation in the depth across the reef terraces; this appears unrealistic, but can only be resolved in the future with comprehensive LIDAR imagery. The $5 \mathrm{~m}$ grid data was combined with the $40 \mathrm{~m}$ grid to create a composite grid (Fig. 7.3) using the $40 \mathrm{~m}$ grid in the deeper parts that were not covered at higher resolution. The resulting merged grid is interpolated at $20 \mathrm{~m}$ intervals, giving an elongate rectangle of $20.2 \times 5.3 \mathrm{~km}$ around the atoll and adjacent reef terraces, and extending into water at least $300 \mathrm{~m}$ deep on all sides. Approximately $50 \%$ of this computational grid is shallower than $40 \mathrm{~m}$. 


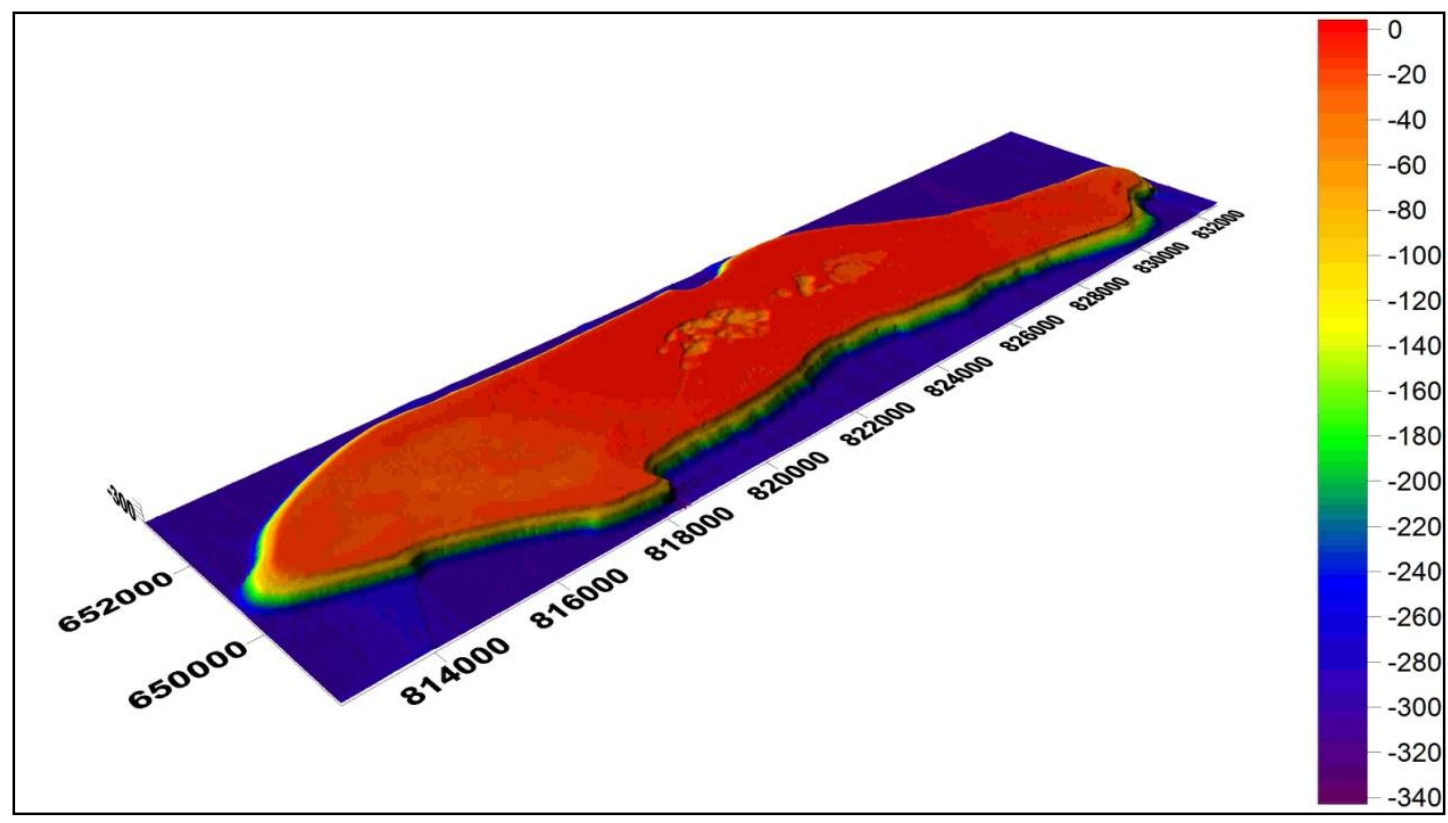

Figure 7.2: $5 \mathrm{~m}$ grid of the bathymetry surrounding Palmyra down to $300 \mathrm{~m}$ depth. No vertical exaggeration has been applied.

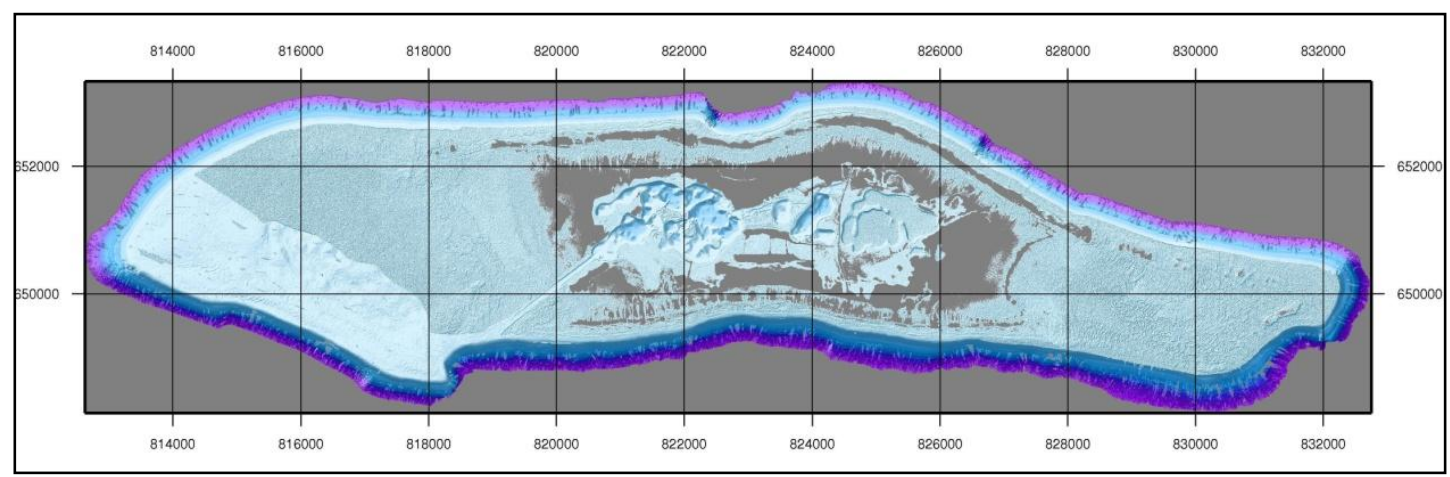

Figure 7.3: Two dimensional image of the bathymetry of Palmyra expressed within the computational grid defined. Depth is indicated by the colour shading from shallow (light blue) to deep ( $300 \mathrm{~m}$; purple); grey indicates depth greater than $300 \mathrm{~m}$ or shallower than the LTL. 
Discrepancies appear between observations and the shallow bathymetry, which show significantly more areas appear to be above high tide than are presently mapped. This may be explained by the satellite mapping occurring at a low tide when some shallow but submerged areas may appear as land. This was compensated for by setting low tide as the current sea level and defining the boundaries from observations. The islet coastlines were then defined using DIGIMAP and assigned an elevation of $+0.6 \mathrm{~m}$ relative to mean sea level, which is equivalent to the mean modern high tide level (the datum level is defined as the mean low tide level). Most conditions were then modelled using SWAN were run with sea level set at "high tide" as most sediment movement in the shallowest areas will occur at higher stages of the tide.

\subsubsection{Bottom friction}

Estimates of wave energy on coastlines are dependent on the empirical wave friction factor $\left(f_{m}\right)$ of the bed surface. The wave friction factor is an essential dimensionless parameter for estimating wave-induced bed shear stress (Le Roux, 2003). Lowe et al. (2005) show that under typical reef conditions, most wave energy dissipation is due to bottom friction rather than wave breaking as previously assumed for coral reefs and sandy beaches. However, $f_{w}$ is difficult to define as it depends on other parameters which are themselves rarely defined accurately. Also, different equations must be employed for hydrodynamically rough or smooth flows, and the boundary between them is also hard to define (Le Roux, 2003). Therefore, correctly estimating this parameter has significant implications for the accuracy of the model results.

Madsen et al. (1988) extended the theory of energy dissipation due to friction in turbulent wave boundary layer flows for monochromatic waves to spectral wave conditions by defining representative flow parameters. This gives the basis for predicting the friction as a function of relative bed roughness $(r / a)$, where $r$ is the hydraulic roughness of the bed and $a$ is the amplitude of the oscillatory wave motion at the bed as estimated from linear wave theory, also known as the orbital excursion distance (Nelson, 1997). For non-breaking waves, $f_{w}$ can be defined by:

$$
f_{w}=\exp \left(5.3\left(\frac{r}{a}\right)^{0.2}-6\right)
$$


Bed roughness ( $\mathrm{r}$ ) is dependent on whether or not the bed is movable (e.g. migrating dune forms). If the bed is movable, then $r$ varies depending on the differences in bed forms, though if the bed is fixed then the applicable relative roughness can be easily determined for any wave and water depth combination because $r$ becomes invariant. Such environments include rock and coral reef platforms. However, field measurements of hydraulic roughness for natural fixed beds, such as those found at Palmyra, are difficult and expensive. This, although ideal, was not possible for the present study and so $r$ is semi-quantitatively estimated from photographs and personal observations of the reef environment at Palmyra, as well as examples from the existing literature. The value of $r$ varies depending on the location on the reef at Palmyra. For instance, the reef terraces have a high hydraulic roughness because of the uneven bed surface and numerous large coral colonies (Fig 7.4). Thus, three zones of differing roughness were identified at Palmyra: the northern and southern reef flats, the eastern and western reef terraces and the sand flats in and around the lagoons (Table 7.2 and Fig. 7.5).

Nelson (1997) showed that $f_{w}$ and $f_{e}$ (the wave energy dissipation factor) are essentially interchangeable. Thus, the dissipation of wave energy is closely related to the bottom friction. Nelson (1997) estimated the hydraulic roughness of the reef platform at John Brewer Reef (Great Barrier Reef) as $0.06 \mathrm{~m}$ based on a mean $a$ value of $0.29 \mathrm{~m}$, which corresponds to wave height and orbital amplitude. This gives the $f_{w}$ a value of 0.13 , which corresponds to the friction exerted by the reef flat. This value was employed for the reef flats of Palmyra and then extended the two other bed environments: sandy beds, which are predominantly within the lagoons and the reef terraces, which are the extensive submerged areas up to $20 \mathrm{~m}$ deep to the east and the west. For these, an average bed roughness of $0.01 \mathrm{~m}$ and $0.2 \mathrm{~m}$ respectively was used. A mean orbital amplitude of $0.29 \mathrm{~m}$ was employed for all three friction environments. These values give $f_{w}$ values ranging from 0.03 to 0.3 depending solely on their bed roughness and are displayed in Table 7.2. 

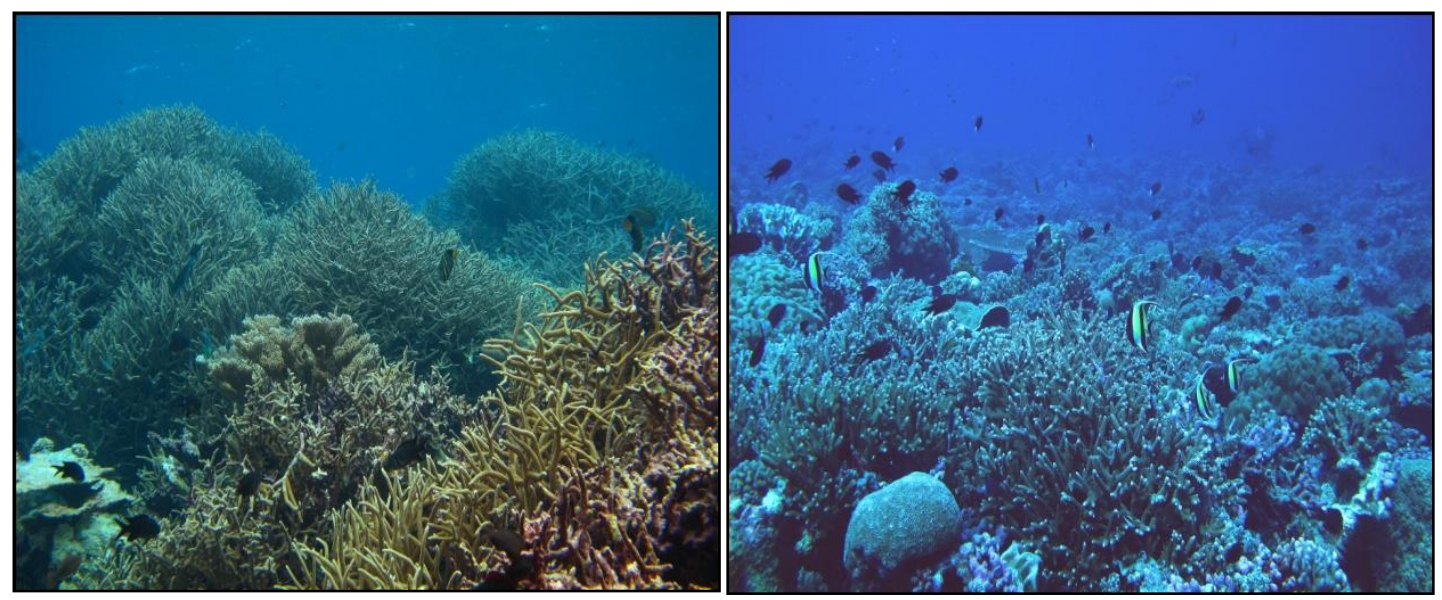

Figure 7.4: (A) Reef-scape photograph of the north-western part of the Western Terrace at a depth of $4 \mathbf{~ m}$ highlighting the rough bed of the reef. (B) Reef-scape photograph of the Eastern Terrace at a depth of 9 meters. (Photographs courtesy of G. Williams)

Table 7.1: Determination of the friction factor for the three main bottom environments at Palmyra

\begin{tabular}{llll}
\hline & $\begin{array}{l}\text { Roughness } \\
\text { length }\end{array}$ & $\begin{array}{l}\text { Orbital } \\
\text { Amplitude }\end{array}$ & $\begin{array}{l}\text { Friction } \\
\text { Factor }\end{array}$ \\
\hline Sandy Beds & $0.01 \mathrm{~m}$ & $0.29 \mathrm{~m}$ & 0.03 \\
Reef Flats & $0.06 \mathrm{~m}$ & $0.29 \mathrm{~m}$ & 0.13 \\
Reef Terraces & $0.20 \mathrm{~m}$ & $0.29 \mathrm{~m}$ & 0.3 \\
\hline
\end{tabular}

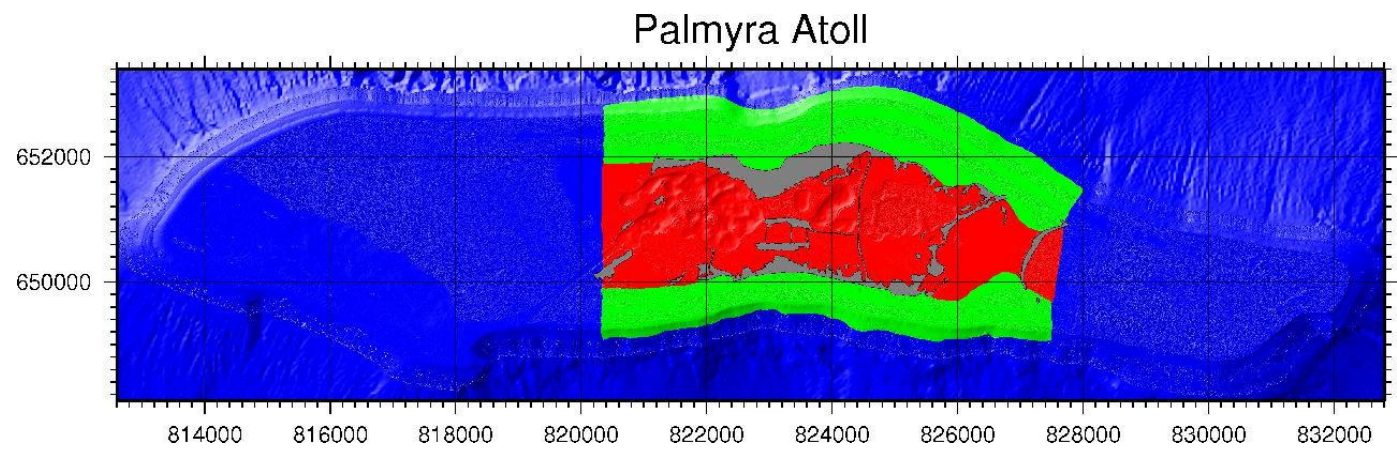

Figure 7.5: Computational grid of Palmyra coloured according to the zonation of friction factor. Blue is high friction factor assigned to the reef terraces and deep ocean; green is a moderate friction factor on the northern and southern reef flats; and red is a very low friction factor assigned to the sand/mud areas on the lagoons and beaches. 
The assumption that these three friction zone are homogeneous and distinct is a significant limitation to the application of the model. There is most likely a large variation within each friction zone that cannot be accurately estimated without extensive observation and measurement. The zones presented here, therefore, are the simplest estimate and are assessed in the review of the model's application. Additionally, sensitivity of the SWAN wave model to variations in the friction factor were not investigated as it was beyond the scope of this thesis. However, Hoeke et al. (in press) show that varying degrees of bottom roughness do not lead to large differences in the resultant shear stress.

\subsubsection{Climate parameters}

SWAN is primarily used to model the effects of the wind climate on waves. However, in this study the effects of the waves are known and the application has been used to retrospectively model the waves needed to create this environment. In this method, local winds are assumed to be minimal and have limited effect on the wave climate at Palmyra. This is due to the small spatial scale of the model in an area with a dominance of large, mature seas. Additionally, due to the location of Palmyra within the doldrums, it typically has only light winds ranging from 5 to $10 \mathrm{~m} / \mathrm{s}$ (see Chapter Three). Seasonal directional wave climatologies were extracted from hindcast WWIII Global Model for the years 1996-2009 (Tolmann, 2002) and are shown in Figure 6.6 for the boreal winter (November to March) and the boreal summer (May to September). Annually there is a bimodal wave climate dominated by waves generated locally from the easterly or north-easterly trade winds and storm swells form distant storm swell (Fig. 7.6). Differences in the trade wind climate between seasons is minor due its location near the equator.

Another consequence of the position of the atoll is that it is not affected by many large local storms (see Chapter Three). However, Palmyra is still affected by large distant storms whose waves propagate across the world's oceans. In the Northern Hemisphere winter, the majority of these occur in the Arctic and off the Alaskan coast, sending large, long period waves down from the north. In the summer, Palmyra is affected by distant storms that are produced during the Southern Hemisphere winter, producing northward-flowing swells. Snodgrass et al. (1966) showed that large storms from as far away as the Indian Ocean can be detected at Palmyra. These waves are not 
generated by local winds and as a result are not indentifiable in the wind climatologies in Figure 3.3.

The bimodal wave climate of each season means that four main wave environments at Palmyra Atoll can be identified (Table 7.3). Trade wind conditions are dominant throughout the majority of the year. However, in winter, these trade winds are strengthened slightly in terms of the significant wave height, although this does not affect the direction or wave period. Two storm swell conditions are also identified at Palmyra during winter and summer respectively. As mentioned above, in winter, Palmyra can be affected by large storms near the Arctic Circle. These are identified as large wave events with long periods travelling south past Palmyra. Alternatively in the summer, Palmyra can be affected by such storms generated in the Southern Hemisphere (Snodgrass et al., 1966). However, these wave events are noticeably lower amplitude, although with just as long wave periods, than those from the north. This is most likely due to a greater distance travelled, or a weaker original storm. This annual wave climate is similar to that experience by the Hawaiian Islands (Harney and Fletcher, 2003).

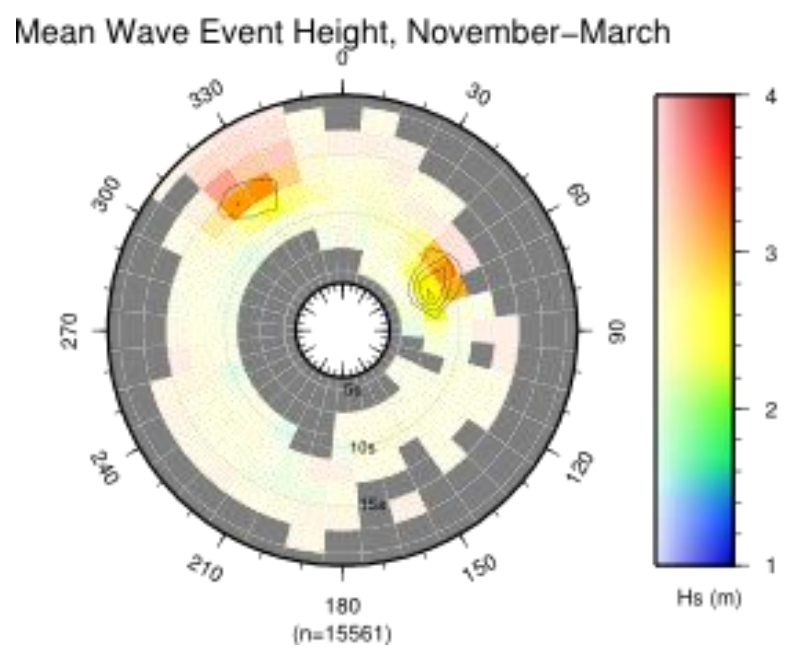

Figure 7.6: Wave climatologies for Palmyra Atoll compiled by D. Zwartz. The two plots represent mean significant wave height for boreal winter (November to March) and summer (May to September) in each respective direction $(\theta)$ and peak period $(T)$ bin. The frequency of each wave observation is represented by the brightness of the bin colour, which is defined as the occurrence of peak direction $(\theta p)$ and peak period (Tp) in each $\theta / T$ bin in the historical data. The frequency is also indicated by the black contour lines, which represent 5 days per season. Additional wave plots are given in appendix $B$. 
Table 7.2: Typical average conditions of the wave climate at Palmyra Atoll, averaged over 13 years of hindcast modelling.

\begin{tabular}{ccccc}
\hline & Direction & $\begin{array}{c}\text { Significant wave } \\
\text { height } \mathbf{( H s )}\end{array}$ & $\begin{array}{c}\text { Wave period } \\
\text { (seconds) }\end{array}$ & $\begin{array}{c}\text { Frequency } \\
\text { (Days/season) }\end{array}$ \\
\hline $\begin{array}{c}\text { Summer } \\
\text { trade winds } \\
\text { Summer } \\
\text { swells }\end{array}$ & $195^{\circ}$ & $2 \mathrm{~m}$ & 8 & 120 \\
$\begin{array}{c}\text { Winter trade } \\
\text { winds }\end{array}$ & $070^{\circ}$ & $2.5 \mathrm{~m}$ & 14 & 25 \\
Winter swells & $330^{\circ}$ & $3 \mathrm{~m}$ & 8 & 94 \\
\hline
\end{tabular}

As mentioned in previous chapters, there has only ever been one cyclone with winds greater than 70 knots recorded near the atoll in recent years. Cyclone Ekeka in 1992 generated significant winds over the lagoons at Palmyra. However, no other climate parameters were recorded for this event. Thus, in the present study, the wave climate associated with storm conditions were estimated using the relationships and patterns of other cyclones. Empirical equations describing the relationship between cyclone wind speed and significant wave height and period are determined by Kumar et al. (2003). These show that with a wind speed of $70 \mathrm{kt}(33.4 \mathrm{~m} / \mathrm{s})$, waves can develop up to $7.9 \mathrm{~m}$ significant wave height with a peak wave period of 11.6 seconds. The design wave height is $9.39 \mathrm{~m}$ for 1 in 100 year return period for a direct hit of a cyclone in the study region (Kumar et al., 2003).

In addition to unknown wave parameters, barometric pressures were not recorded for the cyclone event. This makes estimation of the height of the storm surge above mean high water difficult. Understanding the magnitude of the storm surge during such events is important because increases in sea level decreases the magnitude of wave dissipation due to bottom roughness across the reef. Therefore, during periods of increased sea level, wave energy can propagate further across the reef.

\subsection{Application to sediment movement}

To begin with, it is necessary to apply the known modern conditions to the SWAN model in order to establish the fit of the model compared to the known distribution of modern sediment across the reef. This involves the application of the 
four annual wave regimes to the model. If this is in agreement with the modern reef sediment, then the model and the aforementioned inputs are appropriate for use at Palmyra. Then, as a result of the primary modelled conditions, investigation of the influence of increasing wave strength, changes in wave directions as well as the influence of rise in sea level has been studied.

Since one of the main aims of the SWAN wave model in this thesis is to determine the wave climates necessary to move the sediment required for the formation of beachrock, the threshold for sediment transport must be defined. For sediment to move due to the force imposed from wave action, the critical shear stress on the bed must be exceeded. Bed shear stress due to waves $\left(\tau_{w}\right)$ is a function of the fluid density, bottom velocity, and the dimensionless friction factor described above. The shear stress can be constrained with the simple expression (Madsen et al., 1988; Lowe et al., 2005):

$$
\tau_{w}=\frac{1}{2} \rho f_{w} U_{b}^{2}
$$

where $u_{b}$ is the representative maximum near-bed horizontal orbital velocity calculated by the model. Storlazzi et al. (2009) suggest that a minimum bed shear stress of approximately $0.10 \mathrm{~N} \mathrm{~m}^{-2}$ is required to mobilize the finer terrigenous and marine (calcareous) sediments.

The critical threshold for sediment movement is a function of its diameter, density, and the density of the seawater. It can be describe by the following equation:

$$
\tau_{c}=C_{s}\left(\rho_{s}-\rho_{f}\right) g D
$$

where $D$ is the diameter of the clast (in this case, the average diameter of the beachrock clasts), $\varrho_{\mathrm{s}}$ is the density of the sediment, $\varrho_{\mathrm{f}}$ is the density of seawater $\left(1.025 \mathrm{~g} / \mathrm{cm}^{3}\right), g$ is gravitational acceleration and $C_{s}$ is a dimensionless constant. For turbulent flows with Reynolds numbers greater than 1000 , the value of $C_{s}$ is constant, with a value of about 0.06 (Hsu, 1989). Equation 7.3 was used for sediments with varying densities, and the results are displayed in Table 7.3. This shows, for example, that for a grain with a diameter of $1 \mathrm{~cm}$ and a density of $1.6 \mathrm{~g} / \mathrm{cm}^{3}$, a shear stress of $0.34 \mathrm{Nm}^{-2}$ is required for it to be moved. 
Table 7.3: The calculated critical shear stress for sediment transport for varying clast diameter $(\mathrm{cm})$ and clast density $\left(\mathrm{g} / \mathrm{cm}^{3}\right)$. The column in bold highlights the values for a density of $1.6 \mathrm{~g} / \mathrm{cm}^{3}$, which was used as the average density of clasts on Palmyra Atoll.

\begin{tabular}{|c|c|c|c|c|c|c|c|c|}
\hline $\begin{array}{l}\text { Diameter } \\
(\mathrm{cm})\end{array}$ & $\varrho S=1.4$ & 1.6 & 1.8 & 2.0 & 2.2 & 2.4 & 2.6 & 2.8 \\
\hline 0.01 & 0.00 & 0.00 & 0.00 & 0.01 & 0.01 & 0.01 & 0.01 & 0.01 \\
\hline 0.1 & 0.02 & 0.03 & 0.05 & 0.06 & 0.07 & 0.08 & 0.09 & 0.10 \\
\hline 1 & 0.22 & 0.34 & 0.46 & 0.57 & 0.69 & 0.81 & 0.93 & 1.04 \\
\hline 2 & 0.44 & 0.68 & 0.91 & 1.15 & 1.38 & 1.62 & 1.85 & 2.09 \\
\hline 3 & 0.66 & 1.02 & 1.37 & 1.72 & 2.07 & 2.43 & 2.78 & 3.13 \\
\hline 4 & 0.88 & 1.35 & 1.82 & 2.30 & 2.77 & 3.24 & 3.71 & 4.18 \\
\hline 5 & 1.10 & 1.69 & 2.28 & 2.87 & 3.46 & 4.05 & 4.64 & 5.22 \\
\hline 6 & 1.32 & 2.03 & 2.74 & 3.44 & 4.15 & 4.86 & 5.56 & 6.27 \\
\hline 7 & 1.55 & 2.37 & 3.19 & 4.02 & 4.84 & 5.67 & 6.49 & 7.31 \\
\hline 8 & 1.77 & 2.71 & 3.65 & 4.59 & 5.53 & 6.47 & 7.42 & 8.36 \\
\hline 9 & 1.99 & 3.05 & 4.11 & 5.16 & 6.22 & 7.28 & 8.34 & 9.40 \\
\hline 10 & 2.21 & 3.38 & 4.56 & 5.74 & 6.92 & 8.09 & 9.27 & 10.45 \\
\hline 11 & 2.43 & 3.72 & 5.02 & 6.31 & 7.61 & 8.90 & 10.20 & 11.49 \\
\hline 12 & 2.65 & 4.06 & 5.47 & 6.89 & 8.30 & 9.71 & 11.12 & 12.54 \\
\hline 13 & 2.87 & 4.40 & 5.93 & 7.46 & 8.99 & 10.52 & 12.05 & 13.58 \\
\hline 14 & 3.09 & 4.74 & 6.39 & 8.03 & 9.68 & 11.33 & 12.98 & 14.63 \\
\hline 15 & 3.31 & 5.08 & 6.84 & 8.61 & 10.37 & 12.14 & 13.91 & 15.67 \\
\hline 16 & 3.53 & 5.42 & 7.30 & 9.18 & 11.07 & 12.95 & 14.83 & 16.72 \\
\hline 17 & 3.75 & 5.75 & 7.75 & 9.76 & 11.76 & 13.76 & 15.76 & 17.76 \\
\hline 18 & 3.97 & 6.09 & 8.21 & 10.33 & 12.45 & 14.57 & 16.69 & 18.81 \\
\hline 19 & 4.19 & 6.43 & 8.67 & 10.90 & 13.14 & 15.38 & 17.61 & 19.85 \\
\hline 20 & 4.41 & 6.77 & 9.12 & 11.48 & 13.83 & 16.19 & 18.54 & 20.90 \\
\hline 21 & 4.64 & 7.11 & 9.58 & 12.05 & 14.52 & 17.00 & 19.47 & 21.94 \\
\hline 22 & 4.86 & 7.45 & 10.04 & 12.63 & 15.22 & 17.81 & 20.39 & 22.98 \\
\hline 23 & 5.08 & 7.78 & 10.49 & 13.20 & 15.91 & 18.61 & 21.32 & 24.03 \\
\hline 24 & 5.30 & 8.12 & 10.95 & 13.77 & 16.60 & 19.42 & 22.25 & 25.07 \\
\hline 25 & 5.52 & 8.46 & 11.40 & 14.35 & 17.29 & 20.23 & 23.18 & 26.12 \\
\hline 26 & 5.74 & 8.80 & 11.86 & 14.92 & 17.98 & 21.04 & 24.10 & 27.16 \\
\hline 27 & 5.96 & 9.14 & 12.32 & 15.49 & 18.67 & 21.85 & 25.03 & 28.21 \\
\hline 28 & 6.18 & 9.48 & 12.77 & 16.07 & 19.36 & 22.66 & 25.96 & 29.25 \\
\hline 29 & 6.40 & 9.81 & 13.23 & 16.64 & 20.06 & 23.47 & 26.88 & 30.30 \\
\hline 30 & 6.62 & 10.15 & 13.68 & 17.22 & 20.75 & 24.28 & 27.81 & 31.34 \\
\hline 40 & 8.83 & 13.54 & 18.25 & 22.96 & 27.66 & 32.37 & 37.08 & 41.79 \\
\hline 50 & 11 & 17 & 23 & 29 & 35 & 40 & 46 & 52 \\
\hline 100 & 22 & 34 & 46 & 57 & 69 & 81 & 93 & 104 \\
\hline 500 & 110 & 169 & 228 & 287 & 346 & 405 & 464 & 522 \\
\hline 1000 & 221 & 338 & 456 & 574 & 692 & 809 & 927 & 1045 \\
\hline 2000 & 441 & 677 & 912 & 1148 & 1383 & 1619 & 1854 & 2090 \\
\hline 3000 & 662 & 1015 & 1368 & 1722 & 2075 & 2428 & 2781 & 3134 \\
\hline 4000 & 883 & 1354 & 1825 & 2296 & 2766 & 3237 & 3708 & 4179 \\
\hline
\end{tabular}




\subsection{Limitations}

One of the most important limitations to this study, as previously mentioned, is the lack of long term climate data in the central Pacific and here hindcast modelling is used as a method of overcoming this gap in knowledge. However, the wave parameters used to model the hydrodynamics were averaged for the past 13 years, a time period that does not include some of the extreme events known to have occurred at Palmyra. For instance, Cyclone Ekeka (1992) gave recorded wind speeds of over 60 knots $(111 \mathrm{~km} / \mathrm{hr})$ and a handful of other tropical cyclones have been recorded in the vicinity of the northern Line Islands. There is also photographic evidence of waves completely washing over part of Cooper Island during the period of military occupation (Fig. 7.8) although no climate data recording these events in the area are available. Therefore the wave climatologies generated from WWIII Global Model hindcast cannot be completely representative.

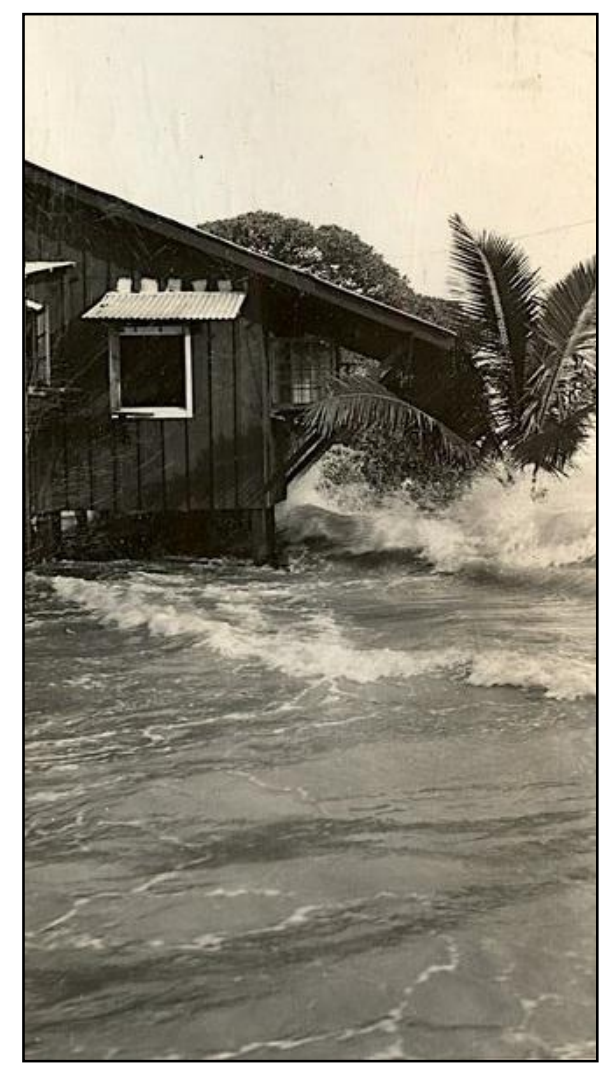

Figure 7.8: Photograph of waves flooding one of the buildings on Cooper Island during the military occupation, date unknown but probably about 1942

Another important physical limitation is the variation in the micro-topography of the reef flat. Bathymetry used for this area was taken from satellite altimetry. When compared to the data acquired by swath mapping in the slightly deeper parts of the $5 \mathrm{~m}$ 
grid (Fig. 7.3) there appears to be considerable noise in the Ikonos data. This leads to variations across the reef terraces, which may have implications for the SWAN results. Although it is most likely that there are fluctuations in depth across these platforms, it is unlikely that these are exactly where they appear on the bathymetry map. The reef flat micro-topography is an important but difficult factor to understand and more research is needed to achieve this.

Quantitatively relating shear stress to sediment transport is difficult in this environment. The total bed shear stress is the sum of the bed shear stress related to unidirectional flows, such as tidal currents and alongshore drift, and the bed shear stress caused by oscillatory waves. Wave-induced currents are not calculated by SWAN and need to be provided as an input. Since in this study only the effects of waves are being examined, the effects of the currents are assumed to be minimal and are therefore neglected. However this may not be the case, especially within the lagoons, where the water is known to dominantly flow from east to west (Maragos et al., 2008a). Although the observed currents mentioned do not affect the outer coast where this study is focused, there are similar alongshore currents (Collen et al., 2009a; Collen et al., 2009b) that are not quantified, which may affect sediment transport across the reef flat.

As a result of the lack of quantitative or observational data from Palmyra, the SWAN wave model cannot be validated in terms of the models performance. Usually, quantification of the performance of ocean wave models is achieved through the use of a scatter index (e.g. Ris et al., 1999), which is defined as the rms error normalized with the average observed value. However, this is not possible for Palmyra Atoll due to the absence of accurate observational data. The validation of the model, therefore, comes only through relating the results to observational records, which are limited to a handful of locations on the coast.

Calculating the critical threshold for sediment movement at Palmyra has inherent limitations because of the variety of density and shapes of the sediment. The critical shear stress calculated in this study is for an average coral density of $1.6 \mathrm{~g} / \mathrm{cm}^{3}$ (Hughes, 1987). However, different morphologies of coral have differing densities and these can range from $0.15 \mathrm{~g} / \mathrm{cm}^{3}$ to $2.8 \mathrm{~g} / \mathrm{cm}^{3}$ (Hughes, 1987). Therefore the threshold only applies to the average clast and does not represent the entire population of sediments. In addition to this, other non-coralline clasts have greatly varying densities. For instance, Tridacna valves are extremely dense as they are almost pure aragonite and have very little porosity. This together with their considerable size (up to $30 \mathrm{~cm}$ ), make 
clear that larger amounts of wave energy than those typically found in the same environments at Palmyra are required to move them. Furthermore, the equation for the critical shear stress assumes that particles are spherical, which clearly does not apply to the majority of clasts on a coral reef. In fact, the sands and gravels at Palmyra Atoll have greatly varying morphologies, from elongate Acropora coral clasts to large, convex Tridacna valves, and these may either enhance or hinder transport.

The SWAN wave model also has limitations that are inherent to the program. These cover aspects such as triad wave-wave interaction and wave-induced set-up as well as internal scenarios and limiters. Complete computation of quadruplet wave-wave interactions are difficult and time consuming and not feasible for wave modelling. Eldeberky and Battjes (1995; in Booij et al., 1999) provide SWAN with an economically feasible formulation of the triad wave-wave interaction and the lumped triad approximation was later derived and employed in SWAN. It is important to note that SWAN may have difficulty accurately modelling wave set-up and run-up across the reef edge. This has yet to be investigated fully and as SWAN has rarely been used to model waves on reefs of any kind, the accuracy of the model on these issues are unknown. Despite such limitations, SWAN provides the most complete, three-dimensional approach available for modelling oceanic atolls and their coastal environments.

\subsection{Summary}

Shallow wave models, such as SWAN, have yet to be applied to an oceanic atoll, such as Palmyra, which is exposed to wave energy from all directions. Although SWAN does not directly model sediment transport, it is inferred from well known relationships between the bed shear stress and the clast size. This study contributes to the understanding of paleo-climate and hydrodynamic environments in an extremely isolated area of the Pacific Ocean. In particular, this impacts on the understanding of processes of atoll island development and their relation to sea level. The possibilities of the application of the SWAN wave model to such unique and dynamic environments have yet to be fully explored but have the potential to become an important tool in the study and management of atolls and shallow reefs. 


\section{SWAN wave model results}

\subsection{Overview of wave modelling results}

Application of the SWAN wave model to Palmyra Atoll determines the impact that both oceanic- and locally-generated waves have on the atoll and its surrounding reefs. Throughout an average year (see Fig. 7.6) two dominant wave conditions are identified: the trade wind conditions due to the fetch built up from the easterly trade winds, and swells generated from distant storms. These conditions vary depending on the season, creating four main wave conditions. In addition to the trade wind and swell conditions defined, very large and infrequent waves are known to impact Palmyra, such as Cyclone Ekeka. Sea level is also an important factor to consider when investigating atoll reefs and particularly when considering future stability of such fragile environments and this is investigated using SWAN

Only large-scale oceanic-waves are considered here because the locally-generated waves have a limited effect only on conditions within the lagoons. Although the use of this wave model allows the conditions of beachrock deposition to be determined, this chapter reports the distribution of energy across the reef as a result of varying wave conditions. The formation of beachrock in terms of the SWAN wave model results is discussed in detail in Chapter Ten.

Variations in wave climates were modelled at both low $(0 \mathrm{~m}$ sea level $)$ high (0.6 m) tide levels. However, the lack of accurate bathymetric data results in an inability to accurately mask the grid for the exposed land at current low tide levels. This is further hindered by the lack of observational records at low tide from the more remote areas of the atoll. This is particularly difficult for the Eastern Flats areas and Barren Island, as travel to these locations is only possible at close to high tide conditions. Overall, the bed shear stress shows a similar distribution to that of the bottom orbital velocities, which highlights the relationship between them.

Each set of wave conditions modelled by SWAN shows a unique distribution of bed shear stress across the reef (Fig. 8.2). However, the patterns of the direction of wave as they propagate across the reef are similar and are not dependent on the wave height or speed. The directional pattern of waves as they propagate across the reef is similar under all wave conditions modelled. As the waves pass the atoll, they increasingly 
curve inland and when they reach the opposite side of the atoll from which they originated, they are refracted and converge, where the energy is then directed both inland and offshore.

The frequent impact of relatively high energy waves results in significant transport of sediment across the reef terraces, as well as influencing sedimentation rates and the circulation of waters, both of which are important for coral health and growth. Determination of the shear stress exerted on the bed during different wave climates allows prediction of the size of sediment clasts that can be moved over specific areas of the reef. This is achieved through equation 7.3 , and depends on the nominal sediment diameter as well as its density. For a grain density of $1.6 \mathrm{~g} / \mathrm{cm}^{3}$ (the average density of coral skeletons comprised of aragonite; Hughes, 1987), the critical shear stress required to move a grain $10 \mathrm{~mm}$ in diameter is $0.33 \mathrm{~N} \mathrm{~m}^{-2}$. For comparison, a boulder $50 \mathrm{~mm}$ in diameter of the same density requires $1.69 \mathrm{Nm}^{-2}$. The critical shear stresses required for varying sediment diameters with the density used for sediment movement at Palmyra are shown in Figure 8.1.

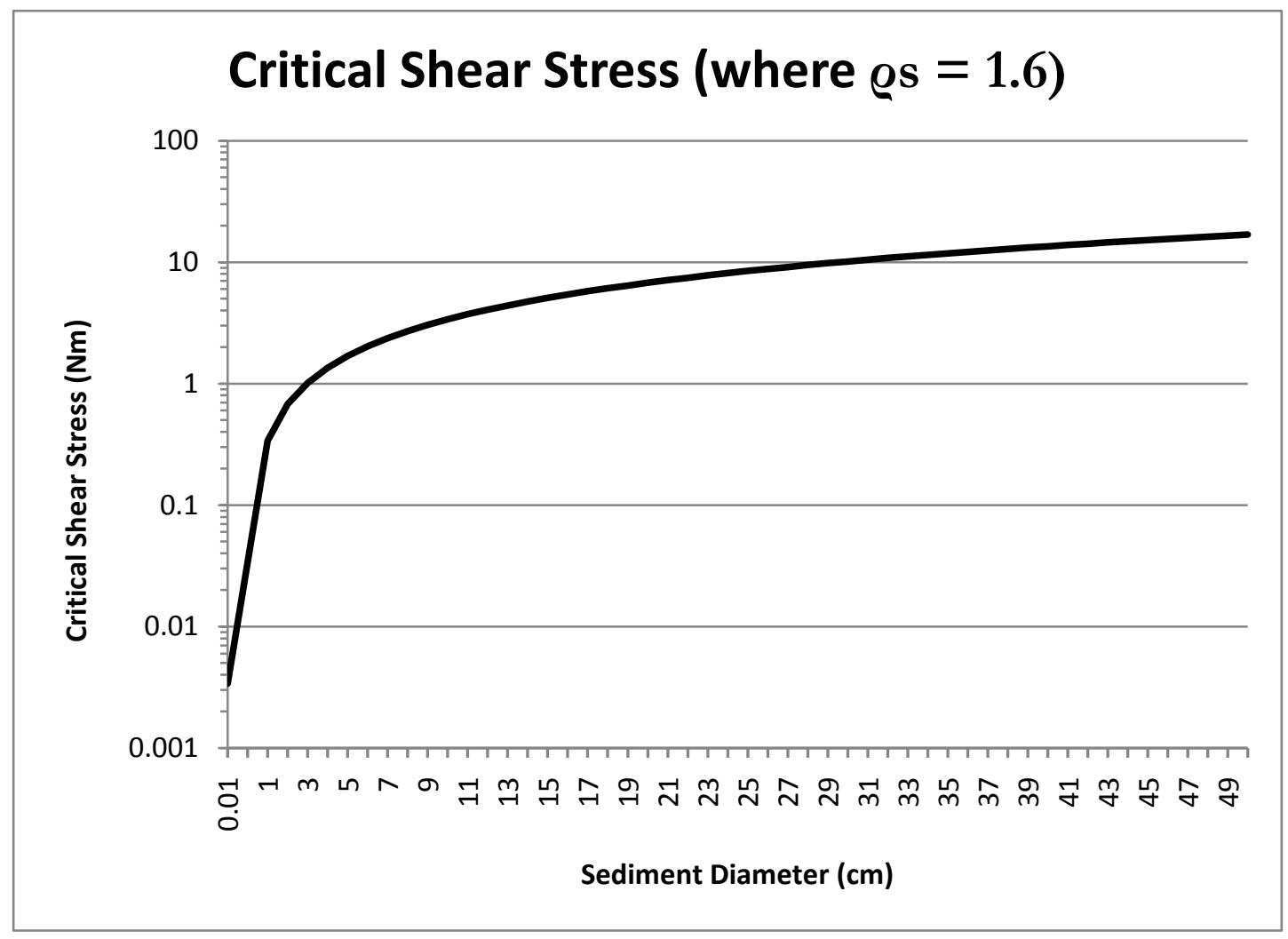

Figure 8.1: Critical shear stress required to move sediment with a density of $1.6 \mathrm{~g} / \mathrm{cm}^{3}$ 
Additionally, some of the variations across the reef terraces in the resulting plots are due to variations inherent in the baseline data. For instance, there is an area of shallow water on the north-eastern edge of the Eastern Terrace for which direct observations are non-existent and its presence is inferred only from remote mapping. This portion of the reef is subject to extremely high shear stress conditions under all modelled conditions, although the validity of this bathymetry is difficult to assess. Therefore, it has been neglected in the following sections.

Selected results of the SWAN wave model are plotted for the bed shear stress as well as the orbital velocity of the waves and selected plots are displayed in Figures 8.2, with selected statistics shown in Table 8.1. The average annual conditions modelled by SWAN, described in the previous chapter, are in agreement with observations of sediment accumulation on the sea bed in and around the lagoon. Of importance, areas within the lagoons and nearshore are protected from most high energy waves due either to the sheltering effects of the islands or through dissipation of the wave energy across the reef flats. There is insufficient fetch or swell waves within the lagoons to cause sediment movement other than that of fine sands and silt.

\subsection{SWAN results and associated sediment movement}

\subsubsection{Modelled annual conditions}

\subsubsection{Summer trade winds}

Summer trade wind conditions occur most frequently throughout an average year and are characterised by $2 \mathrm{~m}$ swells from the east with a moderate wave period of 8 seconds, and thus the lowest energy of any modelled conditions. Such waves have their greatest effect on the eastern side of the Eastern Terrace (Fig. 8.2A), as well as on areas along the north and south reef edges that are impacted by shear stresses greater than 1.5 $\mathrm{N} \mathrm{m}^{-2}$. Therefore these areas of reef are exposed to the highest amount of energy for the longest period of time throughout the year.

There are areas of the reef, such as within the lagoons and in deep water, where essentially no shear stress is exerted on the bed under typical trade wind conditions. Elsewhere, the maximum shear stress obtained during these conditions is $65 \mathrm{~N} \mathrm{~m}^{-2}$ and the bottom velocities reach up to $201 \mathrm{~m} . \mathrm{s}^{-1}$, mainly at isolated parts on the outer edge of the northern reef flats. Therefore at most, these waves have enough energy on the 
bottom to move a boulder approximately $22 \mathrm{~cm}$ in diameter (with a density of $1.6{\mathrm{~g} . \mathrm{cm}^{-3}}^{-3}$ ) on the most exposed part of the reef edge during $\sim 120$ days each summer. This area would thus be cleaned of most sediment produced almost immediately. However, this amount of shear stress only occurs at discrete and isolated areas of the outer reef.

Sediment movement, calculated from the critical shear stress (Eq. 7.3), is significant across much of the reef during such weak wave events. There is sufficient energy across $49 \%$ of the reef at Palmyra Atoll to transport clasts $1 \mathrm{~cm}$ in diameter. As the clast size increases, the area over which clasts can be moved decreases. For instance, clasts $5 \mathrm{~cm}$ in diameter can be moved across $20 \%$ of the reef, and clasts $20 \mathrm{~cm}$ in diameter can only be moved on $4 \%$ of the reef. The movement of these larger clasts occurs on the eastern edge, where the reef absorbs and dissipates the energy emanating from the east.

\subsubsection{Summer swells}

Summer storm swell conditions are characterised by larger, long-period waves originating from storms in the southern hemisphere and occur least frequently throughout an average year ( 25 days/season). However, even though these storm swell events generally have a smaller significant wave height $(2.25 \mathrm{~m})$ than those formed during the Northern Hemisphere winter, they still have a substantial impact on the atoll (Fig. 8.2B). The reef flat on the south coast, where these waves have the greatest impact, is approximately $150 \mathrm{~m}$ narrower that of the north coast and this affects the dissipation of wave energy. As a result, the distance across the reef is not sufficient for the wave energy to dissipate fully and waves still have significant energy when they reach the coastlines of the islets.

At numerous points across the south coast the bed shear stress is at least $10 \mathrm{~N}$ $\mathrm{m}^{-2}$, which is sufficient energy to move boulders as large as $30 \mathrm{~cm}$ in diameter. This energy also propagates across the eastern and western reef terraces, in particular around the perimeter. On the whole, the Eastern Terrace appears to have a higher proportion of its area subject to higher shear stresses. The force on the bed at its maximum can reach a substantial $155 \mathrm{~N} \mathrm{~m}^{-2}$ and the bottom velocities can reach $282 \mathrm{~ms}^{-1}$.

Since the bed shear stress exerted during summer swell wave events is elevated in relation to trade wind conditions, the area of reef over which sediment can be transported increases by around $20 \%$. For instance, $1 \mathrm{~cm}$ and $20 \mathrm{~cm}$ clasts of coral can 
be transported across $70 \%$ and $21 \%$ of the reef respectively, a significant increase from the $49 \%$ and $4 \%$ allowed by the summer trade wind conditions.

It is important to note that during summer swell wave events, there is effectively no wave energy exerted on most of the north coast as well as within the lagoons. This includes areas out to Barren Island in the east and Sand Island in the west, and is due to the sheltering effect of the southern reef crest. On the western portion of the reef flat, the wave direction and therefore the predominant sediment transport direction, is opposite the normal situation during easterly trade wind conditions.

\subsubsection{Winter trade winds}

Winter trade wind conditions are characterised as a strengthened version of the summer trade wind conditions, in that the significant wave height averages $3 \mathrm{~m}$ rather than $2 \mathrm{~m}$ and originating slightly more northeast, though the wave period remains the same. There is a steady change in wave direction from east-northeast to east on the portion of the grid south of the atoll. The closer to the atoll these waves are, the more they begin to curve to the north so that the energy is directed almost entirely at the islets. A similar effect occurs on the northern reef flats as well, where the energy is directed almost directly into North Beach.

The spatial distribution of energy remains essentially the same during these heightened trade wind periods. Shear stress during these conditions (Fig. 8.2C) can reach up to $175 \mathrm{~N} \mathrm{~m}^{-2}$, almost triple that exerted on the bed during the summer equivalent, and orbital velocities can reach $272 \mathrm{~m} / \mathrm{s}$. This energy is mainly concentrated along the north coast and across the Eastern Terrace. Additionally, the area of possible sediment movement during trade wind events increases slightly during the boreal winter from during the summer months. There is a $10 \%$ increase in the area of the reef over which sediment up to $1 \mathrm{~cm}$ in diameter can be transported (Table 8.1).

\subsubsection{Winter swells}

Winter swell conditions occur when Palmyra is subject to storm swells propagating southward from high latitude cyclones and have the greatest effect on the reefs and sediments of the atoll during a typical year. These events are characterised by long period waves with significant wave heights of at least $3 \mathrm{~m}$ from the northwest, and occur on average 54 days per season. 
During winter swell conditions (Fig. 8.2D), the maximum shear stress can reach approximately $320 \mathrm{~N} \mathrm{~m}^{-2}$, which is theoretically, sufficient to move boulders over $1 \mathrm{~m}$ in diameter. The maximum orbital velocities during these conditions also occur in the same areas and can reach approximately $326 \mathrm{~cm} \cdot \mathrm{s}^{-1}$. The northern reef edges, as well as a large proportion of both the Western and Eastern reef terraces, are subject to the highest bed shear stress throughout such wave conditions. Unlike the deeper parts of the reef terraces, this energy is dissipated relatively quickly across the reef flats. Therefore, there are still relatively low energy environments at the shoreline of the reef islands. The only areas of the outer atoll that are unaffected during such events are the central sections of the south coast.

Overall, across $76 \%$ of the reef there is sufficient energy to transport sediment that is $1 \mathrm{~cm}$ in diameter and medium gravel can be moved over $59 \%$ of the reef area. There is sufficient energy to move larger clasts of 10 and $20 \mathrm{~cm}$ in diameter, over $48 \%$ and $31 \%$ of the grid respectively (Table 8.1 ); as mentioned above, this mostly occurs across the large reef terraces and on the reef edge.

Table 8.1: Area of reef over which there is sufficient wave energy at high tide to transport sediment of increasing size under different annual conditions.

\begin{tabular}{lrrrr}
\hline $\begin{array}{l}\text { Size moved } \\
\text { over reef }\end{array}$ & \multicolumn{1}{l}{$\begin{array}{l}\text { Summer: } \\
\text { Trade winds }\end{array}$} & Storm swell & Trade wind & Storm swells \\
\hline $\mathbf{1 ~ c m}$ & $49 \%$ & $70 \%$ & $59 \%$ & $76 \%$ \\
$\mathbf{5} \mathbf{~ c m}$ & $20 \%$ & $55 \%$ & $27 \%$ & $59 \%$ \\
$\mathbf{1 0} \mathbf{~ c m}$ & $11 \%$ & $38 \%$ & $18 \%$ & $48 \%$ \\
$\mathbf{2 0} \mathbf{~ c m}$ & $4 \%$ & $21 \%$ & $10 \%$ & $31 \%$ \\
\hline
\end{tabular}

\subsubsection{Extreme events}

Although there is a wide range of possible scenarios to model extreme $(<5 \mathrm{~m})$ wave events, due to time limitations only a limited number of these events were tested using the SWAN wave model. These included cyclone events, based on the estimates of Cyclone Ekeka wind strengths to determine the wave climate, as well as very large storm swells with a larger significant wave height and longer wave period. Based on winds of $33 \mathrm{~m} . \mathrm{s}^{-1}$, the modelled wave climate produces waves estimated at $7.9 \mathrm{~m}$ in significant 
wave height with a period of 11.6 seconds (Kumar et al., 2003). Under these conditions (Fig. 8.2E), substantial shear stress is exerted on the bed, reaching a maximum of around $830 \mathrm{Nm}^{2}$. Along with the estimated cyclone conditions, a variety of extreme wave events were modelled with variations in both wave height and direction. Wave events of this magnitude are relatively infrequent and do not appear in the 13 year hindcast wave model or by historical evidence. During the modelled cyclone event, extreme bottom shear stress is applied to the outer edge of the Eastern Terrace, which can exceed $1000 \mathrm{~N} \mathrm{~m}^{-2}$ in isolated areas.

SWAN wave modelling of extreme events, such as Cyclone Ekeka, show that the direction of the wave or wind parameters does not have a great effect on the bed shear stress difference between these two environments, although, the atoll does provide some sheltering from waves. However, it is unlikely that the wind or swell directions remain constant throughout a cyclone event and therefore both reef terraces will be subject to similar bottom conditions during cyclone events.

When such cyclone conditions are modelled at high tide, movement of sediment $1 \mathrm{~cm}$ in diameter can occur across $79 \%$ of the grid (rather than a percentage of the reef as used previously), or over $84 \mathrm{~km}^{2}$. Therefore transport of fine sediment is occurring not only on the atoll, but also in some of the deeper water surround the reef edge. Additionally, clasts as large as $10 \mathrm{~cm}$ and $20 \mathrm{~cm}$ can be moved across $32 \%$ and $26 \%$ of the grid respectively. If this only occurs on the reef, then it relates to $57 \%$ and $46 \%$ of the reef at Palmyra Atoll. This is likely to be the outer reef edge and the shallower areas of the reef terraces.

\subsubsection{Influence of sea level variations}

The effect of relative sea level on wave energy was tested by increasing sea level relative to high tide conditions. This sea level rise is a simplistic model that involves an instantaneous rise in sea level where all other parameters are held constant. This showed that additional bed shear stress was exerted on the sea bed inland from the reef edge due to the increased sea level. This additional energy is displayed in $0.2 \mathrm{~m}$ increments in Table 8.2. The results show that the additional bed shear stress forced by elevated sea level increased until sea level has been raised by $1 \mathrm{~m}$, after which the additional bed shear stress resulting from additional sea level elevation was decreasing. These plots (Fig. 
$8.2 \mathrm{~F}$ and $\mathrm{G}$ ) show that during a $1 \mathrm{~m}$ sea level rise, the wave energy can propagate considerably further inwards before the energy is dissipated by friction on the sea bed.

Table 8.2: The additional maximum bottom shear stress caused by $0.2 \mathrm{~m}$ increments of sea level rise during typical summer trade wind wave conditions. The additional energy peaks at $1.6 \mathrm{~m}$, which is $1 \mathrm{~m}$ above the modern high tide level.

\begin{tabular}{rlrr}
\hline Sea level (m) & \multicolumn{1}{l}{$\begin{array}{l}\text { Additional shear stress } \\
\left(\mathbf{N ~ m}^{-2}\right)\end{array}$} & \multicolumn{2}{c}{$\begin{array}{c}\text { Cumulative shear } \\
\text { stress }\left(\mathbf{N ~ m}^{-2}\right)\end{array}$} \\
\hline (modern) $\mathbf{0 . 6 0}$ & 65.49 & $\mathrm{n} / \mathrm{a}$ & 65.49 \\
$\mathbf{0 . 8 0}$ & 10.83 & 16.53 & 76.32 \\
$\mathbf{1 . 0 0}$ & 6.65 & 10.15 & 82.97 \\
$\mathbf{1 . 2 0}$ & 0.00 & 0.00 & 82.97 \\
$\mathbf{1 . 4 0}$ & 10.23 & 15.62 & 93.37 \\
$\mathbf{1 . 6 0}$ & 10.40 & 15.88 & 103.60 \\
$\mathbf{1 . 8 0}$ & 6.11 & 9.33 & 109.71 \\
$\mathbf{2 . 0 0}$ & 4.08 & 6.22 & 113.79 \\
$\mathbf{2 . 2 0}$ & 3.84 & 5.86 & 117.62 \\
$\mathbf{2 . 4 0}$ & 4.25 & 6.48 & 121.87 \\
$\mathbf{2 . 6 0}$ & 3.71 & 5.67 & 125.58 \\
\hline
\end{tabular}

The four average annual conditions were modelled for varying sea levels, and the effect on sediment transport was assessed. The areas of the reef over which sediment transport can take place with a $1 \mathrm{~m}$ sea level rise are displayed in Table 8.3. If the sea level was $1 \mathrm{~m}$ higher than the modern high tide level, then there is at most only a slight increase of area (several $\mathrm{km}^{2}$ of reef) over which sediment can be transported. However, qualitatively, there are significant differences that are highlighted by the plots of increasing sea level (Fig. 8.2F-G). These show that, although the amount of energy has not increased notably, it does propagate further inland than during normal annual conditions at the high tide level, particularly in the eastern flats area. There is sufficient bed shear stress across the reef flats to move sediment in areas that are otherwise too far from the reef edge or too sheltered from other islands to reach the critical shear stress for sediment movement. This has important implications for the deposition of sediment on the inner reef islands, such as Lost and Fern islands.

However, this model of sea level rise has not taken into account growth of the reef or further accumulation of sediment across the reef, and assumes that same bed roughness and friction factor that is estimated for the modern conditions. Thus, if the growth of the reef flat has kept pace with sea level rise then there are unlikely to be any 
significant changes to the wave energy across the reef. Therefore, a higher sea level could be accounted for by the reef unable to keep up with a relative sea level rise, a storm surge, or the possible inability of SWAN to accurately model wave set up across the reef crest.

Table 8.3: The percentage of area of the reef over which sediment can be transported during normal conditions when sea level has been increased $1 \mathrm{~m}$.

\begin{tabular}{lrrrr}
\hline $\begin{array}{l}\text { Size moved over } \\
\text { reef: }\end{array}$ & \multicolumn{1}{l}{$\begin{array}{l}\text { Summer: } \\
\text { Trade wind }\end{array}$} & $\begin{array}{l}\text { Storm swell } \\
\text { Trade wind }\end{array}$ & $\begin{array}{r}\text { Storm swell } \\
\hline \mathbf{1 ~ c m}\end{array}$ \\
$\mathbf{5 ~ c m}$ & $53 \%$ & $73 \%$ & $63 \%$ & $85 \%$ \\
$\mathbf{1 0} \mathbf{~ c m}$ & $20 \%$ & $56 \%$ & $29 \%$ & $66 \%$ \\
$\mathbf{2 0} \mathbf{~ c m}$ & $10 \%$ & $38 \%$ & $18 \%$ & $50 \%$ \\
\hline
\end{tabular}

Figure 8.2 (following pages): Model results for SWAN wave model results over Palmyra Atoll and surrounding reef down to $\sim 300 \mathrm{~m}$. Upper plot colour scale shows the bed shear stress exerted on the bottom under given conditions (inputted wave and wind values given above the plot, including directional arrow), where blue represents shear stress less than 1.5 and hence can move sediment up to $5 \mathrm{~cm}$ in diameter and red describes the shear stress between 1.5 and $10.0 \mathrm{Nm}^{2}$, which has enough force to move material between approximately 5 and $30 \mathrm{~cm}$ respectively. Additionally, grid space with bed shear stress less than $0.001 \mathrm{Nm}^{2}$ is plotted as white and islands are shaded grey. Although most modelled scenarios have a maximum shear stress greater that the upper limit of the scale bar, $30 \mathrm{~cm}$ sediment clasts are the largest clasts found with beachrock outcrops and so it the upper limit of shear stress examined in this study. The lower plot describes the orbital velocity at the bottom over the reef in $\mathrm{cm} / \mathrm{s}$ for the same conditions as the above plot. Directional arrows on both plots describe the change in wave direction as the waves propagate across the reef. Wave directions from within the lagoons have been omitted because of their oversimplification due to the complex nature of currents within the lagoon. A) Summer trade wind conditions. B) Summer swell conditions. C) Winter trade wind conditions. D) Winter swell conditions. E) Estimated Cyclone Ekeka conditions. F) Summer trade wind conditions with a $1 \mathrm{~m}$ sea level rise. G) Winter swell conditions with a $1 \mathrm{~m}$ sea level rise. All plots, apart from $\mathrm{F}$ and $\mathrm{G}$ are modelled at the modern HTL. 
(A) Summer trade wind conditions

Wave-induced Shear Stress
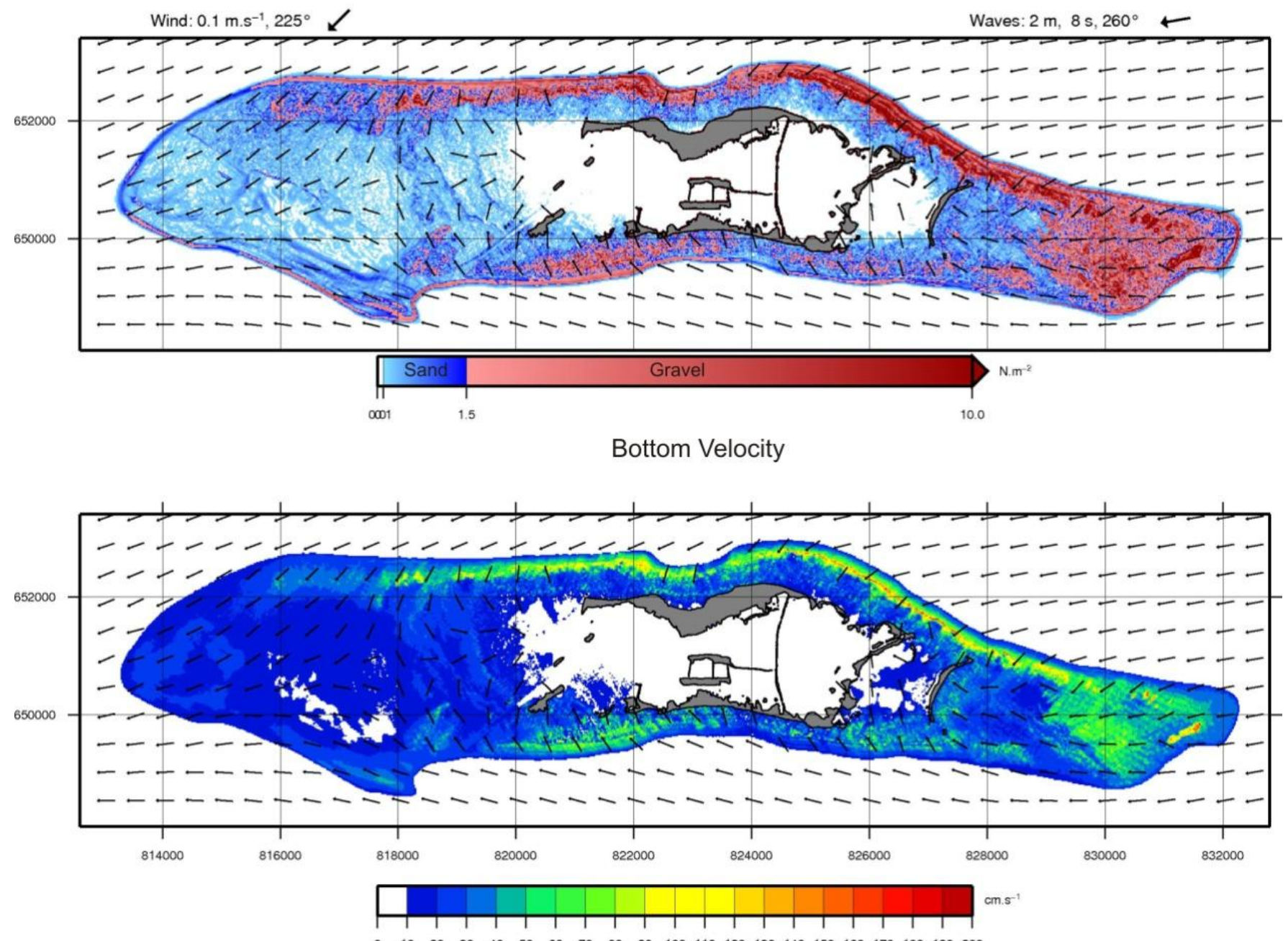

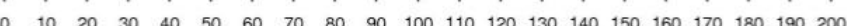


(B) Summer swell conditions

Wave-induced Shear Stress
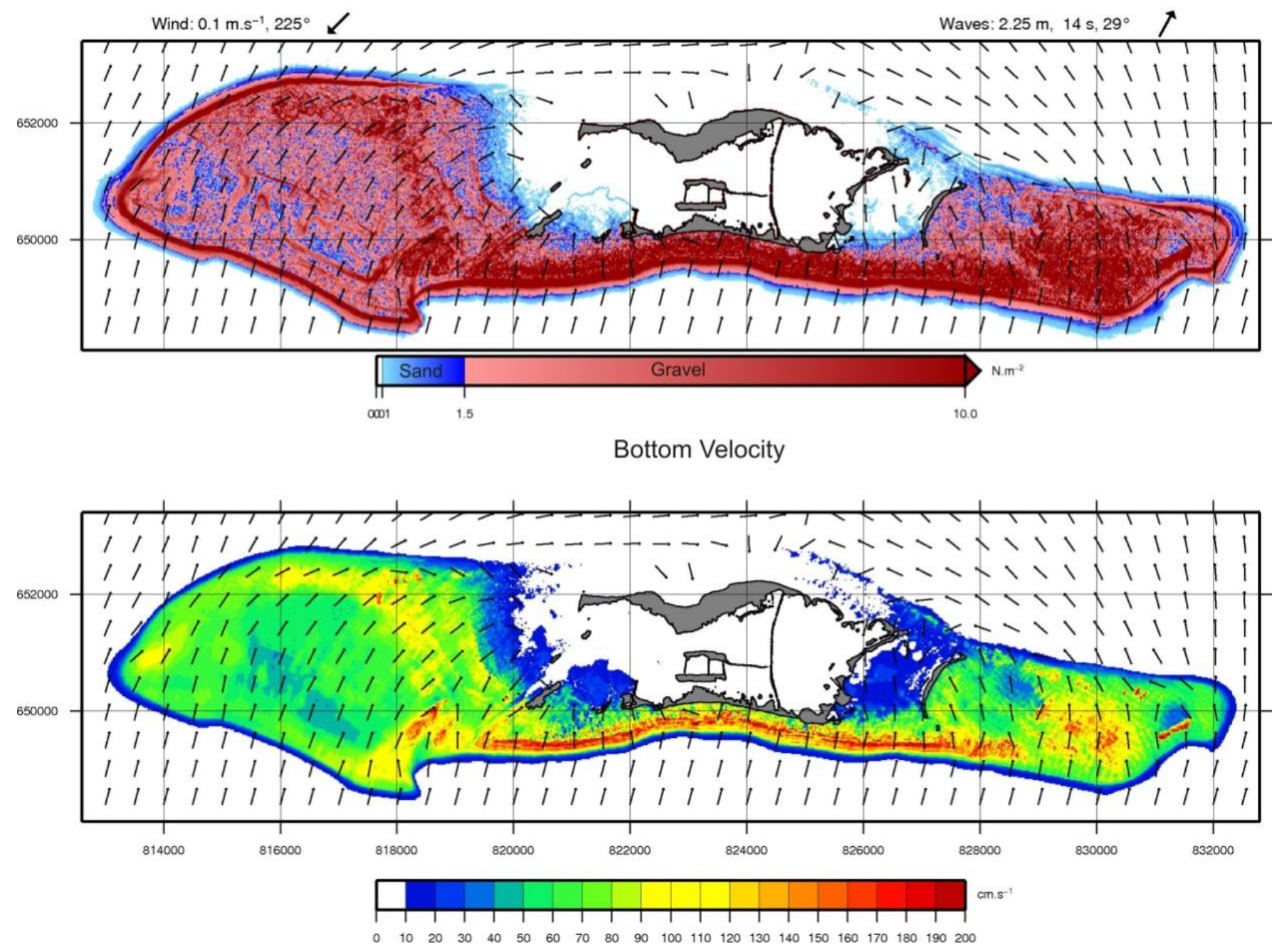
(C) Winter trade wind conditions

Wave-induced Shear Stress

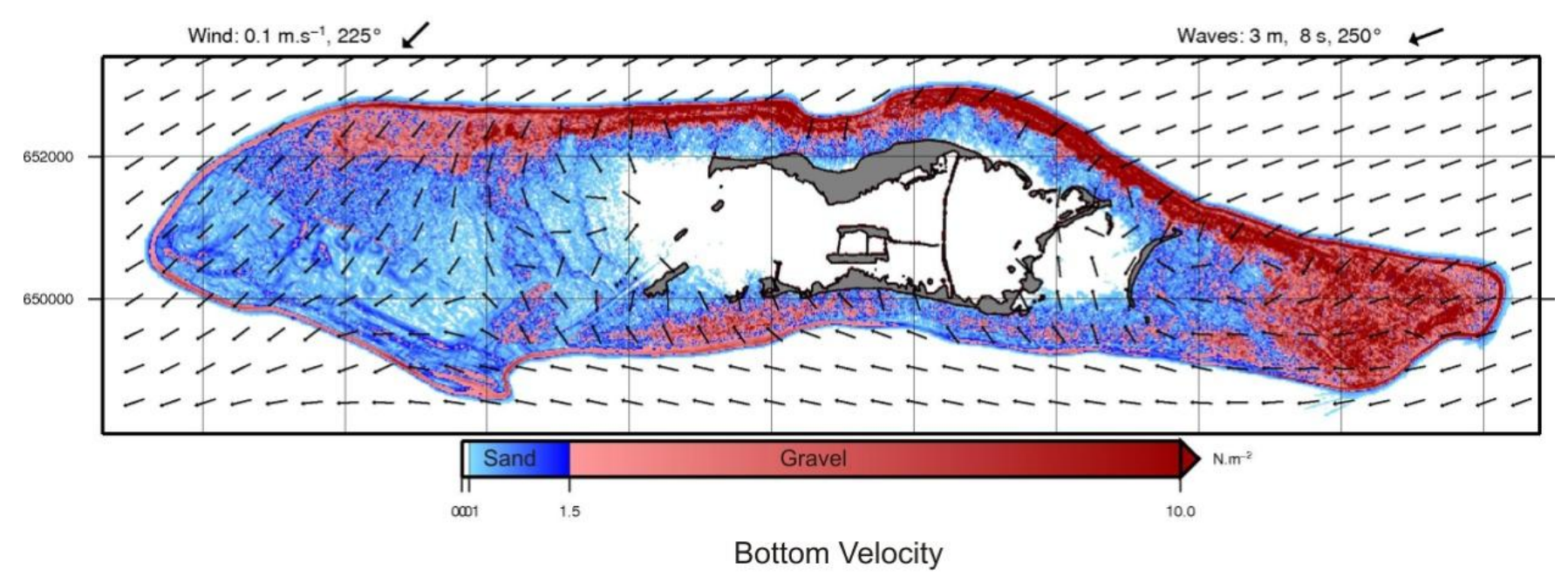

Bottom Velocity

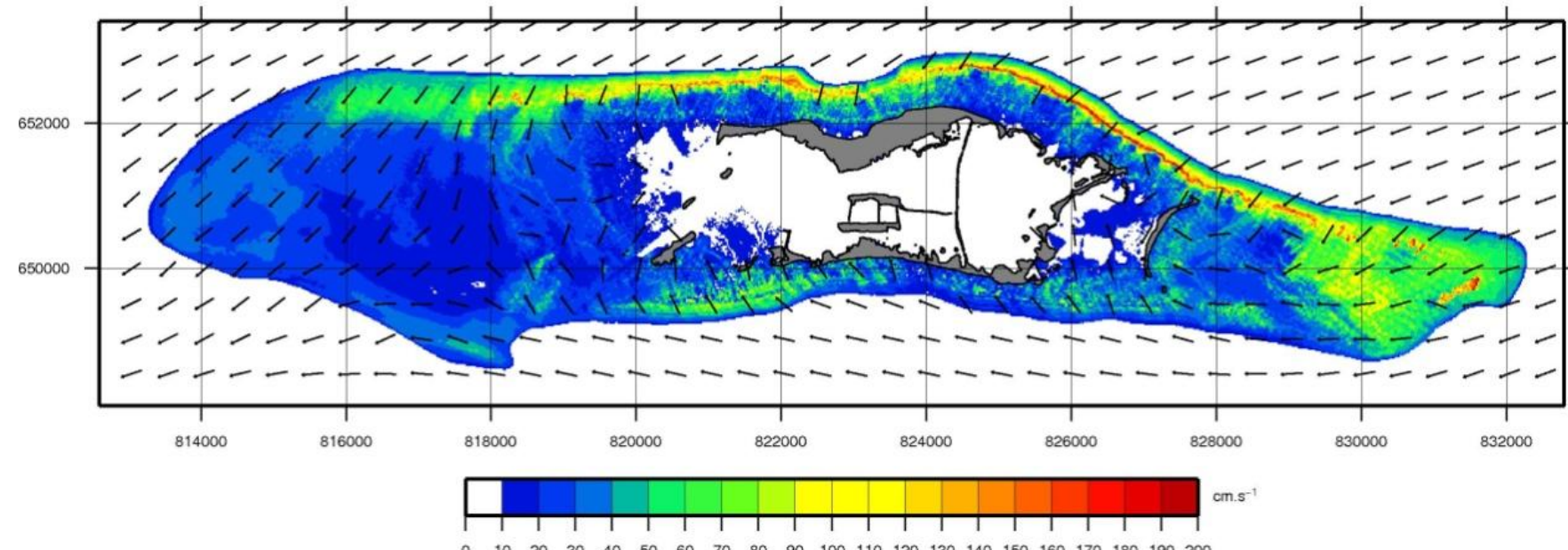


(D) Winter swell conditions

Wave-induced Shear Stress
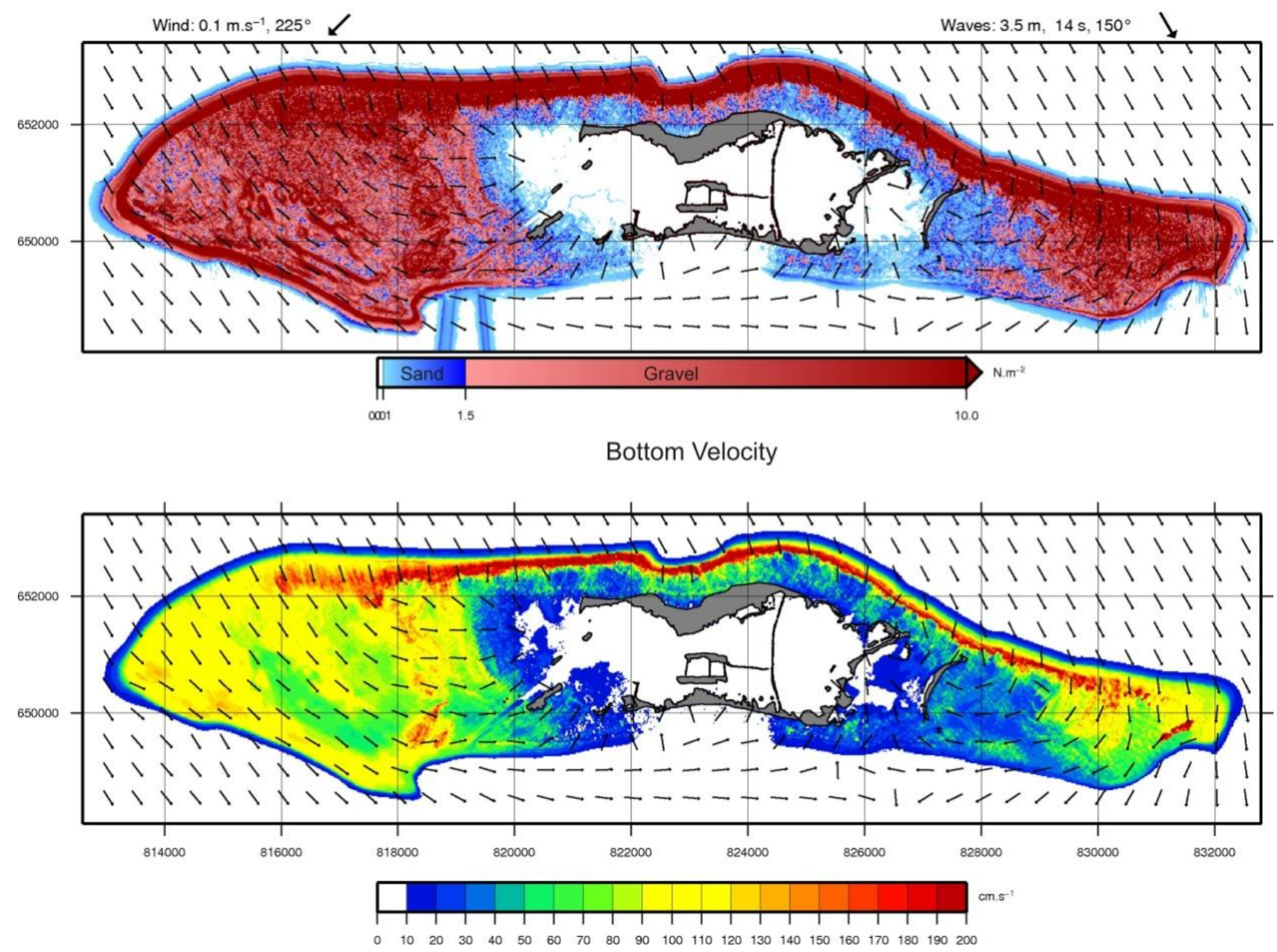
(E) Cyclone Ekeka conditions

Wave-induced Shear Stress
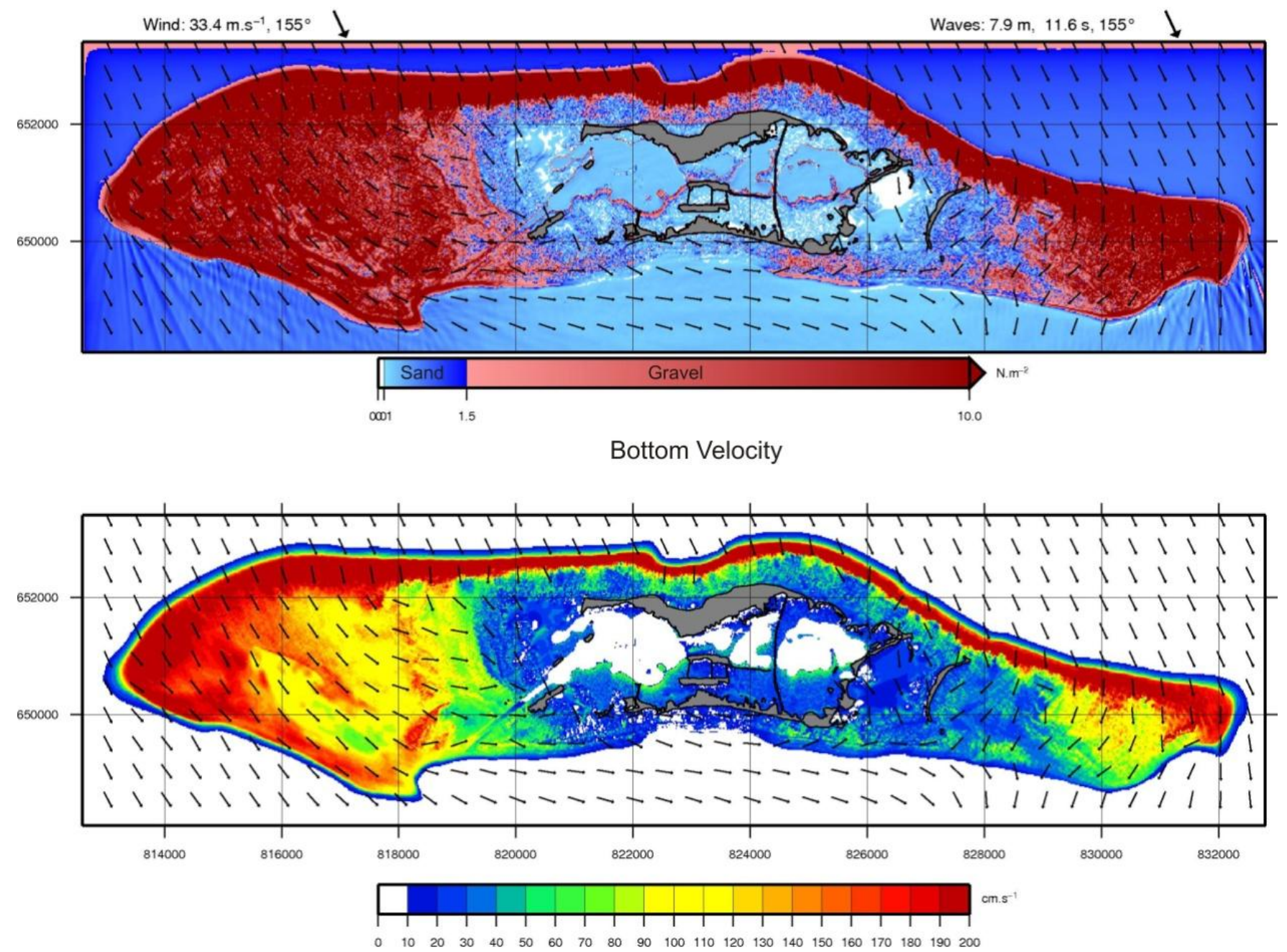
(F) Summer trade wind conditions

$1 \mathrm{~m}$ sea level rise

Wave-induced Shear Stress
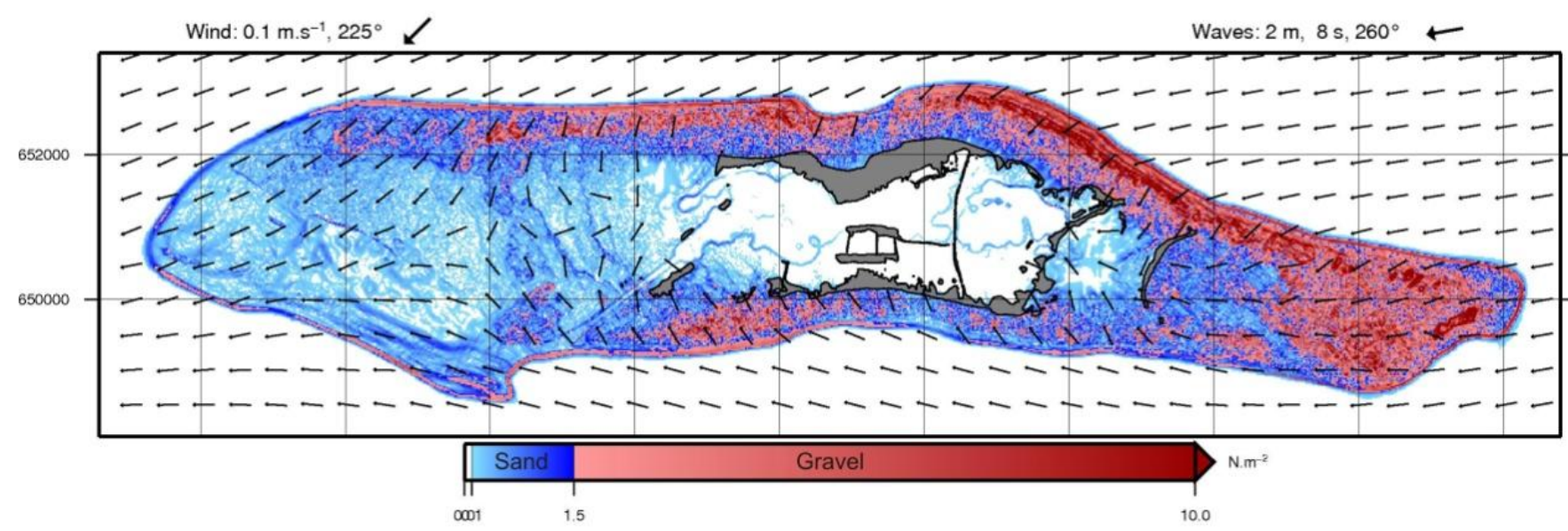

Bottom Velocity

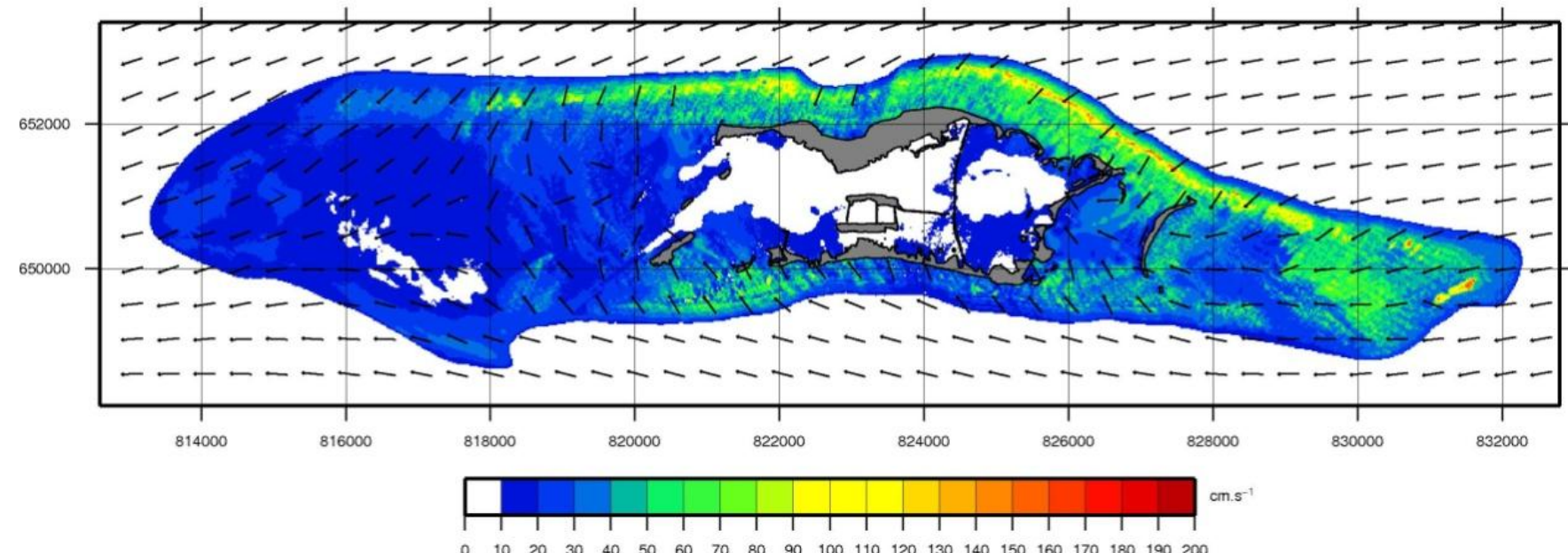


(G) Winter swell conditions

$1 \mathrm{~m}$ sea level rise

Wave-induced Shear Stress

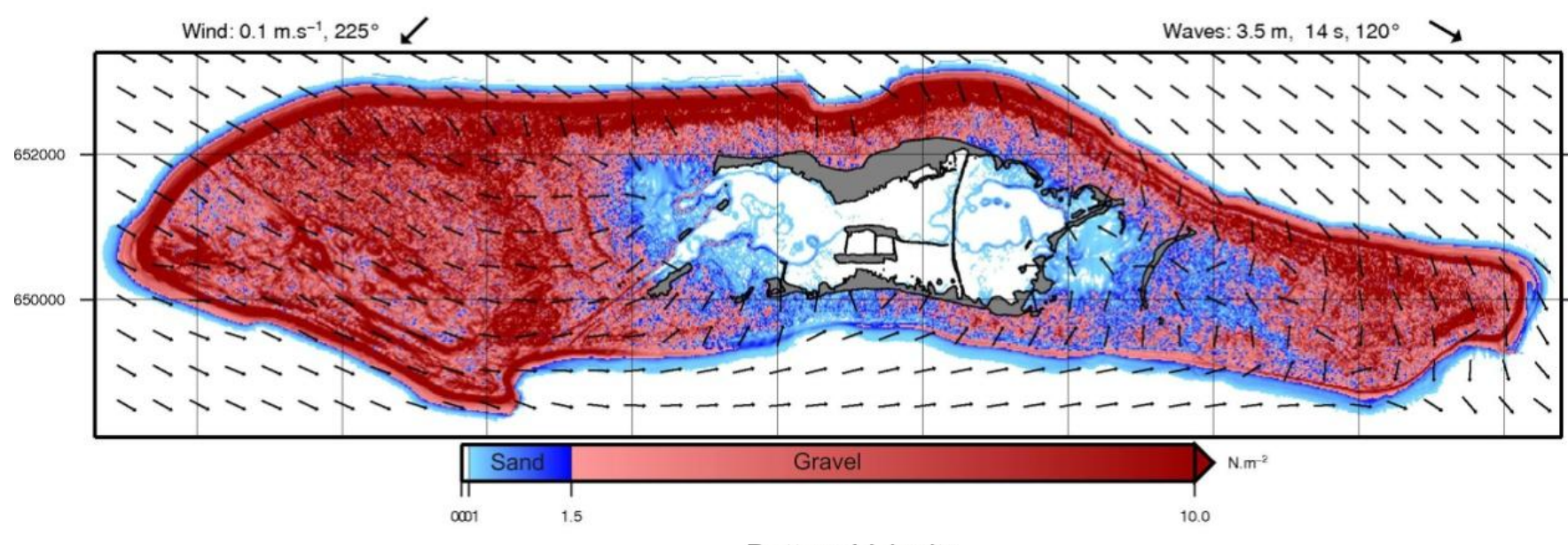

Bottom Velocity

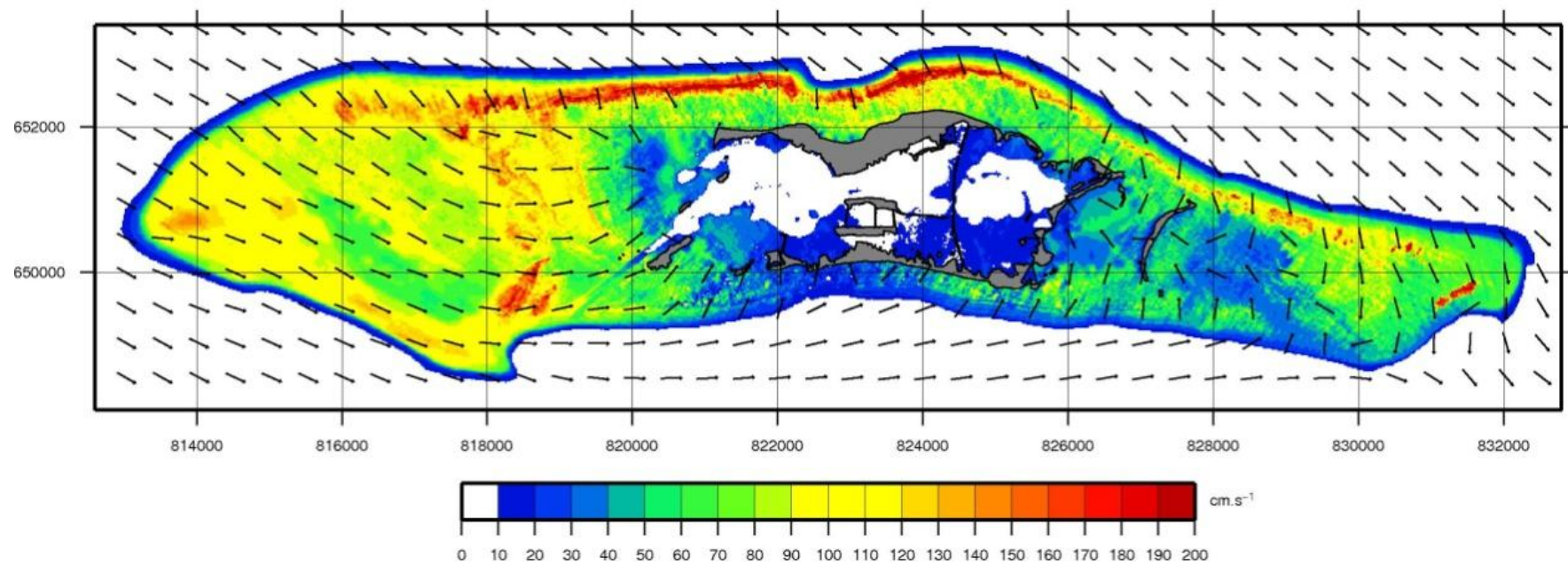




\subsection{Justification of SWAN}

The SWAN wave modelling programme has been quantitatively assessed by Ris et al. (1999), and shown to be able to account for shoaling, refraction, generation by wind, white capping, triad and quadruplet wave-wave interactions, and bottom and depth-induced wave breaking. However, the programme may not accurately predict the wave run-up and set-up over atoll reef edges because it is primarily designed for continental shelves. To assess the accuracy of the application of the SWAN wave model to Palmyra Atoll, modelled conditions are here compared to the limited modern data and observations.

Comparison to the modern environment at Palmyra was achieved by comparing wave height and direction, and the distribution of modern, unconsolidated sediment on the atoll. The distribution of sediment is the most comprehensive approach to validation of the model because there are only very limited records and anecdotal evidence of wave data.

\subsubsection{Wave height and direction}

The only wave records available from Palmyra, in addition to personal, unquantified observations, are short-term records taken near Strawn Peninsula and the lagoon side of the boat channel (pers. comm, G. Dunbar). These are both at the western end of West Lagoon, which receives the maximum fetch developed in the lagoons due to the easterly trade wind. These data show maximum significant wave heights less than $0.2 \mathrm{~m}$ which, when compared to the plots of modelled wave height (Fig. 8.3), suggests adequate correlation between modelled and observed conditions.

Comparisons can also be drawn between the areas and magnitude of breaking waves on the reef edge. Images from both IKONOS satellite and Google Earth were compared to the plotted results of the SWAN wave modelling for low wave conditions during the summer trade wind events (Fig. 8.4). These show that the modelled conditions match the locations of the observed wave breaking in both satellite images. Personal observations at Palmyra show similar agreement. 


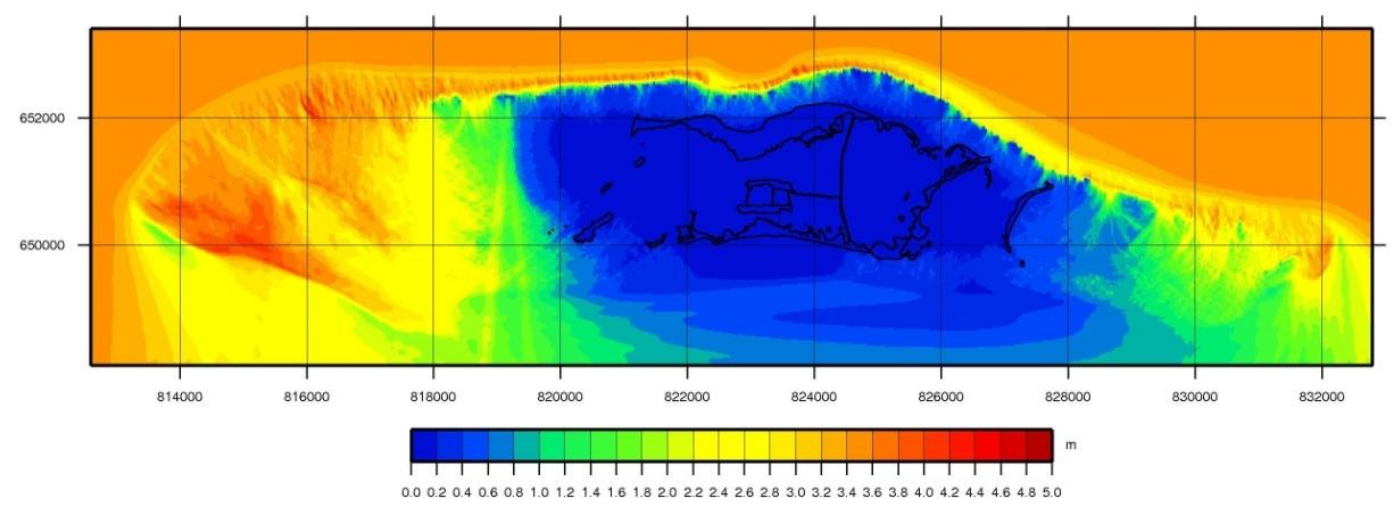

Figure 8.3: Significant wave height across the reef at Palmyra Atoll at high tide during winter storm swell conditions.

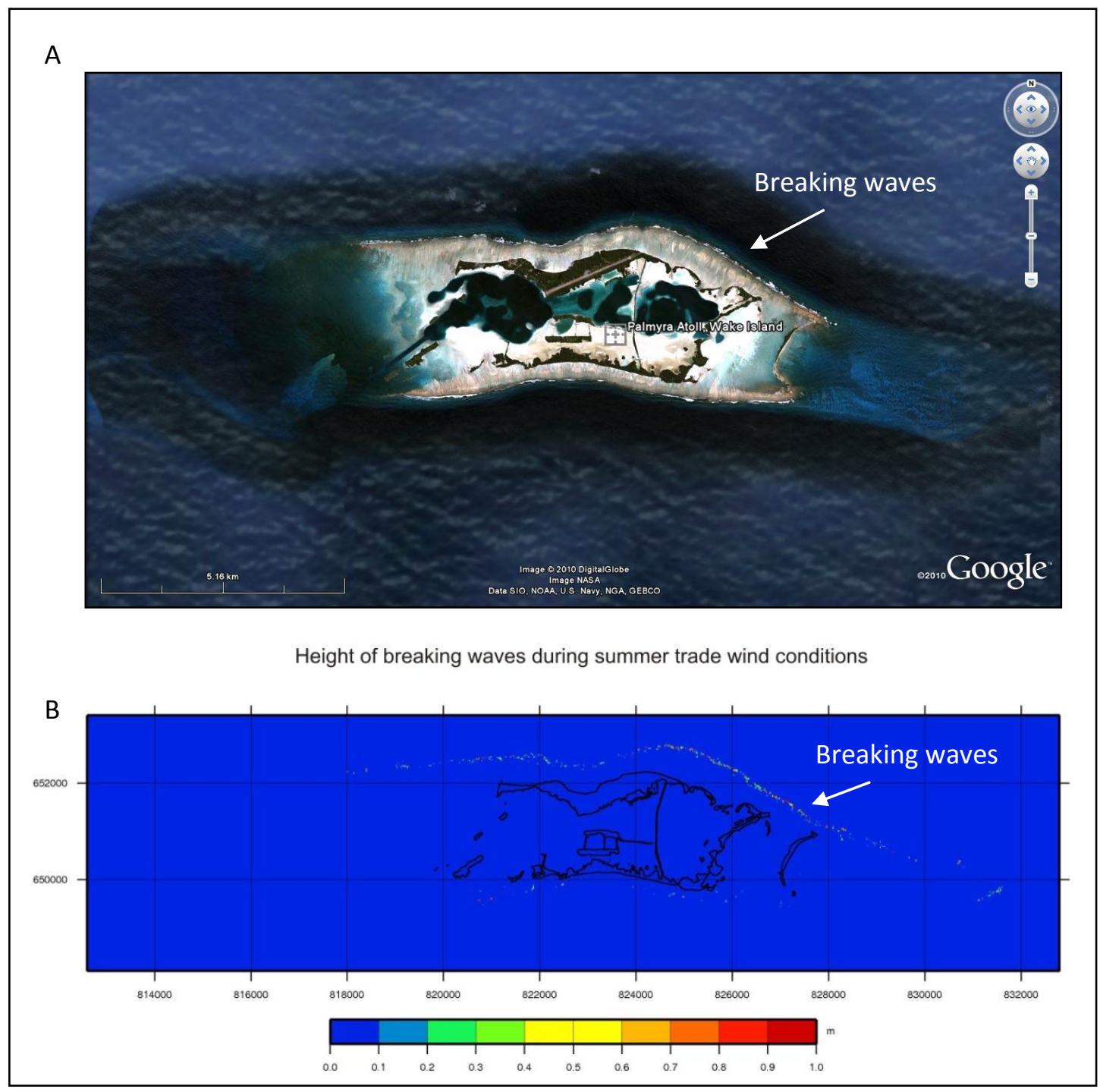

Figure 8.4: (A) A satellite image taken by Google Earth of Palmyra Atoll on the $21^{\text {st }}$ of June, 2009. This shows where waves are breaking during summer trade wind conditions. (B) Plot of the height of breaking waves as calculated by SWAN for summer trade wind conditions, which matches observed conditions. 


\subsubsection{Wave energy and deposits}

The shear stress results modelled by SWAN are in good agreement with the distribution of modern sediment at Palmyra. Observations around the coastline of the atoll today show that there the south coast is often exposed to considerable wave energy, as evidenced by the modern, un-cemented deposits of large coral and shell on the beaches and inland on the edges of vegetation. Also noteworthy are the effects on the bunkers and other large concrete structures built in the 1940s. For example, a bunker situated on the beachrock outcrop of Paradise Island has significant amounts of coarse reefal debris within it (Fig. 8.5). The only opening for entry of this is approximately 1.5 $\mathrm{m}$ above the reef flat. Therefore, there must have been wave events within the past 70 years that were large enough to transport coarse material of this size into the bunker.

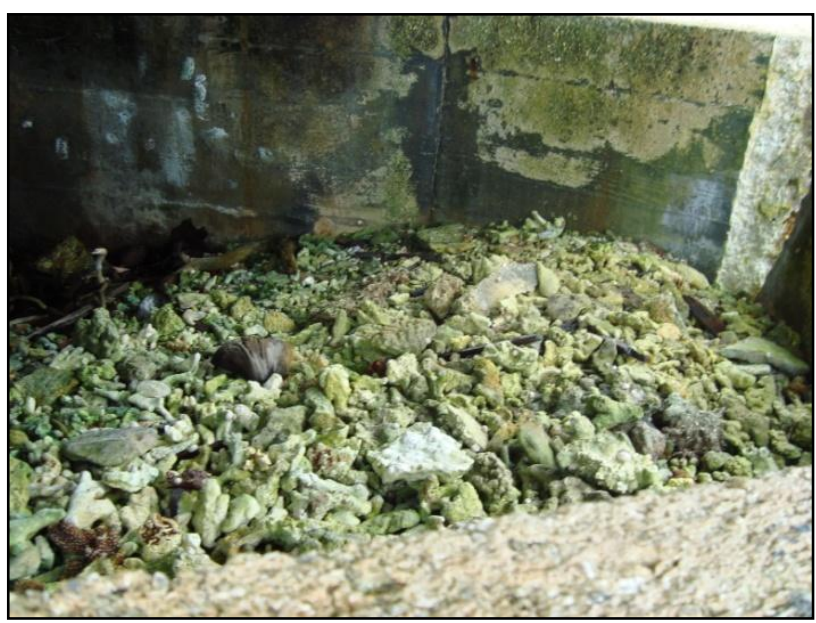

Figure 8.5: Reefal debris found inside an abandoned bunker on Paradise Island, south coast of Palmyra Atoll

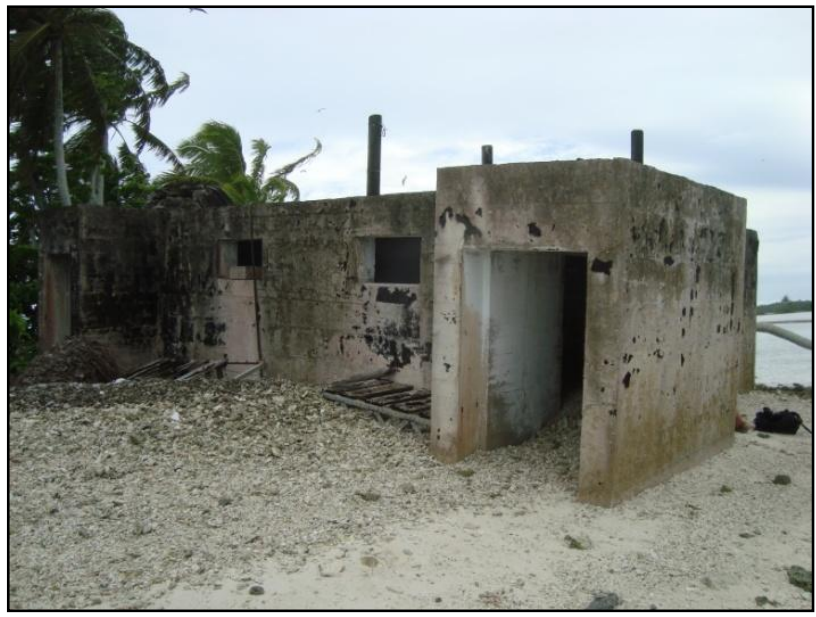

Figure 8.6: A concrete building that was originally constructed in the centre of Home Island now sits on the southern beach and is filled with poorly sorted reefal deposits. 
Similarly, a large concrete structure on the south-eastern end of Home Island (Fig. 8.6) is tilted significantly, as well as also being filled with coarse reefal sediment. Home Island is an unpinned cay, which has migrated northward since the structure was built. Moving sediment from underneath the structure, causing the tilting, and exposure on the coast, would require large energy events on the south coast. A nearby five-inch gun platform on the south-western end of Home Island is now completely disconnected from the island, while another has collapsed from its once high position $(\sim 3 \mathrm{~m})$ on a built platform on the island due to erosion on the southern face. These observations of high energy events on the south coast fit with the results from SWAN model, in that today there can be large wave-induced energy exerted nearer to the southern shoreline in comparison to the north coast.

One of the major accumulations of sand on the outer coast of Palmyra Atoll occurs at North Beach, which was created during the modifications of Cooper Island (Chapter Three). In recent years, the area has been accreting at a rate in excess of $1 \mathrm{~m}$ per year (Collen et al., 2009a). If any significant shear stress was able to be exerted on this area during the annual storm swell events, then it would be washed clean of sand and fine particles on a regular basis. However, the results of the SWAN modelling show that even under significant winter storm swell events little wave-induced bed shear stress is able to affect this area, thus validating the SWAN results and emphasising the ability of the reef flat to dissipate wave energy. This also highlights the critical limit to which the islets can accrete towards the reef edge before the wave energy becomes too great for any sediment to be deposited, cement and thus stabilise islands. Overall, this demonstrates that substantial sediment accumulation can only occur once sufficient dissipation of wave energy from the wave energy has occurred.

Other important areas for examination are Barren Island and the lagoons. The bottom sediments in the lagoons of Palmyra consist largely of sand, silt and mud size particles. Therefore, a good measure of the model is to test under what conditions this sediment is moved, since little shear stress is required for the transport of fine sediment. None of the four average wave climates have sufficient force to propagate inland in order to move this sediment, due to the roughness of the outer reefs dissipating wave energy and the significant sheltering effect of the reef islets. Barren Island, today, is frequently exposed to large wave-induced shear stress, which is a result of bed shear stress that is not completely dissipated across the Eastern Terrace. As described in Chapter Nine, the sediment on Barren Island ranges from coarse sand in the intertidal 
zone to large clasts of coral (mostly Acropora spp.) on the ridge top and down the leeward side. The coarse sand within the normal tidal range is consistent with the normal energy exerted in the area, whereas the larger clasts require greater than normal wave events in order to be deposited.

\subsection{Summary}

Overall, the SWAN wave model is sufficiently accurate, for the purposes of this study, when applied to an oceanic atoll setting despite inherent limitations and uncertainties pertaining to the input data for the model. The results show that the reef at Palmyra is regularly exposed to relatively high energy on the sea bed from both oceanic and locally-generated waves. However, the friction factors employed in this study causes most energy from the waves breaking on Palmyra to be dissipated before it can reach the present coastline. As a result, the shallow areas of reef flats are relatively inert for most of the year except during storm events, whereas the deeper reef terraces are regularly washed clean of sand and gravel.

Global hindcast data were primarily used in this study due to the lack of long term wind and climate data for Palmyra. However, these are significant to the understanding of the wave regime in the equatorial Pacific because they highlight wave events that are not due to local wind. The differences between the wind and wave regimes at Palmyra are illustrated in Figures 7.6 and 3.6. These show that although the high frequency, low energy waves are related to the constant easterly trade winds at Palmyra, the storm swell conditions are not recorded in the wind records. This highlights both the importance of detailed climate records and the risk of only assessing one climate parameter.

Results from an investigation of the impact of the wind regime at Palmyra suggest locally-generated wind effects should be ignored because they have a minor effect on the overall wave regime. At Palmyra, wind has a very small effect during relatively calm conditions $( \pm 0.1 \%$ of reef area across which sediment of a given size can be moved) and an even smaller effect during swell conditions ( $\pm 0.01 \%)$.

Throughout an average year a variety of wave climates are experienced at Palmyra. In trade wind conditions the movement of sediment less than $1 \mathrm{~cm}$ in diameter occurs over $50-60 \%$ of the reef, whereas clasts up to $20 \mathrm{~cm}$ in size can be transported 
over only $5-11 \%$ of the reef. During storm swell conditions, the area of sediment movement for any particular clast size increases by at least 10\%. For instance, sediment $1 \mathrm{~cm}$ in diameter is moved over about $70-77 \%$ of the reef during a swell event, and sediment up to $20 \mathrm{~cm}$ can be moved over approximately $21-32 \%$ of the reef.

Results from modelled extreme events are important because it is under these events that there is the largest increase of energy across the entire computational grid, and therefore, a corresponding ability to transport large clasts over a significantly larger portion of the reef. However, modelling also shows that the reef flats are extremely efficient at dissipating wave energy because there still remains a significant portion of landward edge of the reef flat that is sheltered from these extreme wave events. It is important, as well, to note the effect of a rise of sea level. Even though this does not increase the actual amount of energy exerted on the reef in any given area, a rise in sea level allows wave energy to propagate further across the reef flats and terraces than occurs at the modern high tide level. Therefore, to move gravel sized sediment on the shoreline of the reef islets, large wave conditions must be coupled with a high sea level in order to propagate high energy across the reef flat. 


\section{Associated atoll processes}

Many processes influence the sedimentology on dynamic and fluctuating reef islands, and a key driver of this change is sediment supply and the production of sediment on the reef. This chapter primarily discusses a model of sediment production for the reef at Palmyra. Additionally, although the hydrodynamics of the depositional environment and sediment transport are largely being studied through the use of the SWAN wave model, the directions of the wave energy during periods of beachrock formation have also been studied by analysis of the orientation of the clasts within the beachrock outcrops. The importance of biological erosion is also discussed here.

On small, low-lying atolls, the only source of sediment is biogenically-produced calcium carbonate on the reef. The production of such sediment depends on factors including the wave energy environment, the health of the organism and its morphology and mechanical strength, and the activity of biological agents. Although the framebuilding processes are important to the overall growth of the reef platform, the $\mathrm{CaCO}_{3}$ sediment budget primarily concerns carbonate sediment that is produced through physical, and biological, erosion and subsequently dispersed from the reef by currents and waves (Stern et al., 1977). The main agent for the mechanical production of sedimentary particles is wave energy, particularly during storms, which can produce material ranging in size from coarse rubble to fine sand and suspended particles (Stern et al., 1977). Additionally, organisms that bore into or graze skeletons (e.g. parrot fish; Bellwood, 1995) also produce finer sediments, as well as contributing to the mechanical weakening of the coral. Overall, reef carbonate mass-balance is described by Land (1979) using:

Gross Production $(G)\left[\mathrm{kg}\left(\mathrm{CaCO}_{3}\right) m^{-2} \mathrm{yr}^{-1}\right]=$ Net Accumulation + Sediment Removed Eq. 9.1

where the gross production refers to kilograms of $\mathrm{CaCO}_{3}$ produced per square meter of reef per year. The gross carbonate production can also be described by the following equation:

$$
G=0.01 \times \sum(\mathrm{P} \% \text { cover }) g\left(\mathrm{CaCO}^{3} / \mathrm{m}^{2}\right) / \text { year }
$$

This equation describes the gross production obtained by summing the product of the potential production $(\mathrm{P})$ of each organism in a given reef habitat, multiplied by 
the proportion of reef area covered by the organism (Chave et al., 1971). For the purposes of the present study, the focus is on the gravel transported to the shoreline by mechanical processes, rather than the chemical and biological loss of $\mathrm{CaCO}_{3}$ from the reef.

This study is largely concerned with the biogenic gravel clasts, which are representative of the beachrock components. The sources and mechanisms of gravel supply to carbonate beaches in general have been well documented (e.g. Stern et al., 1977; Blanchon et al., 1997; Harney and Fletcher, 2003). The processes most cited in the literature involve fluvial input, storm mobilization of shallow nearshore sources, sea cliff erosion, reworking or earlier raised gravel beaches, and redistribution along the beach by strong longshore currents. Most of these require a terrestrial sediment source, and the only processes likely to affect the sediments at Palmyra Atoll are storm mobilization and longshore currents. The latter have been examined by Collen et al. (2009a, 2009b) and are important to the distribution of sediment to the west.

\subsection{Sediment production and supply}

\subsubsection{Sediment supply}

All biogenic sediment on Palmyra Atoll has grown, died and been transported across the reef before being deposited on the shoreline and incorporated into the beachrock. Therefore, it is important to understand the production of $\mathrm{CaCO}_{3}$ on and around the island. This mostly takes place on the submerged reef through growth of coral, algae, foraminifera, molluscs, and other organisms. At Palmyra Atoll the main areas are the large reef terraces, as well as smaller areas on the northern and southern reef edges (Maragos, 1987; Williams et al., 2008).

To understand the sediment budget, the production of biogenic sediment over Palmyra's $60 \mathrm{~km}^{2}$ of reef must be understood. The amount of sediment produced over a given area of reef is determined by the sum of the growth rates of the carbonateproducing organisms present, which are dominantly coral, calcareous red algae, and other frame-building organisms. Coral productivity in turn is dependent on the species of coral and its morphology, which are controlled by the environment. As a result, 
different areas of the reef have differing growth rates, and therefore variable rates of carbonate production.

\subsubsection{Carbonate growth zonation}

The distribution, health and productivity of corals at Palmyra is currently the subject of a number of studies (e.g. Williams et al., 2008; Williams et al., 2010) and is not well enough known to allow an precise understanding of sediment production. Therefore, the carbonate production model for Palmyra devised here is based on the notional atoll reef described by Hopley (1987) and the associated production rates from Hopley (1996). The zonation used here is similar to reef zones described by other authors (e.g. Stern et al., 1977; Chave et al., 1971), which are the most appropriate estimates for oceanic reefs. For the purposes of this work, the sandy areas within the lagoons at Palmyra are not considered a significant source of calcium carbonate $(0.8$ $\mathrm{kgm}^{-2} \mathrm{yr}^{-1}$; Smith and Kinsey, 1976) as there is very little coral there. Instead, the outer reef flats and terraces are important as they are the major sources for sediment at Palmyra Atoll. Bulk density used for the sediment is $1.48 \mathrm{gcm}^{-3}$, which is an average of the density of the coral facies $\left(1.4 \mathrm{gcm}^{-3}\right)$ and the coralline algae facies $\left(1.56 \mathrm{gcm}^{-3}\right.$; Harney and Fletcher, 2003; Stern et al., 1977).

These data highlight the importance of the two reef terraces in terms of the annual carbonate production. Under ideal conditions with 100\% coral coverage, corals can produce over $10 \mathrm{kgm}^{-2} \mathrm{yr}^{-1}$ of $\mathrm{CaCO}_{3}$ (Chave et al., 1971) which, assuming a porosity of $50 \%$, is equal to $7-70 \mathrm{~mm} / \mathrm{yr}$ of upward growth (Buddemeier and Smith, 1988). The estimated areas (Fig. 9.1), average production rates and average amounts of annual biogenic production are given in Table 9.1.

The $\mathrm{CaCO}_{3}$ production zonation map illustrated in Figure 9.1 is an estimation based upon zones determined for other reefs, productivity relates to the benthic reef habitat that has also been taken into consideration when procuring this map. Zonation of the map is in agreement with the benthic habitat map for Palmyra (http://ccma.nos.noaa.gov/products/biogeography/biomapper/biomapper.html?id=Pa lmyra), which was released while this thesis was being published. 

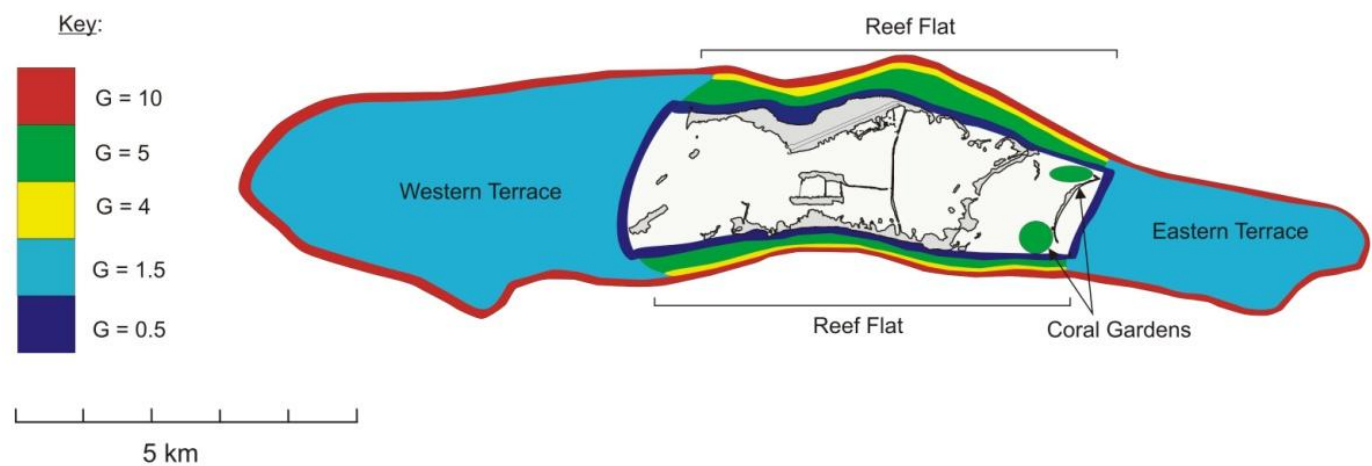

Figure 9.1: Map of Palmyra Atoll and the surrounding reef showing the different zones of estimated calcium carbonate production rates, expressed in $\mathrm{kg} \mathrm{m}^{-2} \mathrm{yr}^{-1} . \mathrm{G}=$ growth rate $\left(\mathrm{kg} \mathrm{m}^{-2} \mathrm{yr}^{-1}\right)$. Areas of little to no calcium carbonate production are represented by white.

Table 9.1: Zones of calcium carbonate growth and their associated growth rates from Hopley (1996), which have been here applied to Palmyra Atoll due to the lack of direct measurements. Area dimensions were estimated using Google Earth.

\begin{tabular}{lclc}
\hline Growth zone & Growth rate & Area at Palmyra & $\begin{array}{c}\text { Estimated area } \\
\left(\mathbf{k m}^{2}\right) \mathbf{a t} \text { Palmyra }\end{array}$ \\
\hline Outer rim & $10 \mathrm{~kg} \mathrm{~m}^{-2} \mathrm{yr}^{-1}$ & $65 \mathrm{~m}$ rim around atoll & 3.57 \\
Submerged terraces & $1.5 \mathrm{~kg} \mathrm{~m}^{-2} \mathrm{yr}^{-1}$ & $\begin{array}{l}\text { Eastern and Western } \\
\text { reef terraces }\end{array}$ & 28.99 \\
Algal ridge & $4 \mathrm{~kg} \mathrm{~m}^{-2} \mathrm{yr}^{-1}$ & $\begin{array}{l}\text { Outer edge of northern } \\
\text { and southern reef flats }\end{array}$ & 0.8 \\
Coral-algal zone & $5 \mathrm{~kg} \mathrm{~m}^{-2} \mathrm{yr}^{-1}$ & $\begin{array}{l}\text { Middle portion of reef } \\
\text { flats }\end{array}$ & 1.35 \\
Rubble and sand zone & $0.5 \mathrm{~kg} \mathrm{~m}^{-2} \mathrm{yr}^{-1}$ & Bordering the outer \\
& & edge of reef islands and \\
& & lagoons & 0.2 \\
\end{tabular}


Optimum production of calcium carbonate is restricted to the outer edges of the reef as a significant amount of material is transported landward during high energy storm or swells events (Hopley, 1996). This area includes the seaward slope, which rises steeply to the reef front of living corals near the LTL (Hopley, 1996), and defines a rim approximately $65 \mathrm{~m}$ wide around the atoll to a depth of $30 \mathrm{~m}$, which produces an of average $10 \mathrm{~kg} \mathrm{~m}^{-2} \mathrm{yr}^{-1}$.

Furthermore, the most important areas for sediment production at Palmyra are the eastern and western reef terraces, which are expansive, relatively shallow $(<30 \mathrm{~m})$ areas that are covered with large colonies of various coral species. During a survey in 2007 a total of 84 coral species/morphological groups representing 31 genera were recorded at Palmyra (Williams et al., 2008). The terraces are assumed to have a comparatively slow overall growth, aside from the high growth rim, due to recent stability of sea level and to produce on average $1.5 \mathrm{~kg} \mathrm{~m}^{-2} \mathrm{yr}^{-1}$. However, the actual production rates across the terraces are likely to be highly variable and there may be local areas of very high productivity that are important to the sediment production.

The reef flats are a dominant feature on the northern and southern shores of Palmyra, and also represent some of the most complicated production zones in atoll settings (Hopley, 1996). Four zones of varying productivity, including the high productivity edge, have been identified at Palmyra in the relatively short distance from reef edge to the shoreline. Shoreward from the high productivity edge is a zone comprising the thin algal ridge, before the coral-algae zone. Beyond this is the innermost rubble and sandy reef flat zone, which is normally intertidal and extends to the base of the beach. This area is dominated by sediment deposition and may occasionally contain cemented deposits (Hopley, 1996) and, as such, productivity is very low. This zone is also used to describe the areas at the edge of the lagoons.

These areas of reef production have been estimated for Palmyra from scaled satellite images and bathymetry. Applying the production rates describe above, the reef system at Palmyra Atoll produces approximately 91500 tonnes of calcium carbonate each year, giving an average rate of $2.33 \mathrm{~kg} \mathrm{~m}^{-2} \mathrm{yr}^{-1}$ (Table 9.2). This remains only an estimate of the $\mathrm{CaCO}_{3}$ produced biogenically at Palmyra, not a direct measurement of the sediment produced each year. The amount of $\mathrm{CaCO}_{3}$ sediment produced depends on the growth of the coral, the amount of bioerosion (especially the dominance of grazers such as fish), and the physical environment. Furthermore, although corals are 
usually mechanically strong (Madin, 2005), they become susceptible to mechanical erosion when weakened or diseased.

Published average carbonate production rates for other regions range from 0.91 $\mathrm{kg} \mathrm{m}^{-2} \mathrm{yr}^{-1}$, for Cane Bay in St Croix (Hubbard et al., 1990) to $8.9 \mathrm{~kg} \mathrm{~m}^{-2} \mathrm{yr}^{-1}$ for protected leeward settings in Barbados (Stern et al., 1977). However, the value calculated here for Palmyra Atoll is very similar to rates calculated for the Tiahura reef in French Polynesia (average $2.5 \mathrm{~kg} \mathrm{CaCO} \mathrm{m}^{-2} \mathrm{yr}^{-1}$; Chazottes et al., 1995). The proportion of this which becomes sediment, as well as the proportion of sediment that remains on the atoll rather than being transported into deeper waters, remain unquantified for Palmyra. However, Harney and Fletcher (2003) show that only 5\% of carbonate sediment over 5,000 years produced on the reef at Kailau Bay, Oahu is stored on the beach. A further $19 \%$ is stored in holes and reef channels in the bay and the majority (51\%) accumulates on the coastal plain.

Table 9.2: Simplified model of calcium carbonate production at Palmyra using the model of reef productivity of Hopley (1996)

\begin{tabular}{|c|c|c|c|}
\hline Area (see Fig. 9.1) & Size $\left(m^{2}\right)$ & $\begin{array}{c}\text { Average production } \\
\text { rate }\end{array}$ & $\begin{array}{c}\text { Annual amount } \\
\text { produced }\end{array}$ \\
\hline Eastern Terrace & $8.77 \times 10^{6}$ & $2.22 \mathrm{kgm}^{-2} \mathrm{yr}^{-1}$ & 19430 tyr $^{-1}$ \\
\hline Western Terrace & $2.2 \times 10^{7}$ & $2.19 \mathrm{kgm}^{-2} \mathrm{yr}^{-1}$ & 48235 tyr $^{-1}$ \\
\hline Reef Flats & $8 \times 10^{3}$ & $2.76 \mathrm{kgm}^{-2} \mathrm{yr}^{-1}$ & 22120 tyr $^{-1}$ \\
\hline Coral Gardens & $3.1 \times 10^{5}$ & $5 \mathrm{kgm}^{-2} \mathrm{yr}^{-1}$ & $1564 \operatorname{tyr}^{-1}$ \\
\hline Total & $3.9 \times 10^{7}$ & $2.33 \mathrm{kgm}^{-2} \mathrm{yr}^{-1}$ & 91349 tyr $^{-1}$ \\
\hline
\end{tabular}

\subsection{Clast-orientation and paleo-flow estimation}

Paleocurrent direction derived from beachrock deposits provide additional understanding on the source of the sediment as well as adding to energy parameters at the time of deposition. Klein (1967, in Selley, 1968) emphasised that paleocurrent patterns recorded in ancient shoreline sediments are rarely unimodel and may bear no relation to paleoslope. Under strong wave energy conditions rods of Acropora clasts 
tend to roll across the bottom but, in the swash zone on beaches, they align normal to the direction of the wave action. In shoreline deposits, bi-polar axes coincide with the axes of alternating currents (Selley, 1968).

As described in Chapter Four, paleocurrent analysis using clast orientation was undertaken for several beachrock beds at three locations (Cooper, Paradise and northern East island outcrops) were selected during field work as they appeared to show orientated clasts on an outcrop scale, as well as the debris platforms found along Barren Island. The debris platforms on Barren Island (Fig. 9.2) were chosen for similar reasons but also because they are unconsolidated material that, although not cemented, has formed solid platforms where little movement of clasts occurs. Therefore, the Barren Island sediments can be treated as a control that is in equilibrium with the modern environment and thus highlights the relationship between currents and clast orientation. The platforms on Barren Island are thought to have formed as the island grew and were supplied with sediments onto and across it from the Eastern Terrace. As the island continued to grow, it reached a height where these platforms were cut off from the effects of the easterly wave energy.

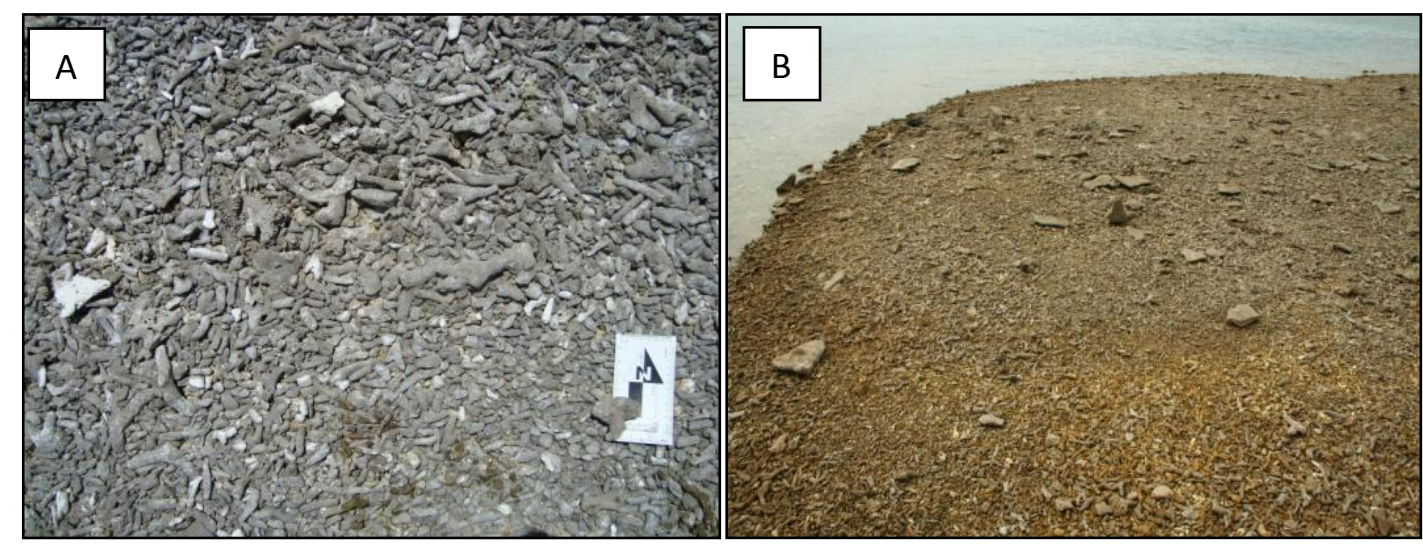

Figure 9.2: A) Debris platform on the leeward side of Barren Island. B) Oblique photograph showing alignment of unconsolidated clasts on the Barren Island debris platform.

The Cooper Island beachrock site is a complex outcrop (Chapter Six) and two separate units were surveyed here. The first is the unit of beachrock at the back of the outcrop, which is comprised of small, well sorted Acropora clasts (Fig. 9.3A). The other bed is a much coarser bed in the middle of the outcrop, more poorly sorted but still appearing to demonstrate a preferential orientation of clasts. The Paradise Island site (Fig. 4.1) also contains numerous beds of which four were analysed to show any change or difference over time. The first bed is the oldest and was surveyed where it has been exposed by erosion it on the western side, near the base of the bunker (Fig. 9.3B). The 
other beds overlie it through the outcrop. The northern East Island outcrop is an extensive area of eroded beachrock beds and a similar approach was taken as for Cooper Island.

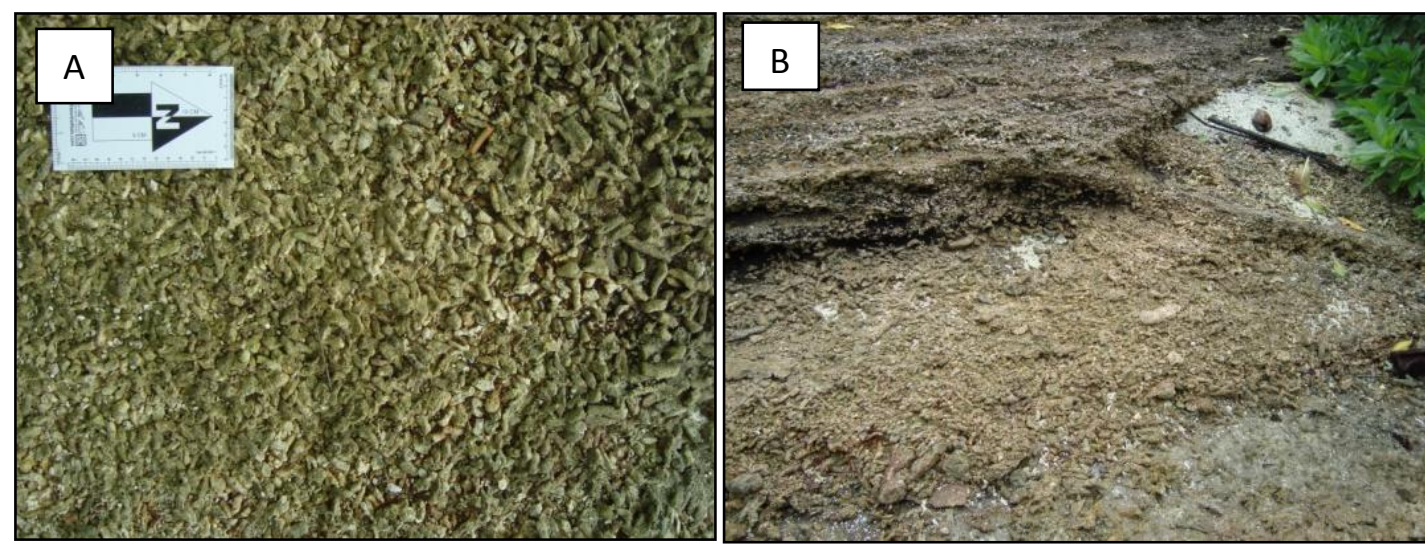

Figure 9.3: A) Orientated Acropora clasts cemented in the beachrock at Cooper Island. B) Beachrock beds at Paradise Island. The first bed is in the lower half of the photograph.

\subsubsection{Results and discussion}

Results from the investigation of clast orientations within the beachrock outcrops at Palmyra are shown as rose diagrams in Figure 9.4, with data given in Appendix C. Comparison of the beachrock paleo-orientations with nearby recent sediments cannot be made because the latter are either primarily sand, or contain insufficient similar clasts to those in the beaches. Patterns of sediment sorting in coarse grained deposits result from the segregation of particles with differing physical characteristics during processes of erosion, transport and deposition. The sorting of gravels is conventionally attributed to size-selective entrainment whereby larger particles, because of their greater inertia, are intrinsically less mobile than smaller particles and require higher shear stresses to entrain them (Powell, 1998), as predicted by Shields criterion.

It is important to note that the majority of beachrock beds at Palmyra Atoll are assumed to be representative of single wave events. Many beachrock beds show bimodal orientations that are generally perpendicular to each other. In most of the beds the primary orientation indicates the main direction of wave action and the other dominant direction suggests subsequent change of depositional orientation due to long shore drift, which rotates some of the clasts. This secondary direction may also be a result of refraction of the wave when it hits the island obliquely. However, by assuming the refraction is to the west as at present, then the primary direction of the waves can be 


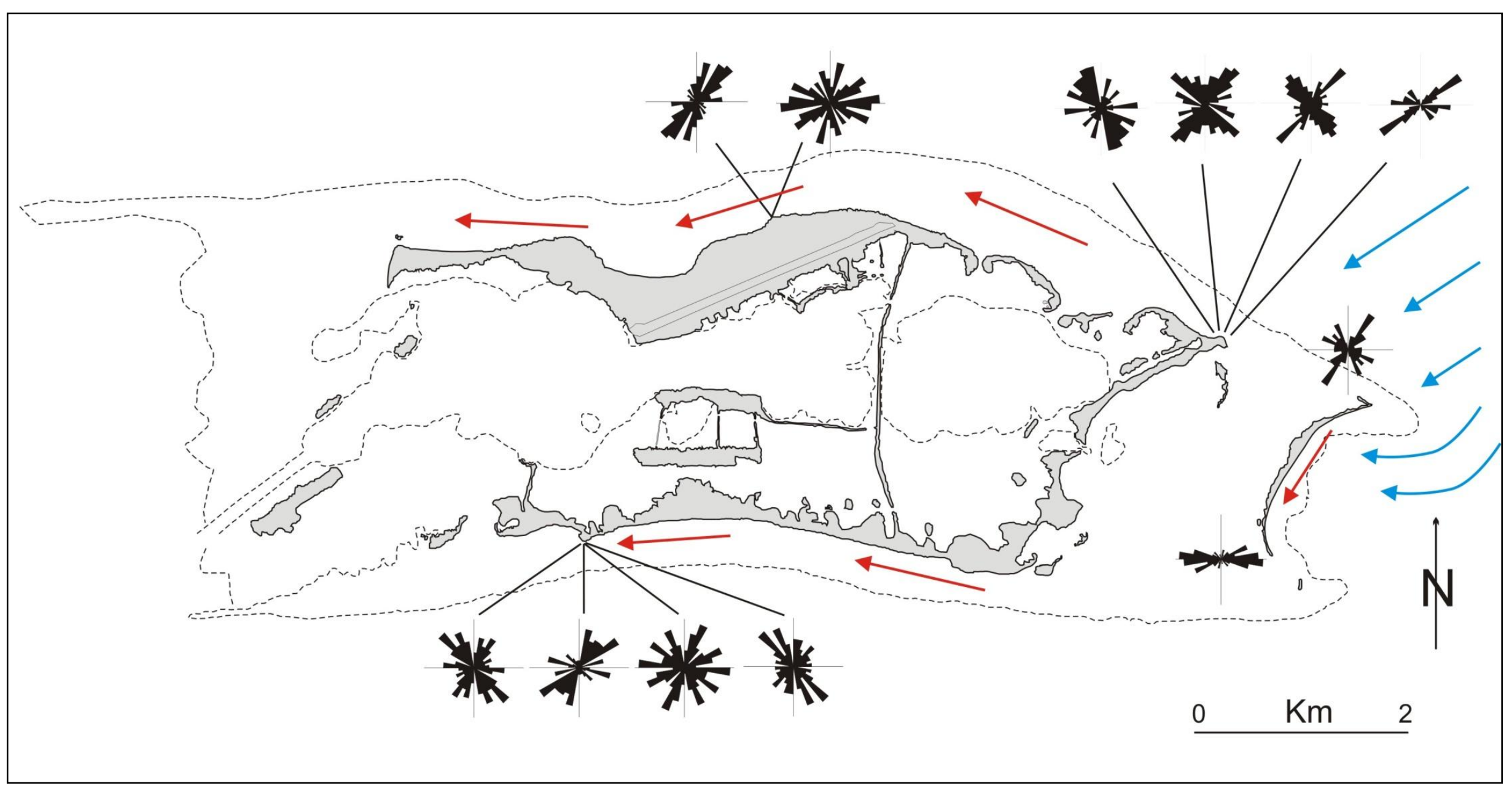

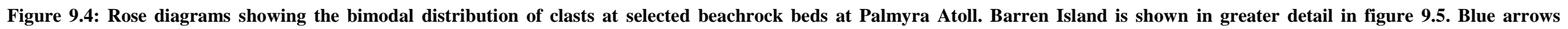
represent the main wave direction and the red arrows represent the direction of sediment transport across the reef. 


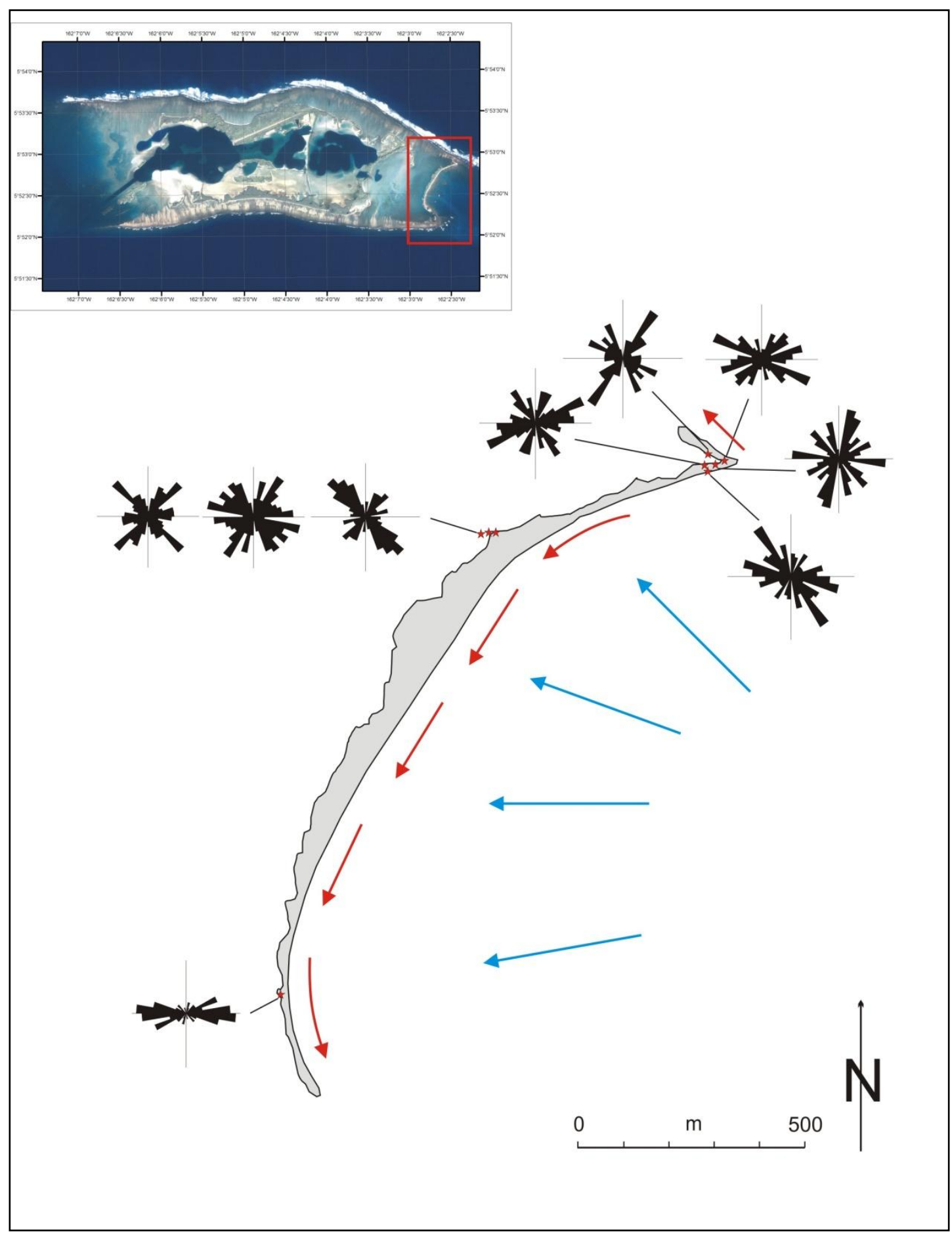

Figure 9.5: Rose diagrams showing the bimodal distribution of clasts for areas of unconsolidated sediment on Barren Island. Inset: IKONOS satellite image of Palmyra showing Barren Island in the red box. Blue arrows represent the main wave direction and the red arrows represent the direction of sediment transport. 
shown to be normal to the dominant paleocurrent direction, particularly on the northern coast. This is consistent with present day conditions. Rose diagrams for beachrock beds on the southern coast show that the primary direction of the wave energy (here assumed to be normal to the predominant orientation) has not remained constant over time. Rose diagrams that show little preferential orientation may be representative of a bed that experienced little to no reworking in the swash zone.

Rose diagrams for the unconsolidated sediment from Barren Island that was analysed for paleocurrent directions are shown in Figure 9.5. These show the bimodal orientation seen in the beachrock beds of other islands. Some appear to align parallel to the main wave direction, while others are dominantly aligned parallel to the direction of longshore drift. The high variability in the dominant current direction is attributed to the variety of locations on the island from which clast orientations were analysed.

\subsection{Erosional processes}

Erosional processes are important to understand at Palmyra because they significantly influence the short- and long-term stability of reef islands. Such processes can be divided into three groups: mechanical, biological and chemical. Mechanical erosion through wave action is a dominant process on Palmyra, particularly for porous or weakly cemented rocks, and is important for the distribution of sediment across the reef. This has largely been addressed through the numerical wave modeling. Chemical erosion is an important factor in $\mathrm{CaCO}_{3}$ environments, such as Palmyra, but has not been assessed here. Lastly, bioerosion plays an important role in weakening the overall structure of beachrock and two forms of bioerosion are discussed here; sipunculid worms and micro-phytokarst erosion. However, this was unable to be quantified in this thesis.

\subsubsection{Sipunculids}

Sipunculans are a small phylum of unsegmented, wormlike, marine invertebrates. They have a cylindrical, sub-cylindrical, muscular and fluid-filled body or trunk and an anterior extensible "introvert" that can be partly or completely withdrawn into the trunk. The mouth is at the anterior end of the introvert and usually has a group 
of tentacles associated with it. Most are burrowers or borers and detritus and algal feeders (Mather and Bennett, 1984).

Sipunculids are difficult to identify, however, the genera present on in the beachrock of Palmyra Atoll appears to be Phascolosoma spp., which exist in tubes or burrows in coral and limestone as well as under stones. The trunk of Phascolosoma spp. is approximately $30 \mathrm{~mm}$ long and contains longitudinal muscles in 20-30 bands. The papillae on trunk are prominent and pigmented. The species are distinguished by size and shape of introvert hooks (Mather and Bennett, 1984). The boring action of the sipunculids is believed to be partly by chemical dissolution and partly mechanical, and contribute to the disintegration of coral reefs.

In certain lithofacies and locations, beachrock is inhabited by sipunculid worms (Fig. 9.6), which burrow into the rock and then appear to secrete a thin burrow lining. Sipunculids appear to be the major form of bioerosion on Palmyra Atoll because they appear in many outcrops and are the only form of bioerosion observed other than the micro-phytokarst development.

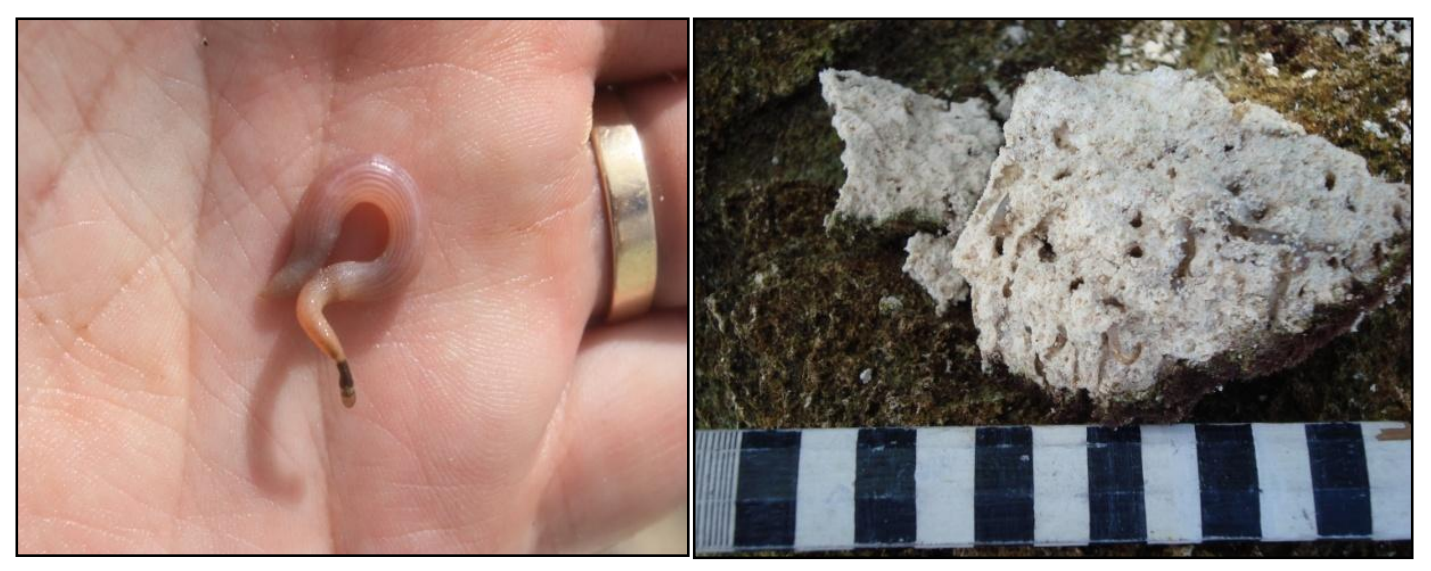

Figure 9.6: Sipunculid worms found in beachrock at Holei Island. Burrows are evident throughout the rock (see left).

\subsubsection{Micro-phytokarst erosion}

At some locations, micro-phytokarst architecture has been observed due to mmscale dissolution. This occurs when exposed surfaces develop an architecture of tiny jagged pinnacles and pits (Fig. 9.7), and also some large pores, as a result of colonization by boring filamentous algae. This also leads to the dark grey colouration of sediments. This surface phenomenon has been reported elsewhere; Folk et al. (1973), for example, were the first to report phytokarst as "an unusually grotesque karst, characterised by jagged, spongy pinnacles of black-surfaced limestone" in the Cayman Islands. The 
process is restricted to the attack of endolithic algal filaments on carbonate rocks, or other susceptible rocks, such as gypsum. Plant filaments cover the entire surface, actively boring and dissolving their way into the rock with no particular orientation. Folk et al. (1973) suggested that the algal coating is darkest where the rock is completely exposed to sunlight and an olive green in shaded areas; however, this is not observed at Palmyra. Scoffin and McLean (1978) record observations on coral shingle islands on the Great Barrier Reef, where severe pitting occurred on gravel clasts. This is similar to that described by Folk et al. (1973), but on a much smaller scale, and thus the term microphytokarst was applied. Scoffin and McLean (1978) reported that up to $49 \%$ of the original coral skeleton was dissolved through the boring algae. On beachrock outcrops dominated by sand sized grains, similar to lithofacies 1a, this micro-phytokarst topography is replaced by smoother shallow pools and pits on the upper surface such as that described on horizontal beachrock beds by Scoffin and McLean (1978), which are also indicative of large scale dissolution.
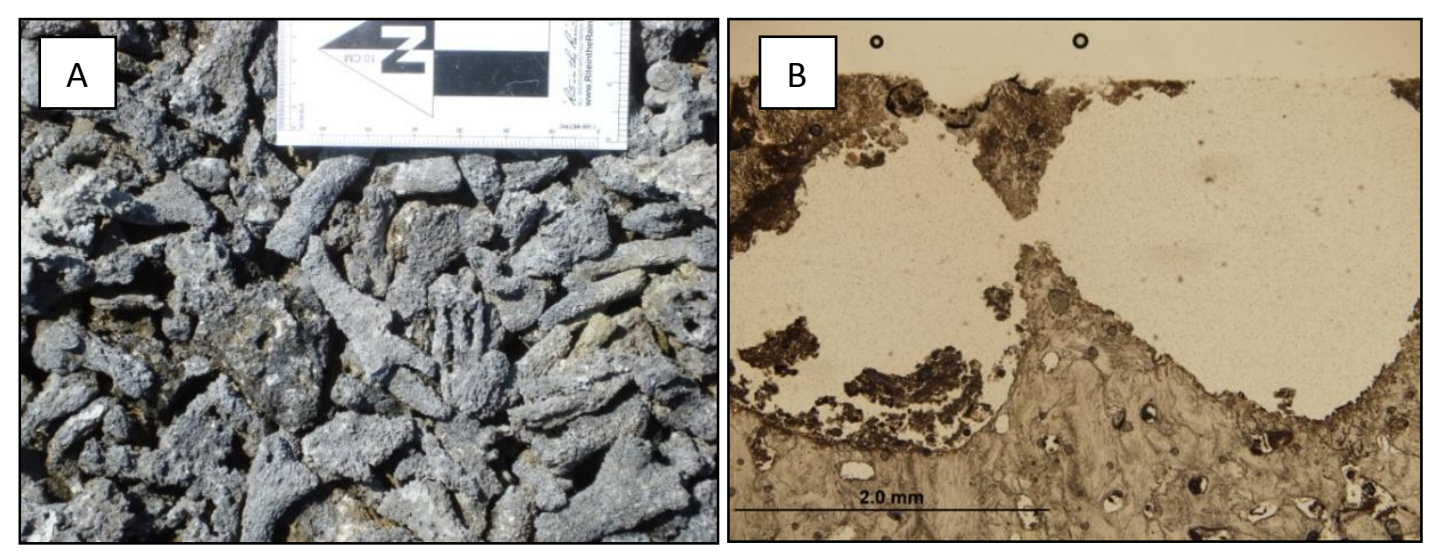

Figure 9.7: (A) Coral rubble on Barren Island exhibiting a dark grey outer surface effected by microphytokarst erosion. (B) Thin section through a coral clast with micro-phytokarst erosion.

\subsection{Insights from incipient beachrock and island growth Barren Island}

Barren Island represents a unique geological setting on the atoll because it is an example of the modern formation of both reef islands and beachrock and is therefore able to promote significant insights into processes of atoll development. The island is also unique because parts of its history have been documented through maps and aerial photographs. Barren Island only appeared in aerial photographs and maps after 1930, when the island first emerged above the tide level, and it has progressively developed 
over the past 80 years. The conditions under which it has formed are broadly known and, therefore, it can be used as an analogue for the formation of other islands and their beachrock deposits. For example, current directions inferred from clast fabric observed on Barren Island sediments must relate to the modern day currents effective in the area.

Barren Island is also central to the debate over the relationship between beachrock elevation and sea level, because the outcrop at Barren Island (Chapter Six) sits within the intertidal zone and has not been subject to sea level change since its formation. Lithification of beachrock is considered to be an extremely rapid process (Frankel, 1968) and, therefore, the beachrock exposed here must have formed soon after the initiation because of the islands young age $\left(104 \pm 55 \mathrm{C}^{14}\right.$ years B.P.). Additionally, beachrock is proposed to cement sub-aerially (Vousdoukas et al., 2007), and therefore, the existence of beachrock in the intertidal zone at Barren Island suggests that the island has migrated westward at least $5 \mathrm{~m}$ since 1935.

\subsubsection{History of Barren Island}

In 1848, reports by Edmund Lucett describe running aground in shallow water where Barren Island is now located and had to wade some distance to reach the eastern islands (Lucett, 1851). This shows that Barren Island was absent 150 years ago and was still absent from aerial photographs taken in 1921 (Fig. 9.7) when the first aerial photographs were taken. It firsts appears as a small islet in aerial photographs from 1935 (Fig. 9.8) but does not appear on maps until military surveys of the late 1930's and 1940's (Collen et al., 2009a). By the 1940s, the island was well established and its clasts had already been subjected to algal staining, creating a dark surface layer (Fig. 9.9).

\subsubsection{Island morphology and sediments}

Barren Island has an elongated morphology and is situated at the eastern-most end of the atoll and aligned north-south on the edge of the eastern flats lagoon (Fig. 1.1), similar to the "rim deposits" on the northern Great Barrier Reef described by Flood and Scoffin (1978). The island is formed largely of coral fragments, predominantly Acropora spp., and has developed very limited soil on which small patches of vegetation, including Scaevola, Tournefolia and Cocos, have grown. The island now extends for $\sim 1700 \mathrm{~m}$ from north to south and is up to $\sim 100 \mathrm{~m}$ wide in the middle, thinning at each end (Collen et al., 2009a). There is a significant westward concavity in the centre of the island. The ends of the island also curve around to the west (Fig. 9.10). 
Most of the waves that affect Barren Island originate to the east as a result of the easterly trade winds. Overall there is a relatively high energy environment observed on the eastern coast of Barren Island. However, due to a sheltering effect cause by the reef front, the waves are refracted eastward and the centre of Barren Island is subject to the strongest wave energy (Fig. 9.5). This results in the westward concavity of the island. Similar curvature is seen in the other north-south structures of the atoll (the reef flats underlying the eastern islands, Lost Island and the North-South Causeway). These may have formed from similar processes as observed today. 


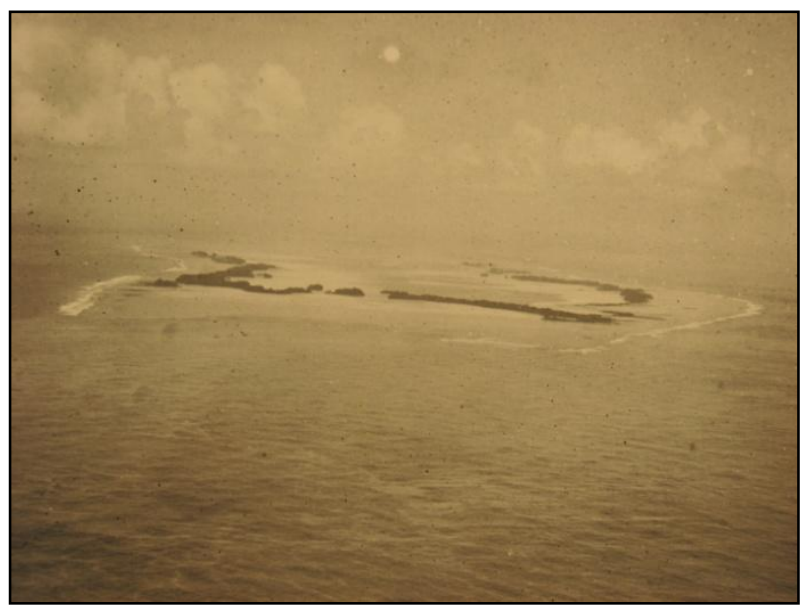

Figure 9.7: Oblique view of Palmyra Atoll, looking west, taken in 1921. Barren Island is absent although a line of surf marks the position it with later occupy.

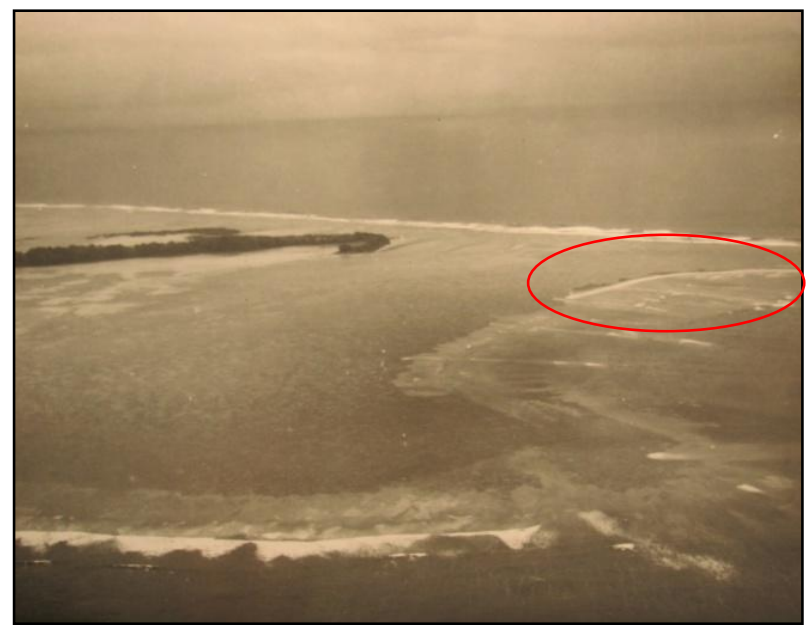

Figure 9.8: 1935, Barren Island is present as a small islet on the right hand side of the photograph (in the red circle).

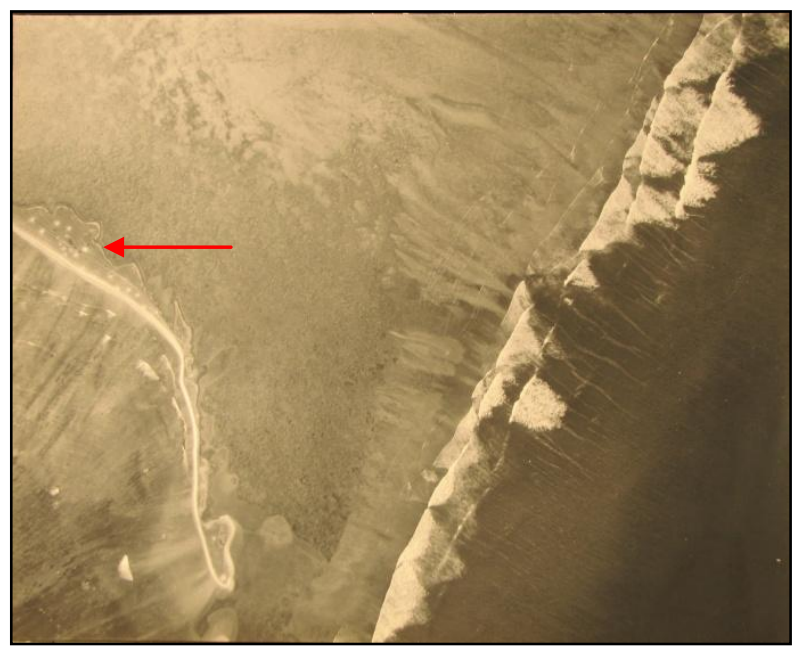

Figure 9.9: In 1942, Barren Island became the target of mortors emplaced by the U.S. Navy. In the photograph the white dots visible are where the dark, eroded surface of the Barren Island deposits is disturbed by the explosions of the shells (red arrow). 
In cross section, Barren Island is asymmetrical (Fig. 9.10), with a steep (35 ) beach on the seaward side, and a gentler slope and a much more irregular coastline on the western side. On the eastern side of Barren Island, several storm berms are present at varying levels and sediment are mainly sand-sized particles near the shoreline, much of which is occupied by the swash zone during high tide. As the island rises sharply away from the low tide level, sediment size changes noticeably, increasing upwards to approximately $15 \mathrm{~cm}$ in maximum dimension near the top of the island. On the western (leeward) shoreline, clasts are fairly homogenous in size, averaging about $10 \mathrm{~cm}$, and show variations in the colour of the surface indicating the age of the material. The youngest, freshest material is pale to white in colour and is found on the eastern slope and close to the island peak on the western slope. Some of this young material overlaps older, darker material on the leeward side of the island. The older material also shows micro-phytokarst topography on its exposed surfaces. The extent of this pitting varies systematically across the platform with the age of the deposit and the length of time exposed.

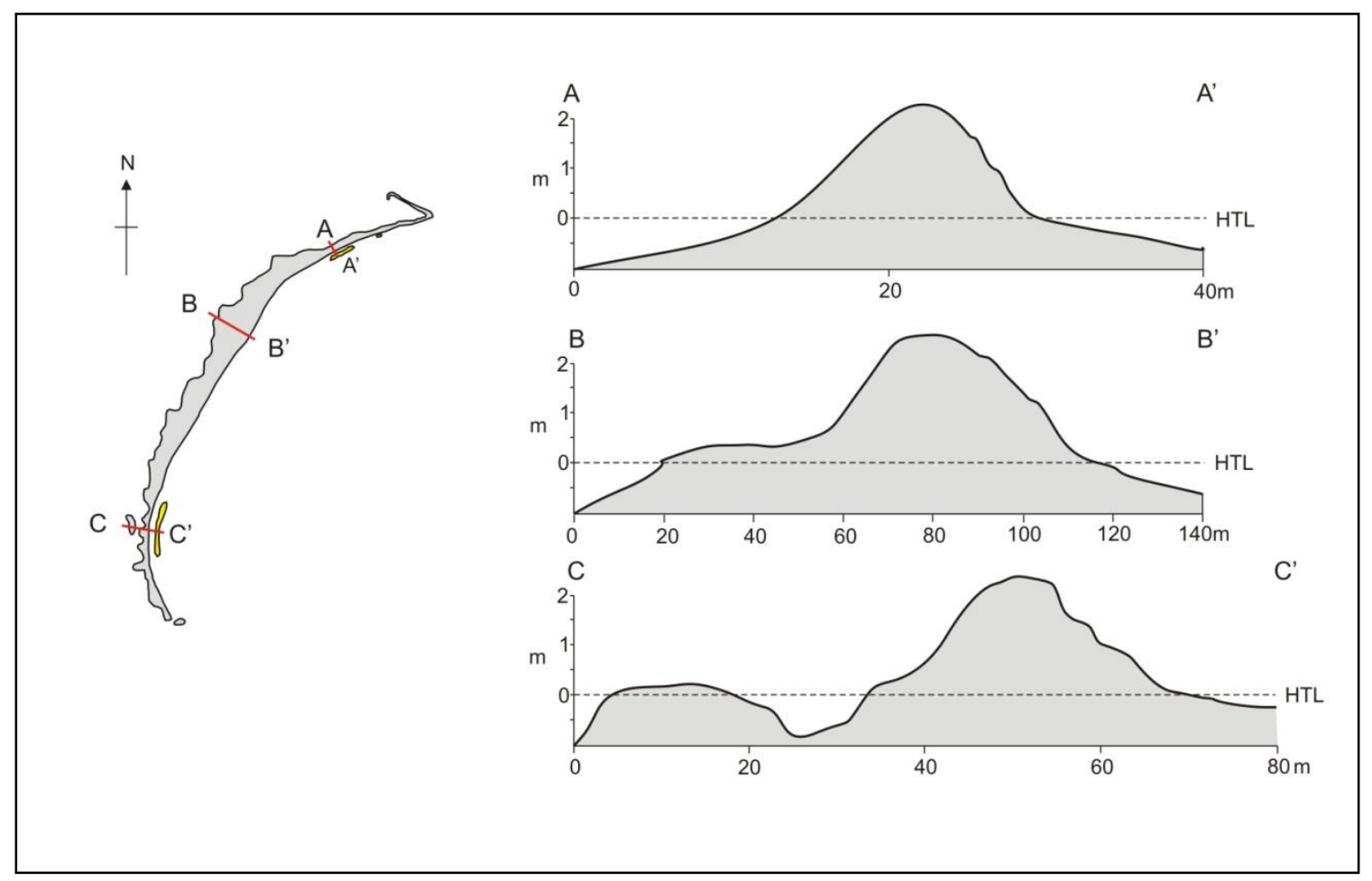

Figure 9.10: Map of Barren Island and cross-sectional sketches taken at three points throughout the island.

The outcrops of beachrock in the intertidal zone are not included in the cross-sections, which have vertical exaggerations of 13,70 , and 40 respectively. 


\subsubsection{A budget of sediment production for Barren Island}

\subsubsection{Growth of Barren Island}

Barren Island has a volume of approximately $180,000 \mathrm{~m}^{2}$, given an area of 0.1 $\mathrm{km}^{2}$ (Collen et al., 2009a) and an average height of $1.8 \mathrm{~m}$. Assuming an average bulk density of $1.6 \mathrm{gcm}^{-3}$ (the average density of coral; Hughes, 1987) implies the island has a mass of 288,000 tonnes. However, considering the island is completely constructed from coral gravel, the sediments have a high inter- and intra-clast porosity resulting in lower bulk density. Most models of reef systems use an average porosity of 50\% (Kinsey and Hopley, 1991), which is employed here for both the reef system as well as the island. This porosity accounts for both the inter- and intra-clast porosity of the gravel (both estimated at about 25\%; Kinsey and Hopley, 1991). Thus the final mass of Barren Island of about 144,000 tonnes, which equates to an average of approximately 1800 tonnes/year for the growth of Barren Island since 1935. This does not account for the mass accumulated below the low tide mark, which is likely to be minimal because of the shallow, consolidated reef flat beneath.

\subsubsection{Source of sediment}

The Eastern Terrace is here defined as the elongate, shallow reef plateau that extends east from Barren Island to maximum depth of $50 \mathrm{~m}$. It has a total area of 8.77 $\mathrm{km}^{2}$, which is approximately $13.5 \%$ of the total reef area at Palmyra $\left(65 \mathrm{~km}^{2}\right)$. The water depth increases towards the edge of the terrace platform which has extremely steep sides similar to the rest of the atoll and drops abruptly to the abyssal plain (Fig. 3.2). Unfortunately, this area is remote and subject to strong currents, onshore winds and heavy surf (Williams et al., 2008) and, as a result, little study has been made of either the benthic communities or bottom conditions (G. Williams, pers. comm.). Despite this, a dominance of the staghorn coral Acropora growing in large colonies has been observed during limited visits. Staghorn coral, despite high growth rates, is also much more susceptible to mechanical breakage than massive coral types due to its fragile structure and shallow water occurrence. It therefore has a higher rate of sediment production under normal conditions than massive and deeper coral species. However, Madin (2005) showed that pruning of coral colonies resulting from impacts with other loose coral fragments is unlikely to occur before whole-colony dislodgement.

The predominant easterly trade winds mean that any course sediment produced on the Eastern Terrace is likely to be moved westward, towards Barren Island and the 
rest of Palmyra. This suggests that the atoll islands may accrete eastward from the original lagoon system and would account for the lack of natural island development on the western side of the atoll, despite there being considerable carbonate production on the Western Terrace. Material produced there is most likely to be moved west or south into deep water off the atoll due to the dominance of the northeasterly trade winds. As most sediment produced on the reefs of Palmyra Atoll is moved westward by the prevailing surface currents, the eastern reef terrace can be the only area supplying sediment to the eastern end of the atoll,

\subsubsection{Sediment flux at Barren Island}

Barren Island needs on average around 1800 tyr $^{-1}$ of calcium carbonate to have accumulated on the island to achieve its growth since 1935 and the dominant current requires that this material must come entirely from the Eastern Terrace. Using the carbonate production values and areas described above, the total productivity for the Eastern Terrace is estimated at 19,430 $\mathrm{tyr}^{-1}$, or $2.22 \mathrm{~kg} \mathrm{CaCO}_{3} \mathrm{~m}^{-2} \mathrm{yr}^{-1}$. This is within the range of average $\mathrm{CaCO}_{3}$ production rates from other reef locations, such as the Tiahura reef in French Polynesia (Chazottes et al., 1995), and so supports the appropriateness of this simplified model. This means that only $9 \%$ of the carbonate estimated to be produced each year from the Eastern Terrace is needed to form Barren Island. Any excess is either lost into deeper water, transported past Barren Island to the rest of the atoll, removed through dissolution, or accumulate on the terrace. Although the unknown mass of Barren Island below sea level may increase the carbonate sediment required, this would still only be a minor proportion of the estimated amount available.

The sediment budget of Barren Island assumes a linear growth rate of the island and steady accretion. This is an unlikely scenario, as the average clast size is larger than can be transported by normal swell conditions. Therefore, it is likely that the majority of the sediment that forms Barren Island was deposited by infrequent storm swells, so the island grew at a faster rate during winter, when influenced by stronger trade winds and large swells from distant storms, than in summer. There may also have been large fluctuations in the rate of growth and island size due to periods where erosion was greater than deposition. However, this currently remains unquantified. 


\subsection{Summary of sediment supply and deposition at Palmyra Atoll}

The production of sediment has a large influence on the sediment budget on any given coastline, and is even more pronounced on oceanic atolls where the only sediment is produced biogenically on the reef. The simple model of $\mathrm{CaCO}_{3}$ production at Palmyra estimates that there is over 9000 tonnes of biogenic calcium carbonate produced on the atoll each year. The growth of Barren Island requires an average accumulation $1800 \mathrm{t} \mathrm{yr}^{-1}$ of carbonate per year, equal to $9 \%$ of the estimated productivity of the Eastern Terrace. Estimated values of sediment accumulation for the eastern reef islands are within the range of those calculated for Barren Island over the past 80 years. This suggests that only around $9 \%$ of the sediment that is produced annually on the atoll is deposited on the beaches or incorporated into the islands and the remaining sediment is either lost into deeper water, transported past Barren Island to the rest of the atoll, removed through dissolution, or accumulate on in situ.

The paleocurrent direction at the time of clast deposition is inferred from examination of the orientation of beachrock clasts. These results have important implications, firstly, in showing that the direction of deposition along the northern and southern reef flats are variable and thus there is no single source for sediment due to varying wave conditions, particularly on the South coast. Secondly, there are two directions that have significant effect on the sediments during their deposition. These are highlighted in the rose diagrams (Fig. 9.4) and represent the primary direction of the waves within the swash zone and the direction of the longshore transport and refraction of the wave. Data from the rose diagrams largely supports the SWAN modelling results and the field observations of wave and current regimes.

Lastly, biogenic erosion impacts the degradation of beachrock outcrops at Palmyra. Sipunculid worms and micro-phytokarst corrosion are the predominant influences, both of which have distinct impacts on the beachrock and sediments of Palmyra Atoll. These, along with mechanical and chemical erosion lead to the degradation of outcrops seen at Palmyra and on tropical coastlines worldwide. 


\section{Discussion and conclusions}

Overall, Palmyra Atoll is an expression of the relationship between the original atoll edifice, karstic morphology, sediment production, sea level changes, and other physical and biological processes. This chapter provides an integrated interpretation of the results presented in this thesis. Results from the study of sedimentary processes exemplifies the delicate balance between sea level, sediment production, and sediment transport, and their influence on reef island development. These influence the atoll's sedimentary processes and an interpretation of the latter requires an understanding of fundamental aspects of the climatic, hydrodynamical and biological processes. Particular attention is paid to the overriding control of sea level on $\mathrm{CaCO}_{3}$ production and sedimentation patterns. This study highlights the concept that in the absence of other proxies, the study of beachrock can prove a useful tool for studying the paleoenvironment, including sea level, and the recent geological development of reef islands.

\subsection{Formation of beachrock at Palmyra Atoll}

\subsubsection{Radiocarbon dating of beachrock outcrops}

Dated beachrock clasts have ages ranging from 1249 yrs BP to modern (Table 6.1; Fig. 10.1), and therefore the beachrocks of Palmyra Atoll are considerably younger than most beachrock elsewhere in the Pacific. For example, beachrock in the Society, Tuamotus, and Gambier Islands range from 5000 to 1250 yrs BP (Pirazzoli, 1987; Pirazzolia and Montaggioni, 1988; Pirazzoli et al., 1988). The beachrock at Lost Island dated at $1249 \mathrm{yrs}$ BP is the older than the oldest date (1100 yrs BP) obtained for Porites heads from Palmyra Atoll by Cobb et al. (2003b). Despite their youth, this is the oldest Holocene age reported for Palmyra Atoll. This suggests that the reef islands are simply very young and did not become stable until the lowering of sea level after the peak of the mid-Holocene Highstand (MHHS; 4000 yrs BP).

The radiocarbon ages given for beachrock on Palmyra records the age of the living animal and thus the oldest possible date for the accumulation of the beachrock in which it was found. The cement of the same bed containing the 1249 year old Tridacna at Lost Island dates to 705 yrs BP, a difference of approximately 600 years. This range is consistent with a range of coral clast ages from a single bed of beachrock on Fongafale, Funafuti. There, six fragments of coral were dated from a single bed of beachrock, 


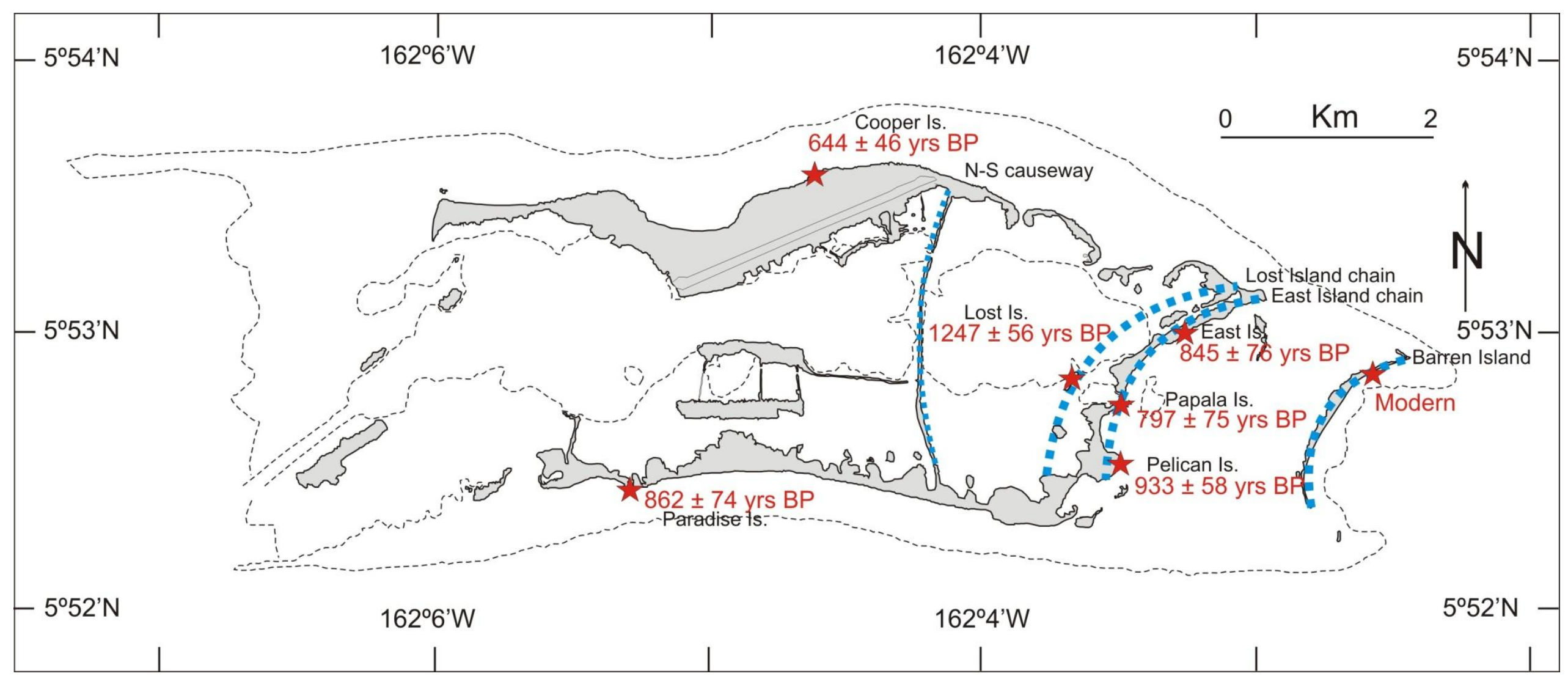

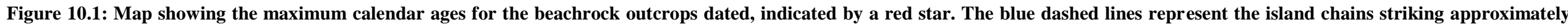

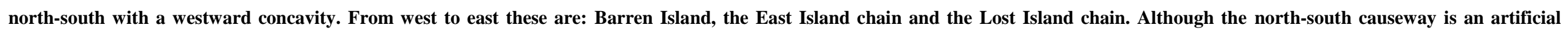
feature, it was built on a shallow reef that was elongated similar to the other island chains and may be an older island chain. 
which ranged from $1517 \pm 41$ yrs B.P. to $2299 \pm 41$ yrs BP (Collen, J.D., unpublished data). This range in ages is due to the variations in the time that material has been loose sediment on the beach prior to incorporation into the beachrock and subsequent cementation.

The radiocarbon results also aid in understanding the process of atoll development over the past $\sim 1000$ years. The ages of beachrock around the islands on the atoll rim (Cooper, East, Pelican, and Paradise; Fig. 10.1) are similar (644 to 933 yrs $\mathrm{BP}$ ), suggesting approximately simultaneous formation. By comparison, Lost Island in East Lagoon is significantly older. This, along with the very coarse sediments cemented within the Lost Island beachrock, in what is presently a very low energy environment, suggests that it was deposited in the absence of more easterly islands and high energy events were able to propagate into East Lagoon. Therefore, at the time of beachrock deposition Lost Island was the easternmost island of Palmyra.

Thus, the radiocarbon results suggest eastward growth of the reef islands that has occurred sequentially by the establishment of at least three concave north-south island chains (the Lost-Fern island chain, the East island chain and, latterly, Barren Island; Fig. 10.1). Each succeeding island chain initiated further eastward, with Barren Island currently the youngest and most eastern island. The limit to this eastward growth of island chains, before the reef becomes too deep or the waves too strong, is unknown.

It is important to note that the sample from the Barren Island beachrock is outside the calibration range for conversion from calibrated radiocarbon ages into calendar years. This shows that the beachrock here has formed simultaneously with the island itself (within the last 80 years). Additionally, since the beachrock is located well within the intertidal zone (see Chapter Nine), this is supporting evidence that beachrock at Palmyra Atoll forms in the intertidal zone since there has been no significant change in sea level during this period ( $\sim 20 \mathrm{~cm} / 100 \mathrm{yrs}$; Church et al., 2006). This observation supports the use of beachrock as a sea level indicator at Palmyra.

\subsubsection{Determination of the beachrock depositional environment by SWAN wave modelling}

The cementation process that forms beachrock "freezes" in situ the clasts in the intertidal zone during its formation. In this way, examining clast size within beachrock allows an assessment of changing hydrodynamic conditions. The results of the SWAN 
wave modelling provide insight into the formation of beachrock at Palmyra Atoll because they illustrate that, under average wave conditions, the gravel sized material that comprise most of the clasts within the beachrock outcrops on the atoll are not in hydrodynamic equilibrium in their present locations. Results showing whether or not the beachrock outcrops can be formed under various conditions are summarised in Table 10.1. For most beachrock units, the location and the high bed roughness of reefs restrict the transport of gravel from the reef edge to the coastline under normal wave conditions. This suggests that, at the time of their formation, either the wave climate at Palmyra was significantly more energetic or that the beachrock formed in a different position on the reef than at present. It is unlikely that there has been any significant horizontal growth of the reef platform and, thus distance of the deposit to the reef edge, since the time of beachrock cementation. Therefore, the most realistic explanation is that the beachrock sediments were deposited under significantly higher wave energy environments than typically occurring today.

During a typical year swells from high latitude winter storms exerts the greatest wave-induced shear stress on the bed and an additional $289 \mathrm{Nm}^{-2}$ on top of the normal low energy wave climate. The distribution of this additional energy is shown in Figure 10.2. Despite the vigorous wave climate there is insufficient wave energy to move and deposit clasts of the size found within much of the beachrock on the atoll at its present location, although finer grained beachrocks may have been deposited during these larger wave events, such as those found at Barren and Holei islands. Furthermore, the direction of these waves cannot explain the accumulation of sediment observed on the eastern end of the atoll as most of the large wave events originate to the northwest of south of Palmyra and, therefore, cannot be responsible for the growth of the atoll eastward.

Even under extremely large wave events, such as the modelled cyclone events, the wave energy is often dissipated too quickly across the reef flat for the beachrock clasts to be deposited in the inner locations on the reef (e.g. Lost Island). Under these large waves $(>5 \mathrm{~m})$, the northern and southern coasts were exposed to sufficient energy to transport large sediment clasts averaging around $15 \mathrm{~cm}$. However, the waves must come almost directly from the east in order to accumulate deposits such as those that form the eastern islands. 

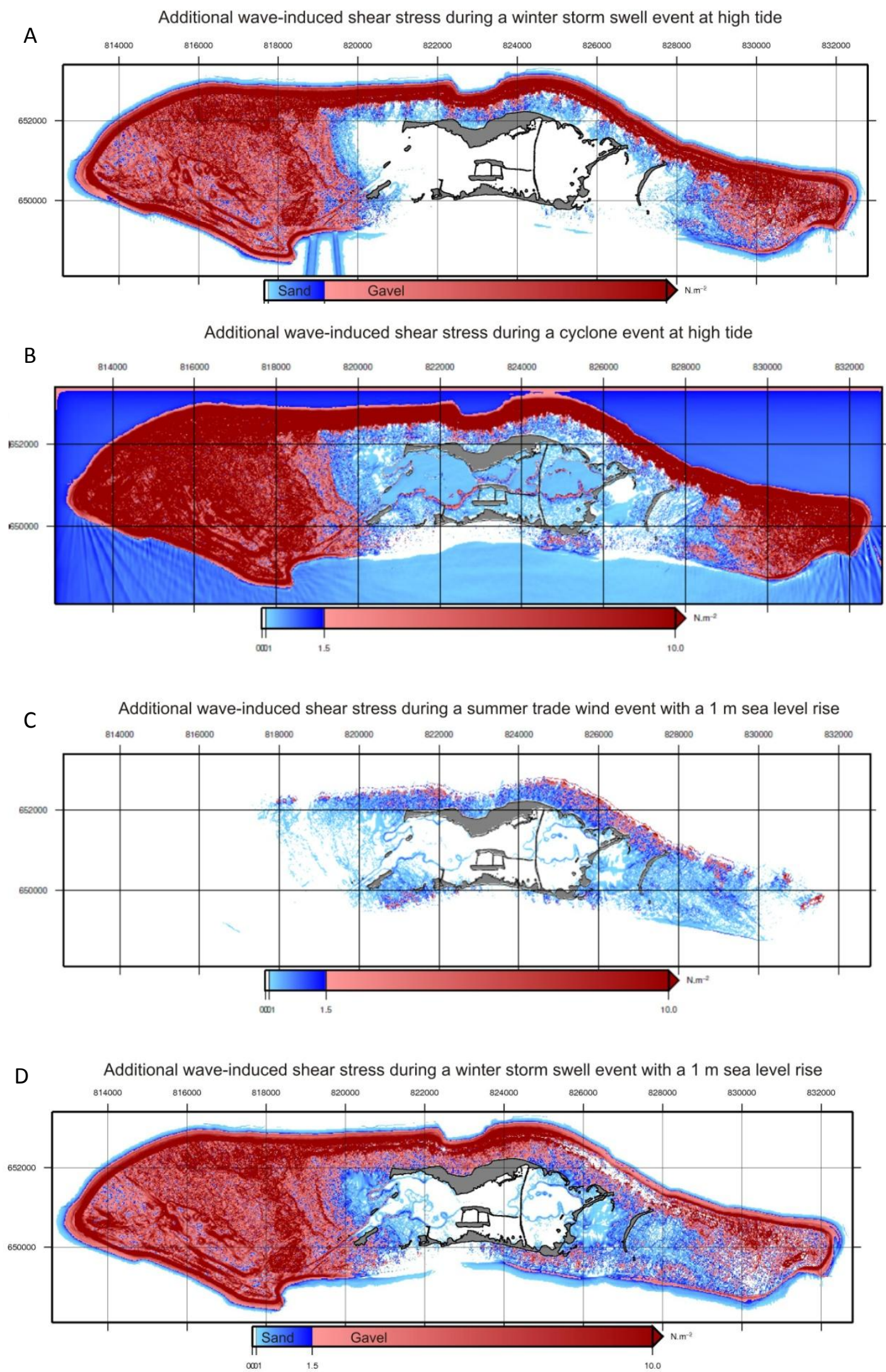

Figure 10.2: Plots of the additional wave -induced bed shear stress, compared to summer trade wind conditions, exerted on the reef during (A) Winter storm swell conditions at high tide, (B) modelled cyclone conditions at high tide, (C) summer trade wind conditions with a $1 \mathrm{~m}$ sea level rise, and (D) winter trade wind conditions with a $1 \mathrm{~m}$ sea level rise. 


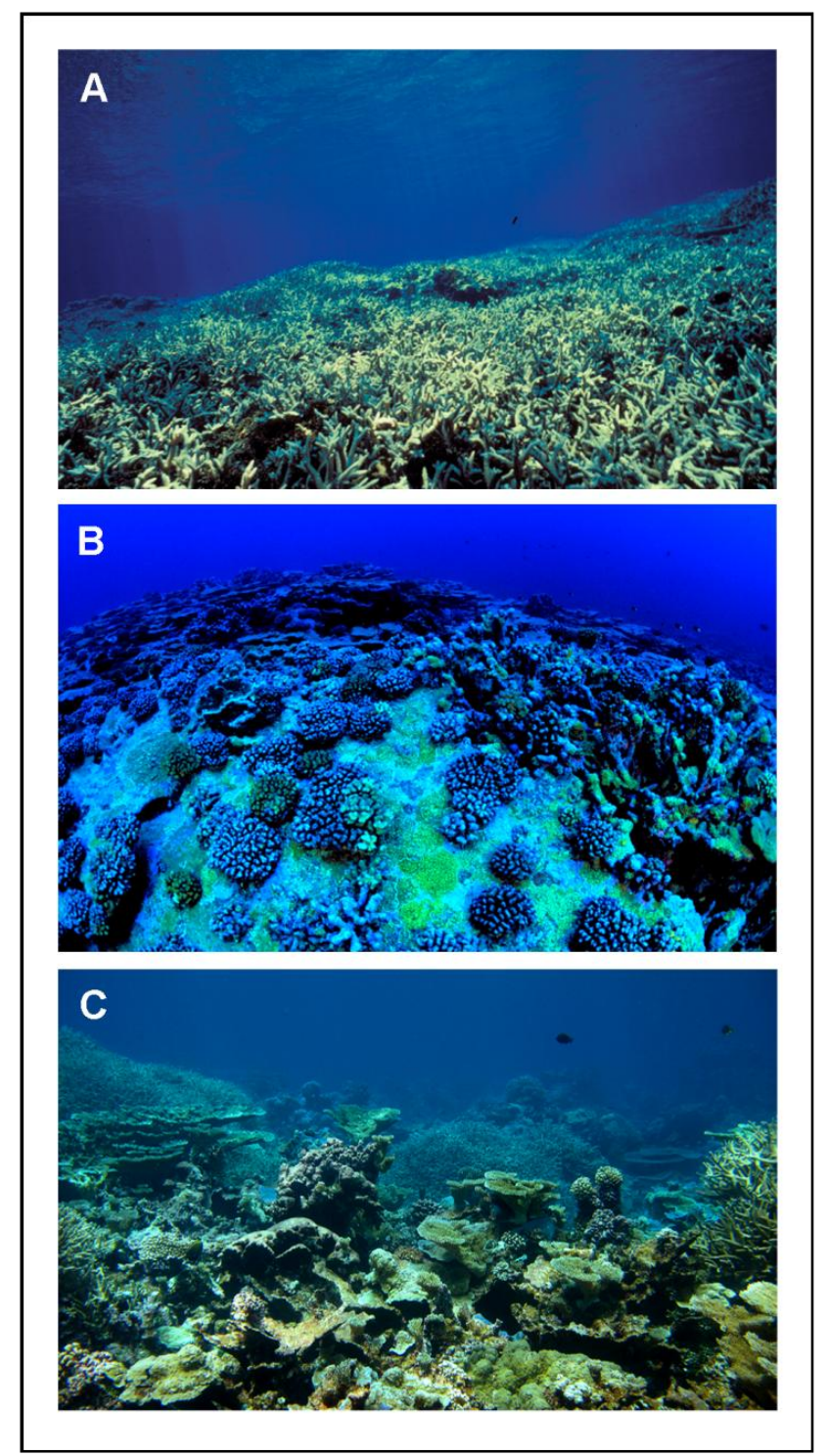

Figure 10.3: (From: Williams et al., 2010) The western terrace of Palmyra Atoll showing (A) high coverage of branching Acropora in 1987, (B) signs of mass coral bleaching across the western terrace in 1998, and (C) the western terrace in 2009 with signs of branching Acropora, but dominated by massive species.

Acropora spp. are widespread on the reefs at Palmyra and therefore are a dominant constituent of the gravel clasts. Maragos (1987) surveyed the Western Terrace (Fig. 10.3) reef in 1987 and reported large, continuous stands of staghorn (Acropora spp.) coral over $90 \%$ of the bottom. This reef was again surveyed in 1998 and substantial changes were recorded (Fig. 10.3). Instead of large, branching Acropora stands, there was a debris field of Acropora clasts and sediment. Maragos et al. (2008a) suggest that a major event, such as bleaching, disease, predation or storm damage, occurred between these two surveys that reduced all of the well established colonies of Acropora to debris, which is slowly being re-colonised. This period between 1987 and 1998 includes Cyclone Ekeka in 1992, the largest known storm to have affected Palmyra Atoll, so storm damage may have been a cause for the destruction of the reef. However, on the 
opposite side of the atoll, there remain large, well established colonies of fragile Acropora on the Eastern Terrace that have not been destroyed. SWAN modelling suggests that during extreme wave events similar energy conditions are observed on both reef terraces (Fig. 8.2). Thus, if Cyclone Ekeka was responsible for the destruction on the Western Terrace then the Eastern Terrace would likely also have been destroyed. As there is no evidence for damage to Acropora on the Eastern Terrace, storm damage alone can be discounted as a cause of the debris field observed by Maragos. This differential damage suggests some other factor other than storm damage is involved. This may be disease, bleaching or predation (Lui et al., 2006; Sandin et al., 2008). However, there is still unknown properties of coral ecology, and other factors involved cannot be pinned down at this stage.

Sea level has been shown to be an extremely influential control on the wave climate, and subsequent sediment transport, at Palmyra as it effects the dissipation of energy through friction of the reef. An increase in sea level without corresponding growth of the reef is necessary to deposit most beachrock clasts because this allows the wave energy is able to propagate further inland before it is dissipated. This allows beachrock at Holei, Papala, Cooper, northern East, and Paradise islands to form under normal wave energy conditions. In contrast, the presence of beachrock containing gravel sized clasts at Lost and Pelican islands can most easily be accounted for by a combination of elevated sea level, large waves, and the absence of younger islands to the east. This allows significant wave energy to propagate further landwards than present and more gravel sized debris in areas which currently experience very low wave energy. The additional distance covered by higher bed shear stress on the reef under a $1 \mathrm{~m}$ sea level rise is shown in Figure 10.2C-D. A higher sea level is also indicated by the position of beachrock outcrops on average $1 \mathrm{~m}$ above the modern high tide level (Chapter Six).

The coarse, poorly sorted beachrock of Lost Island indicates that a high energy environment was required during deposition. This is supported by the SWAN modelling results, which prove that even under relatively large storm events, there are extremely low shear stress values within the lagoons $\left(<5 \mathrm{Nm}^{-2}\right)$. Even under higher sea level conditions there would be insufficient shear stress to deposit the beachrock sediments. Consequently, around $1200 \mathrm{yrs}$ BP the islands to the east of Lost Island, which currently have a considerable sheltering effect on the inner lagoons, must have been absent, and sea level must have been higher than at present in order to deposit the gravel clasts of 
Lost Island. This reinforces the hypothesis of sequential formation of the atoll reef islands eastward, where Lost Island formed prior to the East Island chain.

Beachrock deposition, however, does not necessarily require extreme events or a higher sea level. For instance, lithofacies 1a (Holei Island) and lithofacies 1b (Papala Island) sediments consist of well sorted sand indicative of low energy reworking. The SWAN wave model shows that there is regularly sufficient energy during normal yearly conditions to deposit such sediments at coastal and unsheltered locations. However, Papala is now relatively sheltered and therefore must have formed when it was on a more exposed coastline. The reason behind why lithofacies 1a has only formed at Holei Island on the outer coastline is unclear.

In summary, the beachrock on the eastern end of the atoll requires storms and extreme wave events that occurred during a higher sea level (either due to relative sea level change or storm swells). Both extreme waves and higher sea level conditions are required because it is only during such environments that the bed shear stress is high enough, and can propagate far enough across the reef, that the critical shear stress for the beachrock clasts is exceeded. Such extreme wave events are most likely to occur on at least a decadal timescale as they are not present in the 13 year hindcast model. Furthermore, the waves that form most of the beachrock on the atoll must have originated to the east or the northeast because even during extreme wave events high bed shear stress is easily dissipated before the energy can be refracted around to the eastern end of the atoll. 


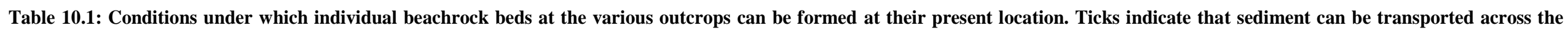

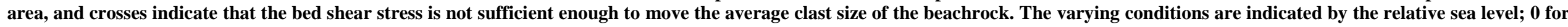

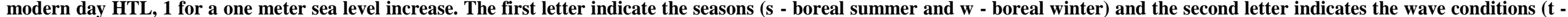
trade winds and $\mathrm{s}$ - storm swells). Additionally, $\mathrm{c}$ indicates cyclone conditions from both the northwest (nw) and the northeast (e).

\begin{tabular}{|c|c|c|c|c|c|c|c|c|c|c|c|c|c|c|}
\hline Location & $\begin{array}{l}\text { Beachrock } \\
\text { bed }\end{array}$ & $\begin{array}{l}\text { Average } \\
\text { clast size }(\mathrm{cm})\end{array}$ & \multicolumn{11}{|c|}{ Conditions } & 1cne \\
\hline \multirow[t]{3}{*}{ Cooper } & 1 & 20 & $\mathrm{X}$ & $\mathrm{X}$ & $\mathrm{X}$ & $\mathrm{X}$ & $\mathrm{X}$ & $\mathrm{X}$ & $X$ & $\mathrm{X}$ & $X$ & $\checkmark$ & $\checkmark$ & $\mathrm{X}$ \\
\hline & 2 & 15 & $X$ & $X$ & $X$ & $X$ & $X$ & $X$ & $X$ & $X$ & $\checkmark$ & $\checkmark$ & $\checkmark$ & $\checkmark$ \\
\hline & 3 & 10 & $X$ & $X$ & $X$ & $\checkmark$ & $\checkmark$ & $\checkmark$ & $X$ & $X$ & $\checkmark$ & $\checkmark$ & $\checkmark$ & $\checkmark$ \\
\hline Northern East & 1 & 5 & $X$ & $X$ & $X$ & $X$ & $\checkmark$ & $\checkmark$ & $\checkmark$ & $X$ & $\checkmark$ & $\checkmark$ & $\checkmark$ & $\checkmark$ \\
\hline Barren & 1 & 2 & $\checkmark$ & $\checkmark$ & $\checkmark$ & $\checkmark$ & $\checkmark$ & $\checkmark$ & $\checkmark$ & $\checkmark$ & $\checkmark$ & $\checkmark$ & $\checkmark$ & $\checkmark$ \\
\hline \multirow[t]{3}{*}{ East } & 1 & 5 & $X$ & $X$ & $X$ & $X$ & $X$ & $X$ & $X$ & $X$ & $\mathrm{X}$ & $X$ & $X$ & $X$ \\
\hline & 2 & 10 & $X$ & $X$ & $X$ & $X$ & $X$ & $X$ & $X$ & $X$ & $X$ & $X$ & $X$ & $X$ \\
\hline & 3 & 5 & $X$ & $X$ & $X$ & $X$ & $X$ & $X$ & $X$ & $X$ & $X$ & $X$ & $X$ & $\mathrm{X}$ \\
\hline \multirow[t]{2}{*}{ Papala } & 1 & 0.1 & $X$ & $X$ & $X$ & $X$ & $\checkmark$ & $\checkmark$ & $X$ & $X$ & $X$ & $\checkmark$ & $\checkmark$ & $\checkmark$ \\
\hline & 2 & 0.2 & $X$ & $X$ & $X$ & $X$ & $\checkmark$ & $\checkmark$ & $X$ & $X$ & $X$ & $\checkmark$ & $\checkmark$ & $\checkmark$ \\
\hline \multirow[t]{3}{*}{ Lost } & 1 & 5 & $X$ & $X$ & $X$ & $X$ & $\checkmark$ & $X$ & $X$ & $X$ & $X$ & $X$ & $\checkmark$ & $X$ \\
\hline & 2 & 10 & $X$ & $X$ & $X$ & $X$ & $X$ & $\mathrm{X}$ & $X$ & $X$ & $X$ & $X$ & $X$ & $X$ \\
\hline & 3 & 15 & $X$ & $X$ & $X$ & $X$ & $X$ & $X$ & $X$ & $X$ & $X$ & $X$ & $X$ & $X$ \\
\hline \multirow[t]{2}{*}{ Pelican } & 1 & 15 & $X$ & $X$ & $X$ & $X$ & $X$ & $X$ & $X$ & $X$ & $X$ & $X$ & $X$ & $X$ \\
\hline & 2 & 10 & $X$ & $X$ & $X$ & $X$ & $X$ & $X$ & $X$ & $X$ & $X$ & $X$ & $X$ & $X$ \\
\hline \multirow[t]{3}{*}{ Holei } & 1 & 0.1 & $\checkmark$ & $\checkmark$ & $\checkmark$ & $\checkmark$ & $\checkmark$ & $\checkmark$ & $\checkmark$ & $\checkmark$ & $\checkmark$ & $\checkmark$ & $\checkmark$ & $\checkmark$ \\
\hline & 2 & 1 & $\checkmark$ & $\checkmark$ & $\checkmark$ & $\checkmark$ & $\checkmark$ & $\checkmark$ & $\checkmark$ & $\checkmark$ & $\checkmark$ & $\checkmark$ & $\checkmark$ & $\checkmark$ \\
\hline & 3 & 3 & $\checkmark$ & $\checkmark$ & $\checkmark$ & $\checkmark$ & $\checkmark$ & $\checkmark$ & $\checkmark$ & $\checkmark$ & $\checkmark$ & $\checkmark$ & $\checkmark$ & $\checkmark$ \\
\hline \multirow[t]{2}{*}{ Paradise } & 1 & 5 & $X$ & $\checkmark$ & $\checkmark$ & $X$ & $X$ & $\checkmark$ & $\checkmark$ & $\checkmark$ & $\checkmark$ & $X$ & $X$ & $\checkmark$ \\
\hline & 2 & 10 & $X$ & $X$ & $X$ & $X$ & $X$ & $\checkmark$ & $\checkmark$ & $\checkmark$ & $X$ & $X$ & $X$ & $\checkmark$ \\
\hline Total & 20 & & 4 & 5 & 5 & 5 & 9 & 10 & 7 & 6 & 8 & 10 & 11 & 11 \\
\hline
\end{tabular}




\subsubsection{Barren Island: incipient island growth and beachrock formation}

Barren Island is a unique example of the modern formation of both beachrock and islets at Palmyra. It is presumed to have formed through similar processes as the other island chains at Palmyra as it has a similar composition and elongate shape with a westward concavity. Importantly, it strongly supports the formation of beachrock within the intertidal zone. The beachrock on Barren Island contains mostly fine gravel that is in equilibrium with modern fair-weather conditions. However, the unconsolidated gravel clasts comprising the island require larger than normal waves to be deposited. This gravel, deposited above the modern tidal range under storm conditions, does not show evidence of cementation and consequently highlights the absence of beachrock formation in the supratidal position.

The location of Barren Island is unique due to its position on the reef, as to the east the sea floor quickly drops to around 20-30 m depth. Barren Island does not show the effects of discrete wave events, but rather it illustrates the result of numerous storm events over a relatively short period of time ( $\sim 80$ years). In contrast, the eastern islands were further from the reef edge and normal wave energy would have dissipated before reaching shore even if the more recent islands weren't there. Thus, only discrete major storms are recorded in the beachrock. Furthermore, the sheltering effect caused by the initiation of the island in the 1930's may have led to increased sedimentation within the Eastern Flats area (Maragos et al., 2008a).

Barren Island allows the budget for calcium carbonate sediment to be analysed, as all of its sediment is produced on the Eastern Terrace. Of the estimated 19,500 tonnes of calcium carbonate produced on the Eastern Terrace each year, only $9 \%$ is required to be deposited at Barren Island since 1930 to account for its current size since 1930.

\subsubsection{Sediment budget and carbonate production}

Sediment is continuously transported from the reefs to the islands as fine sediment or, occasionally, as coarse gravel during large storm events, as shown by the SWAN wave modelling. The overall analysis of $\mathrm{CaCO}_{3}$ production at Palmyra shows

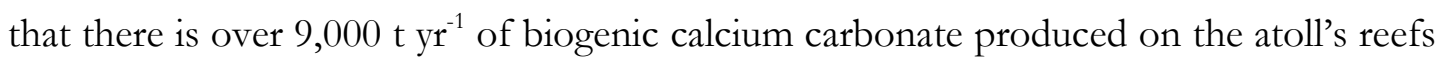
(Fig. 9.1). The ability of reef habitats to produce sediment is a function of the production rate and its position in an area that can exceed the critical shear stress for 
sediment transport. Locations with particularly high amounts of sediment production include the two reef terraces, and the northern and southern reef edges (Fig. 9.1). However, only between $2 \%$ and $10 \%$ of the sediment that is produced on atolls remains on the beaches. The remaining carbonate either remains as framework coral, is deposited in the reef system below high tide or is transported offshore into deeper water.

Due to the dominance of the north-westerly winter swells a large volume of sediment produced is lost off the reef onto the slope and abyssal plain. When considering the current and future distribution of islands on the atoll, the Eastern Terrace is the most important area of $\mathrm{CaCO}_{3}$ production. This is because a higher proportion of $\mathrm{CaCO}_{3}$ produced is moved onto the islands as a result of the dominant easterly trade wind conditions, thus leading to the eastward development of reef islands indicated by the radiocarbon dating. The sediment produced on the Western Terrace, however, is almost entirely lost to deeper waters because the primary direction of strong swells, from the north-west, is not in a landward direction. Consequently, there is no island development on the leeward side of the atoll, and the bottom sediment present is most likely fine sand that has been moved westward by longshore currents or gravel washed in from the reef edge during storm swells from the north and the south.

\subsubsection{Lithofacies and petrologic implications}

Results from the analysis of beachrock lithofacies are in agreement with the literature description of both normal and storm weather deposits on atoll shores (e.g. McKee, 1959), which in turn is consistent with the SWAN results discussed above. That is, most beachrock deposits on Palmyra Atoll are poorly sorted accumulations of pebble to boulder sized clasts, which require depositional energy that exceeds normal weather conditions. This is consistent with the results from the SWAN wave model that show that gravel transport in these positions only occurred under extreme wave events, and mostly at a higher sea level. The exceptions are lithofacies $1 \mathrm{a}$ and $1 \mathrm{~b}$, which are indicative of normal weather conditions and the constant reworking that allows the separation of the fine gravel and sand portions of the deposit.

A large majority of cements show a meniscus fabric binding the grains and enclosing the pore spaces (Fig. 5.13). This is evidence of beachrock formation within the intertidal zone because meniscus fabrics typically form due to the repeated and brief inundation of $\mathrm{CaCO}_{3}$-saturated water. This is also indicated by the presence of aragonite 
as the primary cementing agent, which suggests cementation within the marine phreatic zone. The minor high-Mg calcite cement present in some beachrocks may have formed subsequently in the meteoric vadose zone. The multiple banding in the cement of many samples shows that there were repeated episodes of cement precipitation.

\subsubsection{Orientation of beachrock clasts}

Investigations of the direction of past sediment transport through the measurement of aligned Acropoa sp. clasts show a bimodal distribution of orientations at some, but not all, locations. This is because the deposition of coarse sediments is affected by both the primary direction of the swash, and the refracted direction, which is typically influenced by the direction of long shore transport. Furthermore, the major swash direction has varied through time, particularly on the southern coast. This is most likely due to variations in the direction of the large storm swell waves originating from storm systems in the south Pacific Ocean. For instance, Figure 9.4 shows clast orientations from four beachrock beds that indicate changes in the primary direction of wave energy through time. This may be because storms in the Southern Hemisphere were less constant and varied more in locations through time than their northern counterparts.

\subsection{Sea level in the northern Line Islands}

Sea level data for the central equatorial Pacific Ocean are scarce and many sea level curves are an extension of records from adjacent but distant areas such as the south Pacific. However, Tracey (1972; cited in Grossman et al., 1998) found evidence for a 1-2 $\mathrm{m}$ sea level highstand from studies of emergent coral reef platforms and lagoonal environments on Jarvis, Starbuck, and Malden islands. A 0.5 to $1 \mathrm{~m}$ sea level highstand between 4,500 and 1,500 yrs BP is reported from Christmas (Kiritimati) Island, southeast of Palmyra, by Woodroffe and McLean (1998) from dating of shallow marine biota. These are among the few records of past sea levels in the Line Islands. In addition to these records, interpolated records through sea level highstand date from Pacific islands by Dickinson (2009) suggest a sea level highstand of $\sim 1 \mathrm{~m}$ in the Line Islands around $4000 \mathrm{yrs}$ BP. The sea level record in this thesis is based on observations 
of dated beachrock outcrops at Palmyra. However, beachrock is not often the primary proxy for sea level change, and therefore is discussed in detail here.

\subsubsection{Beachrock as a sea level indicator}

Determining relative sea level change on tropical coastlines is largely dependent on the presence of tidal notches and micro-atolls (Dickinson, 2001). However, these features are often absent on smaller islands, and beachrock may be the only physical record of paleo-sea level. Yet the varying theories of exactly how and where beachrock forms (see Chapter Two) lead to differing opinions about how beachrock is related to sea level change. Many workers (e.g. Hopley, 1986; Kelletat, 2006) suggest that beachrock is not an ideal indicator and warn against its use as proxy for sea level change, particularly in areas with large tidal ranges as this leads to large uncertainty for generally small changes in mean sea level. However, in microtidal environments where other proxies are absent, such as Palmyra, beachrock can be tentatively used as a proxy for relative sea level.

Evidence from Palmyra Atoll agrees with the theory of beachrock formation within the intertidal zone. The beachrock outcrop at Barren Island is presently situated in the intertidal zone and is less than $105{ }^{14} \mathrm{C}$ years old. There is no evidence of supratidal cementation at Palmyra, which is most likely insufficient supply of $\mathrm{CaCO}_{3}$ saturated sea water to precipitate significant amounts of cement. This may be a consequence of wave energy dissipation across the reef flat, where waves lack the energy to create continuous spray into the supratidal zone. Severe or prolonged storm events are a logical exception, but probably occur too infrequently to adequately cement material. Therefore, observational evidence suggests beachrock at Palmyra forms within a narrow $(0.6 \mathrm{~m})$ tidal range, and will record any subsequent meter-scale change in mean sea level. If the relationship between beachrock and sea level holds for older deposits then older beachrock, such as Lost Island, indicate a relative decline in sea level since its formation. However, it is possible that the Palmyra beachrocks were cemented in the subsurface below the beach in a marine - freshwater mixing zone. This would obviously change the utility of such examples as sea level indicators. further examination of the details of their cementation was beyond the scope of the present study.

All paleo-shoreline indicators are measured to the nearest $0.1 \mathrm{~m}$ because greater precision is precluded by natural morphological irregularity or emergent paleo-reef flats (Dickinson, 2001). This precision is considerably worse for paleo-tidal range indicators, 
such as beachrock, because of the inherent limitations due to the extent of the microtidal range (0.6 $\mathrm{m}$ at Palmyra, or greater for areas with larger tidal ranges). Furthermore, the utility of beachrock as a paleo-sea level indicator at Palmyra could be further investigated by comprehensive radiocarbon dating and accurate measure beachrock elevations. This was not achieved in 2010 due to aircraft failure; this will hopefully been achieved in 2011.

\subsubsection{Sea level at Palmyra Atoll}

In 1924, Wentworth (cited in Keating, 1992) visited Palmyra Atoll, saw no evidence for a past higher sea level and suggested that either the islands had not grown to sea level by the mid-Holocene highstand sea level (MHHS), or any features associated with higher sea level had been removed by wave action. However, this thesis suggests beachrock are an indicator of a higher sea level during the mid-Holocene based on two factors. Firstly, evidence from Barren Island shows that beachrock at Palmyra is only formed in the intertidal zone and many outcrops from other islands are now emergent by approximately 0.5 to $1 \mathrm{~m}$. Secondly, results from the SWAN wave model show that an increased sea level is required for wave energy to propagate across the reef flat in order to deposit sediment at the locations further from the reef edge, which were formed in the absence of younger islands to the east. Comparable studies of the late Holocene sea level are often based on emergent reef terraces and microatolls (e.g. Woodroffe and McLean, 1998; Dickinson, 2001). Such investigations at Palmyra may be useful in the clarification of the extent of the MHHS but were beyond the scope of this project.

The maximum age of the beachrock outcrops at Palmyra suggest an unrealistically young age of the MHHS peak compared to other ages given in the Pacific (e.g. Dickinson, 2009). Thus, it is suggested here that beachrock at Palmyra probably corresponds to the falling limb of the sea level curve. This suggestion fits well with the sudden onset and rapid development of the island chains suggested by the radiocarbon dating of the beachrock outcrops. Consequently, beachrock development at Palmyra Atoll may be an indication of the crossover date, the point at which the declining hightide level fell below mid-Holocene low-tide level. Typical dates for this range between 1450 and 550 yrs BP (Table 10.2; Dickinson, 2003), which is similar to the range of radiocarbon ages for Palmyra. A sea level curve (Fig. 10.3) has been determined for 
Palmyra Atoll using the data from the beachrock outcrops and the sea level curves from other locations in the central and south Pacific. This is compared to a similar curve from Dickinson (2009)

Table 10.2: Sea level highstand dates, crossover dates and earliest-known human occupation dates for selected island groups in the Pacific Ocean, including the results of this study (after Dickinson, 2003)

\begin{tabular}{|c|c|c|c|}
\hline Pacific Island/s & $\begin{array}{l}\text { Highstand } \\
\text { date }\end{array}$ & $\begin{array}{l}\text { Crossover } \\
\text { date }\end{array}$ & $\begin{array}{l}\text { Earliest human } \\
\text { occupation }\end{array}$ \\
\hline Cook-Austral groups & 0 B.C.E/0 C.E. & 800 C.E. & 1000 C.E. \\
\hline Fiji-Tonga groups & 1200 B.C.E & 500 C.E. & 950 B.C.E \\
\hline Mariana Islands & 1200 B.C.E & 100 B.C.E & 1800 B.C.E \\
\hline Society Islands & 0 B.C.E/0 C.E. & 500 C.E. & 600 C.E. \\
\hline Tuamotu-Gambier groups & 800 C.E. & 1400 C.E. & 750 C.E. \\
\hline $\begin{array}{l}\text { Tuvalu-Kiribati-Marshall } \\
\text { groups }\end{array}$ & 200 B.C.E & 1100 C.E. & 100 C.E. \\
\hline Palmyra Atoll & 600 C.E. & 1200 C.E. & $\mathrm{Na}$ \\
\hline
\end{tabular}



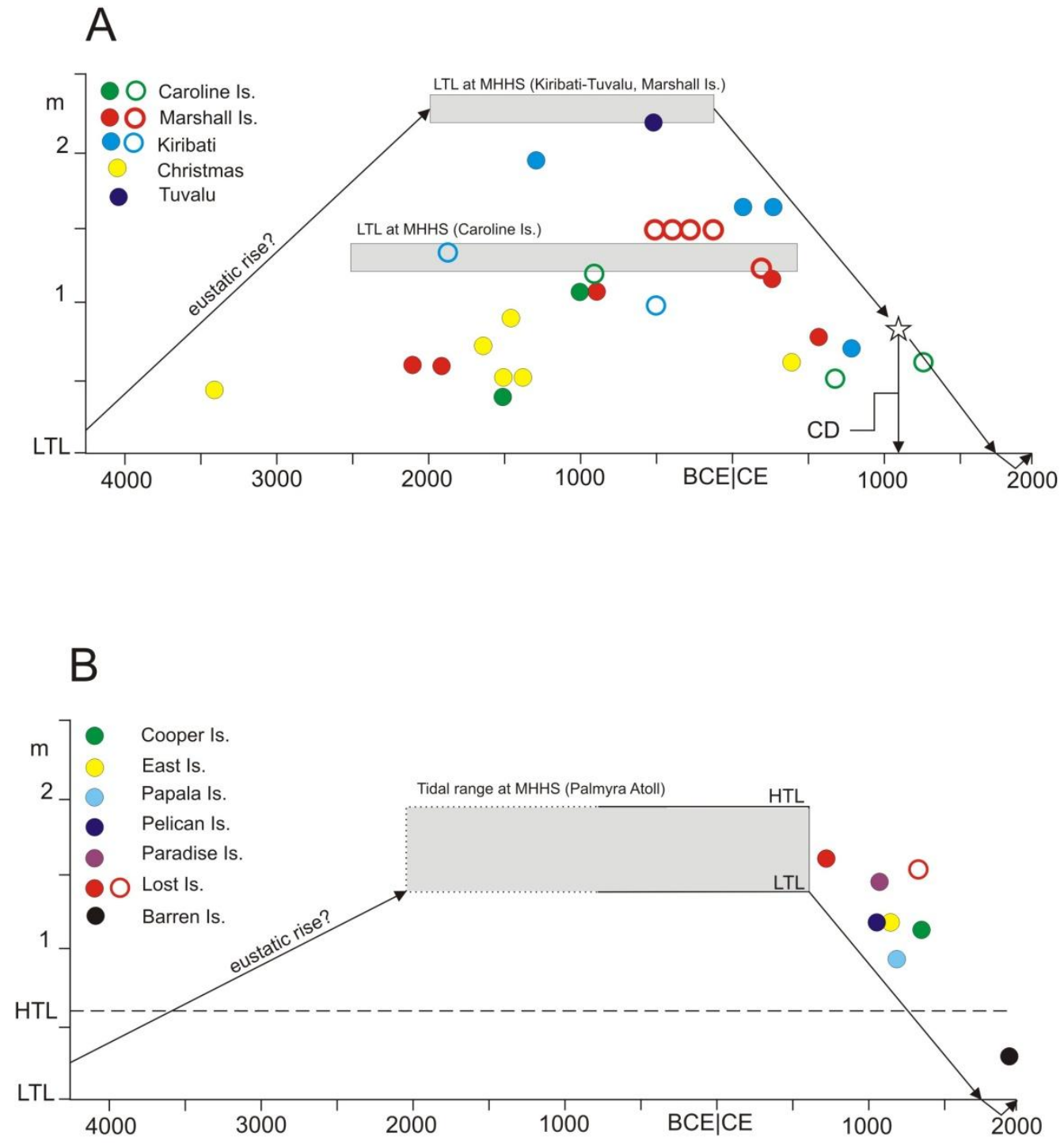

Figure 10.3: (A) (Modified from: Dickinson, 2003) Emergent mid-Holocene paleoreef ages for Caroline $(n=6)$-Marshall $N=10)$ Islands and Kiribati (n=7)-Tuvalu $(n=1)$-Christmas Island $(n=6)$ of the central Pacific region. Solid symbols are paleoreef coral in growth position; open symbols are cemented subtidal paleoreef-flat rubble deposits or calcarenite. Vertical scale is elevation in meters (m) above modern spring low-tide level (LTL); HTL is modern spring high-tide level (tidal range variable by island group. MHHS is the local peak of hydro-isostatic mid-Holocene sea-level highstand as inferred from remnants of midHolocene paleoreef flats or differential elevations of modern shoreline notches and mid-Holocene paleoshoreline notches. Horizontal scale is calendar years. Slopes of inferred early Holocene eustatic rises in sea level and late Holocene hydro-isostatic declines in sea level are hypothetical; CD is resultant crossover date (see text for discussion). (B) Relative sea level change at Palmyra Atoll as indicated by beachrock ages and heights (this study) and the durations of the MHHS from Dickinson (2009). Solid points are position of individual clasts; open points are position of beachrock cement. Tidal range at MHHS (shaded grey) is estimated to have begun 4000 yrs B.P.; the estimated length of the MHHS peak is shown by the dotted line. 
Relative sea level change is a complex relationship between eustatic and isostatic changes and distinguishing between the two is difficult for meter-scale changes over a few thousand years. Mitrovica and Milne (2002) calculated that, following a eustatic sea level rise to modern sea level at 5000 yrs BP, the peak of the MHHS would be over $3 \mathrm{~m}$ at Malden Island, over 200 nautical miles south of the equator in the Line Islands (Fig. 10.4A). Thus, if the eustatic contribution reached modern sea level at the peak of the MHHS, then the isostatic signal is responsible for the $3.4 \mathrm{~m}$ change in sea level over this time. Since Malden Island is relatively close to Palmyra, this situation can reasonably be extrapolated to Palmyra. Therefore, if Palmyra experienced a 1-2 m relative sea level highstand, and there was a $3.4 \mathrm{~m}$ isostatic contribution, then the eustatic contribution did not reach the modern sea level until much later (Fig. 10.4B). That is, some of the sea level fall (due to isostatic processes) has been counteracted by eustatic sea level rise over the same time.

\section{A}

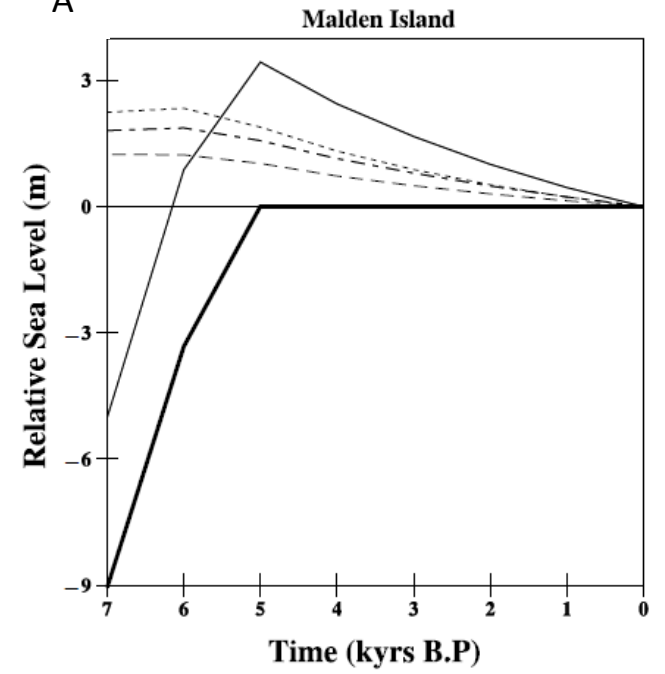

B

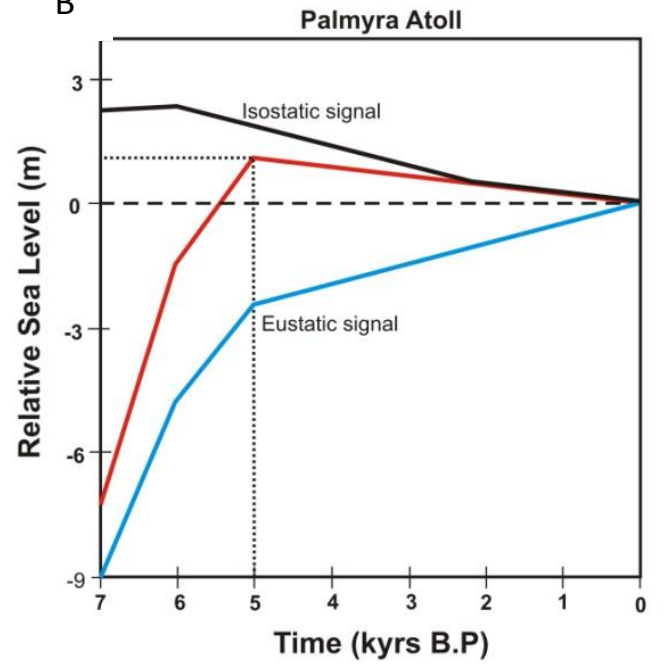

Figure 10.4: (A) (From: Mitrovica and Milne, 2002) Predicted relative sea-level history at Malden Island over the late Holocene and the calculations adopt the test Earth model described by Mitrovica and Milne (2002). The various lines on the figure refer to the sea-level contributions: Thin solid line-the total predicted sea-level variation; thick solid line-the eustatic sea-level trend; dotted line-the sea level change due to ice loading; dashed-dotted line-the sea-level change due to ocean loading; and dashed line-a second estimate of the sea-level change due to ocean loading derived from the 'hypothetical' sea-level variation. (B) Isostatic and eustatic sea level trends at Palmyra Atoll, assuming there is a $3.4 \mathrm{~m}$ isostatic signal based on results from Mitrovica and Milne (2002). This curve uses a theoretical peak of the MHHS at 5 kyr BP. The red line is the total relative sea level trend representing the eustatic sea level plus a $3.4 \mathrm{~m}$ isostatic sea level trend and the blue line is the eustatic sea level and the black line is the isostatic sea level due to ice loading from Mitrovica and Milne (2002). The thin dotted line represents the intersection of the MHHS 5 kyrs B.P. 


\subsection{Quaternary history of Palmyra Atoll}

The geological history of Palmyra is similar to many other oceanic atolls where Cretaceous volcanism, which created the edifice upon which coral reefs grew, has subsequently subsided and eroded to the point where there is no evidence of such material today. The remaining carbonate platform reflects both the inherited morphology from the original volcanic edifice with its overlying coral growth, as well as the subsequent dissolution (karst) morphology developed during periods of low sea level when reef carbonate is exposed to meteoric weathering. Such karst features are manifested in the morphology of the modern atoll as deep $(\sim 60 \mathrm{~m})$ lagoons. Other processes have contributed to the atoll, possibly including slumping, edifice failure, and potential large tsunamis.

\subsubsection{Development of beachrock and reef islands}

Pinned islands are important to the development and stabilisation of the atoll and require the presence of an underlying consolidated base (Dickinson, 2004) and are preferentially formed under falling sea level. Therefore, the carbonate platform of Palmyra must have been within a certain distance of sea level to allow the formation of stable islands. The time of origin of stable reef islands at Palmyra is inferred from the ages of beachrock outcrops, which are assumed to form soon after the initial island growth and to subsequently provide protection from wave erosion

The modern configuration of the reef islands at Palmyra Atoll is largely the result of the underlying carbonate platform and its interplay between sea level, sediment production and transport processes. Results from radiocarbon dating of the beachrock at Palmyra suggest that the reef islands formed rapidly eastward during the falling limb of the MHHS. The progressive formation of reef islands occurred in island chains that subsequently ceased to grow once a younger island chain was formed. Dawson (1959) recognised the progressive formation of the reef islands eastward and that the central and eastern lagoons were formed more recently than West Lagoon. However, this was attributed the raised beachrock outcrops on the eastern side of the atoll to tilting of the atoll, resulting in the deeper Western Terrace (Keating, 1992). This suggestion ignored the deeper Eastern Terrace and implied that Palmyra is not an emergent atoll and thus has seen no sea level change during the late Holocene. This is unlikely due to the extent of the MHHS reported for the Pacific (Chapter Two). Formation of the beachrock, and 
thus reef islands, on Palmyra during a higher sea level is evidenced by the relative height of the beachrock outcrops and the results of the SWAN wave modelling.

The absence of stable landmasses during the peak of the MHHS suggests that the carbonate platform was below the critical depth for which reef islands can be maintained. Thus, the position of carbonate platform relative to sea level is the primary control over the growth of reef islands. For instance, Kingman Reef north of Palmyra has a large reef base but only transient sand cays are able to exist as the sea level is too high above the carbonate platform. It may have been that during the peak of the MHHS Kingman was entirely submerged and at Palmyra only transient sand cays existed, such as those at Kingman today, which agrees with other theories of reef islands formation after the peak of the MHHS (e.g. Barry et al., 2007; Dickinson, 2009). Therefore, although there may have been older beachrock or reef islands on Palmyra, these were most likely destroyed through wave action at the higher sea level. It is also possible that older islands and beachrock were lost due to catastrophic edifice failure leading to slumping of a portion of the atoll. Given the surrounding bathymetry, this is most likely to have occurred on the western or southern sides of the atoll.

The reef islands of Palmyra have developed rapidly eastward over the past millennium after the sudden onset of beachrock deposition. Beachrock deposits are youngest in the east, with the oldest at Lost Island in the centre (Fig. 10.1). This demonstrates formation of reef islands progressively to the east, in the windward direction, during a time when sea level was declining from the MHHS (Fig. 10.4). This has occurred sequentially over approximately $2.5 \mathrm{~km}$ in at least $1200 \mathrm{yrs}$.. This model of islet formation is supported by the SWAN modelling, which shows that to form the inner islands a higher sea level with no sheltering from the east is required.

This accretion is dominated by periods of islet growth, initiated by the accumulation of the storm sediments now cemented in beachrock. These are represented by the Lost-Fern Island chain, the eastern island chain and modern Barren Island. Between these chains the sand flats formed through a relative fall in sea level, which may have been a result of a decrease in the regional sea level, or by a build up of sand on the reef flats. Consequently, there was greater dissipation of wave energy and waves were no longer able to propagate as far inward; hence, coarser clasts were deposited further eastward. 
The periods of island-building events around 1249 yrs BP (Lost Island chain) and 845 yrs BP (East Island chain) highlight the fact that there has not been a steady and gradual accretion of the reef islands. Instead, there may have been an hiatus in the decline of relative sea level, or a period where extreme events were more frequent, to allow the accumulation of sufficient sediment to create pinned islands. The sea level hiatus theory is supported by the development of Barren Island over the past 80 years, a period with a marginal increase in sea level $(2.0 \mathrm{~mm} / \mathrm{yr}$ over the past 20 years; Church et al., 2006), rather than decline. However, the migration of islands may also depend on the nature of the local bathymetry. For instance, if there was a pre-existing high point under Barren Island, this would cause the shore to 'jump' eastward under a falling sea level.

Furthermore, the development of the atoll is not restricted to the windward propagation of island chains. Simultaneously with the growth of the reef islands described above, there was stabilisation of crucial areas on the north and south coast (particularly Cooper, Holei and Paradise islands) through the cementation of large outcrops of beachrock. The thickness of the outcrops suggest that these developed over a longer period of time than their eastern counterparts. Additionally, limited supply of sediment and surrounding bathymetry would reduce the lateral migration of these shorelines. The understanding of the permanence of these outcrops, and their effects on stabilisation of the coastline, is limited by the lack of dates for these area.

\subsubsection{Additional shoreline changes}

Beachrock can be used as an indication of shoreline change due to its position on the beachface during deposition and thus will record any subsequent movement of these positions. The past extent of the original island can be inferred through an investigation of the strike and dip pattern of the eroded beachrock platforms. For instance, the beachrock on Barren Island supports westward migration of the eastern shore of the island of approximately $5 \mathrm{~m}$ over the past 80 years (see section 9.4).

The beachrock outcrop on the northern point of East Island (see Fig. 6.2) contains evidence for significant shoreline shifts in its extensive, eroded beachrock platform in the form of bedding patterns that differ from the trend of the current shoreline. Firstly, there are beachrock remnants which extend seaward from the island and form a point on the north-eastern tip of the island (Fig. 6.2), with the beachrock dipping away from the centre of the original island. To the west, the beachrock 
continues to dip to the west, which may suggest that the original island was significantly greater in area and extended further onto the reef flat, compared to the present day. Beachrock representing the northern edge of this island may have been completely eroded or may have been present below the tide level at the time of mapping. The previous inferred shape of the island suggests that it was the northern end of the Lost Island chain, as mentioned previously (Fig. 6.2).

Subsequently, the second phase of beachrock formation is similar to the other outcrops on East Island in that it forms ledges close to the vegetated edge of the modern island. This beachrock ledge also strikes similarly to sediments of the modern island and dips northward. Therefore, it is assumed that this second phase of beachrock formed when the island was in a orientation similar to today, suggesting there has not been significant changes in sedimentary patterns since the beachrock formed. Dating of these outcrops would further clarify this but no appropriate material was found.

\subsubsection{Effects of beachrock on coastline evolution at Palmyra Atoll}

Beachrock, once lithified, plays a critical role in the development of reef islands. In particular, beachrock outcrops anchor the otherwise dynamic islands, which stabilises the coastline and protects it from erosion (e.g. Dickinson, 2004). This has been suggested by other authors (e.g. Vousdoukas et al., 2007) and appears to be a common feature of microtidal shorelines. Although oceanic atolls and their islands are regarded as very dynamic entities beachrock has a localised effect that limits the erosion and transport of nearby sediment, particularly on the leeward side of outcrops. Consequently, this stabilises portions of land over relatively long time periods (thousands of years). In many locations on Palmyra, the outcrops occur as projecting points on the coastline that have sandy beaches on their leeward sides. This suggests that beachrock is not only stabilising the land behind, but also allowing the accumulation of fine sediment by sheltering it from longshore currents. As a result beachrock may play a critical role in the transformation of the islands from transient sand cays to more stable reef islands that can sustain vegetation and soils over long periods. 


\subsection{Limitations and potential future studies}

\subsubsection{Beachrock: an underdeveloped proxy for environmental changes?}

The occurrence of beachrock has been documented worldwide and its presence is known to have significant impacts on the sediment budget of tropical coasts, however, its potential as an indicator for environmental change is a relatively unrecognised aspect of paleo-climate studies. Despite this, it is often the only record of the past physical environments for some of the world's most vulnerable coastlines. Beachrock can best used as a paleo-environmental change after the MHHS because beachrock at Palmyra is relatively young, and yet there is still significant erosion evident in even the most sheltered of locations. This is in agreement with the typical resilience of beachrock, in that it is stable only over relatively short time periods (thousands of years; Vousdoukas et al., 2007).

In this thesis, beachrock is used primarily as an indication of sea level change and this is discussed throughout this thesis. However, additional information about the paleo-environment may be gained from beachrock and its constituents. It is commonly reported in the literature (e.g. Dickinson, 2001) that the beachrock detritus is identical to the uncemented detritus on the same beaches. However, many outcrops of beachrock at Palmyra show that this is an oversimplification, and where differences occur they may prove useful in the determination of depositional conditions and environmental change, such as those shown on Palmyra through the SWAN wave modelling.

Furthermore, beachrock contains clasts which may prove to be of value for geochemical studies of paleo-SST or SSS. The fossilised Tridacna valves consist of extremely dense calcite that proved suitable for radiocarbon dating and may also be utilised similar to sclerochronology, due to layers of daily growth bands within the shell. This has been accomplished with other bivalve species (e.g. Klein et al., 1996; Freitas et al., 2005). Yet, the relationship between climate parameters and the geochemistry of the Tridacna spp. has not been established and consequently, direct measurements of paleoSST or SSS are not as yet possible (Elliot et al., 2009). Despite the restrictions to geochemical proxies, beachrock outcrops provide a unique opportunity to understand the physical environment, which has important implications to the sedimentary processes of many atolls and low-lying islands. 


\subsubsection{Comparison to coral records}

All of the Palmyra Atoll beachrock dates, with the exception of Barren Island, fall within a relatively narrow age range ( $\sim 03 \mathrm{yrs})$, which overlap with the $\mathrm{U} / \mathrm{Th}$ ages from the Porites corals obtained by Cobb et al. (2003b), the only other record extending into the geological past at Palmyra. Comparison with the climate record of Cobb et al. (2003a; Fig. 10.5) shows that most of the ages of the beachrock clasts overlap with the Medieval Warm Period (MWP), which extended from around 800 to 1200 C.E. and produced relatively warm temperatures in the Northern Hemisphere. However, $\delta^{18} \mathrm{O}$ records from Palmyra show cooling in the Pacific during this time and imply a decrease in latitudinal temperature gradients (Cobb, 2002). This would have caused a weakening of the Hadley Circulation leading to decreased moisture transport out of the tropics and a decrease in trade winds strength. However, no clear relationship between the MWP and the beachrock formation at Palmyra is apparent. Other climatic records, such as temperature or oxygen isotope trends, do not show a relationship so if beachrock formation is influenced at all by these processes then the relationship is unclear.

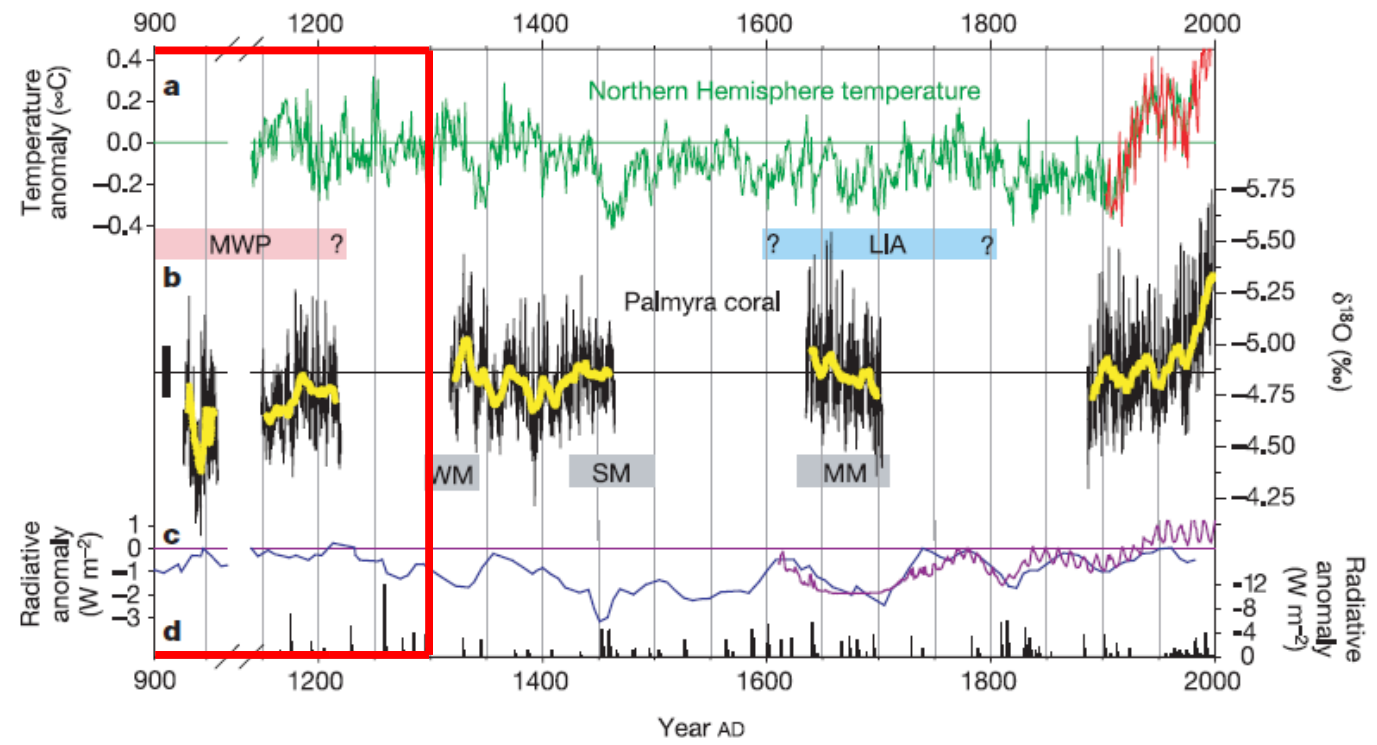

Figure 10.5: Comparison of monthly resolved $\delta^{18} 0$ coral records from Palmyra (black line), shown with a 10 year running average (yellow line) and other proxy climate records and external forcing during the last millennium (from Cobb et al. 2003a). The red box indicates the range of beachrock ages from Palmyra Atoll that overlaps with the Cobb record. 


\subsubsection{Comprehensive dating of reef islands}

The understanding of the geological history of reef islands may be enhanced by more thorough radiocarbon dating. The radiocarbon dating used in this study was restricted to seven samples from six beachrock outcrops. Since most of the beachrock on Palmyra probably formed during infrequent, extreme wave events, it may be possible to date the individual events by dating each bed. This gives the potential to understand the frequency of such large events and to understand the formation period of beachrock outcrops.

Despite the potential to aid understanding through a more comprehensive radiocarbon study, appropriate material is scarce within the beachrock. Tridacna valves were primarily used here, yet these are extremely rare as fossil deposits and are often absent from beachrock exposures. Turbo spp. shells are more common in exposures but are also more susceptible to erosion and are often too degraded to allow accurate dating. Other material in the older beachrock, such as coral fragments, is often too recrystallised for an accurate age to be determined. Uranium series dating would provide a more widely applicable dating method but was not employed here because of lack of funding.

\subsubsection{Baseline data collection}

The Intergovernmental Panel on Climate Change (IPCC) lists wave climate as one of six climate drivers for coastal systems. However, there has been no formal assessment of baseline wave climate conditions, climate change effects on wind waves, or of the likelihood of future extreme wave events at national or island scales for the PICTs (Christensen et al., 2007). Therefore, the limiting factor in assessing the effects of climate change on coastal areas is insufficient information on the variability and trends in surface ocean wind-waves, rather than a lack of awareness of coastal processes. An important aspect to arise from the numerical modelling undertaken for this thesis is the significant lack of long term environmental data for the oceanic Pacific, which produces difficulties when attempting to manage or monitor environmental aspects. In particular, the past wave climate in the Pacific is poorly understood. The present study highlights the importance, and influence, of infrequent, extreme wave events on small, low-lying islands. The hindcast model used in this study only covers the period 1997-2009, which is a short enough period to likely exclude any large, infrequent events and to conceal 
long term trends. It is therefore imperative that there is sufficient baseline data to understand the variability and trends in surface ocean wind-waves.

Furthermore, bathymetry is an important factor for almost all studies of Pacific. In this thesis, the bathymetry used was measured using SWATH mapping for the deeper waters. This is an accurate method of mapping bathymetry but it is limited to waters deeper than $\sim 30 \mathrm{~m}$ and those with ship access. In order to map the expansive shallow waters of Palmyra, satellite altimetry was used. This is relatively inexpensive but is significantly less accurate that other methods. The preferred method for shallow water bathymetry is lidar mapping, which is considerably more accurate but also more expensive. Although lidar bathymetry is beyond the scope of the current project, any improvement to the baseline data in any study will produce more accurate, and thus more applicable, results.

\subsubsection{Developing the appropriate modelling tools}

Currently, global climate models do not provide the necessary resolution needed to assess impacts on coastal areas at Pacific island scales and, therefore, downscaling is required to provide an appropriate basis for disaster risk reduction and adaptation to climate change in coastal areas. SWAN has been useful in this thesis for its ability to sufficiently model conditions on a local scale (less than $30 \mathrm{~km}$ in both distance and in terms of water depth). Although the appropriateness of SWAN for computing wave setup on steep reef crests has yet to be comprehensively assessed, it appears to be the most suitable numerical wave model for this work (see Chapter Seven).

Further potential for the use of the SWAN wave model demonstrated in this study includes investigation of the impact of individual wave parameters, and their effect on the bed shear stress, which has not yet been completed for Palmyra. For instance, wave period varies greatly depending on the source and generation of the wave. The effects of variation in wave period and directional spreading were not fully investigated here but may have a large effect on the wave energy. 


\subsection{Summary: local and global conclusions}

This thesis had four main objectives, which were textural, geochemical, hydrodynamic investigations of the beachrock of Palmyra Atoll, as well as providing a model of how the reef islands and beachrock outcrops of Palmyra Atoll have developed as a consequences of physical and biological processes. These in turn established the relationship between the beachrock characteristics, the paleo-environment and sea level, which ultimately led to the understanding of the development of Palmyra's reef islands throughout the late Holocene. The results from this study assist understanding of the local sedimentary environment, which may aid the management and conservation of this unique environment. Conclusions for the sedimentary processes of Palmyra Atoll are summarised below:

- Six lithofacies identified in the beachrock outcrops on Palmyra Atoll are diagnostic of formation in a shallow marine coastal environment, mostly due to high depositional energy.

- Geochemical evidence is also indicative of the depositional environment. The aragonite cements suggest cementation within the marine phreatic zone and significant banding and meniscus fabrics also indicate formation within the intertidal zone.

- Palmyra Atoll reef islands are comparatively young, with the oldest known age (1249 cal. yrs BP) coming from a fossilised Tridacna shell cemented within the beachrock on Lost Island.

- Textural investigations and numerical wave modelling show that the majority of beachrock on Palmyra forms rapidly during infrequent and extreme wave events during a higher sea level.

- Reef islands have developed windward as the sea level fell from at least a $1 \mathrm{~m}$ high stand in the mid-Holocene over 1250 yrears ago; and subsequent beachrock cementation provided a degree of stability.

- The MHHS is suggested to be prolonged, or delayed, in the central equatorial Pacific.

- Beachrock outcrops anchor the dynamic islets at Palmyra Atoll, helping to transform transient sand cays to pinned islets and protecting some coastlines on a millennial timescale. 
The conclusions drawn from this study also impact on the understanding of tropical coastlines elsewhere, in particular among Pacific islands, which are extremely vulnerable and lack sufficient environment and climate baseline data. These broad, global conclusions are summarised below:

- Beachrock is demonstrated to be cemented within the intertidal zone, and as such can be a useful indication of relative sea level change in locations where other proxies may be missing.

- Textural characteristics of beachrock show a direct relationship to their depositional environment, and as such can be used as an indicator of environmental change.

- The results from the SWAN wave model demonstrate the long term impact of extreme, infrequent wave events and, if cemented, can have permanent effects on the stabilisation and protection of atoll shorelines.

- This study shows that the SWAN model can give relatively robust results for oceanic reef environments, even where long term environmental baseline data is scarce or absent.

- This study highlights the importance of the need for baseline data in order to understand atoll processes and, thus, to effectively manage some of the world's most vulnerable coastlines.

Overall, this study has significant implications for understanding the geological development of Palmyra Atoll, as well as contributing to an holistic understanding of sedimentary processes within complex atoll environments. Although many aspects and results described here are unique to Palmyra Atoll and its beachrock, the processes involved can be applied to oceanic atolls worldwide. In particular, the application of the SWAN wave model to small, low-lying areas of the Pacific is important as it presents an opportunity to obtain robust results relevant to environmental change in areas where long term environmental data is often absent. These results affect not only the understanding of beachrock and reef island development but also atoll sedimentary processes, which are increasingly important as the world enters an era of climatic uncertainty and instability in which low-lying coastlines are extremely vulnerable. 


\section{References}

Adams, A.E., and MacKenzie, W.S. (1998) A colour atlas of carbonate sediments and rocks under the microscope. John Wiley and Sons, New York and Toronto

Andrefouet, S., Ouillon, S., Brinkman, R., Falter, J., Douillet, P., Wolk, F., Smith, R., Garen, P., Martinez, E., Laurent, V., Lo., C., Remoissenet, G., Sourzic, B., Gilbert, A., Deleersnijder, E., Steinberg, C., Choukroun, S., and Buestel, D. (2006) Review of solutions for 3D hydrodynamic modelling applied to aquaculture in South Pacific atoll lagoons. Marine Pollution Bulletin. Vol. 52, Iss. 10, pp. 1138-1155

Anthony, E.J. (2009) Shore processes and their paleoenvironmental applications. Developments in Marine Geology. (Chamley, H. [series ed.]) Vol. 4

Barry, S.J., Cowell, P.J., and Woodroffe, C.D. (2007) A morphodynamic model of reefisland development on atolls. Sedimentary Geology, 107, 47-63

Bayliss-Smith, T.P. (1988) The role of hurricanes in the development of reef islands, Ontong Java Atoll, Solomon Islands. The Geographical Jounral. Vol. 154, No. 3, pp. 377-391

Baines, G.B.K., and McLean, R.F. (1976) Sequential studies of hurricane deposit evolution at Funafuti Atoll. Marine Geology. Vol. 21, pp. M1-M8

Bellwood, D.R. (1995) Direct estimate of bioerosion by two parrotfish species, Chlorurus gibbus and C.sordidus, on the Great Barrier Reef, Australia. Marine Biology. Vol. 12, No. 3, pp. 419-429

Berner, R.A. (1971) Bacterial processes effecting the precipitation of calcium carbonate in sediments. In: Carbonate Cements (Bricker, O.P. [ed.]). Johns Hopkins University Press. Pp. 247-251

Bird, E.(2000) Coastal geomorphology: An introduction. John Wiley and Sons, Chichester. 317 pp.

Blanchon, P., Jones, B., and Kalbfleisch, W. (1997) Anatomy of a fringing reef around Grand Cayman: storm rubble, not coral framework. Journal of Sedimentary Research. Vol. 67, No. 1, pp. 1-16 
Booij, N., Ris, R.C., and Holthuijsen, L.H. (1999) A third-generation wave model for coastal regions 1. Model description and validation. Journal of Geophysical Research. Vol. 14, No. C4, pp. 7649-7666

Brainard, R., Maragos, J., Schoeder, R., Kenyon, J., Vroom, P., Godwin, S., Hoeke, R., Aeby, G., Moffitt, R., Lammers, M., Gove, J., Timmers, M., Holzwarth, S., and Kolinski, S. (2005) The state of coral reef ecosystems of the U.S. Pacific Remote Island Areas.

Brander, R.W., Kench, P.S., and Hart, D. (2004) Spatial and temporal variations in wave characteristics across a reef platform, Warraber Island, Torres Strait, Australia. Marine Geology. Vol. 207, pp. 169-184

Buddemeier, R.W., and Smith, S.V. (1988) Coral reef growth in an era of rapidly rising sea level: predictions and suggestions for long-term research. Coral Reefs. Vol. 7, pp. $51-56$

Bush, G.W. (2009) Establishment of the Pacific Remote Islands Marine National Monument A Proclamation by the President of the United States of America. (http://www.fws.gov/pacificremoteislandsmarinemonument/PP\%20PRIMNM.p df)

Chappell, J. (1980) Coral morphology, diversity and reef growth. Nature. Vol. 286, pp. $249-252$

Chazottes, V., Le Campion-Alsumard, T., and Peyrot-Clausade, M. (1995) Bioerosion rates on coral reefs: interactions between macroborers, microborers and grazers (Moorea, French Polynesia). Paleogeography, Paleoclimatology, Paleoecology. Vol. 113, pp. $189-198$

Christensen, J.H., B. Hewitson, A. Busuioc, A. Chen, X. Gao, I. Held, R. Jones, R.K. Kolli, W.-T. Kwon, R. Laprise, V. Magaña Rueda, L. Mearns, C.G. Menéndez, J. Räisänen, A. Rinke, A. Sarr and P. Whetton, (2007) Regional Climate Projections. In: Climate Change 2007: The Physical Science Basis. Contribution of Working Group I to the Fourth Assessment Report of the Intergovernmental Panel on Climate Change (Solomon, S., D. Qin, M. Manning, Z. Chen, M. Marquis, K.B. Averyt, M. Tignor and H.L. Miller [eds.]). Cambridge University Press, Cambridge, United Kingdom and New York, NY, USA. 
Church, J.A., and White, N.J. (2006) A $20^{\text {th }}$ century acceleration in global sea-level rise. Geophysical Research Letters. Vol. 33, L01602, pp. 1-4

Church, J.A., White, N.J., Hunter, J.R., (2006) Sea-level rise at tropical Pacific and Indian Ocean islands. Global and Planetary Change. Vol. 53, pp. 155-168.

Chave, K.E., Smith, S.V., and Roy, K.J. (1971) Carbonate production by coral reefs. Mairne Geology. Vol. 12, pp.123-140

Clark, P.U., McCabe, A.M., Mix, A.C., and Weaver, A.J. (2004) Rapid rise of sea level 19,000 years ago and its global implications. Science.Vol.304, pp. 1141-1144

Cloud, P.E. (1962) Environment of calcium carbonate deposition of Andros Island, Bahamas: U.S. Geological Survey Professional Papers. Vol. 350, pp. 1-138

Cobb, K.M. (2002) Coral record of the El Niño-Southern Oscillation and tropical Pacific Climate over the last millennium. Thesis ( $\mathrm{PhD})$. University of California, San Diego.

Cobb, K.M., Charles, C.D., Cheng, H., and Edwards, R.L. (2003)a El Nino/Southern Oscillation and tropical Pacific climate during the last millennium. Nature. Vol. 424, pp. $271-276$

Cobb, K.M., Charles, C.D., Cheng, H., Kastner, M., and Edwards, R.L. (2003)b U/Thdating living and young fossil corals from the central tropical Pacific. Earth and Planetary Science Letters. Vol. 210, pp. 91-103

Collen, J.D., Garton, D.W., and Gardner, J.P.A. (2009)a Shoreline changes and sediment redistribution at Palmyra Atoll (Equatorial Pacific Ocean): 1874 Present. Journal of Sediment Research. Vol 25(3), pp. 711-722

Collen, J.D., Gardner, J.P.A., Garton, D.W. (2009)b Application of the littoral cell concept to managing a protected atoll: Palmyra Atoll National Wildlife Refuge . Ocean and Coastal Management. Vol. 52, pp. 628-635.

Cowell, P.J. and Kench, P.S. (2001) The morphological response of atoll islands to sealevel rise. Part 1: modifications to the shoreface translation model. Journal of Coastal Research, 34, 633-644

Darwin, C. (1842) The structure and distribution of coral reefs. Berkeley, University of California Press, reprinted 1962, 214 p. 
David, P., Panagiotis, T, and Konstantinos, A. (2009) Electrical resistivity tomography mapping of beachrocks: application to the island of Thassos (N. Greece). Environment and Earth Science. Vol. 59, pp. 233-240

Davis, P.J., and Kinsey, D.W. (1973) Organic and inorganic factors in recent beach rock formation, Heron Island, Great Barrier Reef. Journal of Sedimentary Research. Vol. 43, pp. 59-81

Davis A.S., Gray, L.B., Clague, D.A., and Hein, J.R. (2002) The Line Islands revisited: New ${ }^{40} \mathrm{Ar} /{ }^{39} \mathrm{Ar}$ geochronologic evidence for episodes of volcanism due to lithospheric extension. Geochemistry, Geophysics, Geosystems. Vol 3(3), pp. 10.

Dawson, E.Y. (1959) Changes in Palmyra Atoll and its vegetation through the activities of man 1931-1958. Pacific Naturalist. Vol. 1, no. 2, pp 3-5

Desruelles, S., Fouache, E., Ciner, A. Dalongeville, R., Pavlopoulos, K., Kosun, E., Coquinot, Y., and Potdevin, J. (2009) Beachrocks and sea level changes in Middle Holocene: Comparison between the insular group of Mykonos-Delos-Rhenia (Cyclades, Greece) and the southern coast of Turkey. Global and Planetary Change. Vol. 66, pp. 19-33

Dickinson, W.R. (1999) Holocene sea-level record on Funafuti and potential impact of global warming on central Pacific atolls. Quaternary Research. Vol. 51, pp. 124-132

Dickinson, W.R. (2001) Paleoshoreline record of relative Holocene sea levels on Pacific islands. Earth-Science Reviews. Vol. 55, pp. 191-234

Dickinson, W.R. (2003) Impact of mid-Holocene hydro-isostatic highstand in regional sea level on habitability of islands in Pacific Oceanic. Journal of Coastal Research. Vol. 19, no. 3, pp. 489-502

Dickinson, W.R. (2009) Pacific atoll living: how long already and until when? GS A Today. Vol 19, no. 3, pp. 4-10

Dollar, S.J. (1982) Wave stress and coral community structure in Hawaii. Coral Reefs. Vol. 1, Iss. 2, pp. 71-81

Dunham, R.J. (1962) Classification of carbonate rocks according to depositional texture. In: Classification of carbonate rocks (Ham, W.E. [eds.]). American Association of Petroleum Geologists Memoir 1, 108-121 
Elliot, M., Welsh, K., Chilcott, C., McCulloch, M., Chappell, J., and Ayling, B. (2009) Profiles of trace elements and stable isotopes derived from giant long-lived Tridacna gigas bivalves: Potential applications in paleoclimate studies. Paleogeography, Paleoclimatology, Paleoecology. Vol. 280, pp. 132-142

Embry, A.F., and Klovan, J.E. (1971) A Late Devonian reef tract on Northeastern Banks Island, NW'T. Canadian Petroleum Geology Bulletin. Vol. 19, p. 730-781.

Fairbanks, R.G., Mortlock, R.A., Tzu-Chien, C., Cao, L., Kaplan, A. et al. (2005) Radiocarbon calibration curve spanning 0 to 50,000 years BP based on paired ${ }^{230} \mathrm{Th} /{ }^{234} \mathrm{U} /{ }^{238} \mathrm{U}$ and ${ }^{14} \mathrm{C}$ dates on pristine corals. Quaternary Science Reviews. Vol. 24, pp. $1781-1796$

Feigl, F. (1958) Spot test in inorganic analysis. $5^{\text {th }}$ ed. Elsevier Publishing Company, Amsterdam, 600 p.

Ferguson, S., Musburger, C., Ayotte, P., Wass, T., Vargas-Angrl, B., et al. (2006) Hi'ialakai HI0604 Cruise Report. NOAA Publication. www.soest.hawaii.edu/pibhmc/

Fernandez, J.M., Ouilon, S., Chevillon, C., Douillet, P., Fichez, R., Le Gendre, R. (2006) A combined modelling and geochemical study of the fate of terrigenous inputs from mixed natural and mining sources in a coral reef lagoon (New Caledonia). Marine Pollution Bulletin. Vol. 52, pp. 320-331

Flood, P.G., and Scoffin, T.P. (1978) Reefal sediments of the northern Great Barrier Reef. Philosophical Transactions of the Royal Society of London. Series A, Mathematical and Physical Sciences. Vol. 291, No. 1378, pp. 55-68

Folk, R.L. (1959) Practical petrographic classification of limestones. American Association of Petroleum Geologists Bulletin. Vol. 43, pp. 1-38

Folk, R.L. (1962) Spectral division of limestone types. In: Classification of carbonate rocks (Ham, W.E. [eds.]). American Association of Petroleum Geologists Memoir 1, 6284

Folk, R.L., Roberts, H.H., and Moore, C.H. (1973) Black phytokarst from Hell, Cayman Islands, British West Indies. Geological Society of America Bulletin. Vol. 4, pp. 23512360 
Frankel, E. (1968) Rate of formation of beach rock. Earth and Planetary Science Letters 4. North-Holland Publishing Company, Amsterdam. Pp. 439-440

Fredsoe, J., and Deigaard, R. (1992) Mechanics of coastal sediment transport. Advanced Series on Ocean Engineering. Vol. 3, World Scientific Publishing, Singapore

Freitas, P., Clarke, L.J., Kennedy, H., Richardson, C., and Abrantes, F. (2005) Mg/Ca, $\mathrm{Sr} / \mathrm{Ca}$, and stable-isotope $\left(\delta^{18} \mathrm{O}\right.$ and $\left.\delta^{13} \mathrm{C}\right)$ ratio profiles from the fan mussel Pinna nobilis: Seasonal records and temperature relationship. Geochemistry Geophysics Geosystems. Vol. 6, no. 4, pp. 1-16

Friedman, G.M. (2005) Climate significance of Holocene beachrock sites along shorelines of the Red Sea. American Association of Petroleum Geologists Bulletin. Vol 89, no. 7 , pp. $849-852$

Gaia Geo-Analytical, Davey Jones Locker GIS Laboratory, Oregon State University for Coral Reef Ecosystem Division, NOAA Pacific Islands Fisheries (2009) Mosaic of bathymetry derived from multispectral IKONOS satellite imagery of Palmyra Atoll, Pacific Remote Island Area, USA. Downloaded from http://soest.hawaii.edu/pibhmc/ pibhmc_pria_pal_bathy.htm on 1/6/2010

Gardner, J.P.A., Garton, D.W., Collen, J.D. (2011) Near-surface mixing and pronounced deep-water stratification in a compartmentalised, human-disturbed atoll. Coral Reefs (in press).

Gischler, E. And Lomando, A.J. (1997) Holocene cemented beach deposits in Belize. Sedimentary Geology. Vol. 110, pp. 277-297

Graham, J. (1988) Collection and analysis of field data. In: Techniques in Sedimentology (Tucker, M [ed.]). Blackwell Scientific Publications Inc. pp. 5-62

Grigg, R.W. (1982) Darwin Point: A threshold for atoll formation. Coral Reefs. Vol. 1 pp. 29-34

Grossman, E.E., Fletcher III, C.H., and Richmond, B.M. (1998) The Holocene sea-level highstand in the equatorial Pacific: analysis of the insular paleosea-level database. Coral Reefs. Vol. 17, pp. 309-327 
Haggerty, J.A., Schlanger, S.O., and Silva, I.P. (1982) Late Cretaceous and Eocene volcanism in the southern Line Islands and implications for hotspot theory. Geology. Vol. 10, pp. 433-437

Hanmann, I.M., Boehlert, G.W., and Wilson, C.D. (2004) Effects of steep topography on the flow and stratification near Palmyra Atoll. Ocean Dynamics. Iss. 54, pp. 460473

Hanor, J.S. (1978) Precipitation of beachrock cements: mixing of marine and meteoric waters vs. $\mathrm{CO}_{2}$-degassing. Journal of Sedimentary Petrology. Vol. 48, no. 2, pp. 489-501

Harney, J.N., and Fletcher III, C.H. (2003) A budget of carbonate framework and sediment production, Kailua Bay, Oahu, Hawaii. Journal of Sedimentary Research. Vol. 73 , no. 6 , pp. $856-868$

Hasselmann, K., Barnett, T.P., Bouws, E., Carlson, H., Enke, K., Ewing, J.A., Gienapp, H., Hasselman, D.E., Kruseman, P., Meerburg, A., Miller, P., Olbers, D.J., Richter, K., Sell, W., and Walden, H.. (1973) Measurements of wind-wave growth and swell decay during the Joint North Sea Wave Project (JONSWAP). Ergnzungsheft zur Deutschen Hydrographischen Zeitschrift Reihe Vol. 12, A8, pp. 1-95

Hoeke, R.K., Storlazzi, C.D., and Ridd, P.V. (in press) Hydrodynamics of a bathymetrically complex fringing coral reef embayment: wave climate, in situ observations and wave prediction. Journal of Geophysical Research.

Hopley, D. (1986) Beachrock as a sea-level indicator. In: Sea-level Research (Van de Plassche, O. [ed.]). Galliard Printers, Great Yarmouth, pp. 157-173

Hopley, D. (1987) Coral reef islands in a period of global sea-level rise. In: Sea Surface Studies (Deroy, R.J.N [ed.]). Crown Helm, London, pp 275-408

Hopley, D. (1996) Coral reeds and small islands - implications of more modest climate and sea-level change predictions. In: Central Great Barrier Reef: terrigenous sediment flux and human impacts. (Larcombe, P., Woolfe, K., and Purdon, R. [eds.]) 76-85

Hsu, K.J. (1989) Physical principles of sedimentology: a readable textbook for beginners and experts. Springer-Verlag, New York, New York. 233 p.

Hubbard, D.K., Miller, A.I., and Scaturo, D. (1990) Production and cycling of calcium carbonate in a shelf-edge reef system (St Croix, U.S. Virgin Islands): Applications 
to the nature of reef systems in the fossil record. Journal of Sedimentary Petrology. Vol. 6, No. 3, pp. 335-360

Huffman, G.J., Adler, R.F., Arkin, P., Chang, A., Ferraro, R., Gruber, A., Janowiak, J., McNab, A., Rudolf, B., and Schneider, U. (1997) The global precipitation climatology project (GPCP) combined precipitation dataset. Bulletin of the American Meteorological Society. Vol. 78, no. 1, pp. 5-20

Hughes, T.P. (1987) Skeletal density and growth form of corals. Marine Ecology - Progress Series. Vol. 35, pp. 259-266

Jouon, A., Douillet, P., Ouillon, S., Fraunie, P. (2006) Calculations of hydrodynamic time parameters in a semi-opened coastal zone using a 3D hydrodynamical model. Continental Shelf Research. Vol. 26, pp. 1395-1415

Karambas, T.V. (2003) Nonlinear wave modelling and sediment transport in the surf and swash zone. In: Advances in Coastal Modelling (Lakhan, V.C. [ed.]). Elsevier Science B.V. pp. 267-298

Keating, B.H. (1992) Insular geology of the Line Islands. In: Geology and offshore mineral resources of the Central Pacific Basin. (Keating, B.H. and Bolton, R.B[eds.]). CircumPacific Council for Energy and Mineral Resources Earth Science Series, 14:95

Keating, B.H., and McGuire, W.J. (2000) Island edifice failures and associated tsunami hazards. Pure and Applied Geophysics. Vol.157, pp. 899-955

Kelletat, D. (2006) Beachrock as sea-level indicator? Remarks from a geomorphological point of view. Journal of Coastal Research. Vol. 22, Iss. 6, pp. 1558-1564

Kelletat, D. (2007) Reply to: KNIGHT, J., 2007. Beachrock Reconsidered. Discussion of: KELLETAT, D., 2006. Beachrock as Sea-Level Indicator? Remarks from a Geomorphological Point of View, Journal of Coastal Research, 22(6), 1558-1564; Journal of Coastal Research, 23(4), 1074-1078. Journal of Coastal Research. Vol. 23, Iss. 6, pp. $1605-1606$

Kinsey and Hopley (1991) The significance of coral reefs as global carbon sinks response to Greenhouse. Paleogeography, Plaeoclimatology, Paleoecology (Global and Planetary Change Section). Vol. 89, pp. 363-37 
Klein, R.T., Lohmann, K.C., and Thayer, C.W. (1996) Bivalve skeletons record seasurface temperatures and $\delta^{18} \mathrm{O}$ via $\mathrm{Mg} / \mathrm{Ca}$ and ${ }^{18} \mathrm{O} /{ }^{16} \mathrm{O}$ ratios. Geology. Vol. 24, no. 5, pp. $415-418$

Kneales, D. And Viles, H.A, (2000) Beach cement: incipient $\mathrm{CaCO}_{3}$-cemented beachrock development in the upper intertidal zone, North Uist, Scotland. Sedimentary Geology. Vol. 132, pp. 165-170

Knight, J. (2007) Beachrock Reconsidered. Discussion of : Kelletat, D., 2006. Beachrock as sea-level indicator? Remarks from a geomorphological point of view. Journal of Coastal Research. Vol. 22, no. 4, pp. 1074-1078

Koman, G.J., Cavaleri, L., Donelan, M., Hasselmann, K., Hasselmann, S., and Janssen, P.A.E.M. (1994) Dynamics and Modelling of Ocean Waves. Cambridge University Press, New York, 532 pp.

Kraines, S.B., Suzuki, A., Yanagi, T., Isobe, M., and Guo, X., and Komiyama, H. (1999) Rapid water exchange between the lagoon and the open ocean at Majuro Atoll due to wind, waves, and tides. Journal of Geophysical Research. Vol. 104, No. C7, pp. 15635-15653

Kumbrien, W.E. (1979) Photolithotropic and chemoorganotrophic activity of bacteria and algae as related to beachrock formation and degradation (Gulf of Aqaba, Sinai). Geomicrobiology Journal. Vol. 1, No. 2, pp. 139-202

Kumar, V.S., Mandal, S., and Kumar, K.A. (2003) Estimation of wind speed and wave height during cyclones. Ocean Engineering. Vol. 30, pp. 2239-2253

Land, L.S., MacKenzie, F.T., and Gould, S.J. (1967) Pleistocene history of Bermuda. Geological Society of America Bulletin. Vol. 78, pp. 993-1006

Le Roux, J.P. (2003) Wave friction factor as related to the Shields parameter for steady currents. Sedimentary Geology. Vol. 155, pp. 37-43

Lowe, R.J., Falter, J., Bandet, M.D., Pawlak, G., Atkinson, M.J., Monismith, S.G., and Koseff, J.R. (2005) Spectral wave dissipation over a barrier reef. Journal of Geophysical Research. Vol. 110, pp. 1-16

Lucett, E. (1851) Rovings in the Pacific, from 1837 to 1849: with a glance at California, Volume 2. Longman, Brown, Green, and Longmans, London. pp. 248-251 
Lui, G., Strong, A.E., Skiring, W., and Arzayus, L.F. (2006) Overview of NOAA coral reef watch program's near-real-time satellite global coral bleaching monitoring activities. Proceedings of $10^{\text {th }}$ International Coral Reef Symposium. pp. 1783-1793

Madin, J.S. (2005) Mechanical limitations of reef corals during hydrodynamic disturbances. Coral Reefs. Vol. 24, pp. 630-635

Madsen, O.S., Poon, Y.-K., Graber, H.C. (1988) Spectral wave attenuation by bottom friction: Theory. In: Coastal Engineering 1988. American Society of Civil Engineering. Vol. 1, pp. 492-505

Mather, P. And Bennett, I. (1984) Phylum Sipuncula. In: A Coral Reef Handbook: A guide to the Fauna, Flora and Geology of Heron Island and Adjacent Reefs and Cays. No. 1, second edition, The Australian Coral Reef Society, Brisbane.

Maragos, J.E. (1987) Notes on the abundance and distribution of reef corals and reef features at Palmyra Atoll Line Islands. U.S. Army Corps of Engineers, Pacific Ocean Division, Defense Environmental Restoration Program, pp. 1-29

Maragos, J.E. (1993) Impact of coastal construction on coral reefs in the U.S.-affiliated Pacific Islands. Coastal Management. Vol. 21, pp. 235-269

Maragos, J.E., Baines, G.B.K., and Beveridge, P.J. (1973) Tropical cyclone Bebe creates a new land formation on Funafuti Atoll. Science. Vol. 181, No. 4105, pp. 1161-1164

Maragos, J.E., Miller, J., Gove, DeMartini, E., Friedlander, A.M. et al. (2008) US coral reefs in the Line and Phoenix Islands, Central Pacific Ocean: history, geology, oceanography, and biology. In: Coral Reefs of the USA. (Riegl, B.M., and Didge, R.E. [eds.]). Springer Science + Business Media B.V.

McKee, E.D. (1959) Storm sediments on a Pacific Atoll. Journal of Sedimentary Petrology. Vol. 29, no. 3, pp. 354-364

McNutt, M.K., and Fischer, K.M. (1987) South Pacific Superswell. In: Seamounts, Islands, and Atolls (Keating, B.H., Fryer, P., Batiza, R., and Boehlert, G.W. [eds.]). Geophysical Monograph 43, American Geophysical Union, Washington, DC, pp. 25-34

McNutt, M., and Judge, A.V. (1990) The superswell and mantle dynamics beneath the South Pacific. Science. Vol. 248, pp. 969-975 
Meyers, J.H. (1987) Marine vadose beachrock cementation by cryptocrystalline magnesian calcite - Maui, Hawaii. Journal of Sedimentary Petrology. Vol. 57, no. 3, pp. $558-570$

Mitrovica, J.X. and Milne, G.A. (2002) On the origin of late Holocene sea-level highstands within equatorial ocean basins. Quaternary Science Reviews. Vol. 21, pp. $2179-2190$

Mitrovica, J.X., and Peltier, W.R. (1991) On postglacial geoid subsidence over equatorial oceans. Journal of Geophysical Research. Vol. 96, pp. 20,053-20,071

Moberly, J. (1968) Loss of Hawaiian littoral sand. Journal Sedimentary Petrology. Vol. 38, pp. $17-34$

Morton, R.A. (2002) Factors controlling storm impacts on coastal barriers and beaches: A preliminary basis for near real-time forecasting. Journal of Coastal Research. Vol., 18, No. 3, pp. 486-501

Morton, R.A., Gonzalez, J.L., Lopez, G.I., and Correa, I.D. (2000) Frequent non-storm washover of Barrier Island, Pacific coast of Colombia. Journal of Coastal Research. Vol. 16, no. 1, pp. 82-87

Muller, R.D., Roest, W.R., Royer, J.Y., Gahagan, L.M., snd Sclater, J.G. (1997) Digital isochrons of the world's ocean floor. Journal of Geophysical Research. Vol. 102, pp $3211-3214$

Nelson, R.C. (1997) Hydraulic roughness of coral reef platforms. Applied Ocean Research. Vol. 18, pp. 265-274

Nixon, F.C., Reinhardt, E.G., and Rothaus, R. (2009) Foraminifera and tidal notches: Dating neotectonic events at Korphos, Greece. Marine Geology. Vol. 257, pp. 41-53

Nuemeier, U. (1999) Experimental modelling of beachrock cementation under microbial influence. Sedimentary Geology. Vol. 126, pp. 35-46

Nunn, P.D. (1998) Sea-level changes over the past 1,000 years in the Pacific. Journal of Coastal Research. Vol. 14, No. 1, pp. 23-30

Nunn, P.D. (1999) Environmental Change in the Pacific Basin: Chronologies, Causes, Consequences. Wiley, London. 
Nunn, P.D. (2007) Climate, environment and society in the Pacific during the last Millenium. In: Climate, environment and society: Global and Regional Perspectives. Vol. 6, pp. $1-302$

Ou, S.H., Liau, J.M., Hsu, T.W., and Tzang, S.Y. (2002) Simulating typhoon waves by SWAN wave model in coastal waters of Taiwan. Ocean Engineering. Vol. 29, pp. 947-971

Peterson, E.M., Beger, M., Pinca, S. (2006) Three dimensional model of atoll hydrodynamics. In: Proceeding of the $10^{\text {th }}$ International Coral Reef Symposium. Okinawa, Japan. Pp. 1434-1439

Philander, S.G.H. (1983) El Niño Southern Oscillation phenomena. Nature. Vol. 302, pp. 295-302

Pirazzoli, P.A. (1987) A reconnaissance and geomorphological survey of Temoe Atoll, Gambier Islands (South Pacific). Journal of Coastal Research. Vol. 3, no. 3, pp. 307323

Pirazzoli, P.A., and Montaggioni, L.F. (1988) Holocene sea-level changes in French Polynesia. Paleogeography, Paleoclimatology and Paleoecology. Vol. 68, pp. 153-175

Piazzoli, P.A., Montaggioni, L.F., Salvat, B., and Faure, G. (1988) Late Holocene sea level indicators from twelve atolls in the central and eastern Tuamotus (Pacific Ocean). Coral Reefs. Vol. 7, pp. 57-68

Powell, D.M. (1998) Patterns and processes of sediment sorting in gravel-bed rivers. Progress in Physical Geography. Vol. 22, no. 1, pp. 1-31

Ramsey, P.J. (1995) 9000 years of sea-level change along the southern African coastline. Quaternary International. Vol. 31, pp. 71-75

Reid, W.P. (1969) Mineral staining tests. Mineral Industries Bulletin. Vol. 12, no. 3, pp. 1-20

Resig, J.M. (2004) Age and preservation of Amphistegina (foraminifera) in Hawaiian beach sand: implication for sand turnover rate and resource renewal. Marine Micropaleontology Vol. 50, Iss. 3-4, pg. 225-236

Rey, D., Rubio, B., Bernabeu, A.M., and Vilas, F. (2004) Formation, exposure, and evolution of high-latitude beachrock in the intertidal zone of the Corrubedo 
complex (Ria de Arousa, Galicia, NW Spain). Sedimentary Geology. Vol. 169, pp. 93 105

Reynolds, R.W., Rayner, N.A., Smith, T.M., Stokes, D.C., and Wang, W. (2002) An improved in situ and satellite SST analysis for climate. Journal of Climate. Vol. 15, pp. $1609-1625$

Richmond, B.M. (1992) Development of atoll islets in the central Pacific. $7^{\text {th }}$ International Coral Reef Symposium Proceedings. University of Micronesia, Guam. Vol. 2, pp. 11851194

Ris, R.C., Holthuijsen, L.H., and Booij, N. (1999) A third-generation wave model for coastal regions, 2. Verification. Journal of Geophysical Research. Vol. 104, no. C4, pp. $7667-7681$

Rock, J.F. (1916) Palmyra Island with a description of its flora. Honolulu Star-Bulletin. Honolulu, Hawai'i

Ropelewski, C.F., and Halpert, M.S. (1987) Global and regional scale precipitation patterns associated with the El Niño/Southern Oscillation. Monthly Weather Review. Vol. 115, pp. 1606-1626

Ryan, W.B.F., Carbotte, S.M., Coplan, J.O., O’Hara, S., Melkonian, A., Arko, R., Weissel, R.A., Ferrini, V., Goodwillie, A., Nitsche, F., Bonczkowski, J., and Zemsky, R. (2009) Global multi-resolution topography synthesis. Geochemistry, Geophysics, Geosystems. Vol. 10, Q03014, doi:10.1029/2008GC002332.

Sandin, S.A., Smith, J.E., DeMatini, E.E., Dinsdale, E.A., Donner, S.D. et al. (2008) Baselines and degradation of coral reefs in the Northern Line Islands. PLOS ONE. Vol. 3, Iss. 2, pp. 1-11

Schlanger, S.O. (1974) Leg 33, Deep Sea Drilling Project; Testing a hot-spot theory. Geotimes. pp. 16-20

Schmalz, R.F. (1971) Formation of beachrock at Eniwetok Atoll. In: Carbonate Cements (Bricker, O.P. [ed.]). John Hopkins Press, Baltimore, pp. 17-24

Scholle, P.A., and Ulmer-Scholle, D.S. (2003) A colour guide to the petrography of carbonate rocks: grains, textures, porosity, diagenesis. American Association of Petroleum Geologists 
Scoffin, T.P., and McLean, R.F. (1978) Exposed limestone of the Northern Province of the Great Barrier Reef. Philosophical Transactions of the Royal Society of London. Series A, Mathematical and Physical Sciences. Vol. 291, No. 1378, pp. 119-138

Scoffin, T.P., and Stoddart, D.R. (1983) Beachrock and intertidal cements. Chemical sediments and geomorphology: Precipitates and residues in the near surface environment. (Gouldie, A., And Pye, K. [eds.]) Academic Press, London and New York, pp. 401-425

Selley (1968) A classification of paleocurrent models. The Journal of Geology. Vol. 76, no. 1, pp. $99-110$

Smith, S.V., and Kinsey, D.W. (1976) Calcium carbonate production, coral reef growth and sea level change. Science. Vol. 194, pp. 937-929

Snodgrass, F.E., Groves, G.W., Hasselmann, K.F., Miller, G.R., Munk, W.H., and Powers, W.H. (1966) Propagation of ocean swell across the Pacific. Philosophical Transactions of the Royal Society of London. Series A, Mathematical and Physical Sciences. Vol. 259, No. 1103, pp. 431-497

Stern, C.W., Scoffin, T.P., and Martindale, W. (1977) Calcium carbonate budget of a fringing reef on the west coast of Barbados; Part 1 - zonation and productivity. Bulletin of Marine Science. Vol. 23, Iss. 3, pp. 479-510

Stoddart, D.R., and Cann, J.R. (1965) Nature and origin of beach rock. Journal of Sedimentary Petrology. Vol. 35, no. 1, pp. 243-273

Storlazzi, C.D., Brown, E.K., Field, M.A., Rodgers, K., and Jokiel, P.L. (2005) A model for wave control on coral breakage and species distribution in the Hawaiian Islands. Coral Reefs. Vol. 24, Iss. 1, pp. 43-55

Storlazzi, C.D., Field, M.E., Bothner, M.H., Presto, M.K., and Draut, A.E. (2009) Sedimentation processes in a coral reef embayment: Hanalei Bay, Kauai. Marine Geology. Vol. 264, pp. 140-151

Tartinville, B., Deleersnider, E., Rancher, J. (1997) The water residence time in the Mururoa atoll lagoon: sensitivity analysis of a three-dimensional model. Coral Reefs. Vol. 16, pp. 193-203 
Tolman (2002) User manual and system documentation of WAVEWATCH-III version 2.22. NOAA/NWS/NCEP/MMAB Technical Note 222, pp. 113

Tomczak M., and Godfrey J.S. (2003) Regional oceanography: an Introduction. 2nd edition, Daya, Delhi.

U.S. Department of Commerce, National Oceanic and Atmospheric Administration, National Ocean Service, National Centres for Coastal Ocean Science, Centre for Coastal Monitoring and Assessment Biogeography Branch, and Analytical Laboratories of Hawai'i, LLC (2010) Palmyra Atoll Coral Reef Habitat Mapping Completion Report. A report submitted to The Nature Conservatory. 37 pp. Downloaded from http://ccma.nos.noaa.gov/ecosystems/coralreef/palmyra/ on $20 / 1 / 2011$

Vieira, M.M., and De Ros, L.F. (2006) Cementation patterns and genetic implications of Holocene beachrocks from northeastern Brazil. Sedimentary Geology. Vol. 192, pp. $207-230$

Vieira, M.M, De Ros, L.F., and Bezerra, F.H.R. (2007) Lithofacies and paleoenvironmental analysis of Holocene beachrocks in Northeastern Brazil. Journal of Coastal Research. Vol., 23, no. 1, pp. 1535-1548

Vousdoukas, M.I., Velegrakis, A.F. and Plomaritis, T.A. (2007) Beachrock occurrence, characteristics, formation mechanisms and impacts. Earth-Science Reviews. Vol. 85, pp. 23-46

Vousdoukas, M.I., Velegrakis, A.F., and Karamba, T.V. (2009) Morphology and sedimentology of a microtidal beach with beachrocks: Vatera, Lesbos, NE Mediterranean. Continental Shelf Research. Vol. 29, pp. 1937-1947

Vroom, P., Dailer, M., Timmers, M., Maragos, J., Vargas-Angel, B., et al. (2006) Hïialakai HI0604 Cruise Report. NOAA Publication. www.soest.hawaii.edu /pibhmc/

WAMDI Group (1988) The WAM model - a third generation ocean wave prediction model. Journal of Physical Oceanography. Vol. 18, pp. 1775-1810

Webb, A.P., and Kench, P.S. (2010) The dynamic response of reef islands to sea level rise: evidence from multi-decadal analysis of island change in the central Pacific. Global and Planetary Change. Vol. 72, iss. 3, pp. 234-246 
Williams, G.J., Maragos, J.E. and Davy, S.K. (2008) Characterization of the coral communities at Palmyra Atoll in the Remote Central Pacific Ocean. Atoll Research Bulletin. No. 557

Williams, G.J., Knapp, I.S., Maragos, J.E., and Davy. S.K. (2010) Modelling patterns of coral bleaching at a remote Central Pacific atoll. Marine Pollution Bulletin. Vol. 60, pp. $1467-1476$

Woodroffe, C.D., and McLean, R.F. (1998) Pleistocene morphology and Holocene emergence of Christmas (Kiritimati) Island, Pacific Ocean. Coral Reefs. Vol. 17, pp. $235-248$

Woodroffe, C.D., and Morrison, R.J. (2001) Reef-island accretion and soil development on Makin, Kiribati, central Pacific. CANTENA. Vol 44, Iss. 4, pp. 245-261

Woodroffe, C.D. (2008) Reef-island topography and the vulnerability of atolls to sealevel rise. Global and Planetary Change. Iss. 62, pp. 77-96

Wyrtki, K. (1981) An estimate of equatorial upwelling in the Pacific. Journal of Physical Oceanography. Vol. 11, pp. 1205-1214

Wyrtki, K., and Eldin, G. (1982) Equatorial upwelling events in the central Pacific. Journal of Physical Oceanography. Vol. 12, pp. 984-988

Wyrtki, K., and Kilonsky, B. (1984) Mean water and current structure during the Hawaii-to-Tahiti shuttle experiment. Journal of Physical Oceanography. Vol. 14, pp. 242-254 


\section{Appendix A - Compositional point counting results}

\begin{tabular}{|c|c|c|c|c|c|}
\hline $\begin{array}{l}\text { Sample } \\
\text { number }\end{array}$ & Island & Easting & Northing & Material & $\begin{array}{l}\text { Associated } \\
\text { facies }\end{array}$ \\
\hline KO002 & Paradise & 822437.62 & 650005.78 & Beachrock & 2.b.ii \\
\hline $\mathrm{KO} 003$ & Paradise & 822451.32 & 650008.77 & Beachrock & 2.b.ii \\
\hline $\mathrm{KO} 009$ & Paradise & 822454.03 & 650009.60 & Beachrock & 2.b.ii \\
\hline KO 010 & Holei & 824935.66 & 649823.11 & Beachrock & 1.a. \\
\hline KO 011 & Holei & 824938.87 & 649822.07 & Beachrock & 1.a. \\
\hline KO 013 & Holei & 824934.69 & 649823.34 & Beachrock & 2.b.ii. \\
\hline KO 016 & Pelican & 825805.84 & 650224.66 & Beachrock & 2.a.i. \\
\hline $\mathrm{KO} 017$ & Pelican & 825805.84 & 650224.66 & Beachrock & 2.a.i. \\
\hline KO 020 & Lost & 825453.41 & 650763.92 & Beachrock & 2.b.ii. \\
\hline KO 025 & Barren & 827467.82 & 650800.92 & Microphytokarst & $\mathrm{Na}$ \\
\hline $\mathrm{KO} 026$ & Barren & 827467.82 & 650800.92 & Beachrock & 2.a.ii \\
\hline KO 027 & Barren & 827459.31 & 650796.78 & Beachrock & 2.a.ii \\
\hline $\mathrm{KO} 029$ & Cooper & 823717.99 & 652169.21 & Beachrock & 2.b.ii \\
\hline $\mathrm{KO} 030$ & Cooper & 823703.26 & 652165.54 & Beachrock & 2.b.ii \\
\hline KO 031 & Cooper & 823706.41 & 652165.06 & Beachrock & 2.b.ii \\
\hline $\mathrm{KO} 033$ & Cooper & 823691.02 & 652153.23 & Beachrock & 2.a.ii. \\
\hline $\mathrm{KO} 035$ & East & 826179.59 & 651053.95 & Beachrock & 2.b.i \\
\hline KO 038 & Papala & 825637.87 & 650598.61 & Beachrock & 1.b. \\
\hline
\end{tabular}

Table A1: UTM coordiantes (UTM zone 3N ) of samples that were used for petrographic analysis and associated lithofacies. 
Results from spot counts of the thin section samples, methods for which are described in Chapter One.

\begin{tabular}{|c|c|c|c|c|c|}
\hline \multicolumn{6}{|l|}{ Sample KO 002} \\
\hline Clast Material & $\begin{array}{c}\text { Frequency } \\
\text { Run } 1\end{array}$ & Run 2 & Run 3 & Average & Percent of total \\
\hline Coral & 131 & 125 & 150 & 135.33 & 27.07 \\
\hline Algae & 154 & 159 & 135 & 149.33 & 29.87 \\
\hline Pore space & 98 & 103 & 83 & 94.67 & 18.93 \\
\hline Cement & 82 & 85 & 63 & 76.67 & 15.33 \\
\hline Bivalve & 0 & 2 & 0 & 0.67 & 0.13 \\
\hline Gastropod & 0 & 0 & 0 & 0.00 & 0.00 \\
\hline Foram & 1 & 3 & 3 & 2.33 & 0.47 \\
\hline Intraclast & 1 & 0 & 0 & 0.33 & 0.07 \\
\hline Echinoid & 33 & 19 & 65 & 39.00 & 7.80 \\
\hline Bryazoa & 0 & 4 & 1 & 1.67 & 0.33 \\
\hline Halimeda & 0 & 0 & 0 & 0.00 & 0.00 \\
\hline Other & 0 & 0 & 0 & 0.00 & 0.00 \\
\hline Total & 500 & 500 & 500 & & \\
\hline
\end{tabular}

\begin{tabular}{|c|ccc|c|c|}
\hline \multicolumn{6}{|c|}{ Sample KO 003} \\
\hline Clast Material & $\begin{array}{c}\text { Frequency } \\
\text { Run 1 }\end{array}$ & Run 2 & Run 3 & Average & Percent of total \\
\hline Coral & 139 & 158 & 133 & 143.33 & 28.67 \\
Algae & 121 & 136 & 112 & 123.00 & 24.60 \\
Pore space & 111 & 103 & 120 & 111.33 & 22.27 \\
Cement & 107 & 97 & 123 & 109.00 & 21.80 \\
Bivalve & 0 & 0 & 0 & 0.00 & 0.00 \\
Gastropod & 0 & 0 & 10 & 3.33 & 0.67 \\
Foram & 0 & 0 & 0 & 0.00 & 0.00 \\
Intraclast & 6 & 0 & 0 & 2.00 & 0.40 \\
Echinoid & 4 & 6 & 2 & 4.00 & 0.80 \\
Bryazoa & 0 & 0 & 0 & 0.00 & 0.00 \\
Halimeda & 0 & 0 & 0 & 0.00 & 0.00 \\
Other & 12 & 0 & 0 & 4.00 & 0.80 \\
\hline Total & 500 & 500 & 500 & & \\
\hline
\end{tabular}




\begin{tabular}{|c|ccc|c|c|}
\hline \multicolumn{6}{|c|}{ Sample KO 009} \\
\hline Clast Material & $\begin{array}{c}\text { Frequency } \\
\text { Run 1 }\end{array}$ & Run 2 & Run 3 & Average & Percent of total \\
\hline Coral & 136 & 156 & 111 & 134.33 & 26.87 \\
Algae & 124 & 122 & 152 & 132.67 & 26.53 \\
Pore space & 114 & 95 & 121 & 108.00 & 21.60 \\
Cement & 102 & 109 & 106 & 105.67 & 21.13 \\
Bivalve & 19 & 14 & 5 & 12.67 & 2.53 \\
Gastropod & 0 & 3 & 0 & 1.00 & 0.20 \\
Foram & 3 & 1 & 0 & 1.33 & 0.27 \\
Intraclast & 0 & 0 & 0 & 0.00 & 0.00 \\
Echinoid & 0 & 0 & 5 & 1.67 & 0.33 \\
Bryazoa & 2 & 0 & 0 & 0.67 & 0.13 \\
Halimeda & 0 & 0 & 0 & 0.00 & 0.00 \\
Other & 0 & 0 & 0 & 0.00 & 0.00 \\
\hline Total & 500 & 500 & 500 & & \\
\hline
\end{tabular}

\begin{tabular}{|c|ccc|c|c|}
\hline Sample KO 010 & \multicolumn{5}{|c|}{} \\
\hline Clast Material & $\begin{array}{c}\text { Frequency } \\
\text { Run 1 }\end{array}$ & Run 2 & Run 3 & Average & Percent of total \\
\hline Coral & 44 & 104 & 46 & 64.67 & 12.93 \\
Algae & 205 & 143 & 190 & 179.33 & 35.87 \\
Pore space & 143 & 124 & 131 & 132.67 & 26.53 \\
Cement & 98 & 112 & 113 & 107.67 & 21.53 \\
Bivalve & 0 & 0 & 1 & 0.33 & 0.07 \\
Gastropod & 0 & 0 & 0 & 0.00 & 0.00 \\
Foram & 10 & 16 & 16 & 14.00 & 2.80 \\
Intraclast & 0 & 0 & 0 & 0.00 & 0.00 \\
Echinoid & 0 & 0 & 0 & 0.00 & 0.00 \\
Bryazoa & 0 & 1 & 3 & 1.33 & 0.27 \\
Halimeda & 0 & 0 & 0 & 0.00 & 0.00 \\
Other & 0 & 0 & 0 & 0.00 & 0.00 \\
\hline Total & 500 & 500 & 500 & & \\
\hline
\end{tabular}




\begin{tabular}{|c|c|c|c|c|c|}
\hline \multicolumn{5}{|c|}{ Sample KO 011} & \multirow[b]{2}{*}{ Percent of total } \\
\hline Clast Material & $\begin{array}{c}\text { Frequency } \\
\text { Run } 1\end{array}$ & Run 2 & Run 3 & Average & \\
\hline Coral & 34 & 31 & 26 & 30.33 & 6.07 \\
\hline Algae & 197 & 223 & 219 & 213.00 & 42.60 \\
\hline Pore space & 147 & 117 & 147 & 137.00 & 27.40 \\
\hline Cement & 110 & 118 & 95 & 107.67 & 21.53 \\
\hline Bivalve & 1 & 0 & 0 & 0.33 & 0.07 \\
\hline Gastropod & 0 & 0 & 0 & 0.00 & 0.00 \\
\hline Foram & 11 & 11 & 13 & 11.67 & 2.33 \\
\hline Intraclast & 0 & 0 & 0 & 0.00 & 0.00 \\
\hline Echinoid & 0 & 0 & 0 & 0.00 & 0.00 \\
\hline Bryazoa & 0 & 0 & 0 & 0.00 & 0.00 \\
\hline Halimeda & 0 & 0 & 0 & 0.00 & 0.00 \\
\hline Other & 0 & 0 & 0 & 0.00 & 0.00 \\
\hline Total & 500 & 500 & 500 & & \\
\hline
\end{tabular}

\begin{tabular}{|c|ccc|c|c|}
\hline Sample KO 013 & \multicolumn{6}{|c|}{} \\
\hline Clast Material & $\begin{array}{c}\text { Frequency } \\
\text { Run 1 }\end{array}$ & Run 2 & Run 3 & Average & Percent of total \\
\hline Coral & 70 & 80 & 76 & 75.33 & 15.07 \\
Algae & 280 & 221 & 218 & 239.67 & 47.93 \\
Pore space & 97 & 115 & 71 & 94.33 & 18.87 \\
Cement & 96 & 64 & 117 & 92.33 & 18.47 \\
Bivalve & 3 & 1 & 0 & 1.33 & 0.27 \\
Gastropod & 0 & 0 & 0 & 0.00 & 0.00 \\
Foram & 11 & 14 & 18 & 14.33 & 2.87 \\
Intraclast & 0 & 0 & 0 & 0.00 & 0.00 \\
Echinoid & 0 & 0 & 0 & 0.00 & 0.00 \\
Bryazoa & 7 & 5 & 0 & 4.00 & 0.80 \\
Halimeda & 0 & 0 & 0 & 0.00 & 0.00 \\
Other & 0 & 0 & 0 & 0.00 & 0.00 \\
\hline Total & 564 & 500 & 500 & & \\
\hline
\end{tabular}




\begin{tabular}{|c|ccc|c|c|}
\hline Sample KO 016 & \multicolumn{7}{|l|}{ Average } & Percent of total \\
\hline Clast Material & $\begin{array}{c}\text { Frequency } \\
\text { Run 1 }\end{array}$ & Run 2 & Run 3 & & \\
\hline Coral & 29 & 36 & 36 & 33.67 & 6.73 \\
Algae & 216 & 202 & 246 & 221.33 & 44.27 \\
Pore space & 68 & 76 & 49 & 64.33 & 12.87 \\
Cement & 182 & 182 & 169 & 177.67 & 35.53 \\
Bivalve & 5 & 0 & 0 & 1.67 & 0.33 \\
Gastropod & 0 & 0 & 0 & 0.00 & 0.00 \\
Foram & 0 & 4 & 0 & 1.33 & 0.27 \\
Intraclast & 0 & 0 & 0 & 0.00 & 0.00 \\
Echinoid & 0 & 0 & 0 & 0.00 & 0.00 \\
Bryazoa & 0 & 0 & 0 & 0.00 & 0.00 \\
Halimeda & 0 & 0 & 0 & 0.00 & 0.00 \\
Other & 0 & 0 & 0 & 0.00 & 0.00 \\
\hline Total & 500 & 500 & 500 & & \\
\hline
\end{tabular}

\begin{tabular}{|c|ccc|c|c|}
\hline \multicolumn{6}{|c|}{ Sample KO 017} \\
\hline Clast Material & $\begin{array}{c}\text { Frequency } \\
\text { Run 1 }\end{array}$ & Run 2 & Run 3 & Average & Percent of total \\
\hline Coral & 89 & 22 & 53 & 54.67 & 10.93 \\
Algae & 262 & 292 & 294 & 282.67 & 56.53 \\
Pore space & 81 & 79 & 41 & 67.00 & 13.40 \\
Cement & 56 & 98 & 107 & 87.00 & 17.40 \\
Bivalve & 12 & 3 & 4 & 6.33 & 1.27 \\
Gastropod & 0 & 0 & 0 & 0.00 & 0.00 \\
Foram & 0 & 6 & 1 & 2.33 & 0.47 \\
Intraclast & 0 & 0 & 0 & 0.00 & 0.00 \\
Echinoid & 0 & 0 & 0 & 0.00 & 0.00 \\
Bryazoa & 0 & 0 & 0 & 0.00 & 0.00 \\
Halimeda & 0 & 0 & 0 & 0.00 & 0.00 \\
Other & 0 & 0 & 0 & 0.00 & 0.00 \\
\hline Total & 500 & 500 & 500 & & \\
\hline
\end{tabular}




\begin{tabular}{|c|ccc|c|c|}
\hline Sample KO 020 & \multicolumn{5}{|l|}{} \\
\hline Clast Material & $\begin{array}{c}\text { Frequency } \\
\text { Run 1 }\end{array}$ & Run 2 & Run 3 & & Pverage \\
\hline Coral & 115 & 122 & 120 & 119.00 & 23.80 \\
Algae & 142 & 163 & 134 & 146.33 & 29.27 \\
Pore space & 83 & 76 & 94 & 84.33 & 16.87 \\
Cement & 135 & 124 & 130 & 129.67 & 25.93 \\
Bivalve & 2 & 0 & 0 & 0.67 & 0.13 \\
Gastropod & 3 & 0 & 4 & 2.33 & 0.47 \\
Foram & 20 & 15 & 18 & 17.67 & 3.53 \\
Intraclast & 0 & 0 & 0 & 0.00 & 0.00 \\
Echinoid & 0 & 0 & 0 & 0.00 & 0.00 \\
Bryazoa & 0 & 0 & 0 & 0.00 & 0.00 \\
Halimeda & 0 & 0 & 0 & 0.00 & 0.00 \\
Other & 0 & 0 & 0 & 0.00 & 0.00 \\
\hline Total & 500 & 500 & 500 & & \\
\hline
\end{tabular}

\begin{tabular}{|c|c|c|c|c|c|}
\hline \multicolumn{6}{|c|}{ Sample KO 024a } \\
\hline Clast Material & $\begin{array}{c}\text { Frequency } \\
\text { Run } 1 \\
\end{array}$ & Run 2 & Run 3 & Average & Percent of total \\
\hline Coral & 178 & 172 & 166 & 172.00 & 34.40 \\
\hline Algae & 130 & 136 & 119 & 128.33 & 25.67 \\
\hline Pore space & 133 & 143 & 135 & 137.00 & 27.40 \\
\hline Cement & 38 & 31 & 49 & 39.33 & 7.87 \\
\hline Bivalve & 7 & 3 & 6 & 5.33 & 1.07 \\
\hline Gastropod & 0 & 0 & 0 & 0.00 & 0.00 \\
\hline Foram & 14 & 15 & 23 & 17.33 & 3.47 \\
\hline Intraclast & 0 & 0 & 0 & 0.00 & 0.00 \\
\hline Echinoid & 0 & 0 & 0 & 0.00 & 0.00 \\
\hline Bryazoa & 22 & 0 & 0 & 7.33 & 1.47 \\
\hline Halimeda & 0 & 0 & 0 & 0.00 & 0.00 \\
\hline Other & 7 & 0 & 2 & 3.00 & 0.60 \\
\hline Total & 529 & 500 & 500 & & \\
\hline
\end{tabular}




\begin{tabular}{|c|ccc|c|c|}
\hline \multicolumn{2}{|c|}{ Sample KO 024b } & Average & Percent of total \\
\hline Clast Material & $\begin{array}{c}\text { Frequency } \\
\text { Run 1 }\end{array}$ & Run 2 & Run 3 & & \\
\hline Coral & 167 & 193 & 167 & 175.67 & 35.13 \\
Algae & 134 & 115 & 123 & 124.00 & 24.80 \\
Pore space & 71 & 90 & 103 & 88.00 & 17.60 \\
Cement & 102 & 82 & 83 & 89.00 & 17.80 \\
Bivalve & 3 & 5 & 0 & 2.67 & 0.53 \\
Gastropod & 0 & 0 & 0 & 0.00 & 0.00 \\
Foram & 19 & 15 & 24 & 19.33 & 3.87 \\
Intraclast & 0 & 0 & 0 & 0.00 & 0.00 \\
Echinoid & 0 & 0 & 0 & 0.00 & 0.00 \\
Bryazoa & 4 & 0 & 0 & 1.33 & 0.27 \\
Halimeda & 0 & 0 & 0 & 0.00 & 0.00 \\
Other & 0 & 0 & 0 & 0.00 & 0.00 \\
\hline Total & 500 & 500 & 500 & & \\
\hline
\end{tabular}

\begin{tabular}{|c|c|c|c|c|c|}
\hline \multicolumn{6}{|l|}{ Sample KO 026} \\
\hline Clast Material & $\begin{array}{l}\text { Frequency } \\
\text { Run } 1\end{array}$ & Run 2 & Run 3 & Average & Percent of total \\
\hline Coral & 176 & 213 & 182 & 190.33 & 38.07 \\
\hline Algae & 126 & 81 & 118 & 108.33 & 21.67 \\
\hline Pore space & 99 & 104 & 106 & 103.00 & 20.60 \\
\hline Cement & 68 & 68 & 61 & 65.67 & 13.13 \\
\hline Bivalve & 11 & 19 & 9 & 13.00 & 2.60 \\
\hline Gastropod & 0 & 0 & 0 & 0.00 & 0.00 \\
\hline Foram & 4 & 9 & 3 & 5.33 & 1.07 \\
\hline Intraclast & 2 & 6 & 0 & 2.67 & 0.53 \\
\hline Echinoid & 0 & 0 & 0 & 0.00 & 0.00 \\
\hline Bryazoa & 14 & 0 & 21 & 11.67 & 2.33 \\
\hline Halimeda & 0 & 0 & 0 & 0.00 & 0.00 \\
\hline Other & 0 & 0 & 0 & 0.00 & 0.00 \\
\hline Total & 500 & 500 & 500 & & \\
\hline
\end{tabular}




\begin{tabular}{|c|ccc|c|c|}
\hline Sample KO 027 & \multicolumn{7}{|c|}{} & Average & Percent of total \\
\hline Clast Material & $\begin{array}{c}\text { Frequency } \\
\text { Run 1 }\end{array}$ & Run 2 & Run 3 & & \\
\hline Coral & 197 & 215 & 184 & 198.67 & 39.73 \\
Algae & 83 & 74 & 84 & 80.33 & 16.07 \\
Pore space & 136 & 132 & 138 & 135.33 & 27.07 \\
Cement & 46 & 38 & 52 & 45.33 & 9.07 \\
Bivalve & 10 & 13 & 9 & 10.67 & 2.13 \\
Gastropod & 0 & 0 & 2 & 0.67 & 0.13 \\
Foram & 16 & 13 & 11 & 13.33 & 2.67 \\
Intraclast & 9 & 10 & 14 & 11.00 & 2.20 \\
Echinoid & 0 & 0 & 0 & 0.00 & 0.00 \\
Bryazoa & 3 & 5 & 6 & 4.67 & 0.93 \\
Halimeda & 0 & 0 & 0 & 0.00 & 0.00 \\
Other & 0 & 0 & 0 & 0.00 & 0.00 \\
\hline Total & 500 & 500 & 500 & & \\
\hline
\end{tabular}

\begin{tabular}{|c|c|c|c|c|c|}
\hline \multicolumn{6}{|l|}{ Sample KO 029} \\
\hline \multirow[t]{2}{*}{ Clast Material } & \multicolumn{3}{|l|}{ Frequency } & \multirow[t]{2}{*}{ Average } & \multirow[t]{2}{*}{ Percent of total } \\
\hline & Run 1 & Run 2 & Run 3 & & \\
\hline Coral & 94 & 109 & 133 & 112.00 & 22.40 \\
\hline Algae & 185 & 183 & 164 & 177.33 & 35.47 \\
\hline Pore space & 112 & 112 & 126 & 116.67 & 23.33 \\
\hline Cement & 76 & 85 & 68 & 76.33 & 15.27 \\
\hline Bivalve & 6 & 0 & 0 & 2.00 & 0.40 \\
\hline Gastropod & 12 & 11 & 9 & 10.67 & 2.13 \\
\hline Foram & 0 & 0 & 0 & 0.00 & 0.00 \\
\hline Intraclast & 0 & 0 & 0 & 0.00 & 0.00 \\
\hline Echinoid & 0 & 0 & 0 & 0.00 & 0.00 \\
\hline Bryazoa & 6 & 0 & 0 & 2.00 & 0.40 \\
\hline Halimeda & 9 & 0 & 0 & 3.00 & 0.60 \\
\hline Other & 0 & 0 & 0 & 0.00 & 0.00 \\
\hline Total & 500 & 500 & 500 & & \\
\hline
\end{tabular}




\begin{tabular}{|c|c|c|c|c|c|}
\hline \multicolumn{6}{|l|}{ Sample KO 030} \\
\hline Clast Material & $\begin{array}{c}\text { Frequency } \\
\text { Run } 1\end{array}$ & Run 2 & Run 3 & Average & Percent of total \\
\hline Coral & 130 & 77 & 82 & 96.33 & 19.27 \\
\hline Algae & 210 & 235 & 206 & 217.00 & 43.40 \\
\hline Pore space & 98 & 113 & 135 & 115.33 & 23.07 \\
\hline Cement & 53 & 58 & 73 & 61.33 & 12.27 \\
\hline Bivalve & 0 & 0 & 0 & 0.00 & 0.00 \\
\hline Gastropod & 0 & 0 & 0 & 0.00 & 0.00 \\
\hline Foram & 3 & 4 & 0 & 2.33 & 0.47 \\
\hline Intraclast & 0 & 0 & 0 & 0.00 & 0.00 \\
\hline Echinoid & 0 & 0 & 0 & 0.00 & 0.00 \\
\hline Bryazoa & 0 & 0 & 0 & 0.00 & 0.00 \\
\hline Halimeda & 6 & 13 & 4 & 7.67 & 1.53 \\
\hline Other & 0 & 0 & 0 & 0.00 & 0.00 \\
\hline Total & 500 & 500 & 500 & & \\
\hline
\end{tabular}

\begin{tabular}{|c|c|c|c|c|c|}
\hline \multicolumn{6}{|l|}{ KO 033} \\
\hline Clast Material & $\begin{array}{c}\text { Frequency } \\
\text { Run } 1\end{array}$ & Run 2 & Run 3 & Average & Percent of total \\
\hline Coral & 176 & 193 & 190 & 186.33 & 37.27 \\
\hline Algae & 170 & 127 & 137 & 144.67 & 28.93 \\
\hline Pore space & 95 & 111 & 107 & 104.33 & 20.87 \\
\hline Cement & 49 & 67 & 64 & 60.00 & 12.00 \\
\hline Bivalve & 0 & 0 & 2 & 0.67 & 0.13 \\
\hline Gastropod & 0 & 0 & 0 & 0.00 & 0.00 \\
\hline Foram & 4 & 0 & 0 & 1.33 & 0.27 \\
\hline Intraclast & 0 & 0 & 0 & 0.00 & 0.00 \\
\hline Echinoid & 0 & 0 & 0 & 0.00 & 0.00 \\
\hline Bryazoa & 0 & 2 & 0 & 0.67 & 0.13 \\
\hline Halimeda & 6 & 0 & 0 & 2.00 & 0.40 \\
\hline Other & 0 & 0 & 0 & 0.00 & 0.00 \\
\hline Total & 500 & 500 & 500 & & \\
\hline
\end{tabular}




\begin{tabular}{|c|c|c|c|c|c|}
\hline \multicolumn{6}{|l|}{ Sample KO 035} \\
\hline Clast Material & $\begin{array}{c}\text { Frequency } \\
\text { Run } 1\end{array}$ & Run 2 & Run 3 & Average & Percent of total \\
\hline Coral & 77 & 92 & 90 & 86.33 & 17.27 \\
\hline Algae & 236 & 210 & 228 & 224.67 & 44.93 \\
\hline Pore space & 122 & 112 & 99 & 111.00 & 22.20 \\
\hline Cement & 49 & 63 & 52 & 54.67 & 10.93 \\
\hline Bivalve & 7 & 2 & 5 & 4.67 & 0.93 \\
\hline Gastropod & 0 & 0 & 0 & 0.00 & 0.00 \\
\hline Foram & 3 & 7 & 4 & 4.67 & 0.93 \\
\hline Intraclast & 0 & 0 & 0 & 0.00 & 0.00 \\
\hline Echinoid & 0 & 0 & 0 & 0.00 & 0.00 \\
\hline Bryazoa & 6 & 14 & 22 & 14.00 & 2.80 \\
\hline Halimeda & 0 & 0 & 0 & 0.00 & 0.00 \\
\hline Other & 0 & 0 & 0 & 0.00 & 0.00 \\
\hline Total & 500 & 500 & 500 & & \\
\hline
\end{tabular}

\begin{tabular}{|c|c|c|c|c|c|}
\hline \multicolumn{6}{|l|}{ Sample KO 038} \\
\hline Clast Material & $\begin{array}{l}\text { Frequency } \\
\text { Run } 1\end{array}$ & Run 2 & Run 3 & Average & Percent of total \\
\hline Coral & 67 & 19 & 69 & 51.67 & 10.33 \\
\hline Algae & 154 & 192 & 164 & 170.00 & 34.00 \\
\hline Pore space & 105 & 112 & 98 & 105.00 & 21.00 \\
\hline Cement & 45 & 80 & 72 & 65.67 & 13.13 \\
\hline Bivalve & 5 & 2 & 4 & 3.67 & 0.73 \\
\hline Gastropod & 0 & 0 & 0 & 0.00 & 0.00 \\
\hline Foram & 112 & 95 & 91 & 99.33 & 19.87 \\
\hline Intraclast & 0 & 0 & 0 & 0.00 & 0.00 \\
\hline Echinoid & 0 & 0 & 0 & 0.00 & 0.00 \\
\hline Bryazoa & 12 & 0 & 2 & 4.67 & 0.93 \\
\hline Halimeda & 0 & 0 & 0 & 0.00 & 0.00 \\
\hline Other & 0 & 0 & 0 & 0.00 & 0.00 \\
\hline Total & 500 & 500 & 500 & & \\
\hline
\end{tabular}




\section{Appendix B - SWAN input file and additional WWIII plots.}

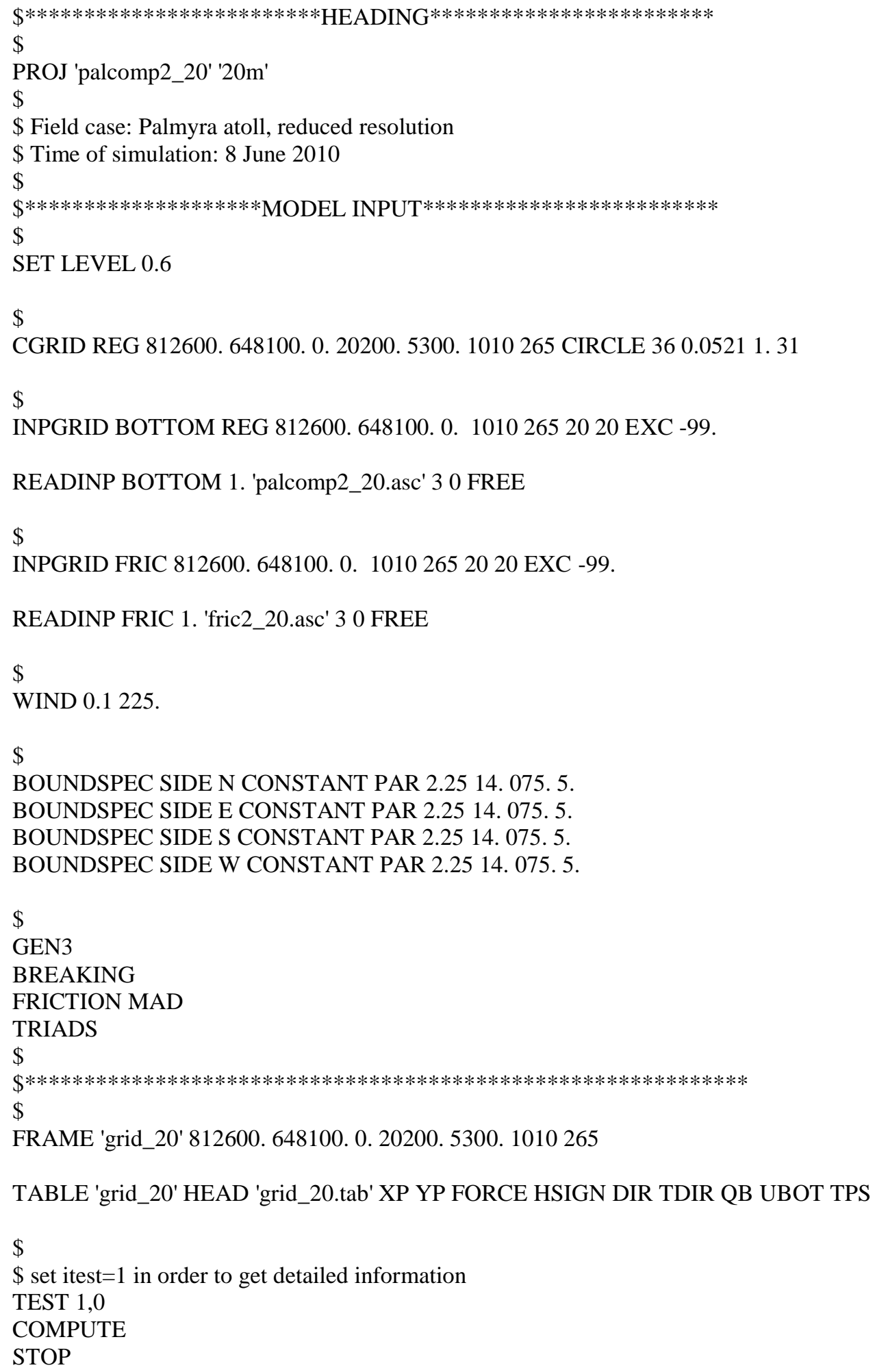


Figure B.1 (previous page): An example of the .swn input file to model the summer swell wave events at high tide.

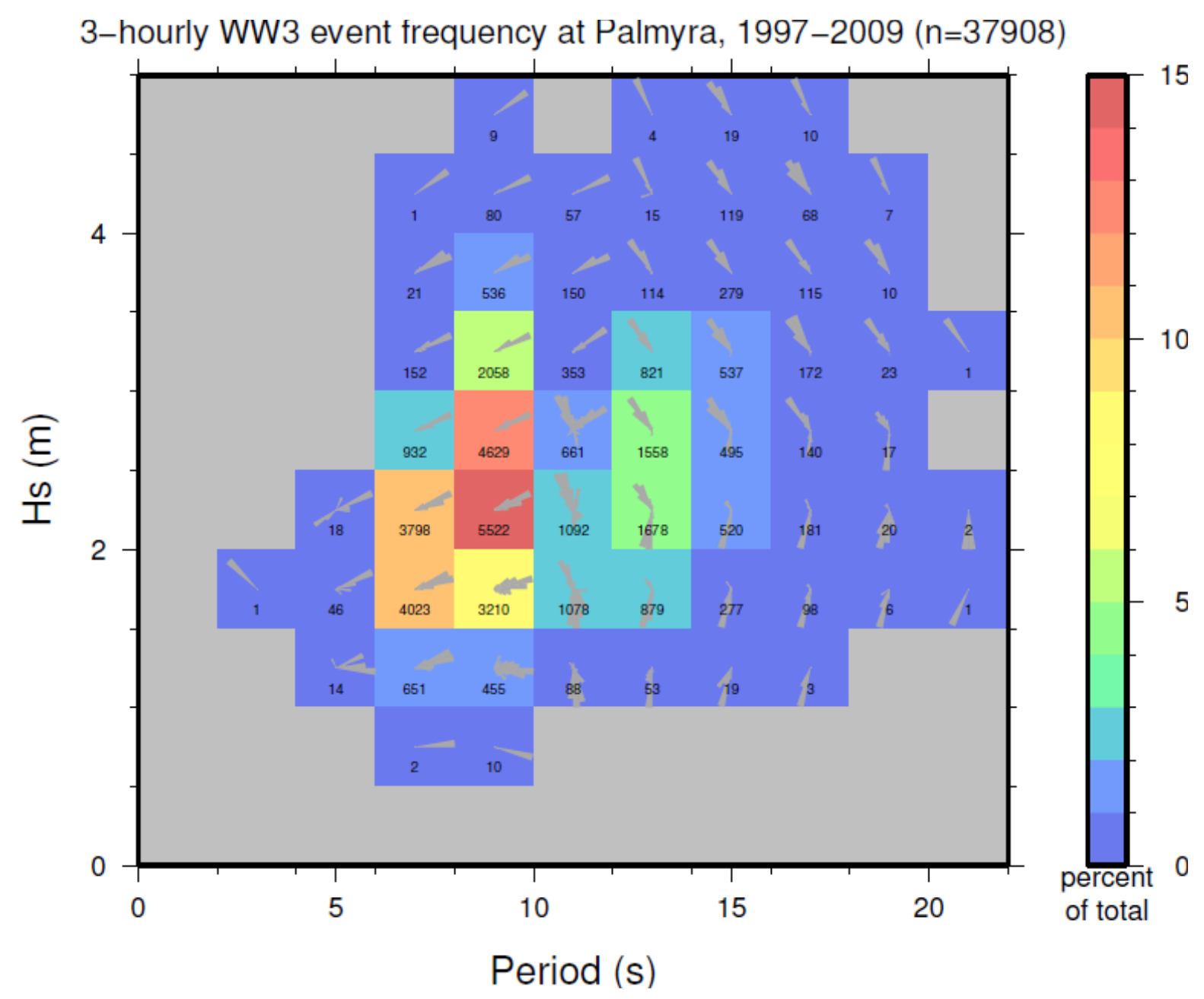

Figure B.2: Wave climatology from the WW3 hindcast for 1997-2009. Directional information are given as rose diagrams within each box. The colour of the box represents the percentage of the time during which conditions occur as shown in the key on the right. The number of days is also given as numbers within each box. 

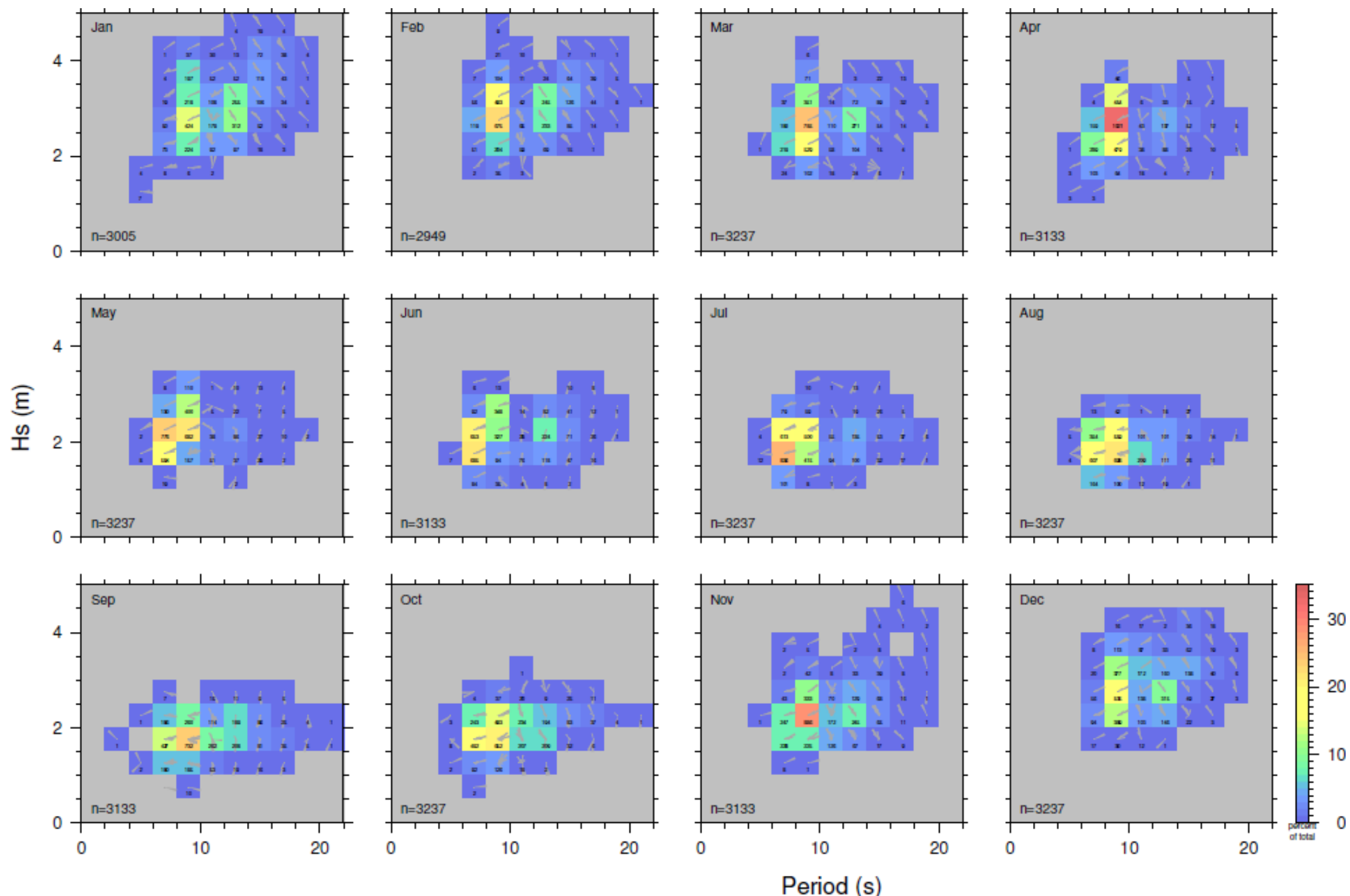

Figure B.3: Monthly wave climatologies for Palmyra Atoll plotted in the two-dimensional space (significant wave height and wave period). The colour of the bin is representative of the event frequency in any given month. 


\section{Appendix C - Paleo-orientation data and statistics}

\section{C.1 Cooper Island}

Table C1: Orientation measurements $\left(^{\circ}\right)$ and statistics from the eastern section of beachrock at Cooper Island.

\begin{tabular}{|c|c|c|c|c|}
\hline 0 & 58 & 90 & 127 & \\
\hline 7 & 59 & 91 & 130 & \\
\hline 13 & 60 & 97 & 140 & \\
\hline 15 & 60 & 98 & 141 & \\
\hline 15 & 63 & 99 & 146 & \\
\hline 16 & 65 & 100 & 148 & \\
\hline 20 & 66 & 101 & 162 & \\
\hline 26 & 70 & 106 & 165 & \multirow{3}{*}{$n=55$} \\
\hline 36 & 75 & 112 & 165 & \\
\hline 40 & 81 & 113 & 169 & \\
\hline 49 & 85 & 118 & 172 & \multirow[t]{2}{*}{ Mean $=89^{\circ}$} \\
\hline 50 & 85 & 118 & 173 & \\
\hline 50 & 87 & 118 & 176 & $S D=49$ \\
\hline 52 & 89 & 122 & & \\
\hline
\end{tabular}

Table C2: Orientation measurements $\left({ }^{\circ}\right)$ and statistics from the eastern section of beachrock at Cooper Island.

\begin{tabular}{|rrrrrr|}
\hline 0 & 17 & 40 & 53 & 86 & 148 \\
1 & 20 & 41 & 57 & 87 & 150 \\
2 & 21 & 41 & 57 & 89 & 152 \\
3 & 26 & 42 & 57 & 89 & 158 \\
4 & 29 & 43 & 58 & 90 & 162 \\
7 & 32 & 43 & 59 & 100 & 165 \\
8 & 34 & 43 & 61 & 103 & 168 \\
11 & 35 & 45 & 62 & 107 & 170 \\
11 & 35 & 45 & 68 & 112 & 170 \\
11 & 35 & 45 & 69 & 115 & 172 \\
11 & 37 & 45 & 72 & 123 & 175 \\
12 & 38 & 48 & 75 & 127 & 175 \\
12 & 40 & 49 & 77 & 130 & 176 \\
14 & 40 & 50 & 78 & 133 & 178 \\
15 & 40 & 51 & 82 & 144 & \\
16 & 40 & 52 & 84 & 147 & \\
Mean $=69^{\circ}$
\end{tabular}




\section{C.2 Paradise Island}

Table C3: Orientation measurements $\left(^{\circ}\right)$ and statistics from bed 1 at Paradise Island.

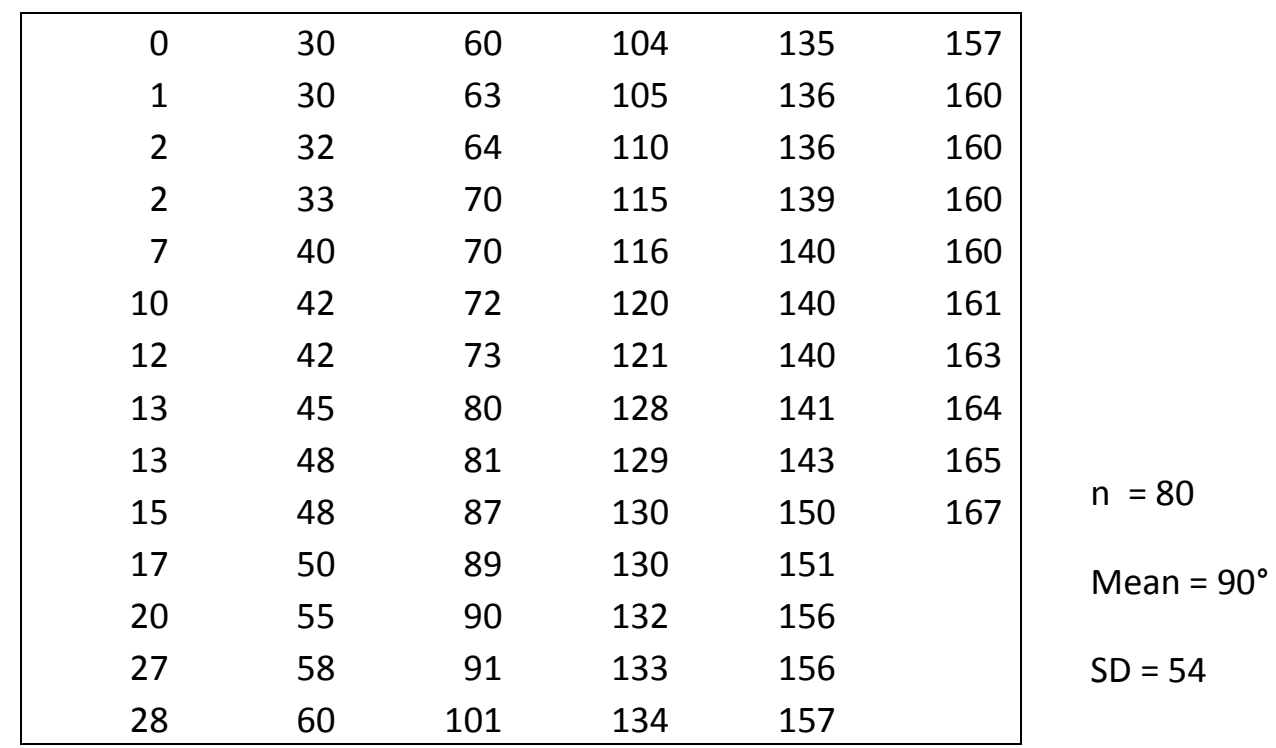

Table C4: Orientation measurements $\left(^{\circ}\right)$ and statistics from bed 2 at Paradise Island.

\begin{tabular}{|c|c|c|c|c|c|c|}
\hline 5 & 30 & 67 & 95 & 122 & 151 & \\
\hline 9 & 30 & 67 & 97 & 122 & 151 & \\
\hline 9 & 30 & 69 & 98 & 123 & 152 & \\
\hline 12 & 31 & 70 & 99 & 124 & 153 & \\
\hline 14 & 35 & 70 & 100 & 129 & 155 & \\
\hline 16 & 40 & 73 & 100 & 130 & 155 & \\
\hline 18 & 40 & 76 & 101 & 130 & 155 & \\
\hline 20 & 42 & 78 & 102 & 131 & 162 & \multirow{3}{*}{$\mathrm{n}=82$} \\
\hline 20 & 52 & 80 & 105 & 134 & 164 & \\
\hline 24 & 53 & 80 & 106 & 138 & 167 & \\
\hline 25 & 58 & 81 & 111 & 143 & 170 & \multirow[t]{2}{*}{ Mean $=89^{\circ}$} \\
\hline 25 & 60 & 89 & 112 & 145 & 178 & \\
\hline 28 & 61 & 91 & 114 & 146 & & \multirow[t]{2}{*}{$S D=49$} \\
\hline 28 & 64 & 94 & 120 & 150 & & \\
\hline
\end{tabular}

Table 5: Orientation measurements $\left(^{\circ}\right)$ and statistics from bed 3 at Paradise Island.

\begin{tabular}{|rrrrrrr|}
\hline 0 & 23 & 37 & 53 & 75 & 109 & 155 \\
2 & 23 & 40 & 55 & 77 & 109 & 155 \\
12 & 25 & 42 & 56 & 77 & 109 & 165 \\
12 & 26 & 42 & 56 & 79 & 118 & 165 \\
13 & 26 & 43 & 56 & 83 & 118 & 172 \\
13 & 30 & 43 & 56 & 98 & 122 & 179 \\
15 & 30 & 45 & 57 & 98 & 134 & \\
15 & 31 & 46 & 57 & 98 & 137 &
\end{tabular}

C2 


\begin{tabular}{|llllll|l}
15 & 33 & 47 & 60 & 105 & 137 & \\
15 & 36 & 49 & 60 & 108 & 140 & $\mathrm{n}=90$ \\
17 & 37 & 50 & 63 & 108 & 140 & Mean $=69^{\circ}$ \\
17 & 37 & 51 & 71 & 108 & 147 & \\
20 & 37 & 51 & 73 & 109 & 150 & SD $=47$ \\
23 & 37 & 53 & 75 & 109 & 150 &
\end{tabular}

Table C6: Orientation measurements $\left(^{\circ}\right)$ and statistics from bed 4 at Paradise Island.

\begin{tabular}{|rrrrrrrr|}
\hline 0 & 26 & 43 & 77 & 103 & 133 & 145 & 164 \\
7 & 28 & 44 & 79 & 104 & 133 & 145 & 164 \\
9 & 28 & 45 & 82 & 105 & 134 & 148 & 166 \\
10 & 30 & 50 & 89 & 106 & 134 & 148 & 168 \\
12 & 32 & 50 & 89 & 109 & 134 & 152 & 170 \\
13 & 35 & 51 & 89 & 120 & 135 & 152 & 170 \\
15 & 36 & 52 & 92 & 121 & 135 & 153 & 170 \\
16 & 36 & 57 & 93 & 122 & 137 & 154 & \\
18 & 36 & 62 & 94 & 126 & 137 & 156 & \\
20 & 38 & 63 & 94 & 127 & 138 & 159 & \\
20 & 39 & 64 & 96 & 129 & 139 & 159 & \\
20 & 39 & 69 & 96 & 129 & 143 & 160 & \\
25 & 40 & 70 & 97 & 130 & 143 & 160 & \\
25 & 42 & 72 & 99 & 132 & 144 & 160 & \\
Mean $=92^{\circ}$ \\
SD $=52$
\end{tabular}

\section{C.3 Northern East Island}

Table C7: Orientation measurements $\left({ }^{\circ}\right)$ and statistics from bed 1 at Northern East Island.

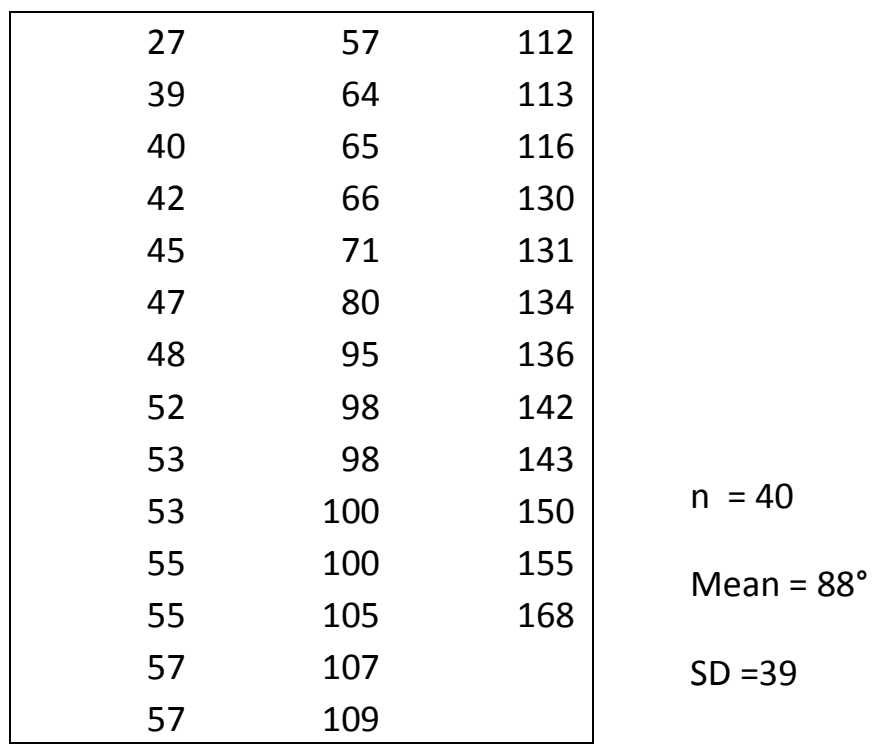


Table C8: Orientation measurements $\left({ }^{\circ}\right)$ and statistics from bed 2 at Northern East Island.

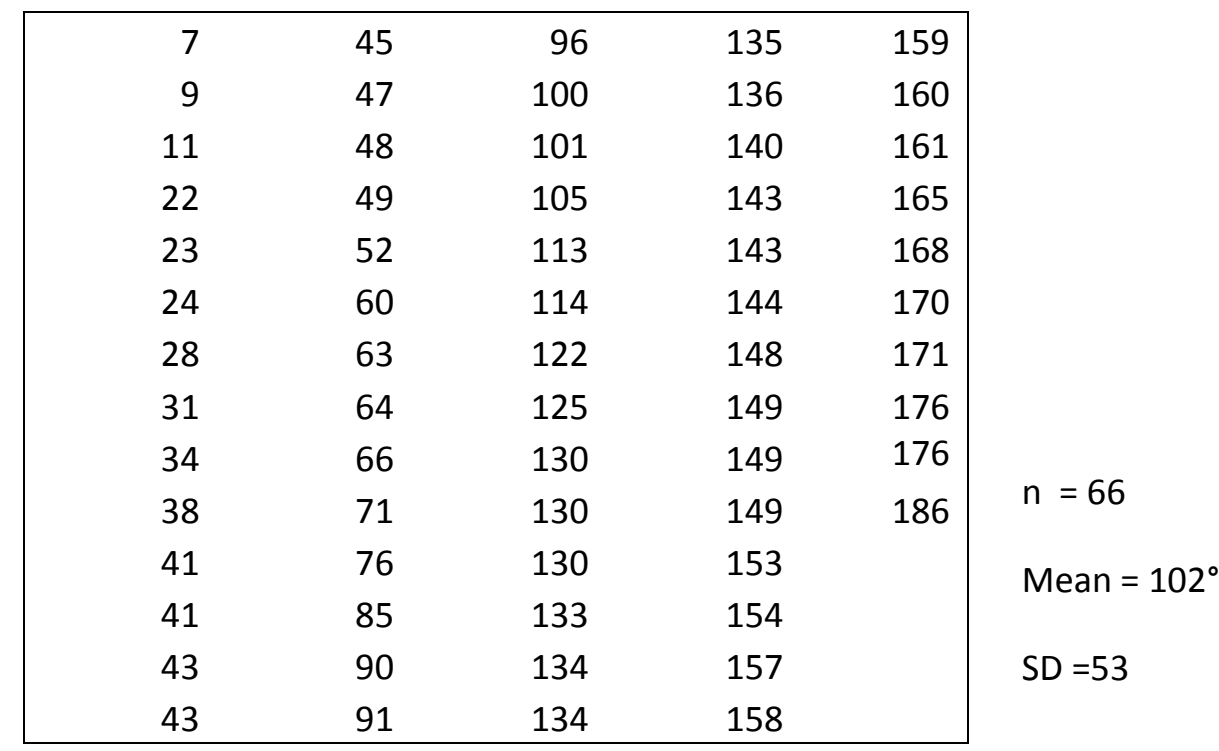

Table C9: Orientation measurements $\left({ }^{\circ}\right)$ and statistics from bed 3 at Northern East Island.

\begin{tabular}{|llllllll|}
\hline 0 & 29 & 43 & 63 & 105 & 132 & 148 & 170 \\
4 & 30 & 47 & 67 & 106 & 133 & 149 & 171 \\
5 & 31 & 47 & 69 & 109 & 134 & 151 & 171 \\
7 & 34 & 49 & 72 & 110 & 135 & 154 & 173 \\
11 & 35 & 49 & 72 & 111 & 135 & 154 & 174 \\
12 & 35 & 50 & 74 & 111 & 138 & 155 & 176 \\
14 & 37 & 50 & 79 & 112 & 139 & 157 & \\
17 & 38 & 54 & 80 & 112 & 140 & 158 & \\
19 & 39 & 55 & 80 & 115 & 141 & 161 & \\
20 & 40 & 55 & 82 & 117 & 142 & 161 & \\
21 & 40 & 58 & 85 & 117 & 143 & 161 & \\
24 & 41 & 59 & 88 & 127 & 144 & 162 & \\
27 & 42 & 59 & 95 & 131 & 144 & 164 & \\
27 & 42 & 60 & 105 & 131 & 147 & 165 & \\
\hline
\end{tabular}

$\mathrm{n}=104$

Mean $=90^{\circ}$

$\mathrm{SD}=53$

Table C10: Orientation measurements $\left(^{\circ}\right)$ and statistics from bed 4 at Northern East Island.

\begin{tabular}{|rrrrr|}
\hline 0 & 47 & 110 & 137 & 157 \\
3 & 56 & 111 & 138 & 160 \\
14 & 60 & 114 & 140 & 162 \\
18 & 64 & 114 & 146 & 162
\end{tabular}




\begin{tabular}{|lllll|l}
19 & 73 & 115 & 148 & 163 & \\
20 & 74 & 119 & 149 & 165 & \\
20 & 84 & 119 & 150 & 165 & \\
28 & 85 & 123 & 150 & 168 & \\
30 & 86 & 126 & 150 & 169 & $\mathrm{n}=66$ \\
31 & 88 & 127 & 152 & 171 & \\
32 & 89 & 129 & 152 & & Mean $=104^{\circ}$ \\
42 & 90 & 131 & 153 & \\
43 & 98 & 132 & 153 & \\
43 & 98 & 132 & 155 & &
\end{tabular}

\section{C.4 Barren Island}

Table C11: Orientation measurements $\left({ }^{\circ}\right)$ and statistics from platform 1 at Barren Island.

\begin{tabular}{|rrrrrrrrrr|}
\hline 0 & 33 & 57 & 76 & 94 & 103 & 121 & 137 & 144 & 162 \\
1 & 35 & 60 & 80 & 96 & 103 & 124 & 138 & 146 & 165 \\
2 & 35 & 64 & 81 & 96 & 106 & 125 & 139 & 146 & 166 \\
6 & 36 & 67 & 81 & 98 & 106 & 125 & 140 & 146 & 167 \\
6 & 37 & 68 & 82 & 98 & 107 & 125 & 141 & 147 & 168 \\
7 & 37 & 69 & 84 & 98 & 109 & 126 & 141 & 147 & 168 \\
10 & 39 & 71 & 84 & 99 & 109 & 126 & 141 & 149 & 169 \\
15 & 40 & 72 & 84 & 100 & 110 & 129 & 142 & 149 & 170 \\
17 & 41 & 72 & 88 & 101 & 110 & 130 & 142 & 151 & 170 \\
18 & 45 & 73 & 88 & 101 & 112 & 131 & 142 & 151 & 170 \\
19 & 50 & 73 & 91 & 101 & 112 & 132 & 143 & 152 & 171 \\
20 & 50 & 73 & 92 & 103 & 117 & 134 & 143 & 153 & \\
20 & 54 & 74 & 92 & 103 & 119 & 135 & 143 & 154 & \\
29 & 55 & 75 & 94 & 103 & 121 & 137 & 144 & 159 & \\
\hline
\end{tabular}

$\mathrm{n}=137$

Mean $=99^{\circ}$

$\mathrm{SD}=47$

Table C12: Orientation measurements $\left({ }^{\circ}\right)$ and statistics from platform 2 at Barren Island.

\begin{tabular}{|rlllllllll|}
\hline 0 & 21 & 42 & 64 & 72 & 88 & 101 & 136 & 147 & 164 \\
6 & 22 & 48 & 66 & 72 & 88 & 102 & 138 & 147 & 164 \\
6 & 22 & 52 & 66 & 73 & 88 & 103 & 139 & 147 & 164 \\
8 & 23 & 52 & 68 & 74 & 88 & 104 & 139 & 147 & 168 \\
12 & 23 & 53 & 68 & 74 & 89 & 104 & 139 & 149 & 169
\end{tabular}




\begin{tabular}{|rrrrrrrrr|}
13 & 26 & 53 & 68 & 75 & 89 & 109 & 139 & 150 \\
14 & 26 & 55 & 70 & 76 & 91 & 109 & 140 & 153 \\
14 & 27 & 56 & 70 & 80 & 92 & 111 & 140 & 156 \\
16 & 27 & 60 & 70 & 81 & 92 & 111 & 141 & 157 \\
16 & 28 & 61 & 70 & 83 & 94 & 112 & 144 & 158 \\
17 & 39 & 61 & 70 & 83 & 98 & 116 & 145 & 160 \\
19 & 40 & 62 & 71 & 85 & 99 & 127 & 145 & 161 \\
20 & 42 & 62 & 71 & 87 & 100 & 128 & 146 & 161 \\
20 & 42 & 63 & 71 & 87 & 101 & 135 & 147 & 162 \\
\hline
\end{tabular}

$\mathrm{n}=131$

Mean $=86^{\circ}$

$S D=47$

Table C13: Orientation measurements $\left(^{\circ}\right)$ and statistics from platform 3 at Barren Island.

\begin{tabular}{|rrrrrrrrr|}
\hline 5 & 31 & 49 & 72 & 84 & 103 & 118 & 134 & 163 \\
7 & 31 & 49 & 73 & 84 & 103 & 120 & 134 & 164 \\
10 & 32 & 51 & 74 & 85 & 104 & 120 & 135 & 167 \\
12 & 32 & 52 & 75 & 86 & 111 & 120 & 136 & 168 \\
13 & 38 & 53 & 75 & 88 & 112 & 121 & 136 & 168 \\
18 & 39 & 54 & 75 & 90 & 112 & 123 & 139 & 169 \\
21 & 41 & 55 & 76 & 90 & 112 & 125 & 140 & 175 \\
22 & 42 & 57 & 76 & 92 & 114 & 125 & 143 & 176 \\
24 & 42 & 57 & 79 & 93 & 115 & 126 & 143 & \\
24 & 43 & 57 & 80 & 94 & 116 & 128 & 147 & \\
25 & 46 & 60 & 80 & 95 & 116 & 129 & 150 & \\
25 & 47 & 63 & 80 & 98 & 116 & 130 & 158 & \\
27 & 47 & 67 & 82 & 99 & 117 & 131 & 160 & \\
30 & 47 & 69 & 84 & 100 & 117 & 134 & 160 & \\
\hline
\end{tabular}

$n=120$

Mean $=89^{\circ}$

$S D=45$

Table C14: Orientation measurements $\left({ }^{\circ}\right)$ and statistics from platform 4 at Barren Island.

\begin{tabular}{|rlllllllll|}
\hline 11 & 20 & 30 & 49 & 70 & 84 & 98 & 124 & 138 & 163 \\
12 & 20 & 30 & 50 & 70 & 87 & 100 & 126 & 139 & 163 \\
13 & 21 & 32 & 50 & 70 & 92 & 100 & 128 & 140 & 164 \\
13 & 21 & 34 & 51 & 70 & 93 & 102 & 129 & 145 & 164 \\
14 & 22 & 34 & 51 & 72 & 94 & 105 & 130 & 149 & 164 \\
15 & 23 & 38 & 53 & 72 & 94 & 110 & 131 & 151 & 164 \\
15 & 24 & 39 & 57 & 74 & 95 & 111 & 132 & 154 & 165 \\
16 & 24 & 40 & 62 & 76 & 95 & 112 & 133 & 157 & 167
\end{tabular}




\begin{tabular}{|llllllllll|}
17 & 24 & 42 & 62 & 76 & 96 & 113 & 133 & 157 & 169 \\
17 & 25 & 43 & 63 & 80 & 96 & 117 & 134 & 157 & 170 \\
18 & 26 & 43 & 66 & 80 & 96 & 121 & 135 & 158 & 170 \\
19 & 26 & 47 & 66 & 82 & 97 & 122 & 135 & 160 & 171 \\
19 & 26 & 47 & 66 & 83 & 97 & 123 & 136 & 160 & 172 \\
20 & 27 & 49 & 69 & 84 & 98 & 124 & 137 & 162 & 176 \\
\hline
\end{tabular}

$n=140$

Mean $=87^{\circ}$

$S D=51$

Table C15: Orientation measurements $\left(^{\circ}\right)$ and statistics from platform 5 at Barren Island.

\begin{tabular}{|rllllllllll|}
\hline 0 & 28 & 42 & 55 & 78 & 107 & 126 & 134 & 140 & 148 & 157 \\
0 & 28 & 44 & 56 & 79 & 110 & 127 & 134 & 140 & 149 & 157 \\
1 & 29 & 45 & 58 & 80 & 113 & 127 & 134 & 143 & 149 & 158 \\
2 & 30 & 45 & 65 & 87 & 115 & 128 & 134 & 143 & 150 & 159 \\
2 & 31 & 45 & 65 & 89 & 116 & 128 & 135 & 144 & 150 & 160 \\
7 & 34 & 45 & 66 & 91 & 118 & 129 & 135 & 144 & 153 & 161 \\
13 & 35 & 46 & 67 & 92 & 119 & 130 & 135 & 144 & 155 & 161 \\
18 & 35 & 47 & 69 & 92 & 120 & 130 & 135 & 145 & 155 & 166 \\
22 & 35 & 48 & 71 & 94 & 120 & 130 & 137 & 145 & 155 & 168 \\
23 & 38 & 50 & 74 & 96 & 121 & 130 & 137 & 145 & 156 & 170 \\
25 & 38 & 50 & 75 & 97 & 123 & 131 & 137 & 146 & 156 & \\
25 & 39 & 50 & 76 & 101 & 123 & 131 & 137 & 146 & 157 & \\
25 & 39 & 52 & 77 & 106 & 124 & 133 & 137 & 147 & 157 & \\
28 & 40 & 52 & 77 & 107 & 126 & 134 & 138 & 147 & 157 & \\
\hline
\end{tabular}

$\mathrm{n}=150$

Mean $=98^{\circ}$

$S D=49$

Table C16: Orientation measurements $\left(^{\circ}\right)$ and statistics from platform 6 at Barren Island.

\begin{tabular}{|rrrrrrrrrrr|}
\hline 0 & 25 & 37 & 46 & 63 & 81 & 94 & 118 & 135 & 143 & 157 \\
10 & 25 & 38 & 46 & 64 & 84 & 95 & 121 & 136 & 146 & 158 \\
13 & 26 & 38 & 47 & 65 & 85 & 95 & 122 & 136 & 147 & 161 \\
14 & 27 & 40 & 49 & 68 & 86 & 95 & 123 & 136 & 147 & 161 \\
14 & 27 & 41 & 49 & 73 & 87 & 97 & 124 & 137 & 148 & 163 \\
15 & 29 & 41 & 50 & 74 & 87 & 103 & 124 & 138 & 148 & 163 \\
16 & 30 & 42 & 50 & 75 & 88 & 107 & 127 & 138 & 150 & 164 \\
19 & 32 & 42 & 52 & 76 & 90 & 109 & 130 & 139 & 152 & 168 \\
19 & 34 & 43 & 55 & 76 & 90 & 109 & 131 & 139 & 152 & 169 \\
21 & 36 & 43 & 55 & 76 & 90 & 113 & 132 & 140 & 152 & 171 \\
21 & 36 & 43 & 55 & 78 & 91 & 114 & 133 & 140 & 154 & 172
\end{tabular}




\begin{tabular}{|lllllllllll|}
23 & 37 & 45 & 57 & 78 & 92 & 115 & 133 & 140 & 155 & 172 \\
24 & 37 & 45 & 61 & 78 & 93 & 116 & 134 & 141 & 156 & 173 \\
24 & 37 & 46 & 62 & 80 & 93 & 117 & 135 & 142 & 157 & \\
\hline
\end{tabular}

$\mathrm{n}=153$

Mean $=89^{\circ}$

$S D=49$

Table C17: Orientation measurements $\left(^{\circ}\right)$ and statistics from platform 7 at Barren Island.

\begin{tabular}{|rllllllllll|}
\hline 0 & 20 & 40 & 52 & 71 & 87 & 108 & 120 & 133 & 147 & 162 \\
0 & 21 & 40 & 53 & 73 & 88 & 108 & 121 & 134 & 147 & 166 \\
6 & 23 & 40 & 55 & 75 & 90 & 109 & 122 & 135 & 149 & 170 \\
9 & 23 & 40 & 55 & 75 & 90 & 110 & 123 & 139 & 153 & 173 \\
10 & 27 & 40 & 55 & 76 & 94 & 110 & 124 & 139 & 153 & \\
14 & 27 & 42 & 60 & 76 & 97 & 110 & 124 & 140 & 154 & \\
14 & 32 & 44 & 61 & 76 & 98 & 112 & 124 & 141 & 157 & \\
14 & 32 & 45 & 61 & 83 & 105 & 112 & 125 & 142 & 157 & \\
17 & 33 & 47 & 62 & 83 & 105 & 113 & 127 & 142 & 158 & \\
17 & 35 & 48 & 67 & 85 & 106 & 113 & 127 & 143 & 159 & \\
18 & 35 & 48 & 67 & 85 & 106 & 114 & 128 & 146 & 160 & \\
19 & 37 & 48 & 68 & 86 & 106 & 115 & 128 & 146 & 160 & \\
20 & 38 & 49 & 68 & 87 & 106 & 115 & 131 & 146 & 160 & \\
20 & 39 & 50 & 71 & 87 & 107 & 117 & 131 & 146 & 161 & \\
\hline
\end{tabular}

$n=144$

Mean $=88^{\circ}$

$S D=48$

Table C18: Orientation measurements $\left({ }^{\circ}\right)$ and statistics of gravel from the first set of photographs on the eastern bank on the south end of Barren Island.

\begin{tabular}{|rrrrr|l}
\hline 0 & 64 & 93 & 123 & 156 \\
0 & 64 & 97 & 126 & 158 & \\
1 & 65 & 100 & 127 & 160 & \\
1 & 65 & 102 & 127 & 161 & \\
10 & 66 & 105 & 129 & 162 & \\
21 & 66 & 109 & 133 & 165 & \\
23 & 67 & 110 & 136 & 167 & \\
31 & 79 & 111 & 138 & 173 & \\
36 & 81 & 112 & 139 & 173 & $\mathrm{n}=67$ \\
38 & 82 & 113 & 146 & 178 & \\
51 & 84 & 114 & 149 & 179 & Mean $=100^{\circ}$ \\
54 & 85 & 117 & 154 & & SD $=50$ \\
57 & 90 & 117 & 155 & &
\end{tabular}


Table C19: Orientation measurements $\left(^{\circ}\right)$ and statistics of gravel from the second set of photographs on the eastern bank on the south end of Barren Island.

\begin{tabular}{|rrrrrr|}
\hline 5 & 32 & 57 & 78 & 102 & 163 \\
5 & 33 & 57 & 80 & 104 & 175 \\
5 & 33 & 60 & 81 & 112 & 176 \\
11 & 34 & 60 & 84 & 120 & \\
12 & 35 & 61 & 85 & 121 & \\
15 & 39 & 63 & 85 & 129 & \\
20 & 40 & 66 & 87 & 131 & \\
24 & 41 & 66 & 90 & 133 & \\
27 & 42 & 67 & 90 & 143 & \\
27 & 47 & 69 & 96 & 150 & \\
28 & 48 & 70 & 100 & 157 & \\
29 & 48 & 71 & 101 & 158 & \\
31 & 49 & 71 & 101 & 159 & \\
31 & 50 & 72 & 102 & 159 & \\
Mean $=74^{\circ}$ \\
S2
\end{tabular}

Table C20: Orientation measurements $\left(^{\circ}\right)$ and statistics of gravel from the third set of photographs on the eastern bank on the south end of Barren Island.

\begin{tabular}{|c|c|c|c|c|c|}
\hline 4 & 60 & 90 & 136 & 158 & \\
\hline 13 & 64 & 98 & 140 & 160 & \\
\hline 14 & 65 & 101 & 140 & 167 & \\
\hline 17 & 65 & 103 & 142 & 167 & \\
\hline 20 & 65 & 107 & 142 & 168 & \\
\hline 23 & 66 & 110 & 145 & & \\
\hline 42 & 68 & 110 & 149 & & \\
\hline 48 & 69 & 111 & 150 & & \\
\hline 50 & 72 & 115 & 152 & & \multirow{3}{*}{$\mathrm{n}=61$} \\
\hline 50 & 73 & 117 & 152 & & \\
\hline 58 & 78 & 121 & 153 & & \\
\hline 58 & 81 & 123 & 154 & & \multirow{3}{*}{$\begin{array}{l}\text { Mean }=98^{\circ} \\
S D=46\end{array}$} \\
\hline 59 & 85 & 133 & 156 & & \\
\hline 59 & 90 & 134 & 156 & & \\
\hline
\end{tabular}

Table C20: Orientation measurements $\left(^{\circ}\right)$ and statistics of gravel from the fourth set of photographs on the eastern bank on the south end of Barren Island.

\begin{tabular}{|rrrr|}
\hline 1 & 35 & 93 & 135 \\
7 & 36 & 94 & 142 \\
10 & 38 & 103 & 145 \\
11 & 42 & 103 & 145 \\
12 & 43 & 107 & 145 \\
14 & 45 & 117 & 152
\end{tabular}




\begin{tabular}{|llll|l}
21 & 52 & 118 & 154 & \\
22 & 55 & 118 & 165 & \\
24 & 65 & 124 & 173 & \\
25 & 75 & 126 & 173 & $\mathrm{n}=52$ \\
28 & 76 & 126 & & \\
31 & 78 & 127 & & Mean $=81^{\circ}$ \\
34 & 80 & 130 & & SD $=52$ \\
35 & 90 & 130 & &
\end{tabular}

Table C22: Orientation measurements $\left(^{\circ}\right)$ and statistics of gravel from the fifth set of photographs on the eastern bank on the south end of Barren Island.

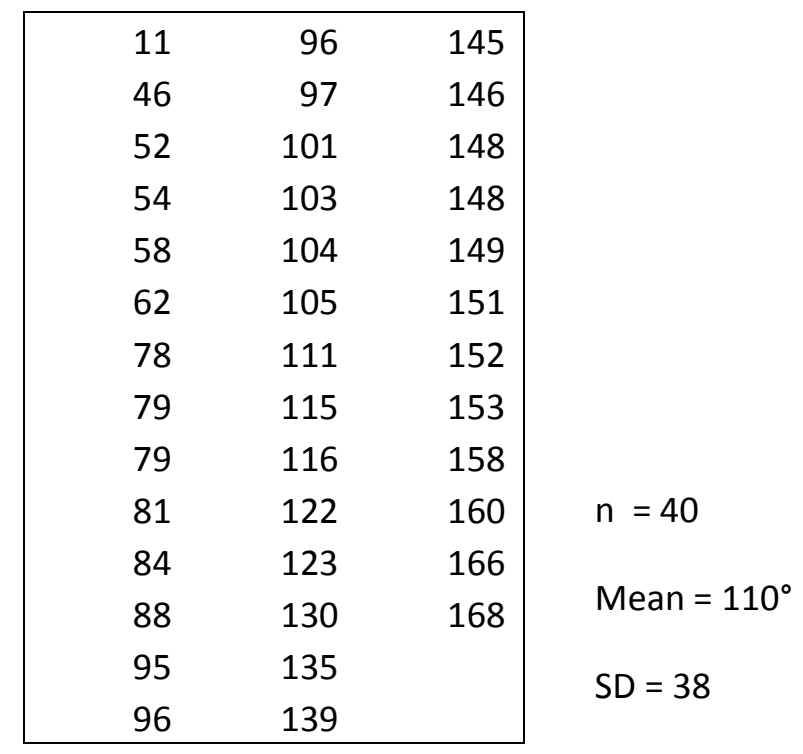

Table C23: Orientation measurements $\left(^{\circ}\right)$ and statistics of gravel from the sixth set of photographs on the eastern bank on the south end of Barren Island.

\begin{tabular}{|c|c|c|c|c|}
\hline 0 & 59 & 84 & 147 & \\
\hline 0 & 60 & 87 & 149 & \\
\hline 4 & 61 & 90 & 151 & \\
\hline 11 & 61 & 91 & 152 & \\
\hline 11 & 61 & 98 & 154 & \\
\hline 13 & 66 & 100 & 157 & \\
\hline 14 & 70 & 101 & 159 & \\
\hline 17 & 71 & 102 & 160 & \\
\hline 30 & 74 & 104 & 160 & \\
\hline 39 & 74 & 111 & 162 & \multirow[t]{2}{*}{$n=53$} \\
\hline 39 & 76 & 131 & 170 & \\
\hline 40 & 79 & 137 & & Mean $=85^{\circ}$ \\
\hline 54 & 82 & 137 & & \multirow{2}{*}{$S D=50$} \\
\hline 55 & 83 & 142 & & \\
\hline
\end{tabular}


Table C24: Orientation measurements $\left(^{\circ}\right)$ and statistics of gravel from the seventh set of photographs on the eastern bank on the south end of Barren Island.

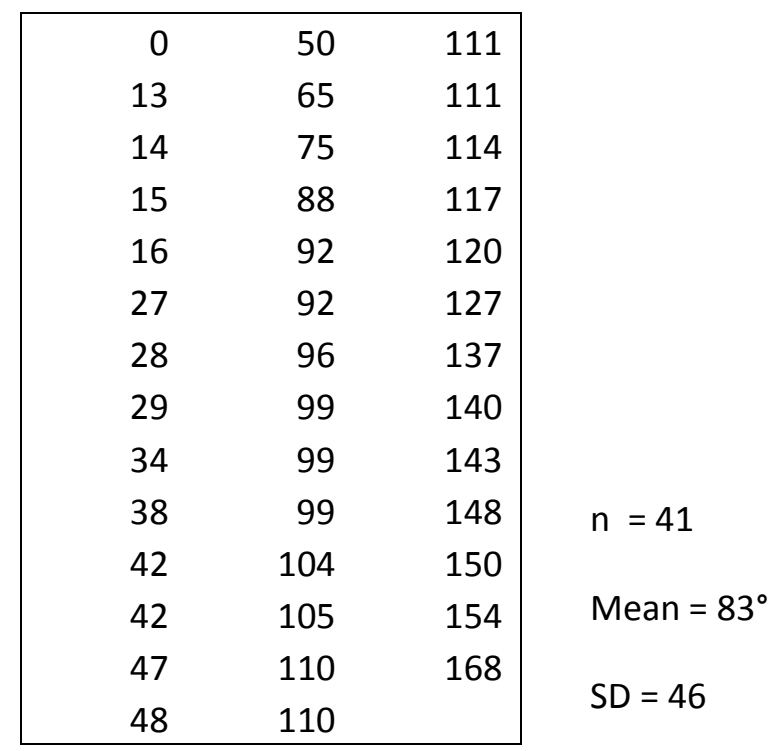

Table C25: Orientation measurements $\left(^{\circ}\right)$ and statistics of gravel from the eighth set of photographs on the eastern bank on the south end of Barren Island.

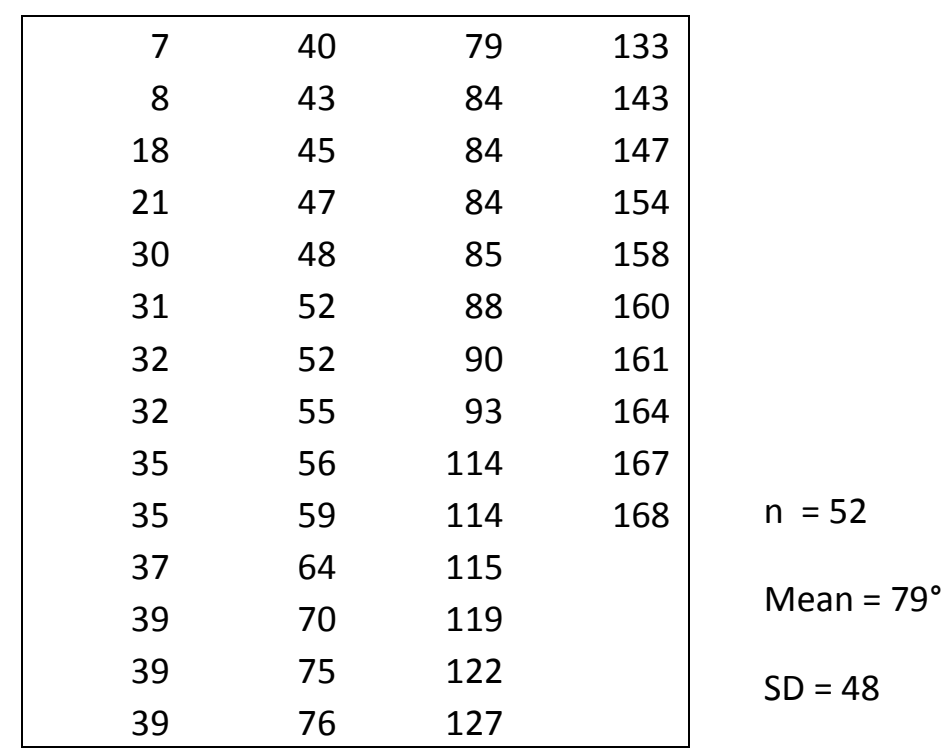

